\title{
AVALIAÇÃO ECOTOXICOLÓGICA DE SEDIMENTOS EM RESERVATÓRIOS DA BACIA DO RIO TIETÊ, SP, COM ÊNFASE NA APLICAÇÃO DO ESTUDO DE AIT - AVALIAÇÃO E IDENTIFICAÇÃO DA TOXICIDADE
}

Clarice Maria Rispoli Botta Paschoal Orientadora: Prof. Dra Odete Rocha

Tese apresentada à Escola de Engenharia de São Carlos, da Universidade de São Paulo, como parte dos requisitos para obtenção do título de Doutor em Ciências da Engenharia Ambiental. 
Ao Thiago, André e Monica, que me ensinaram amar de forma incondicional

A Vida é construída nos Sonhos e concretizada no Amor 


\section{AGRADECIMENTOS}

A FAPESP, pela concessão da bolsa e auxílio financeiro.

A Profa. Dra Odete Rocha, pela orientação, apoio, confiança e incentivos concedidos na elaboração desta tese.

Ao Prof. Dr Evaldo Gaeta Espíndola, que acreditou no Laboratório de Ecotoxicologia e Ecofisiologia Aquática do CRHEA.

Ao Centro de Recursos Hídricos e Ecologia Aplicada (CRHEA), nas pessoas de seu diretor Prof. Dr. Frederico Fábio Mauad e ex- diretores, professores, funcionários e técnicos, pelo apoio logístico, pela convivência e pela amizade que permitiram e contribuíram para a realização deste trabalho.

Ao Miro, Aírton, Valdecir, Luci, Amândio e Marcelo pela realização dos trabalhos de campo e análises de laboratório.

Aos alunos e estagiários que fizeram parte, em algum momento, do Laboratório de Ecotoxicologia, pela amizade, auxílio, e especialmente, pela dedicação exigida na manutenção rotineira dos cultivos. Por todos os finais de semana, feriados, Natal, Ano Novo,... em que um ou outro esteve presente para garantir a qualidade dos nossos resultados.

Ao Abílio pelos muitos momentos de trabalho conjunto, pelo aprendizado, pelo seu incentivo constante, pelos momentos de descontração e pela amizade.

Ao coordenador e sub-coordenadores do QualiSed, Prof. Dr. Antonio Mozeto, Prof. Dr. Wilson Jardim e Dra. Gisela Umbuzeiro pela possibilidade de trabalhar em conjunto; pela utilização dos laboratórios de Biogeoquímica Ambiental da UFSCar e dos Setores de Mutagenicidade e Citotoxicidade e de Ecotoxicologia Aquática da CETESB; e pela realização das análises. A Patrícia, Fernanda, Rosalina, Paulo, Alessandra, Aluísio e demais participantes do QualiSed, que contribuíram de alguma forma para a realização deste trabalho.

A Dra Maria Inês Z. Sato, Gerente do DAM, Dra. Marta Lampareli, Gerente da DHI e Dr. Eduardo Bertoletti, Gerente do Setor de Ecotoxicologia Aquática, da CETESB, pela utilização dos laboratórios e realização dos testes.

Aos amigos do Departamento de Análises Ambientais da CETESB, especialmente, Carlos, Nancy e Célia, pela colaboração nas análises.

Ao Prof. Dr. Armando A.Vieira, do Laboratório de Ficologia do Departamento de Botânica, UFSCar, pela utilização do banho de ultra-som.

Aos Programas PRONEX e PROBIO / CNPq / FINEP / MMA.

A todos que, de uma forma ou de outra contribuíram para a realização deste trabalho.

A José Octavio, pelo companheirismo de todos esses anos.

Aos amigos, por todos os momentos compartilhados.

A Família, sempre um “porto seguro” e, aos meus pais, Shirley e Walter José , por eles..... 


\section{SUMÁRIO}

TABELAS

FIGURAS

RESUMO

vii

ABSTRACT.

1 - INTRODUÇÃO.

2 - OBJETIVOS.

3 - HIPÓTESES.

4 - CAPÍTULO 1: AVALIAÇÃO ECOTOXICOLÓGICA DE SEDIMENTOS DE RESERVATÓRIOS.

4.1 - REVISÃO BIBLIOGRÁFICA.

4.1.1 - Contaminação dos Sedimentos.

4.1.2 - Aspectos Limnológicos, Ecológicos e Ecotoxicológicos dos Reservatórios de Barra Bonita e Salto Grande.

4.2 - MATERIAL E MÉTODO.

4.2.1 - Caracterização da Área de Estudo........................................................... 26

4.2.2 - Coleta e Preparação das Amostras.............................................................. 30

4.2.3 - Métodos de Extração das Fases Líquidas.................................................... 32

4.2.4- Testes de Toxicidade com o Sedimento Total............................................. 33

4.2.5 - Testes de Toxicidade com o Solubilizado e/ou Água Intersticial................ 35

4.2.6 - Cultivo e Manutenção dos Organismos-teste Mantidos no Laboratório de Ecotoxicologia e Ecofisiologia de Organismos Aquáticos.

4.2.7 - Controle de Qualidade dos Cultivos Mantidos no Laboratório de Ecotoxicologia e Ecofisiologia de Organismos Aquáticos.

4.2.8 - Análises Físicas e Químicas do Sedimento, Água Intersticial e Solubilizado.

4.3 - RESULTADOS E DISCUSSÃO.

4.3.1 - Caracterização Físico-química do Sedimento dos Reservatórios de Barra Bonita e Salto Grande.

4.3.2 - Avaliação da Toxicidade do Sedimento dos Reservatórios de Barra Bonita e Salto Grande.

4.3.3 - Controle de Qualidade dos Organismos-Teste: Testes de Sensibilidade...... 68

5 - CAPÍTULO 2: ESTUdO DE AVALIAÇÃO E IDENTIFICAÇÃO DA TOXICIDADE (AIT)...

5.1 - REVISÃO BIBLIOGRÁFICA.

5.1.1 - Estudo de Avaliação e Identificação de Toxicidade - Aspectos Metodológicos............................................................................................... 73 5.1.2 - Utilização do Estudo de Avaliação e Identificação da Toxicidade (AIT)... 77 
5. 2 - MATERIAL E MÉTODO

5.2.1 - Estudo de Avaliação e Identificação da Toxicidade- Fase1....................... 82

5.2.2 - Estudo de Avaliação e Identificação da Toxicidade - Fase II.................... 88

5.2.3 - Estudo de Avaliação e Identificação da Toxicidade - Fase III:

Reservatórios de Salto Grande e Rasgão.............................................................. 88

5.2.4 - Estudo de Avaliação e Identificação da Toxicidade - Considerações

Metodológicas

5.3 - RESULTADOS E DISCUSSÃO.

5.3.1 - Reservatório de Barra Bonita................................................................. 98

5.3.2 - Reservatório de Salto Grande.......................................................... 102

5.3 .3 - Reservatório de Rasgão...................................................................... 118

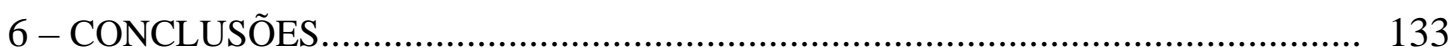

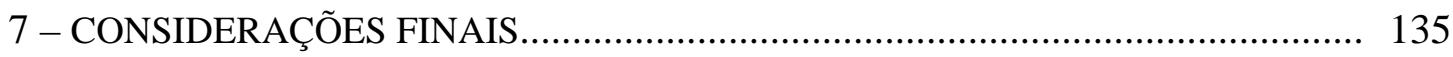

8 - REFERÊNCIAS BIBLIOGRÁFICAS......................................................... 136

ANEXOS 


\section{TABELAS}

Tabela 1- Metais presentes nas diferentes atividades industriais

Tabela 2 - Teores médios (\%) de matéria orgânica, areia, silte e argila em amostras de sedimento coletadas no reservatório de Barra Bonita em abril/99 e junho/00.

Tabela 3 - Valores de $\mathrm{pH}$, oxigênio dissolvido (OD), potencial redox $\left(\mathrm{E}_{\mathrm{H}}\right)$ e temperatura das amostras de sedimento coletadas no reservatório de Barra Bonita (BB).

Tabela 4- Valores de potencial redox $\left(\mathrm{E}_{\mathrm{H}}\right), \mathrm{pH}$, condutividade e oxigênio dissolvido (OD) das amostras de sedimento das estações E1 e E2 coletadas no reservatório de Salto Grande (SG) no período de Agosto/00 a Outubro/01.

Tabela 5 - Concentrações de sulfetos volatilizáveis por acidificação (SVA), nitrogênio total, fósforo total, carbono orgânico total (COT) e amônia nas amostras de sedimento das estações E1, E2 e E3, do reservatório de Barra Bonita (BB).

Tabela 6 - Concentrações de sulfetos volatilizáveis por acidificação (SVA), amônia, ácido sulfídrico, carbono orgânico total (COT) e carbono orgânico dissolvido (COD) encontrados nas amostras de sedimento das estações E1 e E2, coletadas no reservatório de Salto Grande (SG) em novembro/00 e outubro/01.....

Tabela 7 - Concentrações em mg. $\mathrm{kg}^{-1}$ de metais potencialmente biodisponíveis, das amostras de sedimento das estações E1, E2 e E3 coletadas no reservatório de Barra Bonita e estações E1 e E2 do reservatório de Salto Grande.

Tabela 8 - Porcentagens de efeito observado expresso em mortalidade para $C$. xanthus, imobilidade para $D$. similis, $C$. dubia e $C$. silvestrii e inibição da produção de luz para $V$. fisheri, nos testes de toxicidade aguda realizados com as amostras de sedimento das estações E1, E2 e E3 coletadas no reservatório de Barra Bonita.

Tabela 9 a), b), c) e d) - Sobrevivência e número de neonatos de $C$. dubia expostos às amostras sedimento total (ST) e Solubilizado (SOL)das estações E1, E2 e E3 coletadas no reservatório de Barra Bonita (BB) no período de abril/99 a junho/00, em testes de toxicidade crônica.

Tabela 10 - Toxicidade para pelo menos um dos organismos-teste utilizados nos testes de toxicidade aguda ou crônica com as amostras de sedimento total (ST) e solubilizado (SOL) das estações E1, E2 e E3, coletadas no reservatório de Barra Bonita no período de abril/99 a setembro/00.

Tabela 11 -Toxicidade do sedimento da estação E3, obtido em diferentes estudos e para diferentes organismos-teste em 1999 e 2000.

Tabela 12 - Efeito em porcentagem de imobilidade (D. similis e C. dubia no ST), 
CE50, 48h (C. dubia), CE20, 15' (V. fisheri) e MEC90, 30' (Spirillum volutans) para os diferentes organismos-teste, nos testes de toxicidade aguda realizados com as amostras de sedimento das estações E1e E2 coletadas no reservatório de Salto Grande.

Tabela 13 - Resultados obtidos na Fase 1 e classificação do composto suspeito.... 76

Tabela 14 - Resultados obtidos na Fase 1 (parcial) com o solubilizado da amostra de sedimento da estação E2 (aporte do rio Tietê), coletada em junho/00.

Tabela 15 - Valores das concentrações de metais e sulfetos simultaneamente extraídos (SVA) das amostras de sedimento das estações E1, E2 e E3 coletadas no reservatório de Barra Bonita (BB) em setembro/00

Tabela 16 - Relações [ $\Sigma$ MSE]-SVA e [ $\Sigma$ MSE]/SVA para as amostras de sedimento das estações E1, E2 e E3 coletadas no reservatório de Barra Bonita (BB) em setembro/00.

Tabela 17 - Relação [MSE] - [SVA] para as amostras de sedimento das estações E1, E2 e E3 coletadas no reservatório de Barra Bonita em setembro/00.....

Tabela 18 - Porcentagens de efeito e valores de CE50 de Daphnia similis e Vibrio fisheri expostas ao solubilizado da amostra de sedimento da estação E2, antes e após as diferentes etapas do estudo de AIT - Reservatório de Salto Grande em novembro/00.

Tabela 19 - Porcentagens de imobilidade e valores de CE50,48h de Ceriodaphnia dubia expostas ao solubilizado da amostra de sedimento da estação E2, antes e após as diferentes etapas do estudo de AIT - Reservatório de Salto Grande em novembro/00

Tabelas 21 - Porcentagens de imobilidade e valores de CE50,48h de Ceriodaphnia dubia expostas ao solubilizado da amostra de sedimento da estação E2, antes e após as diferentes etapas do estudo de AIT - Reservatório de Salto Grande - outubro/01

Tabela 22 - Concentrações de metais encontradas no solubilizado das amostras de sedimento das estações E1 e E2 coletadas no reservatório de Salto Grande em novembro/00 e outubro/01 e valores de CE50,48h para os referidos metais.....

Tabela 23- Concentrações dos metais e sulfetos simultaneamente extraídos (SVA) das amostras de sedimento das estações E1 e E2 coletadas no reservatório de Salto Grande em novembro/00, fevereiro/01 e outubro/01.

Tabela 24- Relações [ $\sum$ MSE]-SVA e [ $\sum$ MSE]/SVA para as amostras de sedimento das estações E1 e E2 coletadas no reservatório de Salto Grande em novembro/00, fevereiro/01 e outubro/01 
Tabela 25 - Relação [MSE] / [SVA] para as amostras de sedimento das estações E1 e E2 coletadas no reservatório de Salto Grande.

Tabela 26- Distribuição esperada da amônia na água em função do $\mathrm{pH}\left(25^{\circ} \mathrm{C}\right) \ldots .$.

Tabela 27 - Porcentagens de imobilidade de Ceriodaphnia dubia expostas ao solubilizado da amostra de sedimento da estação E2, após o tratamento com EDTA - Reservatório de Salto Grande - outubro/01.

Tabela 28 - Porcentagens de imobilidade de Ceriodaphnia dubia expostas ao solubilizado da amostra de sedimento da estação E2, após o tratamento com tiossulfato de sódio - Reservatório de Salto Grande - outubro/01.

Tabela 29 - Porcentagem de imobilidade de Ceriodaphnia dubia expostas ao solubilizado do sedimento da estação E2 do reservatório de Salto Grande, antes e após o tratamento com a zeólita.

Tabela 30 - Resultados das análises químicas e dos testes de toxicidade realizados nas amostras de sedimento / solubilizado coletadas no reservatório de Rasgão em setembro (Set/01) e dezembro (Dez/01) de 2001.

Tabela 31 - Valores de CE20,15' obtidos nos testes de toxicidade com V. fischeri com o solubilizado do sedimento coletado no reservatório de Rasgão em setembro/2001, antes e após as diferentes etapas do AIT.

Tabela 32 - Comparação das concentrações de metais presentes no solubilizado com os valores de CE50, 15’para $V$. fisheri.

Tabela 33 - Valores de CE50,48h obtidos nos testes de toxicidade aguda com Ceriodaphnia dubia com a amostra solubilizada do sedimento coletado no reservatório de Rasgão em setembro/01, antes e após as diferentes etapas do AIT..

Tabela 34 - Valores de CE50, 48h obtidos nos testes de toxicidade aguda com Ceriodaphnia dubia com a amostra solubilizada do sedimento coletado no reservatório de Rasgão em dezembro/01, antes e após as diferentes etapas do AIT.

Tabela 35- Porcentagens de imobilidade de Ceriodaphnia dubia expostas ao solubilizado da amostra de sedimento coletada no reservatório de Rasgão em dezembro/01, após o tratamento com EDTA, em testes de toxicidade aguda.

Tabela 36- Concentração em ( $\mu g . \mathrm{g}^{-1}$ ) dos metais e sulfetos (SVA) simultaneamente extraídos das amostras de sedimento coletadas no reservatório e Rasgão em setembro/01 e dezembro/01

Tabela 37 - Relações [ $\Sigma$ MSE]-SVA e [ $\Sigma$ MSE]/SVA para as amostras de sedimento coletadas no reservatório de Rasgão em setembro/01 e dezembro/01....

Tabela 38 - Valores das concentrações de metais encontradas no solubilizado das 
amostras de sedimento coletadas no reservatório de Rasgão

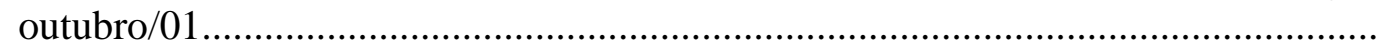

Tabela 39 - Porcentagens de imobilidade de Ceriodaphnia dubia expostas ao solubilizado da amostra de sedimento coletada no reservatório de Rasgão em dezembro01, após o tratamento com tiossulfato de sódio.

Tabela 40 - Efeitos causados pelas diferentes etapas do estudo de AIT, na toxicidade das amostras de sedimento coletadas em setembro/01 e dezembro/01, no reservatório de Rasgão e possíveis tóxicos suspeitos.

Tabela 41 - Porcentagem de imobilidade de Ceriodaphnia dubia nos testes de toxicidade aguda realizados com o solubilizado da amostra de sedimento, antes e após o tratamento com a zeólita..... 


\section{FIGURAS}

Figura 1 - Representação esquemática do reservatório de Barra Bonita com a localização dos pontos de amostragem.

Figura 2 - Representação esquemática do reservatório de Salto Grande com a localização das estações de amostragem.

Figura 3 - Localização do reservatório de Rasgão, Pirapora, SP

Figura 4 - Número de neonatos produzidos por Ceriodaphnia dubia exposta ao sedimento total das estações E1, E2 e E3 coletadas na represa de Barra Bonita, em testes de toxicidade crônica.

Figura 5 - Porcentagens de imobilidade de Daphnia similis e/ou C. dubia expostas às amostras de sedimento total (ST) e solubilizado (SOL) da estação E1 coletada no reservatório de Barra Bonita no período de dezembro/99 a setembro/00, em testes de toxicidade aguda.

Figura 6- Porcentagens de imobilidade de Daphnia similis e/ou C. dubia expostas às amostras de sedimento total (ST) e solubilizado (SOL) da estação E2 coletada no reservatório de Barra Bonita no período de dezembro/99 a setembro/00, em testes de toxicidade aguda....

Figura 6 - Número de neonatos produzidos por Ceriodaphnia dubia exposta ao sedimento total das estações E1, E2 e E3 coletadas na represa de Barra Bonita, em testes de toxicidade crônica.

Figura 8 - Porcentagens de imobilidade de C. dubia expostas ao solubilizado do sedimento coletado nas estações E1, E2 e E3 do reservatório de Barra Bonita no período de dezembro/99 a setembro/00, em testes de toxicidade aguda.

Figura 9- Porcentagens de imobilidade de C. dubia expostas ao sedimento total e solubilizado das estações E1e E2, coletadas no reservatório de Salto Grande no período de março/00 a outubro/01, em testes de toxicidade aguda.

Figura 10 - Valores de CE50, 24h e os intervalos de confiança dos testes de sensibilidade de Daphnia similis ao dicromato de potássio.

Figura 11 - Valores de CE50, 48h e os intervalos de confiança dos testes de sensibilidade de Ceriodaphnia dubia ao cloreto de sódio...

Figura 12 - Valores de CE50, 96h e os intervalos de confiança dos testes de sensibilidade de Chironomus xanthus ao cloreto de potássio.

Figura 13 - AIT: Etapas para a caracterização dos tóxicos na fase I (USEPA, 1992)

Figura 14 - AIT: procedimentos da etapa de aeração com ajuste de pH. 
Figura 16 - Valores de CE50, 48h obtidos nos testes de toxicidade aguda com Daphnia similis antes e após as etapas do estudo de AIT com a amostra da estação E2 coletada no Reservatório de Salto Grande em novembro /01...............

Figura 17 - Valores de CE50,48h obtidos nos testes de toxicidade aguda com Ceriodaphnia dubia antes e após as etapas do estudo de AIT com a amostra da estação E2 coletada no Reservatório de Salto Grande em novembro /01. (>100 = não tóxica).

Figura 18 - Valores de CE50, 48h obtidos nos testes de toxicidade aguda com Ceriodaphnia dubia antes e após as etapas do estudo de AIT - Reservatório de Salto Grande, outubro/01.

Figura 19- Valores de CE50, 48h obtidos nos testes de toxicidade aguda com Ceriodaphnia dubia antes e após as etapas do estudo de AIT - Reservatório de Salto Grande, outubro/01.

Figura 21 - Valores de CE50, 48h obtidos nos testes de toxicidade aguda com Ceriodaphnia dubia antes e após as etapas do estudo de AIT realizado com o solubilizado do sedimento coletado no Reservatório Rasgão em setembro/01......

Figura 22 - Valores de CE50, 48h obtidos nos testes de toxicidade aguda com Ceriodaphnia dubia antes e após as etapas do estudo de AIT realizado com o solubilizado do sedimento coletado no Reservatório Rasgão em setembro/01......

Figura 23 - Valores de CE50, 48h obtidos nos testes de toxicidade aguda com Ceriodaphnia dubia antes e após as etapas do estudo de AIT realizado com o solubilizado do sedimento coletado no Reservatório Rasgão em dezembro/01.... 


\section{RESUMO}

PASCHOAL, C. M.R.B. (2002). Avaliação ecotoxicológica de sedimentos em reservatórios da bacia do rio Tietê, SP, com ênfase na aplicação do estudo de AIT Avaliação e Identificação da Toxicidade. São Carlos. 146 p. Tese (Doutorado). Escola de Engenharia de São Carlos, Universidade de São Paulo.

A avaliação ecotoxicológica dos sedimentos dos reservatórios de Barra Bonita e Salto Grande foi realizada através de testes de toxicidade aguda e crônica com o sedimento total e o solubilizado, com os organismos-teste Chironomus xanthus, Daphnia similis, Ceriodaphnia dubia, Vibrio fisheri e Spirillum volutans, além de análises físicas ( $\mathrm{pH}, \mathrm{E}_{\mathrm{H}}$ e $\left.\mathrm{O}_{2}\right)$ e químicas (fósforo, nitrogênio, carbono orgânico total, sulfetos e amônia e metais potencialmente disponíveis).

A concentrações médias de matéria orgânica e fósforo obtidas para os sedimentos dos reservatórios de Barra Bonita e Salto Grande foram elevadas, e condizentes com a carga de matéria orgânica e com as baixas concentrações de oxigênio dissolvido e de potencial redox. Em relação aos metais, os resultados revelaram que, para o reservatório de Barra Bonita, eles podem estar influenciando a toxicidade detectada através dos testes de toxicidade. Em Salto Grande, os resultados indicaram que os sulfetos estão atuando como fase controladora dos metais, mantendo-os indisponíveis nos sedimentos. Para esse reservatório a principal causa da toxicidade foi a acidez.

O estudo de Avaliação e Identificação da Toxicidade realizado com as amostras de sedimento dos reservatórios de Barra Bonita, Salto Grande e Rasgão mostrou que os possíveis compostos tóxicos responsáveis pela toxicidade são metais (Barra Bonita); amônia (Salto Grande e Rasgão); compostos ácidos voláteis e compostos orgânicos não iônicos (Rasgão). O tratamento com a resina zeolita foi eficiente na remoção da amônia e redução da toxicidade do sedimento do reservatório de Rasgão, confirmando dessa forma, a amônia como o principal composto tóxico.

O estudo de Avaliação e Identificação da Toxicidade deve ser incorporado nos programas de controle, monitoramento e gestão dos recursos hídricos, devido a importância da identificação dos compostos responsáveis pela toxicidade.

Palavras-chave: sedimento; toxicidade; substâncias tóxicas; avaliação e identificação da toxicidade - AIT; reservatórios. 


\begin{abstract}
PASCHOAL, C. M.R.B. (2002). Ecotoxicological Evaluation of Sediments in Reservoirs of the Tietê River Basin SP, with emphasis on the application of the TIE approach- Toxicity Identification and Evaluation. São Carlos. 146 p. PhD Thesis. Engineering School of São Carlos, University of São Paulo.
\end{abstract}

An ecotoxicological evaluation of the sediments of Barra Bonita and Salto Grande reservoirs was performed by carrying out acute and chronic toxicity tests with both the total sediment and elutriate using Chironomus xanthus, Daphnia similis, Ceriodaphnia dubia, Vibrio fisheri and Spirillum volutans as test-organisms, as well as physical $\left(\mathrm{pH}, \mathrm{E}_{\mathrm{H}}\right.$ e $\left.\mathrm{O}_{2}\right)$ and chemical analysis (phosphorus, nitrogen, total organic carbon, sulphide, ammonium and potentially available metals).

The mean concentrations of organic matter and phosphorus obtained for the sediments of Barra Bonita and Salto Grande reservoirs were high and in agreement with the organic matter loading, low dissolved oxygen concentrations and redox potential.

In relation to metals, the results revealed that in Barra Bonita reservoir they might be responsible for the toxicity detected. For Salto Grande, the results indicated that sulphides act as metal controlling phase keeping them unavailable in the sediments. The main cause of the toxicity in this reservoir was acidity.

The Toxicity Identification and Evaluation (TIE) carried out with the sediments of Barra Bonita, Salto Grande and Rasgão have shown that the probable toxic compounds responsible for toxicity are metals (Barra Bonita); ammonium (Salto Grande and Rasgão); volatile acid compounds and non-ionic compounds (Rasgão). The treatment with zeolite was efficient in removing ammonium and reducing toxicity in the sediment of Rasgão reservoir, thus confirming ammonium as the main toxic compound.

The Toxicity Identification and Evaluation approach must be incorporated in the control, monitoring and management of water resources, due to the relevance of identifying the compounds responsible by the toxicity.

Key-Words: sediment; toxicity; toxic substances; toxicity identification and evaluation - TIE; reservoirs. 


\section{1 - INTRODUÇÃO}

A vulnerabilidade dos ambientes aquáticos a substâncias tóxicas depende de vários fatores, entre eles: 1) propriedades físicas e químicas do composto e seus produtos de transformação; 2) concentração e carga total do composto; 3) duração e tipo de impacto; 4) propriedades de "resistência" do ecossistema (por ex. capacidade de tamponamento) às alterações provocadas pelas substâncias tóxicas. No entanto, devido à grande complexidade das interações entre os fatores físicos, químicos e biológicos de cada ecossistema, à habilidade de adaptação e diferenças de respostas estruturais e funcionais do componente biótico e, devido ainda, à grande diversidade de espécies, torna-se difícil entender e prever a resposta do sistema a uma substância tóxica. Embora o emprego de organismos-teste representativos de diferentes níveis tróficos em testes de toxicidade facilite o entendimento dos efeitos que causam perturbações funcionais e estruturais nos ecossistemas, apenas a utilização de uma abordagem multidisciplinar, envolvendo métodos físicos, químicos e biológicos e a integração de estudos de campo com aqueles em laboratório torna possível definir modelos de concentração e estimar riscos biológicos (HARRIS et al., 1990; HOFFMAN, et al., 1994; RAND et al., 1995).

Os ambientes aquáticos são altamente complexos e diversos, incluindo diferentes tipos de ecossistemas (lagos, rios, represas, oceanos, estuários), com diferentes componentes bióticos e abióticos, de características únicas e interrelacionadas de forma bastante complexa, sendo que os sedimentos representam um dos principais componentes desses sistemas. Eles fornecem substrato para uma grande variedade de organismos, de grande importância econômica e/ou ecológica, e funcionam como reservatório e fonte de inúmeros contaminantes aquáticos orgânicos e/ou inorgânicos, de baixa solubilidade. Desempenham ainda um papel importante nos processos de assimilação, transporte e deposição desses contaminantes pois é nos sedimentos que ocorre a maioria dos processos de decomposição da matéria orgânica alóctone ou autóctone e a reciclagem de importantes elementos como o carbono, o nitrogênio, o fósforo e o enxofre (ADAMS et al., 1992; BURTON \& MACPHERSON, 1994; RAND, 1995). 
A avaliação dos sedimentos através de testes de toxicidade tem como vantagem principal diagnosticar qual a porção biodisponível de um contaminante, uma vez que essa porção pode ser muito diferente da quantidade total determinada pelas análises químicas. Além do mais, em locais contaminados por mais de um composto ou por uma mistura de compostos químicos, os testes de toxicidade são as únicas ferramentas capazes de avaliar o potencial tóxico dos sedimentos (SETAC, 1993).

Testes de toxicidade, portanto, são fundamentais para a avaliação do grau de toxicidade de amostras de sedimento. No entanto, uma vez comprovada a toxicidade, a identificação dos compostos responsáveis pela toxicidade é um pré-requisito fundamental para ações de controle e recuperação de ambientes degradados, bem como para o estabelecimento de critérios de qualidade para o sedimento. Nesse sentido, a utilização dos procedimentos de AIT - Avaliação e Identificação de Toxicidade, tem-se mostrado bastante útil.

Os estudos de AIT foram utilizados inicialmente para a avaliação da toxicidade de efluentes industriais, porém estudos mais recentes demonstraram que esses procedimentos podem ser utilizados também com sucesso para a identificação de compostos causadores de toxicidade aguda em águas superficiais (NORBERG-KING et al. 1991), solubilizados de resíduos perigosos e frações aquosas de sedimentos (ANKLEY \& SCHUBAUER-BERINGAN, 1995).

Esse tipo de estudo combina a quantificação da toxicidade com a identificação e quantificação do(s) composto(s) responsável(eis) pela toxicidade e envolve 3 fases distintas. Na Fase I do estudo de AIT as propriedades físicas/químicas das substâncias tóxicas presentes na água intersticial são caracterizadas através de manipulações que alteram a biodisponibilidade de compostos com propriedades semelhantes. As Fases II e III tem por objetivo identificar e confirmar compostos tóxicos específicos dentre as diferentes classes de compostos identificados na Fase I. A utilização do AIT em amostras de sedimento tem-se limitado à identificação de metais, compostos orgânicos não polares, amônia e ácido sulfídrico, sendo esses dois últimos, os contaminantes mais freqüentemente encontrados em amostras de sedimento.

Os estudos de avaliação e identificação de toxicidade (AIT) com sedimentos são realizados com a fração líquida dos mesmos, especificamente a água intersticial, podendo também ser realizados com o solubilizado. 
A utilização da água intersticial se baseia na relação entre a concentração de contaminantes na água intersticial e os efeitos observados na comunidade macrobentônica, assumindo-se que os compostos presentes na água intersticial e que causam toxicidade aos organismos-teste em laboratório são os mesmos que podem causar toxicidade "in situ", no sedimento (USEPA, 1992).

No entanto, o sedimento não é apenas um "compartimento isolado" ou "habitat" da comunidade bentônica, mas, parte integrante dos ecossistemas aquáticos, seja estes rios, oceanos, lagos ou reservatórios. A contaminação dos sedimentos, por excesso de nutrientes provenientes dos esgotos domésticos não tratados ou tratados de forma inadequada ou por compostos inorgânicos e/ou orgânicos provenientes dos efluentes industriais e agrícolas, causa desequilíbrio nos processos biogeoquímicos. Os impactos causados pela presença desses contaminantes não se restringem apenas aos organismos bentônicos. A ressuspensão e a possível liberação de contaminantes do sedimento para a coluna d'água afetam também os organismos pelágicos, e, nesse caso, a fase líquida que mais se aproxima dessa condição é o solubilizado (ROSS \& HENEBRY, 1989; GIESY \& HOKE, 1990). De acordo com NIPPER \& CARR (1998), o solubilizado reflete diretamente a interface sedimento/água de contato, sendo, portanto um indicador das reações dos contaminantes com os compartimentos sedimento/coluna d’água.

Resultados obtidos com água intersticial e solubilizado nem sempre são concordantes, uma vez que representam condições diferentes. Teoricamente, os testes com a água intersticial estão mais diretamente ligados à toxicidade para os organismos bentônicos, como mostraram os resultados obtidos por GIESY et al. (1990) em estudos sobre toxicidade de cádmio, cobre, mercúrio e Dieldrim ${ }^{\circledR}$ realizados com Daphnia magna e Chironomus tentans e por WHITEMAN (1996), nos estudos sobre a toxicidade da amônia em testes com sedimento total, utilizando Lumbriculus variegatus, Chironomus tentans e Hyalella azteca. Por outro lado, os testes com solubilizado permitem avaliar o impacto causado aos organismos pelágicos pela ressuspensão do sedimento de estuários e reservatórios (ROSS \& HENEBRY, 1989; GIESY \& HOKE 1989; GIESY et al, 1990).

ROSS \& HENEBRY (1989), utilizaram três testes agudos (Microtox, Selenastrum capricornutum e Panagrellus redivivus) e um teste "in situ" com a comunidade microbiana para avaliar o impacto de sedimentos contaminados de dois locais do Lago Michigan, USA. Os testes de laboratório foram realizados com o 
solubilizado, para simular possíveis distúrbios no sedimento, capazes de liberar contaminantes para a coluna d'água e os resultados encontrados mostraram concordância com os testes "in situ".

Os estudos conduzidos por ANKLEY (1991), comparando a toxicidade do sedimento total, água intersticial e solubilizado de 29 amostras de sedimento coletadas durante dois anos pela Agência de Proteção Ambiental dos Estados Unidos (EPA), nos Grandes Lagos e rios de Michigan, Nova York e Illinois, mostraram maior toxicidade na água intersticial sendo essa fração a que melhor representava a toxicidade do sedimento total para os organismos bentônicos Hyalella Azteca e Lumbriculus variegatus. No entanto, com relação à toxicidade para os peixes, comparada com a do sedimento total, os autores não observaram diferenças estatisticamente significativas entre as duas frações líquidas, o que confirma a premissa de GIESY et al (1990), de que o solubilizado permite avaliar o impacto causado aos organismos de coluna d'água pela ressuspensão do sedimento em estuários e reservatórios. 


\section{2 - OBJETIVOS}

\section{1 - Objetivo Geral}

Realizar uma avaliação ecotoxicológica do sedimento de reservatórios, analisando de forma integrada os resultados dos testes de toxicidade e das análises químicas utilizando o estudo de Avaliação e Identificação da Toxicidade - AIT.

\section{2- Objetivos Específicos}

2.2.1 - Avaliar a toxicidade do sedimento total e de seu solubilizado utilizando testes de toxicidade aguda e crônica.

2.2.2 - Caracterizar o sedimento em relação às variáveis físico-químicas $(\mathrm{pH}$, potencial redox, oxigênio dissolvido), químicas (fósforo, nitrogênio, carbono orgânico total, sulfetos, amônia) e metais potencialmente disponíveis (cádmio, cobre, cromo, chumbo, zinco, níquel, ferro, manganês e magnésio).

2.2.3 - Realizar o estudo de Avaliação e Identificação da Toxicidade (AIT) no sedimento dos Reservatórios de Barra Bonita, SP, Salto Grande, Americana, SP e Rasgão, São Paulo, SP, utilizando como fase líquida o solubilizado. 


\section{3 - HIPÓTESES}

3.1 - O acúmulo de nutrientes e substâncias tóxicas nos sedimentos representa um risco potencial para a qualidade dos ecossistemas aquáticos, uma vez que os sedimentos funcionam como depósito e fonte de contaminação para os organismos bentônicos e para a coluna d'água.

3.2 - A toxicidade do sedimento pode ser causada por outros fatores que não os contaminantes inorgânicos (metais pesados) e/ou orgânicos sintéticos. Ainda que presentes esses compostos podem estar imobilizados nos sedimentos.

3.3 - Os compostos ou a classe de compostos responsáveis pela toxicidade de sedimentos contaminados podem ser identificados através do estudo de Avaliação e Identificação da Toxicidade - AIT. 
CAPÍTULO 1

AVALIAÇÃO ECOTOXICOLÓGICA DE SEDIMENTOS DE RESERVATÓRIOS 


\section{4 - AVALIAÇÃO ECOTOXICOLÓGICA DE SEDIMENTOS DE RESERVATÓRIOS}

\section{1 - REVISÃO BIBLIOGRÁFICA}

\subsection{1 - Contaminação dos Sedimentos.}

A atual extensão da contaminação de sedimentos continentais e marítimos e as conseqüências dessa contaminação, não apenas à biota aquática como também à saúde humana, mostrou a necessidade do controle de qualidade dos sedimentos. Da mesma forma que no controle da qualidade de água, as avaliações ecotoxicológicas dos sedimentos têm sido reconhecidas como extremamente necessárias. No entanto, a grande variabilidade e a complexidade da composição dos sedimentos naturais dificultam o entendimento das interações entre o sedimento e a coluna d'água e o sedimento e a biota e o estabelecimento das relações entre a toxicidade com as concentrações das substâncias químicas. Alguns fatores específicos, tais como biodisponibilidade, bioturbação, deposição, erosão e compactação do sedimento, entre outros, faz com que o controle de qualidade de sedimentos seja mais complexo que o das águas. Dentre esses fatores, a natureza sedimento-específica da biodisponibilidade dos contaminantes é uma das principais dificuldades ao estabelecimento de critérios de qualidade que possam ser utilizados para diferentes tipos de sedimento (KNEZOVICH et al. 1987; BURTON \& SCOTT, 1992; GIESY \& HOKE , 1989).

Os metais pesados e os compostos orgânicos sintéticos, duas classes importantes de contaminantes ambientais, apresentam, apesar das diferenças químicas, algumas semelhanças em relação ao ciclo biogeoquímico no meio aquático. De modo geral, eles se adsorvem no material particulado orgânico e são assimilados pelos organismos detritívoros e/ou pelo fitoplâncton, através do qual chegam aos peixes e ao homem. Durante o ciclo de assimilação, excreção e reassimilação na cadeia alimentar, esses agentes químicos se concentram e se acumulam ao longo da mesma, em níveis bastante superiores em relação à concentração na água. O sedimento, as manchas de óleo e o tecido gorduroso dos carnívoros constituem os seus principais depósitos, sendo os organismos bentônicos os mais diretamente afetados. A concentração dos metais 
associados ao material particulado, incluindo organismos vivos, é várias ordens de magnitude maior que em solução na água. Em áreas não poluídas a concentração no sedimento chega ser da ordem de $10^{3}$ a $10^{7}$ vezes maior, enquanto que em áreas poluídas pode ser da ordem de $10^{5}$ a $10^{9}$ vezes (WESTMAN, 1985).

\section{a) Metais no Sedimento}

As principais fontes de introdução de metais nos ecossistemas aquáticos são os processos físicos e químicos naturais (lixiviação de solos e rochas e atividade vulcânica) e as atividades humanas, envolvendo a mineração, o processamento e a utilização de metais em diferentes processos industriais. Os processos físicos e químicos são responsáveis pela presença natural de um determinado nível de metais, variável em função da constituição geoquímica dos sedimentos. Um estudo realizado em 74 lagos de várias regiões mostrou que essa variabilidade é menor para zinco e cobre e maior para chumbo, mercúrio, cádmio, manganês, cromo e níquel (FÖRSTNER ${ }^{1}, 1977$ apud JACKSON,1991) .

As atividades antrópicas são responsáveis, principalmente, pelo aumento dos níveis de $\mathrm{Pb}, \mathrm{Cd}$, Hg e Zn em águas de superfície, uma vez que esses metais, entre outros, participam de uma extensa gama de processos industriais, tanto como matéria prima, como na forma de sub-produtos (MEYBECK $^{2}$ et al, 1989 apud JACKSON,1991; ANKLEY et al.,1996). Na Tabela 1 estão apresentadas diferentes atividades industriais que utilizam e liberam metais pesados.

Independente da fonte de contaminação, natural ou antrópica, os rios constituem o principal meio de transporte de metais pesados e outros contaminantes em solução, suspensão ou em associação com sólidos em suspensão, para mares, lagos e reservatórios. Como exemplo temos os rios Niagara e Reno responsáveis,

\footnotetext{
${ }^{1}$ FÖRSTNER ${ }^{1}$, 1977. Metal concentrations in recent lacustrine sediments. Arch. Hydrobiol., 80, 172-191 apud JACKSON, J. (1991) Heavy metals and others inorganic toxic substances. In: MATSUI, S., (ed). Toxic substances management in lakes and reservoirs. OTSU, ILEC - UNEPE .4. Cap5, p:65-79 (Guielines of Lake Management).

${ }^{2}$ MEYBECK' M; CHAPMAN, D.V.;HELMER, R.. 1989. Global freshwater quality: a first assessment. WHO/UNEP. Blackwell Reference, Oxford apud JACKSON, J. (1991) Heavy metals and others inorganic toxic substances. In: MATSUI, S., (ed). Toxic substances management in lakes and reservoirs. OTSU, ILEC - UNEPE .4. Cap5, p:65-79 (Guielines of Lake Management).
} 
respectivamente, pelo transporte de metais para o Lago Ontário e para os sedimentos da costa norte da Europa (THOMAS ${ }^{3}$ et al, 1988 apud JACKSON,1991).

Para muitos lagos ou reservatórios, a atmosfera constitui também uma importante rota de transporte. Sua importância depende da proximidade do corpo d’água com as fontes antropogênicas de poluição do ar e da relação entre a área da bacia de drenagem e a área da superfície do lago, sendo que, quanto menor a área da bacia de drenagem, maior será a importância da atmosfera como rota de contaminação. Segundo SCHMIDTKE \& ANDREN ${ }^{4}$ (1984) apud JACKSON (1991), 50\% dos metais presentes nos Grandes Lagos entraram a partir da atmosfera, na forma de chuva. Em áreas industriais, os despejos industriais líquidos e a atmosfera contribuem com igual importância como fonte de introdução de metais. O inventário de fontes de contaminantes realizado no sedimento do lago Eire, Canadá, mostrou que, em relação aos metais cobre, chumbo e zinco, a atmosfera contribuiu com 20, 35 e 50\%, enquanto que os efluentes contribuíram com 45, 20 e 30\%, respectivamente.

Tabela 1- Metais presentes nas diferentes atividades industriais

\begin{tabular}{|l|c|c|c|c|c|c|c|c|}
\hline Indústria & As & Cd & Cr & Cu & Pb & Hg & Se & Zn \\
\hline Mineração / metalurgia & $\mathrm{x}$ & $\mathrm{x}$ & $\mathrm{x}$ & $\mathrm{x}$ & $\mathrm{x}$ & $\mathrm{x}$ & $\mathrm{x}$ & $\mathrm{x}$ \\
\hline Cosméticos / corantes & & $\mathrm{x}$ & $\mathrm{x}$ & $\mathrm{x}$ & $\mathrm{x}$ & $\mathrm{x}$ & $\mathrm{x}$ & \\
\hline Pesticidas & $\mathrm{x}$ & & & & $\mathrm{x}$ & $\mathrm{x}$ & & $\mathrm{x}$ \\
\hline Elétrica \& eletrônica & & & & $\mathrm{x}$ & $\mathrm{x}$ & $\mathrm{x}$ & $\mathrm{x}$ & \\
\hline Limpeza e reprodução & $\mathrm{x}$ & & $\mathrm{x}$ & $\mathrm{x}$ & $\mathrm{x}$ & & $\mathrm{x}$ & \\
\hline “Eletroplating”/ acabamento & & & $\mathrm{x}$ & $\mathrm{x}$ & & & & $\mathrm{x}$ \\
\hline Química & & & $\mathrm{x}$ & $\mathrm{x}$ & & $\mathrm{x}$ & & \\
\hline Explosivos & $\mathrm{x}$ & & & $\mathrm{x}$ & $\mathrm{x}$ & $\mathrm{x}$ & & \\
\hline Borracha / plástico & & & & & & $\mathrm{x}$ & & \\
\hline Baterias & & $\mathrm{x}$ & & & $\mathrm{x}$ & $\mathrm{x}$ & & \\
\hline Farmacêuticas & $\mathrm{x}$ & & & & & $\mathrm{x}$ & & \\
\hline Têxteis & & & $\mathrm{x}$ & $\mathrm{x}$ & & & & \\
\hline Petróleo e carvão & $\mathrm{x}$ & & & & $\mathrm{x}$ & & & \\
\hline Papel e celulose & & & & & & $\mathrm{x}$ & & \\
\hline Couro & & & $\mathrm{x}$ & & & $\mathrm{x}$ & & \\
\hline
\end{tabular}

Fonte: (FÖRSTNER 1990)

\footnotetext{
3 THOMAS, R.L. (1988) Contaminants in lake Ontário - a case study apud JACKSON, J. (1991) Heavy metals and others inorganic toxic substances. In: MATSUI, S., (ed). Toxic substances management in lakes and reservoirs. OTSU, ILEC - UNEPE .4. Cap5, p:65-79 (Guielines of Lake Management).

${ }^{4}$ SCHMIDTKE, J.A. \& ANDREN, A W. (1984). Deposition of airborne metals in the Great Lakes: An evaluation of past and present estimates. apud JACKSON, J. (1991) Heavy metals and others inorganic toxic substances. In: MATSUI, S., (ed). Toxic substances management in lakes and reservoirs. OTSU, ILEC - UNEPE .4. Cap5, p:65-79 (Guielines of Lake Management).
} 
A importância de cada uma das fontes de introdução de poluentes varia de acordo com o corpo d’água e o poluente em questão. Estimativas do aporte e comportamento dos metais em lagos ou reservatórios podem ser obtidas através de balanço de massa, a partir dos dados do volume do lago, vazão, taxa de sedimentação, concentração de sólidos em suspensão e coeficiente de distribuição do particulado, com base no pressuposto de que os fluxos de entrada, saída e volume do lago ou reservatório são constantes, na simplificação das interações físicas, químicas e biológicas e na diferenciação entre o tempo de residência da água no lago e o tempo de persistência do metal na água (JACKSON,1991).

Transporte de Metais: A mobilização dos metais pesados em lagos ou reservatórios depende da natureza do contaminante e das características do sistema em questão, tais como circulação, estratificação térmica e mistura, que definem, por exemplo, a velocidade e a direção das plumas de contaminação.

De acordo com BOUDOU \& RIBEYRE (1989), os mecanismos que determinam a distribuição dos poluentes na coluna d'água são complexos e dependem da interação de três componentes básicos: condições de descarga, que definem a concentração e o tipo de poluente, as propriedades físicas e químicas do poluente e do meio receptor e as reações e interações entre o poluente e os fatores bióticos e abióticos do meio. Essas interações irão definir, para cada composto químico um padrão específico de distribuição nos diferentes compartimentos do ecossistema (coluna d'água, sedimento e biota), de bioacumulação e de transferência através dos vários níveis tróficos.

Segundo JACKSON (1991), a complexação de metais com substratos orgânicos e/ou inorgânicos é um importante processo de remoção de metais da coluna d’água. No caso dos substratos orgânicos, essa ligação pode ocorrer com as substâncias de baixo peso molecular (aminoácidos e açúcares, por exemplo), com os polímeros (ácidos fúlvicos e húmicos), e/ou com os colóides de alto peso molecular. Através desse processo, quantidades significativas de metais se associam com a matéria orgânica em solução ou com o material particulado orgânico ou inorgânico, diminuindo sua biodisponibilidade. As substâncias orgânicas e/ou inorgânicas em solução ou suspensão e a biota aquática funcionam, portanto, como reservatórios de metais pesados e meio de transporte para os sedimentos. Dentre os diferentes processos responsáveis pela presença de metais pesados nos sedimentos, a complexação e floculação com matéria 
orgânica, a co-precipitação com hidróxido de ferro e óxidos de manganês e a bioacumulação são os mais importantes.

A concentração de metais no sedimento depende do tamanho e composição dos grãos, sendo maior em argila e menor em areia. Uma vez sedimentados, as reações de oxi-redução, muitas delas mediadas biologicamente pelos microrganismos presentes, determinarão a mobilidade e a forma desses contaminantes. Em ambientes reduzidos, alguns metais, por exemplo, ferro e manganês, são liberados para a coluna d’água, tornando-se novamente biodisponíveis. No Lago Ohakuri, Nova Zelândia, a estratificação térmica e a redução da concentração de oxigênio do sedimento e do hipolíminio reduziu o Fe (III) presente na camada superficial do sedimento para Fe(II) e nesse processo houve liberação do arsênio (em sua forma mais tóxica) para a água intersticial e para o hipolímnio. Em condições normais de oxigênio, o arsênio permanece adsorvido ao hidróxido de ferro. Por outro lado, nas mesmas condições de concentração de oxigênio, o Cd, $\mathrm{Cu}, \mathrm{Ni}, \mathrm{Pb}$, e Zn, são imobilizados na forma de sulfetos insolúveis (MATSUI, 1991).

Além das reações de oxi-redução, os processos de ressuspensão de origem física, (correntes e ondas), biológica (atividade dos organismos bentônicos) e humana (dragagens e navegação) são também responsáveis pela liberação dos metais dos sedimentos para a coluna d’água. As dragagens, onde sedimentos contaminados são dragados e depositados em aterros ou mesmo na água, constituem um dos principais processos de remobilização de metais (FÖRSTNER et al 1989).

Toxicidade de Metais: os efeitos tóxicos dos metais sobre a biota dependem de vários fatores, entre eles a forma físico-química do metal (especiação) e as características físico-químicas da água e do sedimento. A especiação é uma característica bastante importante para a biodisponibilidade e a toxicidade, uma vez que, diferentes espécies químicas de um mesmo elemento apresentam diferentes efeitos biológicos (MORRISON, et al. 1989).

Os metais-traço, dissolvidos ou ligados ao material particulado, estão presentes em águas superficiais sob diferentes formas. Na fase solúvel, formada por íons hidratados, complexos orgânicos e inorgânicos e por espécies associadas com dispersões coloidais heterogêneas, os metais se encontram em mais de um estado de valência. As diferentes espécies de metais coexistem no ambiente aquático, nem sempre 
em equilíbrio e a diferenciação das espécies é dificultada pelo fato de que as concentrações em águas naturais podem ser menores que $10 \mu \mathrm{g} . \mathrm{L}^{-1}$. A identificação das diferentes formas de metal presentes é importante para o entendimento das relações entre as fases solúvel, particulada, sedimentada e biológica e para a identificação da toxicidade e biodisponibilidade. A interação dos metais com os compartimentos intracelulares é altamente dependente de sua forma química. Algumas espécies são ligadas com proteínas extracelulares, outras são adsorvidas às paredes celulares e outras são difundidas através das membranas celulares, são assimiladas e influenciam reações enzimáticas. A inativação química de proteínas constitui a principal ação tóxica. Todas os metais divalentes reagem rapidamente com os grupos amino, imino e sulfídrico das proteínas e alguns deles competem com os elementos essenciais, como o zinco, por exemplo, deslocando-os de seus sítios de ligação. Mesmo em concentrações inferiores aos limites de potabilidade, a prata e o cobre são prejudiciais à biota aquática (MORRISON, et al. 1989; FORSTNER, 1990).

Em relação às características das águas, a dureza e a concentração de ácidos orgânicos, principalmente os húmicos e fúlvicos, atuam reduzindo ou aumentando a toxicidade de alguns metais, tais como cádmio, cobre e chumbo, seja pelo antagonismo entre cálcio/magnésio e cádmio, no caso da dureza, ou pela capacidade dos ácidos húmicos e fúlvicos complexarem o cobre e o chumbo (MORRISON et al., 1989; MATSUI, 1991).

Os estudos realizados por WINNER (1985) e WINNER \& GAUSS (1986), sobre a influência da dureza e a concentração dos ácidos húmicos na toxicidade e bioacumulação de cobre, cádmio e zinco para Daphnia magna e Daphnia pulex, mostraram que, em relação ao cobre, a concentração dos ácidos húmicos reduziu significativamente a toxicidade aguda e crônica, independentemente da dureza, enquanto que variações na dureza influenciaram a bioacumulação; quanto ao cádmio a toxicidade diminuiu com o aumento da dureza de 57 para 115 ou 230 mg. $\mathrm{L}^{-1}$ e a bioacumulação não foi modificada na presença ou ausência de ácidos húmicos; em relação ao zinco, o aumento na dureza e a associação ácido húmico/água mole, reduziram significativamente a toxicidade crônica, após 50 dias de exposição a $125 \mu$ g Zn.L ${ }^{-1}$ e o acúmulo de zinco pelo exoesqueleto, mas não influenciou a bioacumulação.

De acordo com HALL Jr et al. (1998), os sais de cobre, especialmente cloreto e sulfato, são solúveis em água, permanecem no ambiente ligados ao material particulado 
e são concentrados nos organismos aquáticos com fatores de bioconcentração de 2.000 vezes, no caso de algas continentais e de até 28.000 vezes, nos bivalvos marinhos. Apesar de ser um micronutriente para plantas e animais, o cobre é tóxico para a biota aquática em concentrações maiores. Embora pouco se conheça sobre o mecanismo primário de toxicidade para plantas, os principais efeitos são inibição da fotossíntese e ruptura no crescimento. Os efeitos adversos em peixes estão relacionados com alterações histológicas nas guelras, nos rins, no tecido hematopoiético e nos receptores mecânicos e químicos. Efeitos sobre a reprodução, tais como redução na produção de ovos e na sobrevivência de jovens, também têm sido relatados. O cádmio, menos solúvel que o cobre, permanece nos sedimentos sendo bioacumulado nos organismos aquáticos com fatores de bioconcentração bastante elevados (cerca de 12.000 para peixes e 3.000 para poliquetos marinhos). Ao contrário do cobre, o cádmio é um elemento não essencial, com efeitos tóxico e mutagênico para a biota aquática. Os efeitos para algas e invertebrados estão relacionados com o aumento no volume celular e a inibição do fluxo de cálcio. Para peixes os efeitos estão relacionados com inibição de vários sistemas enzimáticos, tais como os envolvidos na neurotransmissão, no transporte transepitelial, no metabolismo intermediário e nas atividades antioxidantes. A exposição por longos períodos a concentrações não letais tem sido relacionada com deformações no esqueleto. Para vertebrados, os efeitos estão relacionados de um modo geral, com hipocalcemia, decorrente da inibição do fluxo de cálcio.

BODAR et al. (1988), estudaram os efeitos nas taxas de consumo e de assimilação de alimento e nos níveis de glicogênio, lipídios e proteínas de Daphnia magna expostas às concentrações de 1,0 e 0,5 ppb de cádmio. Os resultados mostraram a inibição dos processos metabólicos como um todo, embora nenhum processo tenha sido individualmente afetado.

Em relação à concentração ao longo da cadeia alimentar, segundo LAWS (1993), para alguns metais, como zinco, chumbo e cobre, parece haver de fato uma biomagnificação, enquanto que para outros esse aumento não é muito evidente. Resultados obtidos com amostras de fitoplâncton e zooplâncton marinhos, coletadas na região entre a Califórnia e o Havaí, mostraram que a concentração no zooplâncton foi substancialmente maior que no fitoplâncton. Para cádmio, mercúrio, prata e manganês, no entanto, essa diferença foi insignificante, o que impossibilita dizer até que ponto a biomagnificação ou as diferenças no equilíbrio de troca dos metais entre organismos e 
água são responsáveis pelo aumento na concentração de metais nos diferentes níveis tróficos.

Toxicidade e Biodisponibilidade: inúmeras pesquisas têm mostrado que a concentração de um determinado metal, capaz de causar efeito tóxico, pode variar de uma a várias ordens de magnitude entre diferentes sedimentos e, essas diferenças estão relacionadas com a biodisponibilidade do metal. A fração biodisponível de metais é definida como a fração da concentração total em cada reservatório abiótico que é absorvida pelos organismos. Essa fração compreende os metais fracamente ligados ao sedimento, que podem ser facilmente mobilizados (PLETTE et al., 1999). Vários estudos sugerem que uma maior fração dos metais é imobilizada nos sedimentos sob formas não biodisponíveis, levando a um decréscimo na concentração disponível para a biota (CALMANO et al., 1993; LACERDA, 1998).

De acordo com ANKLEY et al. (1996), os primeiros pesquisadores a elucidar a questão da biodisponibilidade foram W. J. Adams e colaboradores e R. C. Swartz e colaboradores. Esses autores demonstraram que a toxicidade de sedimentos contaminados com kepone ${ }^{\circledR}$, um pesticida organoclorado, e zinco estava relacionada com a concentração do contaminante na água intersticial. Posteriormente, Di TORO et al. (1992), propuseram as bases técnicas para o estabelecimento de critérios de qualidade de sedimentos para compostos orgânicos não iônicos, utilizando o modelo do equilíbrio de partição (Eq P) com base na concentração na água intersticial.

Existem evidências de que a biodisponibilidade está relacionada com as atividades químicas do metal no sistema sedimento/água intersticial, sendo fortemente influenciada pela concentração dos sulfetos volatilizáveis por acidificação (SVA). A base química que sustenta as relações metal/SVA/biodisponibilidade é que, em condições de equilíbrio o íon sulfeto compete, e ganha, em relação a outras possíveis fases de ligação com metal (por exemplo, matéria orgânica) formando sulfetos metálicos insolúveis (Di TORO et al., 1992).

Os sulfetos volatilizáveis por acidificação (SVA), definidos como a fração dos sulfetos extraída pelo ácido clorídrico, são constituídos, primariamente, em monosulfetos de ferro, encontrados nos sedimentos continentais ou marinhos anóxicos. Em ambientes marinhos que contêm grandes quantidades de sulfato (cerca de $28 \mathrm{mM}$ ) a redução microbiológica do sulfato constitui o principal processo de produção de 
sulfetos. Embora a concentração de sulfato em ambientes de água doce seja bem menor, da ordem de $0.12 \mathrm{mM}$, as concentrações elevadas de matéria orgânica, principalmente em lagos, são suficientes para a produção de concentrações detectáveis de sulfetos. Esses sulfetos reagem com ferro $\left(\mathrm{Fe}^{2+}\right)$ e com o manganês $\left(\mathrm{Mn}^{2+}\right)$ para formar o sulfeto de ferro e de manganês, facilmente extraídos por ácidos (WANG \& CHAPMAN, 1999).

Alguns metais catiônicos divalentes, tais como cádmio, cobre, mercúrio, níquel, chumbo e zinco, substituem o ferro formando sulfetos menos solúveis que os sulfetos de ferro. A concentração de SVA tem sido utilizada na predição da toxicidade para organismos bentônicos, com base na teoria do equilíbrio de partição, onde a biodisponibilidade de um metal depende da interação tripartite entre a água intersticial, a concentração de SVA e os organismos (PESCH et al., 1995; SIBLEY et al., 1996).

Inúmeros estudos foram realizados com o objetivo de avaliar a relação dos sulfetos volatilizáveis por acidificação com a bioacumulação e toxicidade aos organismos bentônicos (PESCH et al., 1995; BERRY et al., 1996; HANSEN et al., 1996; LIBER et al., 1996; SIBLEY et al., 1996). De acordo com a revisão realizada por ANKLEY (1996), a maioria dos resultados obtidos em 12 estudos com sedimentos de campo e sedimentos contaminados em laboratório com cádmio, cobre, chumbo, níquel e/ou zinco indicaram, de forma predominante, a redução na bioacumulação dos metais para a razão metal/SVA inferior a 1. No entanto, alguns estudos com sedimentos contaminados com cádmio e zinco mostraram resultados contrários, sugerindo a presença de outros fatores atuando também como controladores da bioacumulação de metais a partir dos sedimentos (por exemplo, a matéria orgânica). A aplicabilidade dos SVA na normalização de sedimentos de água doce pode ser complicada pela variabilidade espacial e temporal da concentração de SVA. A formação e estabilidade de sulfetos em ambientes continentais são influenciadas pela interação de vários fatores bióticos e abióticos, incluindo a concentração de sulfatos, carga de matéria orgânica, condições redox e temperatura (BESSER et al., 1996).

\section{b) Compostos Orgânicos no Sedimento}

De acordo com ASHLEY \& BAKER (1999), os contaminantes orgânicos hidrofóbicos, tais como os hidrocarbonetos policíclicos aromáticos (PAHs) e bifenilas policloradas (PCBs), são chamados de “new”ou “in-place”contaminantes, sendo “new” aqueles que chegam nos ecossistemas aquáticos via escoamento urbano e agrícola ou 
deposição atmosférica. Os chamados “in-place” são aqueles existentes no ambiente e que foram remobilizados para a coluna d'água. A preocupação com tais contaminantes levou a Agência de Proteção Ambiental dos Estados Unidos, EPA, a estabelecer critérios de qualidade de sedimentos para proteção dos organismos bentônicos e epibentônicos para inúmeros compostos orgânicos não-iônicos. Da mesma forma, desde 1984, a National Oceanic and Atmospheric Administration's (NOAA) National Status \& Trends (NS\&T) vem monitorando tais contaminantes nos sedimentos costeiros e estuarinos. Toda essa preocupação decorre da persistência, toxicidade e carcinogenicidade potencial aos organismos aquáticos, principalmente aos peixes e ao homem. Cerca de $70 \%$ dos compostos químicos orgânicos sintéticos produzidos nos Estados Unidos são utilizados na agricultura e até a década de 50 pouco se conhecia sobre a importância desses compostos como contaminantes ambientais.

Dentre os agrotóxicos, os compostos organoclorados têm uma grande importância ambiental devido a sua alta toxicidade e persistência no ambiente. Comparados às outras classes de agrotóxicos, os organofosforados, carbamatos, os piretróides e os derivados da uréia entre outros, são muito mais estáveis devido às ligações carbono-cloro ( $\mathrm{CHEE}^{5}$ et al., apud BRONDI, 2000)

Existem três grupos principais de agrotóxicos organoclorados: 1) DDT e substâncias relacionadas, tais como DDE e DDD, utilizadas na saúde pública para o controle da malária; 2) lindano (hexaclociclohexano) ou BHC e produtos relacionados; e 3) grupo dos “drins”, tais como aldrin e dieldrin, utilizados para proteção de sementes (BRONDI, 2000).

Os PCBs são formados pela cloração direta das bifenilas e são quimicamente muito parecidos com DDT, dieldrin e aldrin mas, ao contrário dos pesticidas, eles foram desenvolvidos principalmente para uso em sistemas fechados (transformadores, capacitores, bombas de vácuo e compressores e fluídos hidráulicos). Semelhantes aos agrotóxicos em suas propriedades físicas, químicas e toxicológicas e disseminação nos

${ }^{5}$ CHEE, K.K; WONG, M.K.; LEE, H.K. (1996). Determination of oragnochlorine pesticides in water bymenbranous solid-phase extraction and in sediment by microwave-assisted solvent extraction with gas chromatography and eletron capture and mass spectrometric detection. J. Chromatogr.A, 736, 211-218.apud BRONDI, S..H.G. (2000). Determinação de multiresíduos de agrotóxicos em águas de abastecimento.do município de Araraquara: Ribeirão das Cruzes, Ribeirão Anhumas e Córrego do Paiol. p:5-15. Tese (Doutorado). Escola de Engenharia de São Carlos-USP 
diferentes ambientes, as bifenilas policloradas (PCBs) têm sido abordadas em conjunto nos estudos sobre poluentes químicos no meio aquático.

De acordo com CALHEIROS (1993), a contaminação do meio aquático pelos agrotóxicos e PCBs ocorre através do escoamento agrícola, lixiviação profunda, via lençol freático, operações agrícolas de pulverização, limpeza e manejo de embalagens, efluentes industriais e urbanos e deposição atmosférica. Para os PCBs, as principais fontes são transporte atmosférico devido a incineração incompleta de produtos contendo PCBs, descarte inadequado de transformadores e capacitores, efluentes industriais, tintas utilizadas na pintura de cascos de embarcações e extravasamento acidental de capacitores. Tanto um como outro pode ser transportado a longas distâncias através da volatilização e das partículas de água.

$\mathrm{Na}$ água, esses compostos e seus produtos de degradação se distribuem entre formas dissolvidas e incorporadas nos compartimentos bióticos (plâncton, plantas aquáticas e peixes) e abióticos (material em suspensão e sedimentos).

PAHs, HAHs (hidrocarbonetos aromáticos halogenados), tais como DDTs e derivados, HCH (hexaclorobenzenos), PCBs, PCDs, (dibenzo-p-dioxinas policloradas) PCDFs (dibenzofuranos policlorados) têm sido detectado no ambiente nos últimos 30 anos, mas na maior parte das vezes, em concentrações inferiores às concentrações de efeito tóxico.

OKAMURA et al. (1996), fizeram uma avaliação ecotoxicológica no entorno do lago Kojima, um lago artificial situado no sudoeste do Japão, que recebe contribuições de áreas agrícolas e industriais. Amostras concentradas de água e sedimento de 16 locais foram analisadas por uma série de testes de toxicidade com diferentes organismos-teste (Bacillus cereus, Saccharomices cerevisiae, Selenastrum capricornutum, Daphnia magna e sementes de alface). As amostras de água causaram toxicidade diferenciada para cada organismo-teste utilizado. Dentre os pesticidas analisados, foram identificados dymron $^{\circledR}$, mefenacete ${ }^{\circledR}$ e flutolanil ${ }^{\circledR}$, em concentrações que variaram de 1 a $30 \mu \mathrm{g} . \mathrm{L}^{-1}$ de água. Uma vez que essas concentrações são inferiores aos valores de CE50,48h determinados para Daphnia magna (5 e >10 mg. $\mathrm{L}^{-1}$ ), os autores relacionaram a toxicidade da água aos efeitos sinérgicos dos diferentes pesticidas. Em relação ao sedimento, o enxofre elementar foi o composto responsável pela toxicidade.

BESSER et al. (1996a) avaliaram a qualidade do sedimento em duas áreas, dragadas e não dragadas do canal de Trenton, rio Detroit, USA utilizando a tríade de 
qualidade, e os resultados mostraram relação entre as concentrações de metais e de PHAs, a toxicidade dos sedimentos e as características da comunidade bentônica. As concentrações de PHAs totais variaram entre 24.3 e $218.4 \mu \mathrm{g}^{-\mathrm{g}^{-1}}$ e, dentre os compostos detectados, os mais abundantes foram fluoranteno, pireno e benzo (a) antraceno.

Embora as concentrações de PAHs, PCBs e pesticidas que tem sido encontradas nos ambientes aquáticos estejam abaixo dos valores de efeito agudo, os estudos realizados por FAIREY et al (1998) e CARR et al. (2000) nos sedimentos da baia de San Diego, Califórnia e baia de Corpus Christi, Texas, detectaram PAHs, PCBs, clordane, dieldrin, DDT total, DDD, DDE, antraceno, fluorantraceno, naftaleno e muitos outros em concentrações de efeito provável (PEL), efeito baixo (ER-L) ou efeito médio (ER-M). Essas concentrações são utilizadas para avaliar os impactos da presença de contaminantes associados ao sedimento.

ASHLEY \& BAKER (1999), realizaram um estudo no sistema Baltimore Harbor/Patapsco river/Back river, uma das regiões mais poluídas da baia de Chesapeake, USA, envolvendo a análise de 32 PAHs e 113 PCBs. As concentrações de PAHs e PCBs variaram entre 90 - 46.200 e 8 - 2150 ng.g g $^{-1}$ de peso seco, respectivamente. As maiores concentrações de PCBs foram encontradas próximas aos locais com maior escoamento urbano, enquanto que as de PHAs, estavam próximas a um complexo industrial, provenientes da pirólise do carvão.

KHIM et al (1999) caracterizaram os compostos orgânicos alquilfenois , tais como nonilfenol e octilfenol, PAHs e organoclorados presentes no lago Shiwwa, um lago artificial, construído em 1994, na costa oeste da Coréia. Esse lago recebe contribuições de zonas densamente habitadas e complexos industriais e, a construção da barragem resultou em uma grave deterioração ambiental. Os compostos nonilfenol (NP) e octilfenol (OP) foram detectados em concentrações de 20,2 a 1850 e 4,69 a 50,5 ng.g ${ }^{-1}$ de peso seco respectivamente. As concentrações de NP foram semelhantes às encontradas nos sedimentos dos grandes lagos e rios dos Estados Unidos. Em relação aos PCBs, as concentrações encontradas variaram entre 16,9 e 30,8 ng.g ${ }^{-1}$ e dentre os PAHs analisados só foram encontrados fluoranteno e pireno. As concentrações dos compostos organoclorados foram inferiores a $10 \mathrm{ng} \mathrm{g}^{-1}$ para todos os pontos amostrados.

Os alquilfenois são produtos da degradação do etoxilato de alquilfenois, largamente utilizado em detergentes, pinturas, agentes emulsificantes e agentes dispersantes de uso agrícola e industrial. Esses produtos têm sido utilizados e 
descartados no ambiente desde a década de 40, porém existem poucos estudos sobre a ocorrência desses contaminantes nos sedimentos .

No Brasil, o estudo recentemente realizado por ALMEIDA (2002), nos reservatórios do sistema Tietê, detectou concentrações de PAHs totais da ordem de 0,29 ng. $\mathrm{g}^{-1}$ no sedimento do reservatório de Promissão até 7,85 ng. $\mathrm{g}^{-1}$ para o do reservatório Billings, seguido pelo reservatório de Rasgão, com 4,143 ng.g ${ }^{-1}$. Nos sedimentos dos reservatórios de Bariri e Barra Bonita as concentrações encontradas variaram entre 0,331 a 0,783. Em relação aos PCBs, as concentrações variaram entre 4,4 e 2.846 ng.g ${ }^{-1}$ de arocloro, sendo que os valores mais altos foram encontrados no reservatório Billings.

Transporte dos Compostos Orgânicos: o transporte e o acúmulo de compostos orgânicos hidrofóbicos nos ambientes aquáticos são controlados pelos processos de adsorção e desadsorção nas partículas em suspensão e nos sedimentos. O processo de deposição nos sedimentos pode imobilizá-los permanentemente ou temporariamente. Em um reservatório, espera-se que as maiores concentrações de pesticidas e PCBs sejam encontradas próximo à barragem, onde se depositam as partículas mais finas do sedimento, que apresentam o maior grau de adsorção. Quanto menor o tamanho da partícula, maior sua área superficial e maior a adsorção das moléculas de pesticidas e PCBs. Tal como ocorre nos compartimentos água e solo, o processo de adsorção no material particulado em suspensão está diretamente relacionado com o conteúdo de matéria orgânica. Maiores ou menores quantidades de matéria orgânica e argila determinam a distribuição dos pesticidas e PCBs na coluna d’água ou sedimentos. Em ambientes não poluídos a concentração desses compostos na água e nos peixes tende a ser maior que em ambientes eutrofizados no qual, o sedimento com alto teor de matéria orgânica promove a rápida adsorção, mantendo-os disponíveis para ressuspensão por períodos de 8 a 15 anos (CALHEIROS, 1993; BORGLIN et al., 1996).

SHARON $^{6}$ et al.(1980), apud CALHEIROS, (1993) testaram a adsorção e desadsorção de alguns organoclorados em solos e sedimentos com diferentes teores de matéria orgânica e composições de areia, silte e argila. Maior quantidade de MO e a associação MO e areia foram as condições de maior adsorção. Em relação a desadsorção

\footnotetext{
${ }^{6}$ SHARON, H.S. et al. (1980). Behavior of 12 insecticides in soil and aqueous suspensions of soil and sediment. Water Res.. v14. p:1095-100 apud CALHEIROS, D.F. (1993. Ecotoxicologia de compostos organoclorados persistentes em um sistema eutrófico: represa de Barra Bonita (Médio Tietê, SP). São Carlos. 168p. Dissertação. (Mestrado). Universidade São Paulo).
} 
os resultados foram inversos. Entre os compostos testados, a ordem de adsorção foi DDT $>$ dieldrin $>$ endrin $>$ lindano.

$\mathrm{Na}$ interface água-sedimento esses compostos podem ser transformados e incorporados na biomassa dos microrganismos presentes, como podem também permanecer disponível para a biota, em sua estrutura química original. De acordo com STRACHAN $^{7}$ et al (1982) apud CALHEIROS (1993), os principais fatores que determinam o processo de adsorção de pesticidas em sedimentos são: concentração de material em suspensão; conteúdo de argila e matéria orgânica; granulometria; concentração do composto; $\mathrm{pH}$; temperatura e oxigênio.

BORGLIN et al. (1996), estudaram o processo de desadsorção do hexaclorobenzeno e de três diferentes PCBs e os resultados mostraram que para o HCB, ela estava relacionada com o tamanho e densidade das partículas, o tipo de água, o conteúdo de matéria orgânica dos sedimentos e o tempo de adsorção do composto, antes da desadsorção. Em relação aos PCBs, esse processo é dependente do coeficiente de partição do composto químico, sendo que, quanto maior esse coeficiente, mais lenta será a desadsorção. Para PCBs altamente clorados e outros compostos químicos com coeficientes de partição altos, o tempo para a desadsorção é da ordem de anos.

Uma vez nos sedimentos, a teoria do equilíbrio de partição assume que a distribuição dos compostos químicos orgânicos não-iônicos entre os diferentes compartimentos sedimento, água intersticial e biota pode ser predita em função da hidrofobicidade do composto químico em questão e que a concentração dos compostos químicos entre os diferentes compartimentos se mantem em equilíbrio. A hidrofobicidade é dada pelo coeficiente de partição $\left(\mathrm{K}_{\mathrm{OW}}\right)$ entre n-octanol e água (HOKE et al., 1995).

Toxicidade e Biodisponibilidade: de acordo com KHIM et al. (1999), e CALHEIROS (1993), os efeitos da toxicidade dos compostos orgânicos hidrofóbicos aos organismos aquáticos incluem desde mortalidade até hepatotoxicidade, imunotoxicidade, carcinogenicidade e alterações no metabolismo que podem levar a diminuições nas taxas de reprodução, predação e decomposição.

\footnotetext{
7 STRACHAN, W.M.J. et al.(1982).Environmental impactand significance of pesticides. Analysis of pesticides im water Boca Raton, CRC Press, 82 v1, p:1-23.apud CALHEIROS, D.F. (1993. Ecotoxicologia de compostos organoclorados persistentes em um sistema eutrófico: represa de Barra Bonita (Médio Tietê, SP). São Carlos. 168p. Dissertação. (Mestrado). Universidade São Paulo).
} 
A susceptibilidade a um composto é intra-específica e, dentro de uma mesma espécie, ela depende tanto do tamanho e idade do organismo como também da quantidade do composto a que o organismo está exposto.

As rotas de entrada dos pesticidas e PCBs nos organismos ocorrem via absorção através do tegumento externo e brânquias, ou via ingestão de água e alimentos. Uma vez incorporados, os compostos organoclorados ou seus metabólitos passam para o conteúdo lipídico e as diferenças ou mudanças nesse conteúdo determinarão o grau de contaminação de cada organismo. O sexo, a idade, o tamanho e a fase do desenvolvimento influenciam o conteúdo lipídico em uma mesma espécie. Quando a quantidade de lipídeos é alta, os compostos assimilados ficam “armazenados”, evitando dessa forma sua entrada nas vias metabólicas e, conseqüentemente, o efeito tóxico (CALHEIROS, 1993).

O potencial de bioacumulação na biota é um dos principais aspectos da ecotoxicologia de compostos tóxicos persistentes. Esse processo é influenciado por vários fatores, entre eles as características químicas do composto, as condições físicas do meio, as características do próprio organismo, a concentração do composto no meio, a quantidade de alimento ingerido e as taxas de eliminação.

KNEZOVICH et al. (1987) fizeram uma revisão sobre os trabalhos de biodisponibilidade de compostos químicos associados ao sedimento e mostraram, desde então, que a bioacumulação estava associada a três fatores: 1) características da água intersticial; 2) taxa de ingestão do sedimento, tanto orgânico como inorgânico; e 3) contato direto com as partículas de sedimento e que a contribuição relativa de cada uma dessas fases era, até então, pouco entendida e dependia do tipo de sedimento, da classe do composto químico em questão e da espécie de organismo utilizado nos estudos.

Dentre as características químicas do composto, as principais são a estabilidade ou, o grau de persistência no ambiente, e o coeficiente de partição entre este e a mistura n-octanol/água. Teoricamente, os compostos com baixos $\mathrm{K}_{\mathrm{OW}}$, deveriam apresentar fatores de bioacumulação altos, pois, estando fracamente ligados e, portanto mais biodisponíveis, apresentam maior eficiência de assimilação. No entanto, nessas condições eles são também mais rapidamente eliminados, de forma que, ao contrário do esperado, apresentam fatores de bioacumulação baixos (CALHEIROS, 1993).

As relações entre o Kow e a intensidade de bioacumulação não são tão simples e existem outros fatores que interagem no processo. Segundo LANDRUM \& ROBBINS 
(1990), embora a principal característica que controla a bioacumulação dos compostos orgânicos apolares a partir dos sedimentos seja a hidrofobicidade, representada pelo coeficiente de partição $\mathrm{K}_{\mathrm{OW}}$, outros fatores, tais como a ionização ou reatividade química, que influenciam os processos de adsorção ou complexação às partículas de sedimento, reduzem também a biodisponibilidade.

Em relação ao sedimento, o conteúdo de matéria orgânica e de argila, tamanho e distribuição das partículas capacidade de troca iônica e pH são características importantes na relação adsorção e disponibilidade. Dentre essas, o carbono orgânico constitui um dos fatores mais importantes. A importância do carbono orgânico nesse processo, no entanto, varia em função do composto químico em questão. Embora os vários estudos revisados por KNEZOVICH et al. (1987), mostrassem que as interações entre compostos químicos orgânicos hidrofóbicos e as partículas de sedimento estivessem correlacionados com o conteúdo de carbono orgânico, para outros compostos, outros fatores, tais como o pH, são tão importantes quanto o carbono.

Dentre as características dos organismos, o estágio de desenvolvimento, tamanho, conteúdo lipídico e hábitos alimentares são fatores importantes que influenciam a transferência e a bioacumulação dos contaminantes a partir dos sedimentos (CALHEIROS, 1993). Esses fatores variam de importância, dependendo dos organismos e das condições ambientais. Em relação aos PCBs, KNEZOVICH et al. (1987) mostraram que, para as espécies marinhas Nereis virens e Crangon septenspinosa, a bioacumulação apresentava uma relação direta com o tempo de exposição ao composto e inversa com a idade dos organismos.

\subsection{2 - Aspectos Limnológicos, Ecológicos e Ecotoxicológicos dos Reservatórios de Barra Bonita e Salto Grande}

\section{a) Reservatório de Barra Bonita, SP}

O reservatório de Barra Bonita, por ser parte integrante do Sistema de Hidrovia do Tietê-Paraná e ser utilizado para irrigação, piscicultura, recreação, controle de enchentes, navegação, produção de energia elétrica e, principalmente, abastecimento da população local, tem sido objeto de estudo desde 1979 com o projeto “Tipologia de Reservatórios do Estado de São Paulo”. Estudos mais intensivos ou de longo prazo sobre variados aspectos físicos, químicos e biológicos, considerando-se, entre outros, o 
aporte de nutrientes, a sedimentação, o balanço de massa e a estrutura das comunidades, estão sendo realizados entre 1992 e 1996, através do Projeto Temático FAPESP $n^{0}$ 91/06212-5. Estes estudos mostraram um processo de eutrofização crescente (grandes “blooms de cianofíceas e proliferação de macrófitas) decorrente da alta carga orgânica recebida do aporte de tributários com alto grau de poluição e a conseqüente liberação de nutrientes, no corpo do reservatório. (CALIJURI \& TUNDISI (1990). Quanto aos aspectos ecotoxicológicos, os primeiros estudos datam da década de 80 (NAVAS-PEREIRA, et al., 1985; CÁCERES et al., 1987; CALHEIROS, 1993). Estudos limnológicos, ecotoxicológicos e de biodiversidade mais recentes tem sido realizados através dos projetos PRONEX (1997 a 2001), PROBIO (1998 e 2001) e QualiSed (2001).

Os estudos realizados por COSTA (2001), FRACACIO (2001) e RODGHER (2001), mostraram um comprometimento do sedimento em relação à toxicidade estando, essa toxicidade, nem sempre relacionada com a concentração dos compostos químicos detectados mas, provavelmente, ao estado geral de eutrofização e degradação do ambiente.

\section{b) Reservatório de Salto Grande, SP}

O reservatório de Salto Grande, Americana, SP, localiza-se numa região altamente industrializada do interior do Estado de São Paulo, com elevada demanda de água para os processos industriais e agrícolas. Este reservatório, formado pelo represamento do rio Atibaia, foi construído em 1940, com a finalidade de geração de energia elétrica, mas após apenas 60 anos, em decorrência dessa demanda e de sua utilização mal planejada, este corpo d’água encontra-se em estágio avançado de eutrofização e contaminação, comprometendo a capacidade para usos múltiplos do reservatório, principalmente em relação à utilização da água para abastecimento público.

Vários estudos limnológicos e ecológicos têm sido desenvolvidos a partir da década de 70 envolvendo diferentes aspectos da estrutura e funcionamento do reservatório. Os estudos ecotoxicológicos foram iniciados a partir de 1996, com o subprojeto "Avaliação do grau de toxicidade de água e sedimento do reservatório de Salto Grande, SP, e sua influência sobre organismos aquáticos" (projeto CNPq $\mathrm{N}^{\circ}$ 610.047/96-5 “Bases Limnológicas e Ecológicas para o Manejo da Qualidade da Água e 
Usos Múltiplos do Reservatório de Salto Grande”). Os resultados obtidos no período de setembro de 1996 a janeiro de 1998, mostraram alto potencial de toxicidade do sedimento, especialmente na porção final do reservatório, mais próxima à barragem. (ESPINDOLA et al., 1998).

TONISSI (1999), encontrou concentrações elevadas de metais biodisponíveis nos sedimentos analisados em diferentes pontos do reservatório de Salto Grande e nos tecidos de peixes coletados no reservatório. Em relação à toxicidade, os resultados dos testes "in situ" realizados com peixes e dos testes crônicos realizados com as larvas de Danio rerio confirmaram a toxicidade do local.

PAMPLIN (1999), encontrou indícios de toxicidade do sedimento da porção central deste reservatório para a espécie de peixe Hyphessobrycon eques, no período chuvoso e alterações na composição da comunidade macrobentônica, causada, provavelmente, por essa toxicidade.

Os resultados obtidos por DORNFELD (2002), sobre a comunidade macrobentônica evidenciaram não só alterações na composição da comunidade, com predominância de espécies indicadoras de poluição orgânica, como também contaminação dos organismos com metais. Em relação à toxicidade, a autora encontrou toxicidade aguda ou indícios de toxicidade em todas a amostragens realizadas.

FONSECA (1997) e MELETTI (1997), avaliando a toxicidade do sedimento de vários pontos da bacia do rio Piracicaba, encontraram toxicidade para invertebrados e peixes no ponto do rio Piracicaba correspondente à captação de água da cidade de Sumaré, ponto esse situado próximo à entrada do reservatório. 


\section{2 - MATERIAIS E MÉTODOS}

\subsection{1 - Caracterização da Área de Estudo}

\section{a) Reservatório de Barra Bonita}

O reservatório de Barra Bonita está localizado na região central do Estado de São Paulo, entre os municípios de Barra Bonita e Igaraçu, na latitude $22^{\circ} 29^{\prime}$ Sul e longitude $48^{\circ} 34^{\prime}$ Oeste, na região do Médio Tietê, no interior do estado. Construído em 1963 com a finalidade de geração de energia hidroelétrica, tem sido utilizado também para irrigação, piscicultura, recreação, abastecimento, controle de enchentes e para navegação, dentro da atual concepção de usos múltiplos.

Sua bacia de drenagem tem uma extensão de $32.330 \mathrm{~km}^{2}$ e seus principais formadores, os rios Tietê e Piracicaba, recebem descargas de águas residuárias de núcleos urbanos altamente povoados e industrializados, como São Paulo, Campinas, Sorocaba e Piracicaba. Além da contribuição industrial, a monocultura da cana de açúcar na bacia, predominantemente em seu entorno e ocupando uma área de mais de $1.100 \mathrm{~km}^{2}$, na parte média do vale do Tietê, é responsável pela introdução de agrotóxicos no reservatório.

Em relação às características morfométricas, o reservatório apresenta uma área inundada de 324,84 km², perímetro de $525 \mathrm{~km}$, profundidades média e máxima de 10 e $30 \mathrm{~m}$, respectivamente, e volume total de $3 \cdot 160.10^{6} \mathrm{~m}^{3}$.

A representação esquemática do Reservatório com a localização das estações de coleta das amostras de sedimento está apresentada na figura 1. As estações E1 e E2 estão localizadas nos aportes dos rios Piracicaba e Tietê, respectivamente. A estação E3 fica no final do reservatório, próximo à barragem. 


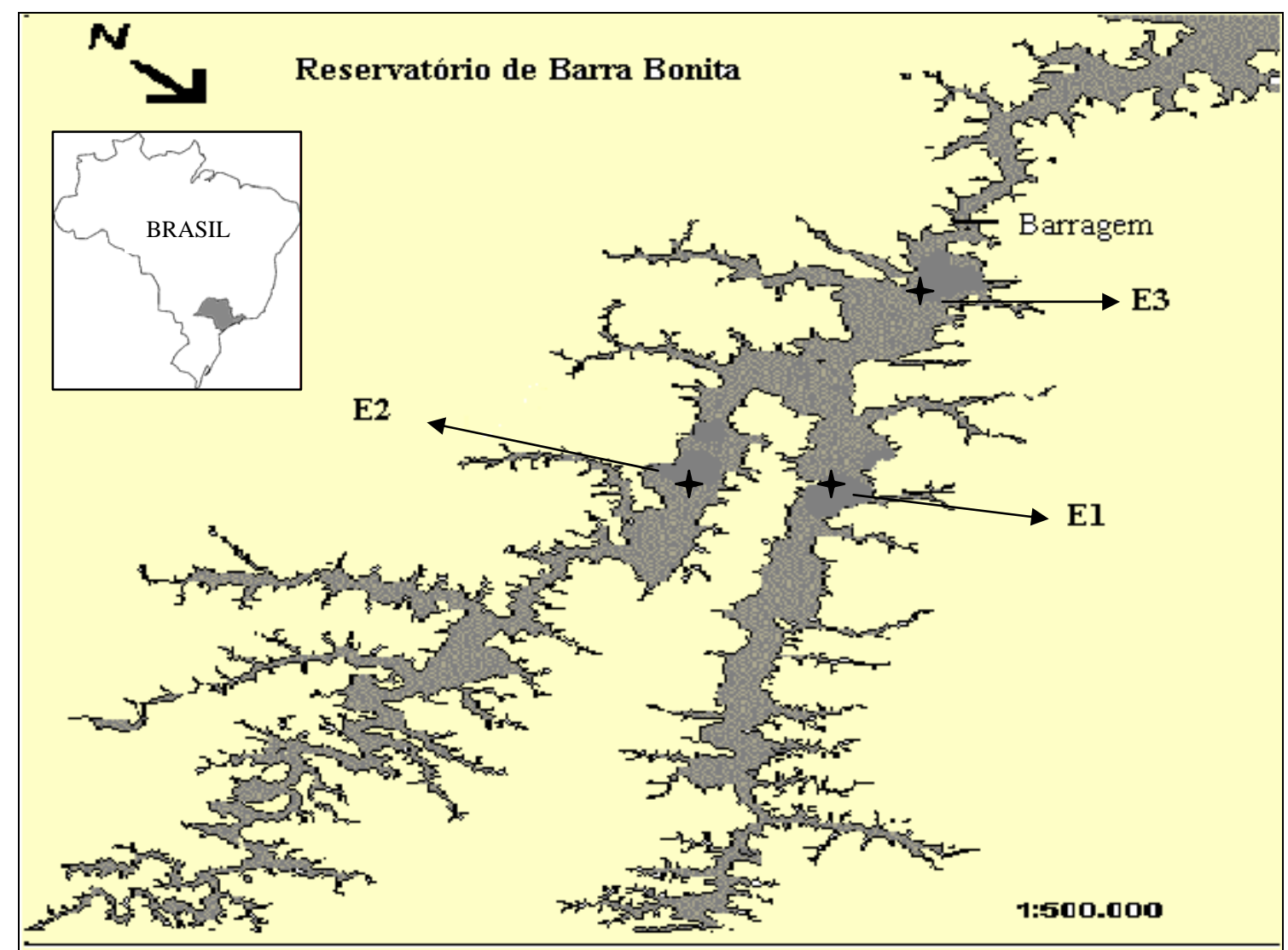

Figura 1 - Representação esquemática do reservatório de Barra Bonita com a localização das estações de amostragem.

\section{b) - Reservatório de Salto Grande}

O reservatório de Salto Grande está localizado no município de Americana, Estado de São Paulo, a $22^{\circ} 44^{\prime}$ de latitude sul, $44^{\circ} 19^{\prime}$ de longitude oeste e altitude de 530 metros, na bacia do rio Piracicaba. Foi construído também com a finalidade de geração de energia hidroelétrica pelo barramento do rio Atibaia. Atualmente é utilizado também para fins de abastecimento e recreação, apesar do avançado grau de eutrofização e contaminação de suas águas, resultante, principalmente, do lançamento de resíduos industriais e esgoto doméstico.

Sua bacia de drenagem tem uma extensão de $2.650 \mathrm{~km}^{2}$ e seu principal formador, o rio Atibaia, recebe contribuição de núcleos urbanos industrializados como Campinas e Paulínia, além de Piracaia, Nazaré Paulista, Bom Jesus dos Perdões, Atibaia, Jarinú, Vinhedo e Valinhos.

Em relação às suas características morfométricas, o reservatório apresenta uma área inundada de $11,5 \mathrm{~km}^{2}$, perímetro de $64 \mathrm{~km}$, comprimento de $17 \mathrm{~km}$, profundidade 
média e máxima de 9 e $19 \mathrm{~m}$, respectivamente, volume máximo de $1,06.10^{8} \mathrm{~m}^{3}$ e tempo de retenção médio de 30 dias.

A representação esquemática do reservatório com as estações de coleta das amostras de sedimento está apresentada na figura 2. A estação E1 se localiza ao longo do curso do rio, no $2^{0}$ compartimento do reservatório e a estação E2, na porção final, na área de estreitamento do reservatório.

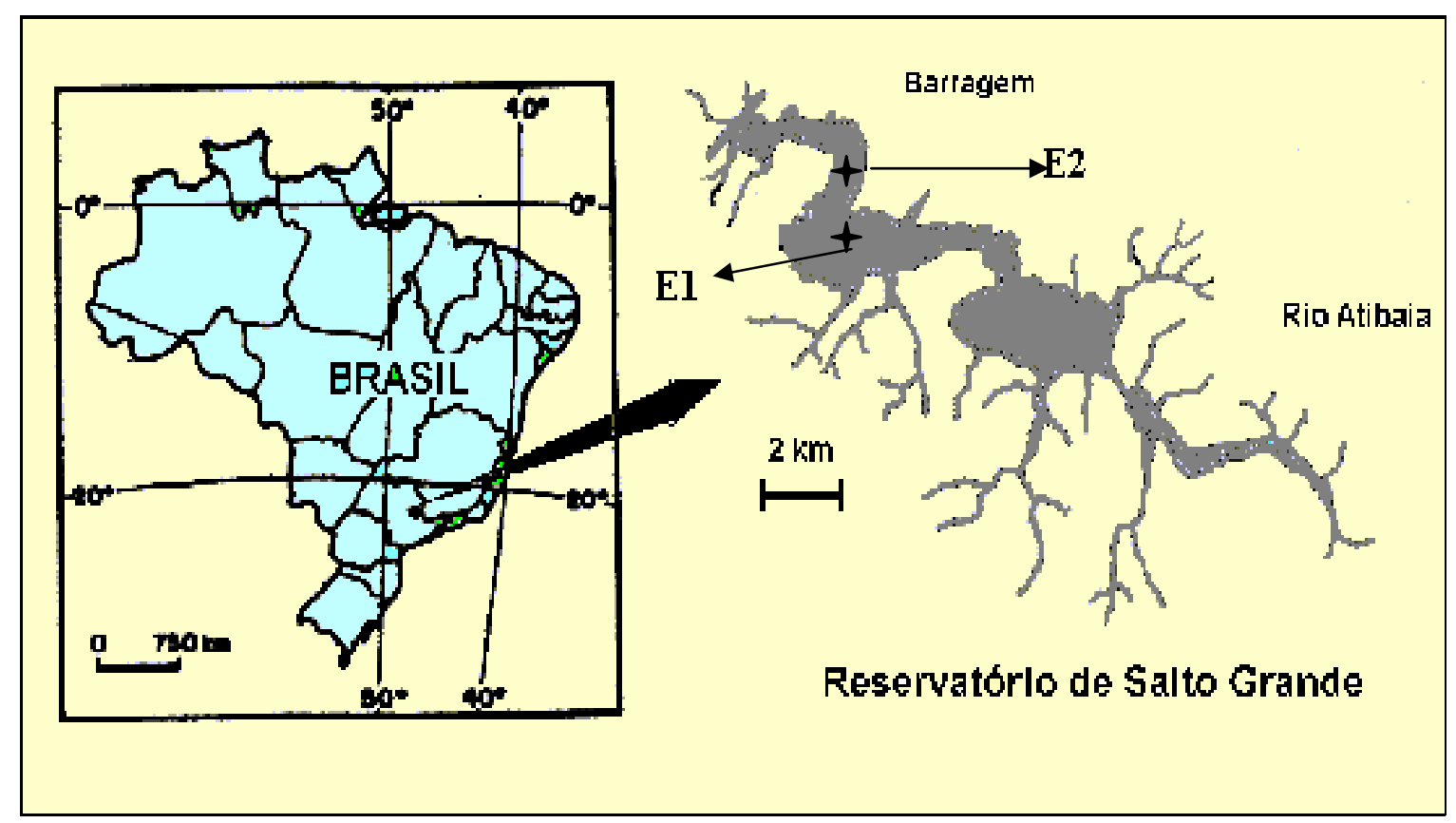

Figura 2 - Representação esquemática do reservatório de Salto Grande com a localização das estações de amostragem.

\section{c) - Reservatório de Rasgão}

O reservatório de Rasgão, construído na década de 20, em uma curva do rio Tietê, está localizado no município de Pirapora do Bom Jesus, SP. Sua área inundada é de $128 \mathrm{Km}^{2}$ e as principais fontes de contaminação provêm dos esgotos domésticos e industriais (MOZETO, 2001).

A localização do reservatório está apresentada na Figura 3. 


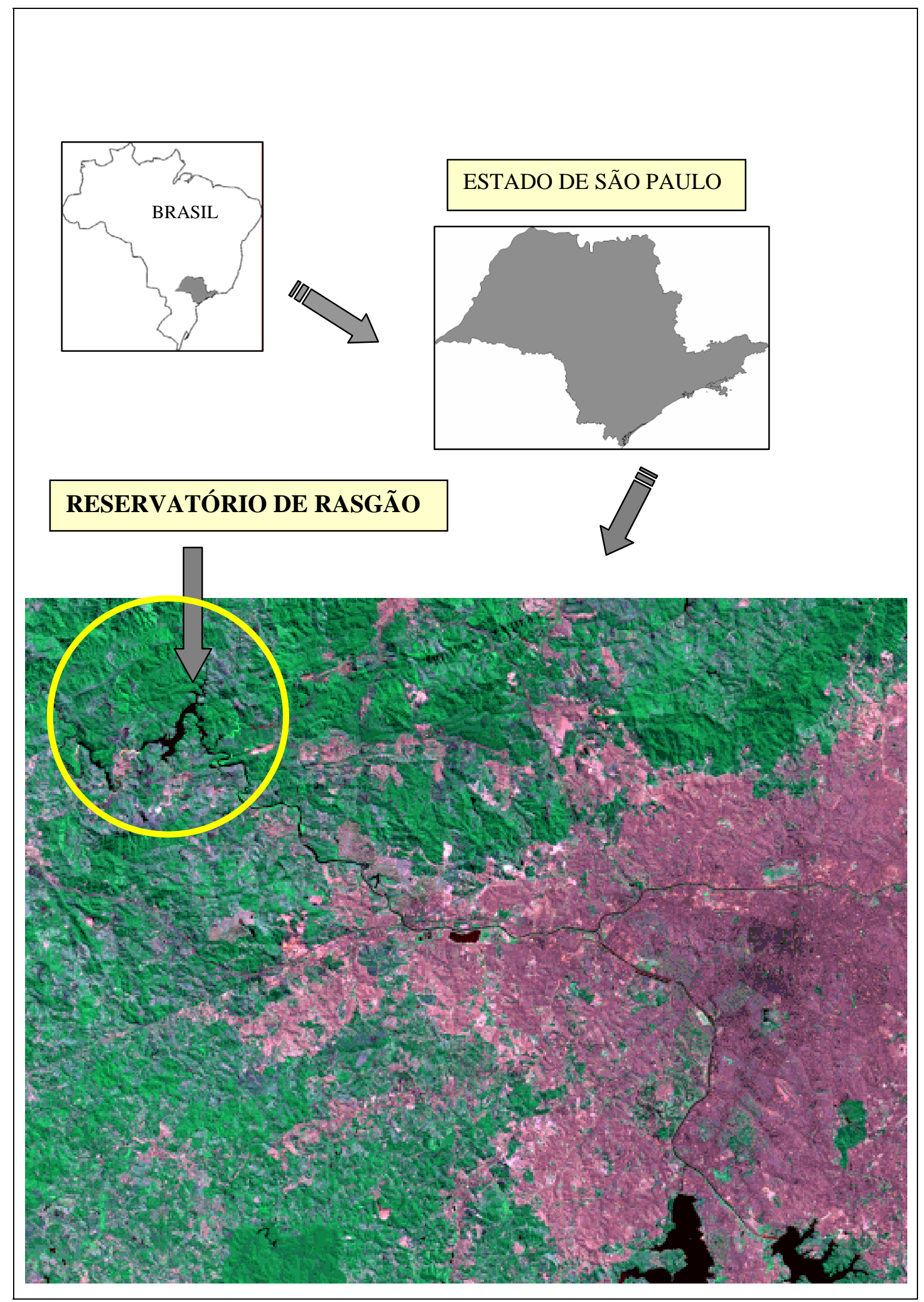

Figura 3 - Localização do reservatório de Rasgão, Pirapora, SP. 


\subsection{2 - Coleta e Preparação das Amostras}

\section{a) Procedimentos de Coleta e Freqüência de Amostragem}

As amostras de sedimento foram coletadas a uma profundidade de 6 a $10 \mathrm{~cm}$ da superfície, com pegador de fundo tipo van Veen de $0.059 \mathrm{~m}^{2}$. Para cada ponto de coleta foram realizadas de 3 a 10 pegadas, de forma a se obter volume de sedimento suficiente para a realização dos testes de toxicidade, análises químicas e extração da fase líquida (solubilizado e água intersticial). Após homogeneização as amostras foram acondicionadas em sacos ou potes plásticos não tóxicos e mantidas em isopor com gelo, até chegar ao laboratório. As medidas de $\mathrm{pH}$, temperatura e potencial redox foram realizadas em campo, logo após a coleta, ainda no barco.

A freqüência de amostragem para cada um dos reservatórios foi a seguinte:

- Reservatório de Barra Bonita: abril, setembro e dezembro/99; janeiro, março, junho e setembro/00.

- Reservatório de Salto Grande: março, maio, agosto e novembro/00; fevereiro, abril, maio e outubro/01; abril/02.

- Reservatório de Rasgão: setembro e dezembro/01

\section{b) Preparação das amostras}

No laboratório, porções adequadas de cada amostra (sedimento total, solubilizado e/ou água intersticial) foram separadas, preparadas e acondicionadas de acordo com os requisitos exigidos para cada tipo de análise, descritos a seguir:

- Testes de toxicidade aguda e crônica, extração do solubilizado e água intersticial, determinação da umidade, análise dos sulfetos volatilizáveis por acidificação (SVA) e metais simultaneamente extraídos (MSE): as amostras foram mantidas úmidas, em geladeira, a $4{ }^{\circ} \mathrm{C}$.

- Granulometria, nitrogênio, fósforo, carbono orgânico total e metais biodisponíveis: as amostras de sedimento foram colocadas para secar em estufa a $50{ }^{\circ} \mathrm{C}$, por um período de até 3 dias. Após estarem totalmente secas, foram maceradas em cadinhos de porcelana, acondicionadas em potes plásticos, com exceção das amostras para análise de carbono orgânico total, que foram 
acondicionadas em frascos de vidro. Após secas e maceradas, as amostras foram mantidas em temperatura ambiente.

- Nitrogênio, fósforo e amônia na água intersticial e/ou solubilizado: as amostras foram filtradas em filtros de $45 \mu \mathrm{m}$ e mantidas congeladas até a realização das análises.

- Carbono total dissolvido no solubilizado/água intersticial: após filtração em filtros de acetato de celulose de $45 \mu \mathrm{m}$ de porosidade e $47 \mathrm{~mm}$ de diâmetro, previamente secos, as amostras foram preservados com $\mathrm{H}_{3} \mathrm{PO}_{4} 10 \%(\mathrm{v} / \mathrm{v})$, na proporção de 5: 100 ml (ácido: amostra) e mantidas em geladeira.

- Metais na água intersticial e/ou solubilizado: após filtração em filtros de acetato de celulose de $45 \mu \mathrm{m}$ de porosidade e $47 \mathrm{~mm}$ de diâmetro, as amostras foram preservadas com ácido nítrico ultra puro, na proporção de $10 \mu \mathrm{L}$ de $\mathrm{HNO}_{3}$ para $50 \mathrm{~mL}$ de amostra, armazenadas em frascos de PVC de alta densidade e mantidas em geladeira.

- Testes de toxicidade: as amostras foram mantidas em geladeira, por um período não superior a 36 horas para o solubilizado e/ou água intersticial e 4 semanas para o sedimento total.

c) Considerações Sobre a Freqüência de Amostragem, Análises Químicas e Testes deToxicidade Realizados com as Amostras dos Reservatórios Estudados.

Em relação ao reservatório de Barra Bonita, as amostragens realizadas entre abril/99 e março/00, tiveram por objetivo: 1) avaliar a toxicidade do sedimento desse reservatório, uma vez que para a utilização do estudo de avaliação e identificação da toxicidade - AIT, é necessário que a mostra apresente toxicidade; 2) escolher, dentre as três estações de amostragem, uma para ser utilizada no estudo de AIT; 3) avaliar a viabilidade da utilização do solubilizado, como fase aquosa do sedimento, comparando sua toxicidade com a do sedimento total.

Definido o local e confirmada a possibilidade de utilização do solubilizado, as amostras da estação E2 coletadas em junho/00 e setembro/00 foram submetidas ao estudo de AIT.

As medidas de $\mathrm{pH}$, oxigênio dissolvido e potencial redox foram realizadas em campo, em quase todas as amostragens. Na primeira coleta (abril/99) foram feitas análises de sulfetos (SVA), nitrogênio, fósforo, carbono (COT) e granulometria, para 
uma caracterização inicial do ambiente em relação à esses parâmetros. Essas análises, acrescidas da análise de metais simultaneamente extraídos, foram repetidas em junho/00.

A escolha das estações E1 e E2 do reservatório de Salto Grande foi feita com base nos resultados do projeto "Avaliação do grau de toxicidade de água e sedimento do reservatório de Salto Grande, SP, e sua influência sobre organismos aquáticos", parte do projeto CNPq N 610.047/96-5 “Bases Limnológicas e Ecológicas para o Manejo da Qualidade da Água e Usos Múltiplos do Reservatório de Salto Grande, que mostraram, um alto potencial de toxicidade do sedimento da porção final do reservatório. Do total de amostras de sedimento coletadas, 75\% causaram toxicidade aguda para Daphnia similis (ESPINDOLA et al., 1998). Em março, maio e agosto/00 foram realizados testes de toxicidade com o sedimento total e solubilizado para confirmação da toxicidade do sedimento total e para avaliação do solubilizado. Sempre que possível, os testes de toxicidade com o sedimento total foram feitos com diferentes organismos-teste (Daphnia similis, Ceriodaphnia dúbia, Ceriodaphnia silvestrii, Spirillum volutans e Vibrio fisheri). Os testes de toxicidade do solubilizado para comparação com o sedimento total foram realizados com Daphnia similis ou Ceriodaphnia dúbia. As análises de granulometria, nitrogênio e fósforo foram feitas por DORNFELD (2002). O estudo de AIT foi realizado em novembro/00 e outubro/01 com a amostra da estação E2.

No reservatório de Rasgão foram realizadas duas amostragens, em setembro e dezembro/00, para o estudo de AIT. A caracterização físico-química e ecotoxicológica desse reservatório foi realizada no projeto QualiSed (FAPESP - 98/12177-0.)

\subsection{3 - Métodos de Extração das Fases Líquidas}

\section{a) Água intersticial}

As amostras de sedimento foram centrifugadas a $3000 \mathrm{rpm}$ por 20 minutos em centrífuga refrigerada, segundo a metodologia descrita por GIESY et al.(1988).

\section{b) Solubilização}

Para obtenção do solubilizado, uma parte de sedimento foi misturada com 4 partes de água destilada e deixada em agitação por 24 horas, seguida por um período de 
decantação de 24 horas em geladeira (SETAC, 1993). Após decantação, retirou-se o sobrenadante, que foi sub-amostrado, preparado e acondicionado de acordo com os requisitos das análises químicas e de toxicidade descritas no item 4.2.2.b.

\subsection{4 - Testes de Toxicidade com o Sedimento Total}

Volumes adequados de sedimento de cada ponto foram misturados com água utilizada na manutenção das culturas, na proporção de 1 para 4, respectivamente, e deixadas em repouso por 24 horas para permitir a decantação do sedimento, de acordo com a metodologia descrita em BURTON \& MACPHERSON (1994). Os testes de toxicidade aguda com Daphnia similis e Ceriodaphnia dubia foram realizados com 3 réplicas, cada uma delas com $20 \mathrm{~g}$ de sedimento e $80 \mathrm{ml}$ de água de cultivo; os testes com Chironomus xanthus foram feitos com 3 réplicas, cada uma delas com 60 g de sedimento e $240 \mathrm{ml}$ de água de cultivo Para os testes de toxicidade crônica com Ceriodaphnia dubia e Ceriodaphnia silvestrii utilizou-se 5 g de sedimento e $20 \mathrm{ml}$ de água para cada uma das 10 réplicas.

a) Teste de Toxicidade Aguda com Daphnia similis/Ceriodaphnia dúbia/Ceriodaphnia silvestrii

Esses testes foram realizados de acordo com os procedimentos descritos por BURTON \& MACPHERSON (1994). O princípio do método consistiu na exposição de organismos jovens (neonatos com idade entre 0 a 24horas) às amostras de sedimento com água, além de um controle de laboratório, durante um período de 48 horas nas condições prescritas de temperatura e fotoperíodo. Os testes foram realizados com 3 réplicas, com 10 neonatos por réplica e mantidos em sala com fotoperíodo de 12 horas, intensidade luminosa de 1000 lux e temperatura de $23 \pm 2{ }^{0} \mathrm{C}$, sem alimentação. Após o período de exposição, procedeu-se à contagem dos organismos imóveis, sendo considerados imóveis aqueles que não conseguiram nadar no intervalo de 15 segundos após leve agitação da amostra. Os organismos desaparecidos foram considerados mortos. A resposta dos organismos às amostras testadas, isto é, a imobilidade, foi comparada à dos controles, adotando-se testes estatísticos do tipo hipótese, descrito pela USEPA (1994). As amostras que apresentaram diferenças significativas, sob um 
determinado nível fixo de erro (5\%), foram consideradas tóxicas. Os testes foram considerados válidos quando a sobrevivência no controle foi igual ou maior que $90 \%$.

\section{b) Teste de Toxicidade Aguda com Chironomus xanthus}

Esses testes foram realizados de acordo com metodologia descrita por (FONSECA, 1997). O princípio do método consiste em expor organismos com idade de 7 a 8 dias às amostras de sedimento durante um período de tempo de 96 horas. Ao final do período de exposição, a resposta dos organismos (mortalidade) é comparada com o sedimento controle, utilizando-se testes estatísticos do tipo hipótese, descrito pela USEPA (1994).

As amostras que apresentaram diferenças significativas, sob um determinado nível fixo de erro, foram consideradas tóxicas. Os testes foram considerados válidos quando a sobrevivência no controle for igual ou maior que $80 \%$.

\section{c)Teste de Toxicidade Crônica com Ceriodaphnia dúbia}

Esses testes foram realizados de acordo com os procedimentos descritos em BURTON \& MACPHERSON (1994). Neonatos com 24 horas, foram colocados em contato com as amostras de sedimento, durante 7 dias, até obtenção da terceira cria. Os testes foram mantidos em sala com fotoperíodo de 12 horas, intensidade luminosa de 1000 lux e temperatura de $23 \pm 2{ }^{0} \mathrm{C}$, com alimentação diária. Os organismos foram mantidos individualmente, com 10 réplicas por amostra e, a cada 2 dias, foi feita a reposição de 1/3 do volume de água, anotando-se o número de organismos adultos vivos e de neonatos, por réplica. Os neonatos foram descartados após a contagem. A cada troca foram medidos o $\mathrm{pH}$, a condutividade, o oxigênio dissolvido e a dureza da água de cultivo a ser adicionada e também do sobrenadante retirado de cada amostra.

As variáveis avaliadas foram a sobrevivência ao final dos 7 dias e a fecundidade (número médio de neonatos por fêmea). Os testes foram considerados válidos quando a sobrevivência no controle foi igual ou maior que $80 \%$ e a reprodução média maior ou igual a 15 neonatos por fêmea (CETESB, 1992)

A análise estatística dos resultados foi realizada através dos métodos Fisher’ s Exact Test, que verifica diferenças significativas na sobrevivência dos organismos teste entre a amostra e o controle. A normalidade dos dados de reprodução foi analisada através do teste Q-quadrado, seguido por uma análise de variância (ANOVA), testes de 
comparações múltiplas de Tukey (distribuição normal) ou Kruskal-Wallis (distribuição não normal) e Dunnett's Procedure, que analisa os dados de reprodução, nas concentrações em que a sobrevivência dos organismos teste não foi significativamente diferente do controle (CETESB, 1992). O programa computacional TOXSTAT 3.3. foi utilizado para a aplicação destes testes.

\subsection{5 - Testes de Toxicidade com o Solubilizado e/ou Água Intersticial}

Os testes de toxicidade com Vibrio fisheri - sistema Microtox e com Spirillum volutans foram realizados no setor de Mutagenicidade e Citotoxicidade da Divisão de Toxicologia e Genotoxicidade Ambiental da CETESB

\section{a) Teste de Toxicidade Aguda com Daphnia Similis e Ceriodaphnia dubia}

Esses testes foram realizados de acordo com os procedimentos descritos em CETESB (1992). O princípio do método consiste na exposição de organismos jovens (neonatos) às amostras de água sem diluição, durante 48 horas nas condições prescritas. Após o período de exposição, procedeu-se à contagem dos organismos imóveis, sendo considerados imóveis aqueles que não conseguiram nadar após leve agitação da amostra. São consideradas tóxicas as amostras de água que causaram imobilidade igual ou superior a 50\% dos organismos-teste. Os resultados foram expressos como "tóxica" ou "não tóxica".

Os testes foram considerados válidos quando a taxa de imobilidade do controle foi igual ou menor que 10\%. Quando necessário, o valor de CE50, bem como do intervalo de confiança 95\%, foram calculados através do método estatístico Trimmed Spearman Karber, disponível em programa de micro-computador (HAMILTON et al., 1977). É um método não paramétrico, modificado do original desenvolvido por Spearman-Karber, e exige apenas a simetria da distribuição de tolerância para estimar a CE50 e seu intervalo de confiança no nível de 95\%. Mesmo que não ocorram concentrações com 0 e/ou 100\% de mortalidade, a CE50 pode ser calculada (ARAÚJO, 1998).

b) Teste de Motilidade com Spirillum volutans 
Esses testes foram realizados de acordo com a metodologia descrita em CETESB (1988), que consiste em misturar volumes adequados das amostras ou diluições das amostras $(0, .9 \mathrm{ml})$ a $0,1 \mathrm{ml}$ de uma cultura de S.volutans - 24 horas e após homogeneização, preparar lâminas para análise em microscópio de campo escuro, nos intervalos de tempo de 0, 5, 15, 30, 60 e 120 minutos.

Foram consideradas tóxicas as amostras que causaram perda da motilidade típica e/ou imobilização total em 90\% das bactérias. Água destilada estéril e substância referência (sulfato de cobre) foram utilizadas como controles negativo e positivo.

\section{c) Teste com Vibrio fischerii - Sistema Microtox}

Os testes com o sistema Microtox foram realizados de acordo com a metodologia descrita em CETESB (2001). Esse ensaio utiliza uma bactéria marinha luminescente, Vibrio fischeri sensível a grande variedade de compostos químicos. As substâncias químicas presentes na amostra podem interferir no sistema enzimático bacteriano, causando um decréscimo na produção de luz. Uma vez que esse decréscimo é proporcional à concentração das substâncias presentes, a toxicidade relativa das amostras pode ser calculada. Os resultados foram expressos em CE20 ou 50,15', que é a concentração efetiva da amostra que causa 20 ou 50\% de redução da quantidade luz produzida pelo microrganismo, após 15 minutos de contacto a $15^{\circ} \mathrm{C}$. A CE foi calculada a partir de uma regressão entre os logaritmos das concentrações testadas e os logaritmos dos valores de gama $(\gamma)$ obtidos para cada uma das diluições. O efeito gama é definido como sendo a razão entre o decréscimo na quantidade de luz produzida e a quantidade de luz remanescente e existe uma relação entre os valores de gama e a CE, sendo que o gama igual a 1 corresponde a 50\% de inibição de luz. O gama é calculado de acordo com a fórmula:

$$
\gamma=\mathrm{I} \text { oa } \mathrm{x} \mathrm{RB}-1 / \mathrm{I} \text { ta, onde: }
$$

I oa = luminescência de cada cubeta no tempo zero;

I ta = luminescência de cada cubeta no tempo t, sendo $t=15^{\prime}$.

$\mathrm{RB}=$ razão do branco (fator de correção para a variação da luminescência da cubeta do controle negativo).

$$
\mathrm{RB}=\mathrm{I} \text { tb / Iob, onde: }
$$

I tb = luminescência do controle negativo no tempo zero; e I ob = luminescência do controle negativo no tempo t 


\subsection{6 - Cultivo e Manutenção dos Organismos-Teste Mantidos no Laboratório de Ecotoxicologia e Ecofisiologia de Organismos Aquáticos.}

Fatores como qualidade da água de cultivo, qualidade e quantidade de alimento fornecido, temperatura e oxigênio são fundamentais na manutenção dos organismos para os testes de toxicidade e, alterações em qualquer um destes fatores podem afetar a variabilidade dos resultados (USEPA, 1989).

\section{a)Família Daphnidae}

Os gêneros Daphnia e Ceriodaphnia são microcrustáceos de água doce pertencentes à classe Crustacea, ordem Cladocera, família Daphnidae. Apresentam uma ampla distribuição em ambientes temperados, sendo que, ambos os gêneros, abundantes em lagos e reservatórios, desempenham um papel importante para a transferência de energia de um nível trófico a outro, além de serem alimento para muitas espécies de peixes. São planctônicos, reproduzem-se por partenogênese e durante a maior parte do ano a população natural é constituída apenas de fêmeas. O número de ovos partenogenéticos é variável entre e inter-espécies e está relacionado com a qualidade e quantidade de alimentos e outros fatores físicos tais como, temperatura, intensidade luminosa, OD, pH, concentração de íons e outros. Os ovos produzidos se desenvolvem rápida e diretamente em miniaturas dos adultos, sem um estágio larval intermediário. Após um número variável de instares (geralmente 5 ou 6) as fêmeas completam o ciclo partenogenético e, devido a um estímulo ambiental, alguns ovos se desenvolvem em machos e outros em fêmeas sexuadas, que após a fertilização, dão origem aos ovos de resistência, efípios, facilmente visualizados devido ao escurecimento de parte das valvas que cobrem a câmara incubadora e aumento dos tegumentos. O aparecimento de machos parece estar associado a condições de "stress" causadas por baixas temperaturas, alta densidade de organismos com acúmulo subseqüente de produtos de excreção e baixa disponibilidade de alimentos. (ALLAN, 1976; FONSECA, 1991; RAND, 1995).

O gênero Daphnia tem sido amplamente utilizado para a avaliação da toxicidade de produtos químicos, efluentes líquidos, amostras ambientais, lixiviados de resíduos sólidos e no estabelecimento de critérios de qualidade. Embora não seja um organismo bentônico, ele tem sido utilizado em testes de toxicidade de sedimentos, seja com o 
sedimento total ou água intersticial (GERSICH, et al., 1986; ZAGATTO, 1988; GIESY \& HOKE, 1989; BERVOETS et al., 1996).

Espécies do gênero Ceriodaphnia são morfologicamente semelhantes às do gênero Daphnias, só que menores e com ciclo de vida mais curto, o que permite maior rapidez de resposta nos testes crônicos (7 dias). Pouco utilizada até 1984, a partir de então, sua utilização se tornou freqüente, principalmente em testes de toxicidade agudos e crônicos com efluentes industriais, produtos químicos e águas superficiais. Ceriodaphnia dubia têm sido cultivada e testada com sucesso em águas naturais e sintéticas de durezas variadas, desde 20 a $25 \mathrm{mg} / \mathrm{L}$ (águas moles) até 160 a $180 \mathrm{mg} / \mathrm{L}$ (águas duras) (RAND, 1995; STEWART \& KONETSKY,1998).

O cultivo dos organismos Daphnia similis e Ceriodaphnia dubia no Laboratório de Ecotoxicologia e Ecofisiologia Aquática, no CRHEA-USP, foi iniciado a partir de culturas obtidos na CETESB, SP, e no Laboratório de Ecotoxicologia do Departamento de Ecologia e Biologia Evolutiva da UFSCAR, São Carlos.

Manutenção e Cultivo: a manutenção das culturas foi realizada dentro das condições padronizadas (CETESB, 1992) e exigidas para utilização em testes de toxicidade, com algumas modificações de acordo com os procedimentos descritos abaixo:

Os organismos foram mantidos em cristalizadores com capacidade para 2 litros, com 50 (Daphnia similis) e 60 (Ceriodaphnia dúbia) organismos/cristalizador, em estufa incubadora com controle de temperatura e luz (fotoperíodo de 12 horas de luz e 12 horas de escuro, intensidade luminosa de aproximadamente 1000 lux e temperatura de $23+/-2^{0} \mathrm{C}$ ).

A água de cultivo (ou diluição) foi preparada misturando-se 1 parte de água natural coletada nos tanques de cultivo de zooplancton da UFSCar, misturada com 6 partes de água destilada. Antes de misturar, a água dos tanques foi filtrada em redes de plâncton com malhas de $300 \mu \mathrm{m}$ e em seguida $20 \mu \mathrm{m}$ e autoclavada. Após a mistura, ajusta-se a dureza para a faixa requerida de 40 a $48 \mathrm{mg} / \mathrm{L}$ de $\mathrm{CaCO}_{3}$, $\mathrm{pH}$ para a faixa de 7.2 - 7.6 e condutividade de $160 \propto \mathrm{S}^{-1} \mathrm{~cm}^{-1}$.

O ajuste da dureza foi feito utilizando-se uma solução contendo 1,5 g.L ${ }^{-1}$ de sulfato de cálcio (solução1) e uma segunda solução contendo 0,2 g.L ${ }^{-1}$ de cloreto de potássio, 4,80 g.L - $^{-1}$ e bicarbonato de sódio e 6,10 g.L $\mathrm{L}^{-1}$ de sulfato de magnésio (solução 2), considerando que, para cada miligrama de dureza a ser aumentada, deve-se 
acrescentar 0,5 mL da solução 1 e 0,25 ml da solução 2 por litro de água. A medida da dureza da água foi feita por titulação com solução de EDTA (APHA, 1992; CETESB, 1992). O procedimento completo para determinação da dureza está descrito no anexo1.

Alimentação: como alimento foi utilizada cultura de Selenastrum capricornutum em fase exponencial de crescimento e alimento composto, preparado com ração para truta e levedura.

Para utilização como alimento, a suspensão de Selenastrum capricornutum, em meio L C Oligo (anexo 1), deve ser centrifugada ou mantida em geladeira para decantação, após o que o sobrenadante é desprezado e o decantado é ressuspendido em água de manutenção das culturas.

O número de células da suspensão foi determinado através de contagem em microscópio óptico, utilizando-se câmaras de contagem. A partir do resultado obtido, calculou-se o volume a ser adicionado nas culturas, de forma que fossem fornecidas $1.10^{5}$ células por litro, por dia para .Daphnia e $0,6.10^{5}$ células por litro, por dia para Ceriodaphnia. O cálculo do volume foi feito de acordo com a expressão:

$$
\mathrm{V}_{1} \mathrm{~N}_{1}=\mathrm{V}_{2} \mathrm{~N}_{2} \text {, onde: }
$$

$\left(\mathrm{V}_{1}\right)=$ volume da suspensão algácea a ser adicionado na cultura

$\left(\mathrm{N}_{1}\right)$ = número de células / $\mathrm{mL}$ da suspensão algácea

$\left(\mathrm{V}_{2}\right)=1$ litro

$\left(\mathrm{N}_{2}\right)$ = concentração desejada $\left(10^{5}\right.$ células/litro $)$.

O alimento composto foi preparado misturando-se partes iguais de ração para truta e levedura (anexo 1). Após o preparo, o alimento deve ser mantido em geladeira por um período máximo de uma semana..

\section{b) Chironomus xanthus}

Dentre os organismos bentônicos, algumas espécies da família Chironomidae (Chironomus tentans, nos USA e Chironomus riparius, na Europa) tem sido utilizadas em testes de toxicidade com sedimento, pois, além de apresentarem os requisitos básicos necessários para um organismo teste, tais como relevância ecológica, sensibilidade aos compostos químicos e facilidade de cultivo, eles estão diretamente expostos aos agentes químicos por viverem a maior parte do ciclo de vida em contato 
direto e alimentando-se das partículas do sedimento (GIESY \& HOKE 1989; USEPA, 1994; REYNOLDSON \& DAY 1995).

No Brasil, os organismos da família Chironomidae passaram a ser utilizados na avaliação da toxicidade dos sedimentos a partir dos estudos realizados por STRIXINO \& STRIXINO (1981) e FONSECA (1997), que mostraram que a espécie Chironomus xanthus possui os requisitos necessários para ser utilizado como organismo-teste em testes de toxicidade com sedimentos.

As primeiras desovas de Chironomus xanthus foram obtidas no Laboratório de Ecotoxicologia do Departamento de Ecologia e Biologia Evolutiva da UFSCAR, São Carlos e o cultivo e manutenção dos organismos foram feitos de acordo com os procedimentos descritos por FONSECA (1997).

Manutenção e Cultivo: o cultivo das larvas foi feito a partir das desovas gelatinosas, depositadas pelas fêmeas adultas. Os ovos, cerca de 500 a 600, são envolvidos por uma massa gelatinosa e ficam presos, por um pedúnculo nas paredes das bandejas em contato com a água. Essas desovas, retiradas com auxílio de uma espátula, foram colocadas em placas de Petri contendo água de manutenção, onde permaneceram até a eclosão das larvas, o que ocorreu entre 40 a 48 horas à temperatura de $23+/-2{ }^{0} \mathrm{C}$.

Após a eclosão e posterior abandono da mucilagem gelatinosa, um total de 250 larvas foi transferido para bandejas plásticas de 45x35x6 cm de tamanho, contendo uma camada de areia esterilizada (substrato) e 4 litros de água de manutenção. As bandejas foram mantidas sob aeração contínua em sala com temperatura entre 23 e $25^{\circ} \mathrm{C}$, fotoperíodo de 12 horas. Entre o décimo segundo e o décimo quinto dia do desenvolvimento larval, as bandejas foram cobertas por gaiolas de nylon para retenção dos adultos.

O estágio larval dura em média de 12 a 15 dias e, para essas condições de alimento e temperatura, a emergência ocorre em torno do $15^{0}$ dia.

A água de cultivo é preparada com água destilada reconstituída, de dureza variando de 10 a 15 mg. $\mathrm{L}^{-1}$ de $\mathrm{CaCO}_{3}$ e $\mathrm{pH}$ entre 7,0 e 7,5. O ajuste da dureza foi feito seguindo os mesmos procedimentos já descritos.

Alimentação: como alimento foi utilizada a ração de peixes TETRAMIN na proporção de 0,04 mg.mL ${ }^{-1}$ de SSV/ dia (sólidos suspensos voláteis), até o início da eclosão. No 
primeiro dia em que as larvas foram transferidas para as bandejas, elas foram alimentadas também com cultura de Selenastrum capricornutum em fase exponencial de crescimento na concentração de $1.10^{5}$ cél. $\mathrm{L}^{-1}$.

\section{c) Bactérias}

Os testes microbianos têm sido utilizados, a partir da década de 70, no monitoramento de amostras ambientais devido à sua sensibilidade, rapidez de resposta, relativo baixo custo, alta reprodutibilidade e alta significância estatística por empregar um grande número de organismos. Além dessas vantagens, as bactérias têm um ciclo de vida curto e um crescimento extremamente rápido, o que permite que os efeitos tóxicos sejam medidos por várias gerações em um intervalo de tempo muito pequeno, realizam a maioria dos processos bioquímicos que ocorrem em organismos superiores e representam o denominador comum primário na cadeia alimentar tanto em ecossistemas continentais, como marinhos (CETESB, 1991; SCHIEVE et al, 1995). De acordo com GIESY \& HOKE (1989), a utilização de bactérias como organismos teste se baseia no fato de que alguns sistemas químicos e fisiológicos são conservativos do ponto de vista evolucionário e os efeitos tóxicos, no nível molecular, são semelhantes em diferentes organismos.

\subsection{7 - Controle de Qualidade dos Cultivos Mantidos no Laboratório de Ecotoxicologia e Ecofisiologia de Organismos Aquáticos.}

A avaliação rotineira da sensibilidade com substâncias de referência permite avaliar o estado fisiológico dos organismos, isto é, a saúde dos organismos (USEPA, 1994), garantindo dessa forma a qualidade e a confiabilidade dos resultados dos testes de toxicidade.

\section{a) Avaliação da Sensibilidade de Daphnia similis ao Dicromato de Potássio}

A avaliação da sensibilidade das culturas de Daphnia similis foi feita mensalmente com solução de dicromato de potássio, de acordo com os procedimentos descritos em CETESB (1992). As concentrações-teste $(0,02 ; 0,04 ; 0,16 ; 0,32)$ foram preparadas com água de cultivo, a partir de duas soluções estoque $\left(1,0\right.$ e $\left.0,1 \mathrm{mg} . \mathrm{L}^{-1}\right)$, em água destilada. 
Neonatos com idade de 0 a 24 horas foram expostos às diferentes concentrações de dicromato de potássio além de um controle com organismos apenas em água de cultivo. Para cada concentração foram realizadas 3 réplicas, com 5 organismos cada. Durante o período de teste, os organismos foram mantidos no escuro e sem alimento em sala com temperatura de $22 \pm 2{ }^{0} \mathrm{C}$. Após o período de exposição (24 horas), procedeuse à contagem dos organismos imóveis, sendo considerados imóveis aqueles que não conseguiram nadar dentro de um intervalo de 15 segundos, após leve agitação da amostra. A CE50, 24h foi calculada através do método Trimmed Spearman - Karber (HAMILTON et al., 1977). As culturas que apresentaram valores de CE0,24h dentro da faixa de sensibilidade já estabelecida de 0,04 a $0,17 \mathrm{mg} \cdot \mathrm{L}^{-1}$, foram consideradas adequadas para serem utilizadas em testes de toxicidade (ZAGATO, 1988).

\section{b) Avaliação da Sensibilidade de Ceriodaphnia dubia ao Cloreto de Sódio}

Os testes de toxicidade aguda para avaliação da sensibilidade da espécie Ceriodaphnia dubia ao cloreto de sódio $(\mathrm{NaCl})$ foram feitos de forma semelhante aos testes realizados com Daphnia similis (CETESB, 1992).

As concentrações teste $\left(1,0 ; 1,3 ; 1,6 ; 2,0\right.$ e 2,2 g.L $\left.{ }^{-1}\right)$ foram preparadas em água de cultivo, a partir de uma solução estoque de 10 g.L ${ }^{-1}$ em água destilada.

Foram consideradas adequadas para utilização em testes de toxicidade as culturas que apresentaram valores de CE50,48h dentro da faixa de sensibilidade estabelecida para Ceriodaphnia dubia, de 1,33 a 1,82 g.L.-1 de $\mathrm{NaCl}$ (BOHRER, 1995).

\section{c) Avaliação da Sensibilidade de Chironomus xanthus ao Cloreto de Potássio}

Os testes de sensibilidade com cloreto de potássio foram feitos mensalmente, a partir de janeiro de 1999, de acordo com os procedimentos descritos por FONSECA (1997). Larvas do $4^{0}$ ínstar (7/8 dias) foram adicionadas às diferentes concentrações da solução teste $\left(1,5 ; 2,25 ; 3,4 ; 5,0\right.$ e 7,5 g.L $\left.{ }^{-1}\right)$, além de um controle e mantidas por 96 horas em sala com temperatura variando de 22 a $25^{0} \mathrm{C}$, fotoperíodo de 12 horas, sendo alimentadas apenas no primeiro dia. Para cada concentração foram feitas 3 réplicas contendo, cada uma delas, $200 \mathrm{ml}$ de solução-teste e 6 larvas de Chironomus xanthus. Medidas de $\mathrm{pH}$, condutividade, temperatura e dureza foram realizadas no início e ao término dos experimentos, para as diferentes concentrações testadas. Após o período de exposição, foi registrado o número de organismos mortos em cada concentração e os 
valores de CE50,96h foram calculados através do método Trimmed Spearman - Karber (HAMILTON et al., 1977). As culturas para as quais os valores de CE50, 96h ficaram dentro da faixa de sensibilidade estabelecida de 3,3 a 6,0 g. $\mathrm{L}^{-1}$ de $\mathrm{KCl}$ foram consideradas adequadas para serem utilizadas em testes de toxicidade (FONSECA, 1997).

\subsection{8 - Análises Químicas do Sedimento, Água Intersticial e Solubilizado}

As análises de caracterização física e química do sedimento total, água intersticial e solubilizado foram realizadas no Laboratório de Limnologia do Centro de Recursos Hídricos e Ecologia Aplicada, EESC -USP, no Laboratório de Geoquímica Ambiental, da Universidade Federal de São Carlos (carbono orgânico total, sulfetos volatilizáveis por acidificação-SVA, extração simultânea de metais/SVA, sulfetos dissolvidos, e surfactantes) e no Laboratório de Química Ambiental da UNICAMP (compostos orgânicos não polares)

\section{a) Sedimento}

- Determinação da Matéria Orgânica: a porcentagem de matéria orgânica do sedimento foi determinada pelo método de calcinação em mufla e cálculo através de diferença de peso das amostras de sedimento previamente secas e maceradas, antes e após incineração a $550^{\circ} \mathrm{C}$, por 1 hora, conforme descrito por TRINDADE (1980). Os valores de matéria orgânica, expressos em \%, foram calculados através da fórmula:

$$
\% \mathrm{M}^{\mathrm{o}}=\underline{(\mathrm{CSE}-\mathrm{CSQ}) \times 100}
$$

P.S.

onde: P.S. $=$ peso do sedimento seco em estufa $($ P.S. $=$ CSE - CS $)$

$\mathrm{CSE}=$ peso do cadinho com sedimento (g);

C.S. = peso do cadinho vazio;

CSQ $=$ peso do cadinho com sedimento após incineração

- Granulometria; a granulometria foi determinada conforme a metodologia descrita na Norma ABNT (ABNT, 1968) As análises foram feitas com as amostras de 
sedimento previamente secas, maceradas e calcinadas (extração da matéria orgânica), através de sedimentação e peneiramento.

- Nitrogênio Total: as análises para determinação do nitrogênio foram feitas de acordo com a metodologia descrita por GOLTERMAN et.al., (1978), através de digestão ácida com sulfato de potássio, sulfato de cobre e ácido sulfúrico, seguida por destilação com água deionizada e NaOH. A concentração final foi dada por titulação com solução de $\mathrm{H}_{2} \mathrm{SO}_{4}$ e os resultados, expressos em \%, foram tansformados em $\mathrm{mg} \cdot \mathrm{g}^{-1}$..

- Fósforo Total: as análises para determinação do fósforo total foram feitas de acordo com a metodologia descrita em APHA (1992). Para a digestão do fósforo total, 200 mg de sedimento seco e macerado adicionado de $0.5 \mathrm{~g}$ de $\mathrm{Na}_{2} \mathrm{CO}_{3}$, foram aquecidos em mufla a $550^{\circ} \mathrm{C}$ durante 1 hora. Em seguida, o material foi transferido para um frasco erlenmeyer de $250 \mathrm{~mL}$, com $25 \mathrm{~mL}$ de $\mathrm{HCl} 1 \mathrm{~N}$ e aquecido em placa de aquecimento por 15 minutos. Completou-se o volume para $100 \mathrm{~mL}$ com água deionizada. A seguir, uma alíquota de $6 \mathrm{~mL}$ da solução foi transferida para um tubo de ensaio, adicionado de $1 \mathrm{~mL}$ de reagente misto e lido em espectrofotômetro à $880 \mathrm{~nm}$, após um intervalo de tempo mínimo de 15 minutos e máximo de 30 minutos.

- Sulfetos Volatilizáveis por Acidificação (SVA): o sistema de geração de SVA foi constituído de um “impinger” de $30 \mathrm{~mL}$, dotado de entrada vertical de gás N2 e saída para um balão de 25,00 mL, com uma solução absorvedora contendo $200 \mathrm{~mL}$ de solução de acetato de zinco 1M, Zn(OAc)2, $200 \mathrm{~mL}$ de solução de acetato de sódio 3,75M, $\mathrm{Na}(\mathrm{OAc}) .3 \mathrm{H} 2 \mathrm{O}$ e aproximadamente $5 \mathrm{~mL}$ de água. As soluções de acetato foram preparadas com água desaerada (BEVILACQUA, 1996, apud SILVÉRIO, 1999). Após a acidificação da amostra com $\mathrm{HCl}$ 6M, previamente desaerado com $\mathrm{N}_{2}$, o gás de arraste $\left(\mathrm{N}_{2}\right)$ foi introduzido no sistema. O sulfeto ácido volátil foi então arrastado durante 20 minutos pelo gás de arraste através de um tubo capilar mergulhado dentro de um balão volumétrico. As quantificações foram realizadas por espectrofotometria, via análise por injeção em fluxo (FIA), utilizando-se o método do azul de metileno (SILVÉRIO, 1999). 
A análise química por injeção em fluxo contínuo pode ser definida como um processo de automatização de procedimentos analíticos, no qual a amostra na forma de uma solução aquosa é introduzida em um fluido carregador que a transporta em direção a um detector. Durante o transporte, a amostra pode receber reagentes, sofrer reações químicas e passar por etapas de separação, concentração, etc. Este tipo de análise pode determinar com maior precisão a concentração de sulfeto em uma dada amostra, uma vez que o sulfeto é um ânion instável, oxidando-se pela exposição ao ar.

- Extração Simultânea de Metais/SVA (MSE): o procedimento para extração de SVA e MSE foi proposto por ALLEN et al (1993). A amostra de sedimento total (úmido) foi pesada (2 a 8g) e introduzida no balão de reação juntamente com 100mL de água Milli-Q. Fechou-se o balão e a suspensão foi agitada (agitação magnética) durante dez minutos sob fluxo de nitrogênio (ultrapuro). Em seguida, 20ml de $\mathrm{HCl} 6 \mathrm{M}$, previamente desaerado com $\mathrm{N}_{2}$ foram introduzidos através de seringa hipodérmica conectada a um tubo de silicone. O sulfeto ácido volátil foi arrastado pelo gás de arraste $\left(\mathrm{N}_{2}\right)$, por um tempo de $30 \mathrm{~min}$. através de tubos de vidro mergulhados dentro dos frascos receptores contendo 80,0mL de $\mathrm{NaOH} \mathrm{0,5} \mathrm{M.} \mathrm{As} \mathrm{quantificações} \mathrm{foram}$ realizadas por espectrofotometria, utilizando-se o método do azul de metileno. Ensaios em branco foram simultaneamente realizados e os resultados foram expressos em $\mathrm{mg} / \mathrm{Kg}$ de sedimento úmido.

- Metais Potencialmente Biodisponíveis: as amostras de sedimento seco e macerado foram misturadas com ácido clorídrico $0,1 \mathrm{~N}$ na proporção de $1.0 \mathrm{~g}$ de sedimento para 25.0 mL de ácido clorídrico, e mantidas em agitação a 200 rpm por 2 horas a temperatura ambiente. Após esse período, as amostras foram filtrados em papel de filtro quantitativo (FRAMEX, faixa azul), acondicionados em frascos de vidro e mantidos em geladeira para posterior determinação dos metais por espectrofotometria de absorção atômica por chama ou forno de grafite.

- Carbono Orgânico Total (TOC): para a determinação do carbono total as amostras de sedimento secas e maceradas foram queimadas a $900{ }^{0} \mathrm{C}$ em tubos de combustão contendo catalizador de platina. Na queima, o carbono total passa a $\mathrm{CO}_{2}$, que é 
detectado em um analisador de $\mathrm{CO}_{2}$ (Analisador de Carbono Orgânico Total (TOC) Shimadzu modelo 5000, acoplado a um Analisador de Amostras Sólidas (SSM) modelo 5000).

1. Carbono inorgânico (IC): uma alíquota da amostra foi acidificada com ácido fosfórico $\left(\mathrm{H}_{3} \mathrm{PO}_{4}\right)$ e queimada a $200{ }^{0} \mathrm{C}$. O teor de carbono inorgânico foi detectado em analisador, na forma de $\mathrm{CO}_{2}$.

2. Carbono Orgânico Total (TOC): a quantidade de carbono orgânico total foi determinada pela diferença entre o carbono total e o carbono inorgânico total.

\section{b) Água Intersticial/Solubilizado}

- Fósforo Total: as análises para determinação do fósforo total foram feitas pelo método de digestão com perssulfato de potássio e ácido ascórbico com leitura em espectrofotômetro à 880 nm (APHA, 1992).

- Amônia: as análises para determinação de amônio realizadas no Laboratório de Limnologia do Centro de Recursos Hídricos e Ecologia Aplicada, EESC -USP (amostras de Barra Bonita e Salto Grande) foram feitas de acordo com Karoleff apud GOLTERMAN et al, (1978). O princípio do método baseia-se no fato de que em solução alcalina, com pH entre 8,0 e 11,5, o radical amônia reage com o hipoclorito para formar a monocloroamina. Em presença de fenol, a monocloroamina forma o azul de indofenol, que obedece a lei de Beer em concentrações $<500 \mu$ g. $\mathrm{L}^{-1}$ de $\mathrm{N}-\mathrm{NH}_{3}$. As leituras foram feitas em espectofotômetro a $630 \mathrm{~nm}$.

- Carbono Orgânico Total (TOC): as amostras de água intersticial e/ou solubilizado foram filtradas a vácuo em filtros de $0,45 \mu \mathrm{m}$ previamente secos e preservadas com $\mathrm{H}_{3} \mathrm{PO}_{4} 10 \%$. As determinações foram realizadas no Analisador de Carbono Orgânico Total (TOC) Shimadzu modelo 5000 (SILVÉRIO, 1999).

- Metais Biodisponíveis: as amostras do solubilizado e água intersticial foram filtradas a vácuo em filtros de acetato de celulse de 0,45 $\mu \mathrm{m}$ de porosidade e $47 \mathrm{~mm}$ de diâmetro, preservadas com $\mathrm{HNO}_{3}$ concentrado na proporção de $10 \mu \mathrm{L}$ de $\mathrm{HNO} 3$ 
para $50 \mathrm{~mL}$ de amostra (ROSA \& ASCUE, 1997, apud SILVÉRIO, 1999), armazenadas em frascos de PVC de alta densidade e mantidas em geladeira até a leitura no espectrofotômetro de absorção atômica.

- Surfactantes Aniônicos: o princípio do método consiste na associação dos detergentes ABS (sulfonato alkil benzeno) ou LAS (sulfonato alkilato linear) com um cristal violeta e extração líquido-líquido do complexo com benzeno (solvente). A leitura foi feita no espectrofotômetro DR/2010.

- Sulfeto Dissolvido: o sulfeto foi removido da amostra de água através do mesmo sistema de extração de SVA e analisado no espectrofotômetro: DR/2010 A amostra foi purgada com $\mathrm{N}_{2}$ em pH3 e o sulfeto volátil recuperado em uma solução ajustada com pH9.

- Compostos Orgânicos: o princípio do método consistiu na separação das fases orgânica e aquosa através de extração líquido-líquido com diclorometano e eluição da fase orgânica com $\mathrm{Na}_{2} \mathrm{SO}_{4}$, A extração foi repetida por três vezes e todos os extratos foram recolhidos no mesmo conjunto funil - balão de evaporação. O $\mathrm{Na}_{2} \mathrm{SO}_{4}$ foi lavado com diclorometano para garantir a transferência quantitativa da fase orgânica. As leituras foram feitas em cromatógrafo gasoso acoplado a um espectrômetro de massas (GC-MS), utilizado para quantificar compostos da classe dos PAHs e cromatógrafo gasoso acoplado a um detetor de captura de elétrons (GCECD), utilizado para quantificar compostos da classe dos PCBs e pesticidas clorados. 


\section{3 - RESULTADOS E DISCUSSÃO}

\subsection{1 - Caracterização Físico-química do Sedimento dos Reservatórios de Barra Bonita e Salto Grande}

As análises físico-químicas das amostras do sedimento, cujos resultados estão apresentados nas Tabelas 2 a 7, mostraram de um modo geral, um sedimento reduzido e anóxico, com alta carga de nutrientes provavelmente provenientes de esgotos domésticos, em sua maioria não tratados e da atividade agrícola do entorno e que junto com os contaminantes provenientes de fontes industriais, podem estar causando a toxicidade detectada através dos testes de toxicidade aguda ou crônica (Tabelas 8 a 12 e Figuras 4 a 8$)$.

As análises granulométricas, de nitrogênio e de fósforo das estações E1 e E2 do reservatório de Salto Grande, citadas nesse estudo, foram realizadas por DORNFELD (2002), como parte de sua dissertação de mestrado “Utilização de análises limnológicas, bioensaios de toxicidade e macroinvertebrado bentônicos para o diagnóstico ambiental do reservatório de Salto Grande (Americana, SP)”.

\section{a) Granulometria}

Os resultados da análise granulométrica das amostras de sedimento coletadas no reservatório de Barra Bonita, apresentados na Tabela 2, mostraram predominância das frações argila e silte, para as 3 estações amostradas. Resultados semelhantes foram encontrados por SILVÉRIO (1999), COSTA (2001), FRACCÁCIO (2001), RODGHER (2001) e NASCIMENTO \& MOZETO (2001), para o sedimento da estação E3, cujos valores da somatória dessas duas frações variaram entre 68 e 99\%. 
Tabela 2 - Teores médios (\%) de matéria orgânica, areia, silte e argila em amostras de sedimento coletadas no reservatório de Barra Bonita em abril/99 e junho/00.

\begin{tabular}{|l|c|c|c|c|}
\hline \multicolumn{1}{|c|}{ Estações } & $\begin{array}{c}\text { Matéria } \\
\text { Orgânica (\%) }\end{array}$ & $\begin{array}{c}\text { Areia } \\
\mathbf{( \% )}\end{array}$ & $\begin{array}{c}\text { Argila } \\
\mathbf{( \% )}\end{array}$ & $\begin{array}{c}\text { Silte } \\
\mathbf{( \% )}\end{array}$ \\
\hline BB-E1-Piracicaba & 17,7 & 9 & 47 & 41 \\
\hline BB-E2-Tietê & 17,7 & 1 & 64 & 35 \\
\hline BB-E3-Barragem & 17,3 & 3 & 58 & 36 \\
\hline
\end{tabular}

De acordo com os resultados obtidos por DORNFELD (2002) para o reservatório de Salto Grande, o sedimento das estações E1 e E2 são formados por areia fina, argila e silte, sendo os valores médios dessas frações de 41,7, 27,8 e 17\% para a estação E1 e 35,4, 30,1 e 15\% para a estação E2.

A importância dessa análise em relação à toxicidade reside nas correlações existentes entre o tamanho de grão, a matéria orgânica e a distribuição de metais e compostos orgânicos não iônicos. FÖRSTNER (1990) mostrou que os metais pesados associam-se preferencialmente às frações finas do sedimento, através de processos de adsorção e complexação. Dessa forma, com base na granulometria, o sedimento dos dois reservatórios estudados tem grande capacidade de agregar metais.

\section{b) Análises Químicas}

Os resultados das análises de $\mathrm{pH}, \mathrm{OD}, \mathrm{E}_{\mathrm{H}}$ e temperatura das estações de coleta dos reservatórios de Barra Bonita e Salto Grande são apresentados nas Tabelas 3 e 4.

Tabela 3 - Valores de $\mathrm{pH}$, oxigênio dissolvido (OD), potencial redox $\left(\mathrm{E}_{\mathrm{H}}\right)$ e temperatura das amostras de sedimento coletadas no reservatório de Barra Bonita (BB).

\begin{tabular}{|c|c|c|c|c|c|}
\hline \multirow[b]{2}{*}{ Estação } & \multirow[b]{2}{*}{$\mathrm{pH}$} & \multirow{2}{*}{$\begin{array}{c}\text { OD } \\
\left(\mathrm{mg} \cdot \mathrm{L}^{-1}\right)\end{array}$} & \multirow{2}{*}{$\begin{array}{c}\mathrm{E}_{\mathrm{H}} \\
(\mathrm{mV})\end{array}$} & \multicolumn{2}{|c|}{$\mathrm{T}\left({ }^{0} \mathrm{C}\right)$} \\
\hline & & & & Água & Sed. \\
\hline \multicolumn{6}{|l|}{ BB - E1 } \\
\hline Abril/99 & 6,5 & 1.6 & -47 & 23 & 22 \\
\hline Junho/00 & 4,48 & na & na & 23 & 22 \\
\hline Setembro/00 & 6,65 & 1.8 & -89 & 24 & 23 \\
\hline \multicolumn{6}{|l|}{ BB - E2 } \\
\hline Abrril/99 & 6,9 & 1.8 & -105 & 23 & 22 \\
\hline Junho/00 & 7,4 & na & na & 23 & 22 \\
\hline Setembro/00 & 6,71 & 1.5 & -143 & 24 & 23 \\
\hline \multicolumn{6}{|l|}{ BB - E3 } \\
\hline Abril/99 & 6,7 & 1.7 & -149 & 23 & 22 \\
\hline Junho/00 & 5,45 & na & na & 23 & 22 \\
\hline Setembro/00 & 6,77 & 1.5 & -174 & 24 & 23 \\
\hline
\end{tabular}


Tabela 4- Valores de potencial redox $\left(\mathrm{E}_{\mathrm{H}}\right), \mathrm{pH}$, condutividade e oxigênio dissolvido (OD) das amostras de sedimento das estações E1 e E2 coletadas no reservatório de Salto Grande (SG) no período de Agosto/00 a Outubro/01.

\begin{tabular}{|c|c|c|c|c|c|c|c|}
\hline \multirow[t]{2}{*}{$\begin{array}{l}\text { Estação/ } \\
\text { Data }\end{array}$} & \multirow{2}{*}{$\begin{array}{c}\begin{array}{c}\mathrm{E}_{\mathrm{H}} \\
(\mathrm{mV})\end{array} \\
\mathrm{ST}\end{array}$} & \multicolumn{2}{|c|}{$\mathrm{pH}$} & \multicolumn{2}{|c|}{$\begin{array}{c}\text { Condutividade } \\
(\mu \mathrm{Scm})\end{array}$} & \multicolumn{2}{|c|}{$\begin{array}{c}\text { OD } \\
(\mathrm{mg} / \mathrm{l})\end{array}$} \\
\hline & & ST & SOL & ST & SOL & ST & SOL \\
\hline \multicolumn{8}{|l|}{ SG-E1 } \\
\hline Agosto/00 & na & 4,9 & 3,9 & 387 & 177,3 & 1,2 & 7.1 \\
\hline Novembro/00 & -368 & 5,2 & 4,2 & 376 & 116,8 & 1,8 & 6.2 \\
\hline Fevereiro/01 & -362 & 6,8 & 7,2 & 175 & na & 2,5 & 6.4 \\
\hline Abril/01 & -381 & 6,9 & 6,4 & 313 & 62,1 & 1,9 & 7.4 \\
\hline Maio/01 & na & 6,5 & 6,3 & na & na & 1.5 & 6.9 \\
\hline Outubro/01 & -371 & 6,7 & 4,04 & 324 & 174 & 0,0 & 7.3 \\
\hline \multicolumn{8}{|l|}{ SG-E2 } \\
\hline Agosto/00 & na & 4,3 & 4,0 & 367 & 182,7 & 1,9 & 7,2 \\
\hline Novembro/00 & -384 & 5,6 & 3,9 & 337 & 119,8 & 1,8 & 6,3 \\
\hline Fevereiro/01 & -398 & 7,2 & na & 194 & na & 2,7 & 7,2 \\
\hline Setembro/01 & -391 & 7,1 & 6,6 & 434 & 83,3 & 0,8 & 7,1 \\
\hline Outubro/01 & -389 & 6,8 & 3,9 & 334 & 204 & 0,0 & 7,2 \\
\hline
\end{tabular}

ST: Sedimento Total SOL: Solubilizado na: não analisado

Em relação ao pH, os valores encontrados para as estações E1, E2 e E3, coletadas no reservatório de Barra Bonita (Tabela 3), estiveram entre 6,5 e 7,5, com exceção das estações E1 e E3 em junho/00, que apresentaram valores mais ácidos (4,5 e 5,5, respectivamente). Para o reservatório de Salto Grande (Tabela 4), o pH das amostras de sedimento variou entre 4,9 a 6,9 para a estação E1 e 4,3 e 7,2 para a estação E2, sendo que os valores mais baixos foram encontrados em agosto/00 e novembro/00.

A comparação dos dois ambientes mostrou, para os locais analisados, uma tendência do reservatório de Salto Grande à maior acidificação, refletida também na solubilização das amostras. Conforme pode ser observar na Tabela 4, em agosto/00, novembro/00 e outubro/01, o pH das duas estações após a solubilização, ficou em torno de 3 e 4, sendo essa acidez uma das possíveis causas de toxicidade (vide Tabela 8), tanto como fator indutor de reações de remobilização de contaminantes, especialmente metais, a partir do sedimento ou pela própria acidez.

Os valores de oxigênio dissolvido (OD) encontrados para as estações amostradas no reservatório de Barra Bonita variaram entre 1,5 e 1,7 mg. $\mathrm{L}^{-1}$. SOARES \& MOZETO (2001) encontraram valores semelhantes $\left(1,5 \mathrm{mg} . \mathrm{L}^{-1}\right)$ na interface água/sedimento para a 
estação E3. Tanto para o pH, como para o OD, não foram observadas diferenças significativas entre as três estações (Tabela 3).

Para o reservatório de Salto Grande, as concentrações de oxigênio dissolvido variaram de zero a 2,5 e 2,7 mg. $\mathrm{L}^{-1}$, respectivamente para as estações E1 e E2 (Tabela 4), sendo que os menores valores foram encontrados em agosto/00, setembro/01 e outubro/01. Os resultados encontrados por DORNFELD (2002), na interface água/sedimento para as mesmas estações de amostragem foram semelhantes, com variação entre 0,3 e 4,7 mg. $\mathrm{L}^{-1}$, predominando valores inferiores a $2 \mathrm{mg} \cdot \mathrm{L}^{-1}$.

Baixas concentrações de oxigênio são características de ambientes com intensa atividade biológica, tais como decomposição microbiológica e respiração de organismos bentônicos. Variações nas concentrações de oxigênio dissolvido influenciam vários fatores físico-químicos do meio, entre eles o potencial de oxi-redução.

Em relação ao potencial redox, no reservatório de Barra Bonita, as medidas foram realizadas em abril/99 e setembro/00 e os valores encontrados para as 3 estações amostradas foram de -47 e -89 para a estação E1, -105 e -143 mV para a estação E2 e -149 e -174 mV para a estação E3 (Tabela 3) SILVÉRIO (1999), encontrou valores crescentes de $-228 \mathrm{mV}$ (camada de $0-1 \mathrm{~cm}$ de profundidade) até $-187 \mathrm{mV}$ (7 a $9 \mathrm{~cm}$ de profundidade) para a estação E3, sendo o valor médio para os 9 primeiros centímetros de $-218 \mathrm{mV}$.

Em Salto Grande, os valores de potencial redox das amostras de sedimento variaram entre -362 e $-381 \mathrm{mV}$ para a estação E1 e -384 e $-398 \mathrm{mV}$ e para a estação E2. Os resultados estão apresentados na Tabela 4.

Valores de potencial redox reduzidos ou negativos estão relacionados com ambientes ricos em matéria orgânica, onde o oxigênio é consumido nos processos microbiológicos de oxidação do enxofre $\left(E_{H}\right.$ entre -75 a $\left.-150 \mathrm{mV}\right)$ e carbono ( $-250 \mathrm{a}-$ $350 \mathrm{mV}$ ). Portanto, para os valores de $E_{H}$ encontrados nos três ambientes, eram esperadas altas concentrações de matéria orgânica e de sulfeto (ESTEVES, 1988).

Conforme o esperado, o conteúdo de matéria orgânica encontrado nas amostras de sedimento dos dois ambientes foi superior a 10\% em relação ao peso seco, classificando-os como "sedimento orgânico" (ESTEVES, 1988). Para o reservatório de Barra Bonita o teor de matéria orgânica foi de 17\% para as três estações (Tabela 2). Valores médios de 12,2 e 17,5\% foram encontrados por COSTA (2001), FRACCÁCIO 
(2001) e RODGHER (2001) para o sedimento a montante da barragem, que corresponde à estação E3.

Em Salto Grande, os teores médios de matéria orgânica encontrados por DORNFELD (2002), para o sedimento das duas estações foram de 14,7 e 16,4 \%, respectivamente.

Nas Tabelas 5 e 6 estão apresentados os resultados das análises químicas de sulfetos volatilizáveis por acidificação (SVA), nitrogênio e fósforo totais, amônia (solubilizado) e carbono (carbono orgânico total - COT e carbono orgânico dissolvido COD), realizadas com as amostras de sedimento de Barra Bonita e Salto Grande.

Tabela 5 - Concentrações de sulfetos volatilizáveis por acidificação (SVA), nitrogênio total, fósforo total, carbono orgânico total (COT) e amônia nas amostras de sedimento das estações E1, E2 e E3, do reservatório de Barra Bonita (BB).

\begin{tabular}{|c|c|c|c|c|c|c|c|c|c|}
\hline \multirow{2}{*}{ Estação } & \multicolumn{2}{|c|}{$\begin{array}{l}\text { SVA } \\
\left(\mu g \cdot g^{-1}\right)\end{array}$} & \multicolumn{2}{|c|}{$\begin{array}{l}\text { Nitrogênio total } \\
\left.\text { (mg.g }{ }^{-1}\right)\end{array}$} & \multicolumn{2}{|c|}{$\begin{array}{l}\text { Fósforo total } \\
\left.\text { (mg.g }{ }^{-1}\right)\end{array}$} & \multirow{2}{*}{$\begin{array}{c}\begin{array}{c}\mathrm{COT} \\
\left(\mathrm{mg}^{-1} \mathrm{~g}^{-1}\right)\end{array} \\
\text { Abr//99 }\end{array}$} & \multicolumn{2}{|c|}{$\begin{array}{l}\text { Amônia* } \\
\left(\mathrm{mg.L} \mathrm{L}^{-1}\right)\end{array}$} \\
\hline & $\mathrm{Abr} / 99$ & Set/00 & Abr/99 & Jun/00 & Abr/99 & Jun/00 & & Dez/99 & Jun/00 \\
\hline $\begin{array}{c}\text { BB-E1- } \\
\text { Piracicaba }\end{array}$ & $51, .9$ & 42.45 & 9,8 & 6,3 & 0,88 & 1,16 & 28,0 & 0,112 & 1,04 \\
\hline $\begin{array}{c}\text { BB-E2- } \\
\text { Tietê }\end{array}$ & 66,7 & 132 & 11,4 & 7,5 & 0,88 & 1,29 & 27,0 & 0,108 & 2,93 \\
\hline $\begin{array}{l}\text { BB-E3- } \\
\text { Barragem }\end{array}$ & na & 63 & 4,0 & 2,0 & 0,97 & 1,02 & 30,4 & 0,288 & 2,6 \\
\hline
\end{tabular}

Tabela 6 - Concentrações de sulfetos volatilizáveis por acidificação (SVA), amônia, ácido sulfídrico, carbono orgânico total (COT) e carbono orgânico dissolvido (COD) encontrados nas amostras de sedimento das estações E1 e E2, coletadas no reservatório de Salto Grande (SG) em novembro/00 e outubro/01.

\begin{tabular}{|c|c|c|c|c|c|c|c|}
\hline \multirow[b]{3}{*}{ Estação } & \multirow{2}{*}{\multicolumn{2}{|c|}{$\begin{array}{l}\mathrm{SVA}^{*} \\
\left(\mu g . g^{-1}\right)\end{array}$}} & \multirow{2}{*}{\multicolumn{2}{|c|}{$\begin{array}{l}\text { Amonia** } \\
\left(\mathrm{mg}^{-L^{-1}}\right)\end{array}$}} & \multirow{3}{*}{$\begin{array}{c}\text { Ácido. } \\
\text { Sulfídrico** } \\
\left(\mathrm{mg}^{*} \mathrm{~L}^{-1}\right)\end{array}$} & \multicolumn{2}{|c|}{ Carbono } \\
\hline & & & & & & \multirow{2}{*}{$\begin{array}{c}\mathrm{COT}^{*} \\
\left(\mathrm{mg} \cdot \mathrm{g}^{-1}\right)\end{array}$} & \multirow{2}{*}{$\begin{array}{l}\mathrm{COD}^{* *} \\
\left(\mathrm{mg} \cdot \mathrm{L}^{-1}\right)\end{array}$} \\
\hline & nov/00 & out/01 & nov/00 & out/01 & & & \\
\hline SG E1-ST & 2473 & na & na & na & na & 13,1 & na \\
\hline SG E1-SOL & na & na & 2,44 & na & 0,63 & na & 12,7 \\
\hline SG E2-ST & 2088 & 1570 & na & na & na & 16,7 & na \\
\hline SG E2-SOL & na & na & 2,75 & 3,24 & 0,47 & na & 3,9 \\
\hline
\end{tabular}

ST: Sedimento Total SOL: Solubilizado na: não analisado

*: análises realizadas no sedimento total **: análises realizadas no solubilizado 
Em relação aos sulfetos volatilizáveis por acidificação - SVA, para as amostras de sedimento coletadas no reservatório de Barra Bonita (Tabela 5), os valores encontrados variaram entre 42 e $67 \mu$ g... $g^{-1}$ de $S^{2-}$, com exceção da estação E2 em setembro/00, onde foi encontrada uma concentração maior, de $132 \mu \mathrm{g} . \mathrm{g}^{-1}$. Esses valores foram mais baixos, comparados com o valor médio de $201 \mu$ g. $\mathrm{g}^{-1}$ de $\mathrm{S}^{2-}$, obtido por SILVÉRIO (1999) para os primeiros $10 \mathrm{~cm}$ da camada superficial do sedimento da estação E3, desse mesmo reservatório.

No reservatório de Salto Grande a concentração de SVA no sedimento das duas estações foi muito maior. Os valores obtidos para as estações E1 e E2 em novembro/00 foram de 2473 e $2088 \mu \mathrm{g} \cdot \mathrm{g}^{-1}$, respectivamente. Em outubro/01 a concentração na estação E2 foi de $1570 \mu g^{-1} g^{-1}$ Tabela 6).

Em sedimentos anóxicos, o sulfeto produzido reage com ferro $\left(\mathrm{Fe}^{2+}\right)$ e com o manganês $\left(\mathrm{Mn}^{2+}\right)$ para formar o sulfeto de ferro ou de manganês, facilmente extraído por ácidos. São os chamados sulfetos volatilizáveis por acidificação (SVA). Alguns metais catiônicos divalentes, tais como cádmio, cobre, mercúrio, níquel, chumbo e zinco, substituem o ferro/manganês e formam sulfetos menos solúveis que os sulfetos de ferro.

A importância da determinação do sulfeto reside no fato desta espécie ser fundamental no controle da distribuição de metais pesados nos ambientes aquáticos, contribuindo para a definição da toxicidade. Os sulfetos, formados pela decomposição anaeróbia da matéria orgânica que utilizam o sulfato como aceptor de elétrons, é um contaminante comum e muitas vezes abundante nos sedimentos aquáticos, desempenhando um papel importante na toxicidade desses ambientes. Eles influenciam a toxicidade de três formas principais: 1) como tóxico propriamente dito; 2) reduzindo a toxicidade de metais pela formação de complexos metálicos; e 3) afetando o comportamento animal, especialmente os organismos bentônicos que vivem em sedimentos contaminados com sulfeto, levando a alterações da toxicidade de outros contaminantes, que não o próprio sulfeto (WANG \& CHAPMAN, 1999).

Embora seja um constituinte natural dos sedimentos marinhos e de água doce, seja tóxico para os organismos aquáticos e desempenhe um papel fundamental na toxicidade dos metais, o entendimento das interações envolvendo os sulfetos nos sedimentos ainda é limitado. Devido à sua importância como contaminante de sedimentos, a Agencia de Proteção Ambiental dos Estados Unidos estabeleceu 
procedimentos específicos para a identificação de sulfetos nos protocolos de AIT (Avaliação e Identificação da Toxicidade) específicos para sedimentos (WANG \& CHAPMAN, 1999).

No reservatório de Barra Bonita, as concentrações de nitrogênio total encontradas nas estações E1 e E2 foram típicas de ambientes eutrofizados, superiores àquelas correspondentes a ambientes oligotróficos . Comparando-se com os limites canadenses de 'nível de efeitos severos’ preconizados pelo 'Ontario Sediment Quality Guidelines', observa-se que as concentrações nas duas estações ultrapassaram em quase 2 vezes o limite preconizado por estes índices que é de $4800 \mathrm{mg} \cdot \mathrm{kg}^{-1}$ ou de $0,48 \%$. Os valores obtidos para a estação E3 foram muito baixos, comparados com os resultados obtidos por SILVÉRIO (1999), FRACCACIO (2001) e RODGHER (2001).

Para o fósforo total, esse limite é de $2000 \mathrm{mg} / \mathrm{Kg}$ ou 0,2\%. Considerando os valores obtidos nesse estudo, observa-se que todas as estações apresentaram valores inferiores a esse limite. No entanto, de acordo com o critério de classificação proposto por THOMAS ${ }^{1}, 1987$ (apud FRACCACIO, 2001), o sedimento das três estações pode ser considerado poluído por terem apresentado concentrações de fósforo superiores a 420 ppm ou $0,04 \%$.

Em Salto Grande os valores médios de nitrogênio e fósforo, obtidos por DORNFELD (2002), para as estações E1 e E2 foram respectivamente de 2.5 e 2.3 mg.g $^{1}$ de nitrogênio total e 0.9 mg.g $^{1}$ de fósforo para as 2 estações. Os valores de fósforo foram semelhantes aos de Barra Bonita, estando da mesma forma, acima do referido critério de qualidade de sedimentos (0,04\%).

Os diferentes estudos realizados no reservatório de Salto Grande nos últimos 4 anos (BITAR, 1998; PAMPLIN, 1999; ZANATA, 1999; DORNFELD, 2002) evidenciaram que se trata de um sistema eutrófico, devido às altas cargas de nutrientes, especialmente fósforo, transportadas pelo rio Atibaia, junto com os contaminantes tóxicos provenientes principalmente do complexo industrial de Paulínia e entorno, e com reflexos na comunidade bentônica. Os resultados obtidos por PAMPLIN (1999) e

\footnotetext{
${ }^{1}$ THOMAS, R.L. (1987) A protocol for the selection of process-oriented remedial options to control "in situ”sediments contaminants. Hidrobiologia. 149:247-258 apud FRACCACIO, R. (2001) Utilização de bioensaios ecotoxicológicos com Danio rerio (Cypriniformes, Cyprinidae) e análises limnológicas para a avaliação ambiental dos reservatórios do médio e baixo Tietê. São Carlos. 233p. Dissertação (Mestrado). Escola de Engenharia de São Carlos-USP
} 
DORNFELD (2002) mostraram uma comunidade alterada, com predominância de espécies resistentes à poluição orgânica e à toxicidade.

Embora não faça parte das chamadas "substancias tóxicas”(metais, orgânicos sintéticos e radionuclídeos, conforme classificação de WESTMAN, 1985), o fósforo deve ser considerado um poluente importante dos ecossistemas aquáticos, especialmente lagos e reservatórios devido sua contribuição ao processo de eutrofização. O acúmulo de substancias, tais como toxinas de algas, amônia e ácido sulfídrico, provenientes da decomposição da biomassa fitoplanctônica e da matéria orgânica, contribuem de forma significativa para a deterioração da qualidade da água tornando-a imprópria à manutenção da vida aquática (GÄCHTER \& MEYER, 1990).

Os valores de carbono orgânico total (COT) obtidos nas amostras de sedimento coletadas no reservatório de Barra Bonita foram de 28, 27 e 30,4 mg.g ${ }^{-1}$ para as três estações amostradas (Tabela 5). Esses valores foram semelhantes aos encontrados por SILVERIO (1999) e NASCIMENTO \& MOZETO (2001). No reservatório de Salto Grande, os valores de COT das amostras coletadas em outubro/01 foram de 13,1 e 16,7 mg.g ${ }^{-1}$, para as estações E1 e E2, respectivamente. Esses valores foram menores comparados com os obtidos nas amostras de Barra Bonita. No solubilizado dessas amostras foram encontrados 12,7 e 3,9 mg.L $\mathrm{L}^{-1}$ de carbono orgânico dissolvido (COD).

O carbono orgânico total (COT) dos sedimentos é formado pelo carbono orgânico dissolvido (COD) na água intersticial e do carbono orgânico particulado do sedimento. O COD se origina principalmente da decomposição de plantas e animais e do produto de excreção destes organismos, sendo seus principais constituintes as proteínas, os carboidratos, os lipídios e os ácidos húmicos e fúlvicos. O COD influencia a dinâmica dos ecossistemas aquáticos de diferentes formas, sendo uma delas como agente complexador de metais, especialmente os metais pesados $\mathrm{Cd}, \mathrm{Zn}, \mathrm{Cu}, \mathrm{Ni}, \mathrm{Pb}, \mathrm{Co}$, Mn, Mg e Cr (ESTEVES, 1988 e SILVERIO, 1999), arrastando-os para o sedimento.

Os sedimentos da maioria dos ecossistemas aquáticos continentais constituem o compartimento que apresenta as maiores concentrações de nutrientes, funcionando como reservatório para os demais compartimentos. Essa capacidade de estocagem depende, no entanto, da composição dos mesmos, sendo maior em sedimentos orgânicos. A dinâmica de retenção/liberação de nutrientes para o sedimento/coluna d’água depende tanto de fatores biológicos como físicos e químicos e, as condições de 
anoxia ou de baixas concentrações de oxigênio, como as encontradas nos ambientes de estudo, favorecem os processos de liberação sedimento/coluna d’água.

Se compararmos as concentrações médias de nitrogênio e fósforo obtidas para o sedimento do reservatório de Barra Bonita em 1983, de 0,29 e 0,05\% respectivamente (ESTEVES, 1988) com a média das concentrações obtidas nesse estudo para es estações E1 e E2, de 0,87 e 0,10\% respectivamente, observamos concentrações bastante superiores, condizente com as altas cargas de nutrientes de origem doméstica, industrial e agrícola, que chegam no reservatório via tributários ou fontes agrícolas não pontuais. Como conseqüência desse aumento de nutrientes, aumentam também as concentrações de amônia, provenientes da degradação microbiana de compostos orgânicos nitrogenados. Em ambientes eutrofizados os processos de degradação microbiana são muitas vezes, mais importantes que as fontes industriais, pela presença de concentrações elevadas de amônia nos sedimentos. (BESSER et al., 1998).

Na Tabela 5 estão apresentadas as concentrações de amônia dos solubilizados das amostras das estações E1, E2 e E3 coletadas no reservatório de Barra Bonita em dezembro/99 e junho/00. As maiores concentrações encontradas foram de 2,6 e 2,9 mg. $L^{-1}$ para as estações E3 e E2 respectivamente. Os resultados obtidos para o reservatório de Salto Grande, apresentados na Tabela 6 foram semelhantes aos encontrados para as estações E2 e E3 coletadas em junho/00 no reservatório de Barra Bonita. Vários estudos têm mostrado que a toxicidade de amostras de água intersticial ou solubilizado de sedimentos marinhos ou de água doce pode ser devida à amônia (WHITEMAN, 1996).

\section{c) Metais Potencialmente Biodisponíveis}

As concentrações dos metais potencialmente biodisponível extraídos com $\mathrm{HCl}$ 0.1 M, obtidas para as amostras das estações E1, E2 e E3, coletadas nos reservatórios de Barra Bonita e estações E1 e E2 de Salto Grande estão apresentadas na Tabela 7 .

Conforme já citado anteriormente, a fração potencialmente biodisponível dos metais é definida como a fração da concentração total em cada reservatório abiótico que é incorporada pelos organismos. Essa fração compreende os metais fracamente ligados ao sedimento, que podem ser facilmente mobilizados (PLETTE et al., 1999). Nos ambientes aquáticos, todos os organismos estão expostos aos metais e organismos de diferentes níveis tróficos possuem diferentes mecanismos de assimilação, que variam 
desde a simples ingestão de íons em solução até a assimilação de metais incorporados em material biológico sólido (SALOMONS \& FORSTNER, 1984). A biodisponibilidade é um processo complexo onde propriedades físicas químicas e biológicas desempenham papeis importantes e distintos. Mais recentemente tem sido demonstrado que a biodisponibilidade pode ser diferente para diferentes organismos e essas diferenças estão relacionadas, entre outras coisas, por exemplo, com tamanho e com a forma de obtenção de alimentos (SIJM et al, 2000).

Tabela 7 - Concentrações em mg. $\mathrm{kg}^{-1}$ de metais potencialmente biodisponíveis, das amostras de sedimento das estações E1, E2 e E3 coletadas no reservatório de Barra Bonita e estações E1 e E2 do reservatório de Salto Grande.

\begin{tabular}{|c|c|c|c|c|c|c|c|}
\hline \multirow{3}{*}{$\begin{array}{l}\text { Metais } \\
\text { mg.Kg-1 }\end{array}$} & \multicolumn{3}{|c|}{ Barra Bonita } & \multicolumn{4}{|c|}{ Salto Grande } \\
\hline & \multirow{2}{*}{$\begin{array}{c}\text { E1 } \\
\text { junho/00 }\end{array}$} & \multirow{2}{*}{$\begin{array}{c}\text { E2 } \\
\text { jun/00 }\end{array}$} & \multirow{2}{*}{$\begin{array}{c}\text { E3 } \\
\text { jun/00 }\end{array}$} & \multicolumn{2}{|c|}{ E1 } & \multicolumn{2}{|c|}{ E2 } \\
\hline & & & & nov/00* & out/01 & nov/00* & out/01 \\
\hline $\mathrm{Cd}$ & $<\mathrm{LD}$ & 0,15 & $<\mathrm{LD}$ & 0,3 & 0,15 & 0,7 & 0,26 \\
\hline $\mathrm{Cu}$ & 5,8 & 4,2 & 4,75 & 41 & 7,5 & 29,9 & 8,8 \\
\hline $\mathrm{Cr}$ & na & $1, .6$ & na & 59 & 1,4 & 48,5 & 1,7 \\
\hline $\mathrm{Pb}$ & 2,8 & 4,4 & 4,5 & 48,7 & $1, .6$ & 40,8 & 2,1 \\
\hline $\mathrm{Ni}$ & na & 6,4 & na & na & 1,8 & na & 2,3 \\
\hline Zn & 5,5 & 11,3 & 12,7 & 50,7 & 13,9 & 34 & 14,8 \\
\hline $\mathrm{Fe}$ & 1542 & 3462 & 2152 & 4739 & 2115 & 4311 & 3261 \\
\hline $\mathrm{Mg}$ & 49 & 39,7 & 53,5 & 132,3 & 100,3 & 107,3 & 101,4 \\
\hline Co & 2,4 & 1,3 & 4,3 & na & na & na & na \\
\hline $\mathrm{Mn}$ & $132, .5$ & 127,5 & 117,5 & 267,1 & 285,3 & 280,3 & 324 \\
\hline
\end{tabular}

Considerando que a maior fração de metais é imobilizada nos sedimentos sob formas não biodisponíveis, (CALMANO et al., 1993; LACERDA, 1998), estimativas do potencial de risco de toxicidade à biota pela presença desses metais nos sedimentos, devem ser baseadas na concentração biodisponível e não na concentração total.

\subsection{2 - Avaliação da Toxicidade do Sedimento dos Reservatórios de Barra Bonita e Salto Grande.}

Os testes de toxicidade realizados com as amostras de sedimento coletadas nos reservatórios de Barra Bonita (setembro/99 a junho/00) e Salto Grande (março/00 a outubro/01) comprovaram o potencial tóxico dos ambientes de estudo. 
Os resultados das amostras de Barra Bonita estão apresentados nas Tabelas 8, 9 e 10 e nas Figuras 4 a 8.

Na Tabela 8 são apresentados os resultados (em \% de efeito) dos testes de toxicidade aguda realizados com o sedimento total e o solubilizado para todos os organismos-teste utilizados. Os destaques em negrito, na Tabela 8, indicam toxicidade aguda.

As amostras de sedimento total e solubilizado que não apresentaram toxicidade aguda para Daphnia similis (abril/99, janeiro/00, março/00 e junho/00) foram analisadas quanto à toxicidade crônica com Ceriodaphnia dubia. Nas Tabelas 9a, b, c e d estão apresentados os dados de sobrevivência, número de neonatos e as varáveis finais dos testes de toxicidade crônica. De acordo com as análises estatísticas, as taxas de reprodução e sobrevivência dos organismos-teste expostos às amostras de sedimento total das estações E1, E2 e E3 coletadas em abril/99, janeiro/00 e março/00 apresentaram diferenças estatisticamente significativas quando comparadas com o controle, indicando que essas amostras causaram toxicidade crônica (Tabelas 9a, b e c). Nos testes realizados em junho/00, com as amostras de sedimento total e solubilizado das três estações, o sedimento total das estações E1 e E2 e o solubilizado das estações E2 e E3 apresentaram toxicidade aguda para Ceriodaphnia dubia com porcentagens de mortalidade de 80 a 100\% em 48 horas. As demais amostras causaram toxicidade crônica (Tabela 9d). Analisando as variáveis finais dos testes apresentados na Tabela 9, observa-se uma diminuição muito grande na dureza, chegando a zero nos testes realizados com o sedimento total em abril/99 e junho/00. A comparação dos resultados obtidos em abril/99 (Tabela 9a) com os resultados obtidos em junho/00 (Tabela 9c) mostrou, no entanto, que a toxicidade aguda encontrada para C.dubia não está relacionada com essa variável, uma vez que nas mesmas condições, as porcentagens de mortalidade nas amostras das estações E2 (Tabela 9a) e E3 (Tabela 9c) foram de 60\% e 30\% respectivamente.Na Figura 4 estão apresentados os dados de reprodução em números de neonatos de Ceriodaphnia dubia obtidos nos testes de toxicidade crônica.das amostras de sedimento total das três estações de coleta. 
Tabela 8 - Porcentagens de efeito observado expresso em mortalidade para C. xanthus, imobilidade para $D$. similis, $C$. dubia e $C$. silvestrii e inibição da produção de luz para $V$. fisheri, nos testes de toxicidade aguda realizados com as amostras de sedimento total (ST) e Solubilizado (SOL) das estações E1, E2 e E3 do reservatório de Barra Bonita.

\begin{tabular}{|c|c|c|c|c|c|}
\hline \multirow[t]{2}{*}{ Período } & \multirow[t]{2}{*}{ Fração } & \multirow[t]{2}{*}{ Organismo-teste } & \multicolumn{3}{|c|}{$\%$ de Efeito } \\
\hline & & & E1 & E2 & E3 \\
\hline \multirow[t]{2}{*}{ Abril/99 } & \multirow[t]{2}{*}{ ST } & C. xanthus & 10 & zero & 10 \\
\hline & & D. similis & 03 & zero & 15 \\
\hline \multirow[t]{2}{*}{ Setembro/99 } & \multirow[t]{2}{*}{ ST } & D. similis & 65 & 67 & 70 \\
\hline & & C. dubia & 90 & 100 & 100 \\
\hline \multirow[t]{2}{*}{ Novembro/99 } & ST & D. similis & nc & nc & 52 \\
\hline & SOL & D. similis & nc & nc & 100 \\
\hline \multirow{2}{*}{$\begin{array}{l}\text { Dezembro/99 } \\
\text { (Teste 1) }\end{array}$} & ST & D. similis & $53 *$ & $60 *$ & 60* \\
\hline & SOL & D. similis & 60* & $100 *$ & 80* \\
\hline \multirow{4}{*}{$\begin{array}{l}\text { Janeiro/00 } \\
\text { (Teste 2) }\end{array}$} & ST & D. similis & $20 *$ & $03^{*}$ & $07 *$ \\
\hline & \multirow{3}{*}{ SOL } & D. similis & zero* & $33 *$ & $16^{*}$ \\
\hline & & C. dubia & zero & 13 & zero \\
\hline & & C. silvestrii & 07 & 20 & 07 \\
\hline \multirow{3}{*}{$\begin{array}{l}\text { Março/00 } \\
\text { (Teste 3) }\end{array}$} & \multirow{2}{*}{ ST } & C. xanthus & 27 & 44 & 44 \\
\hline & & D. similis & $20^{*}$ & $10^{*}$ & $23 *$ \\
\hline & SOL & C. dubia & $33 *$ & 66* & 66* \\
\hline \multirow{5}{*}{$\begin{array}{l}\text { Junho/00 } \\
\text { (Teste 4) }\end{array}$} & \multirow{3}{*}{ ST } & C.xanthus & 55 & 77 & 66 \\
\hline & & D. similis & zero & 07 & 17 \\
\hline & & C. dubia & $100 *$ & 100* & $30 *$ \\
\hline & \multirow[t]{2}{*}{ SOL } & D. similis & zero & 86 & 20 \\
\hline & & C. dubia & zero* & 90* & 80* \\
\hline \multirow{5}{*}{$\begin{array}{l}\text { Setembro/00 } \\
\text { (Teste 5) }\end{array}$} & ST & D. similis & $65 *$ & $67 *$ & 70* \\
\hline & \multirow{4}{*}{ SOL } & D. similis & 13 & 13 & zero \\
\hline & & C. dubia & $20 *$ & $20 *$ & 07* \\
\hline & & C. silvestrii & 07 & 13 & 13 \\
\hline & & $V$. fisheri & 6,5 & 08 & 07 \\
\hline
\end{tabular}

*: utilizados na construção das figuras 4, 5, 6 e 7.

nc: não coletado 
Tabela 9 a), b), c) e d) - Sobrevivência e número de neonatos de $C$. dubia expostos às amostras sedimento total (ST) e Solubilizado (SOL)das estações E1, E2 e E3 coletadas no reservatório de Barra Bonita (BB) no período de abril/99 a junho/00, em testes de toxicidade crônica.

\begin{tabular}{|c|c|c|c|c|c|c|c|c|c|c|c|c|}
\hline a) abr/99 & \multicolumn{2}{|c|}{$\begin{array}{l}\text { Número de } \\
\text { Organismos }\end{array}$} & \multirow{2}{*}{$\begin{array}{c}\text { Sobrevivência } \\
\text { (\%) }\end{array}$} & \multirow{2}{*}{$\begin{array}{l}\text { Número } \\
\text { de } \\
\text { neonatos }\end{array}$} & \multicolumn{2}{|c|}{$\mathrm{OD}\left(\mathrm{mg} \cdot \mathrm{L}^{-1}\right)$} & \multicolumn{2}{|c|}{$\mathrm{pH}$} & \multicolumn{2}{|c|}{$\begin{array}{l}\text { Cond. } \\
\mu \text { S.cm }^{-1}\end{array}$} & \multicolumn{2}{|c|}{$\begin{array}{c}\text { Dureza } \\
\mathrm{Mg} / \mathrm{lCaCO}{ }_{3}\end{array}$} \\
\hline Estações & $\mathrm{Ni}$ & $\mathrm{Nf}$ & & & I & $\mathrm{F}$ & I & $\mathrm{F}$ & I & $\mathrm{F}$ & I & $\mathrm{F}$ \\
\hline Controle & 10 & 10 & 100 & 292 & 7.7 & 7.7 & 7.3 & 7.7 & 144 & 147 & 47 & 47 \\
\hline BB-E1 ST & 10 & 5 & 50 & $22 *$ & 7.6 & 6.6 & 7.6 & 6.5 & 144 & 216 & 47 & 2 \\
\hline BB-E2 ST & 10 & 4 & 40 & $54^{*}$ & 7.6 & 6.2 & 7.6 & 6.3 & 144 & 196 & 47 & 0.0 \\
\hline BB-E3 ST & 10 & 4 & 40 & $12 *$ & 7.6 & 6.1 & 7.6 & 6.4 & 144 & 246 & 47 & 9 \\
\hline
\end{tabular}

\begin{tabular}{|c|c|c|c|c|c|c|c|c|c|c|c|c|}
\hline b) jan/00. & \multicolumn{2}{|c|}{$\begin{array}{l}\text { Número de } \\
\text { Organismos }\end{array}$} & \multirow{2}{*}{$\begin{array}{c}\text { Sobrevivência } \\
\text { (\%) }\end{array}$} & \multirow{2}{*}{$\begin{array}{l}\text { Número } \\
\text { de } \\
\text { neonatos }\end{array}$} & \multicolumn{2}{|c|}{$\mathrm{OD}\left(\mathrm{mg} \cdot \mathrm{L}^{-1}\right)$} & \multicolumn{2}{|c|}{$\mathrm{pH}$} & \multicolumn{2}{|c|}{$\begin{array}{l}\text { Cond. } \\
\mu S . \mathrm{cm}^{-1}\end{array}$} & \multicolumn{2}{|c|}{$\begin{array}{c}\text { Dureza } \\
\mathrm{Mg} / \mathrm{CaCO}_{3}\end{array}$} \\
\hline Estações & $\mathrm{Ni}$ & $\overline{\mathrm{Nf}}$ & & & I & $\mathrm{F}$ & I & $\mathrm{F}$ & I & $F$ & I & $F$ \\
\hline Controle & 10 & 10 & 100 & 186 & 7.8 & 7.5 & 7.6 & 7.6 & 124 & 111 & 42 & 36 \\
\hline BB-E1 ST & 10 & 5 & 50 & $22 *$ & 7.6 & 6.2 & 7.6 & 7.4 & 121 & 119 & 42 & 32 \\
\hline BB-E2 ST & 10 & 4 & 40 & $54 *$ & 7.3 & 6.8 & 7.6 & 7.2 & 121 & 177 & 42 & 30 \\
\hline BB-E3 ST & 10 & 4 & 40 & $18^{*}$ & 7.7 & 6.3 & 7.6 & 7.2 & 121 & 152 & 42 & 28 \\
\hline
\end{tabular}

\begin{tabular}{|c|c|c|c|c|c|c|c|c|c|c|c|c|}
\hline \multirow{2}{*}{$\begin{array}{l}\text { d) mar/00 } \\
\text { Estações }\end{array}$} & \multicolumn{2}{|c|}{$\begin{array}{l}\text { Número de } \\
\text { Organismos }\end{array}$} & \multirow{2}{*}{$\begin{array}{c}\text { Sobrevivência } \\
\text { (\%) }\end{array}$} & \multirow{2}{*}{$\begin{array}{c}\text { Número } \\
\text { de } \\
\text { neonatos }\end{array}$} & \multicolumn{2}{|c|}{ OD $\left(\mathrm{mg} \cdot \mathrm{L}^{-1}\right)$} & \multicolumn{2}{|c|}{$\mathrm{pH}$} & \multicolumn{2}{|c|}{$\begin{array}{l}\text { Cond. } \\
\mu \mathrm{S} \mathrm{cm}^{-1}\end{array}$} & \multicolumn{2}{|c|}{$\begin{array}{c}\text { Dureza } \\
\mathrm{Mg} / \mathrm{CaCO}_{3} \\
\end{array}$} \\
\hline & $\mathrm{Ni}$ & $\mathrm{Nf}$ & & & $\mathrm{I}$ & $\mathrm{F}$ & $\mathrm{I}$ & $\mathrm{F}$ & $\mathrm{I}$ & $\mathrm{F}$ & $\mathrm{I}$ & $F$ \\
\hline Controle & 10 & 9 & 90 & 189 & 7.2 & 7.7 & 7.2 & 6.6 & 144 & 130 & 42 & 50 \\
\hline BB-E1 ST & 10 & 3 & 30 & zero* & 7.5 & 6.3 & 7.2 & 5.5 & 117 & 119 & 42 & 28 \\
\hline BB-E2 ST & 10 & 7 & 70 & $4^{*}$ & 7.6 & 6.1 & 7.2 & 6.4 & 117 & 210 & 42 & 56 \\
\hline BB-E3 ST & 10 & 3 & 30 & $18^{*}$ & 7.6 & 6.6 & 7.2 & 5.4 & 117 & 161 & 42 & 32 \\
\hline
\end{tabular}

\begin{tabular}{|c|c|c|c|c|c|c|c|c|c|c|c|c|}
\hline \multirow{2}{*}{$\begin{array}{l}\text { c) jun/00 } \\
\text { Estações }\end{array}$} & \multicolumn{2}{|c|}{$\begin{array}{l}\text { Número de } \\
\text { Organismos }\end{array}$} & \multirow{2}{*}{$\begin{array}{c}\text { Sobrevivência } \\
\text { (\%) }\end{array}$} & \multirow{2}{*}{$\begin{array}{l}\text { Número } \\
\text { de } \\
\text { neonatos }\end{array}$} & \multicolumn{2}{|c|}{ OD $\left(\mathrm{mg} \cdot \mathrm{L}^{-1}\right)$} & \multicolumn{2}{|c|}{$\mathrm{pH}$} & \multicolumn{2}{|c|}{$\begin{array}{l}\text { Cond. } \\
\mu \text { S.cm }^{-1}\end{array}$} & \multicolumn{2}{|c|}{$\begin{array}{c}\text { Dureza } \\
\mathrm{Mg} / \mathrm{lCaCO}_{3}\end{array}$} \\
\hline & $\mathrm{Ni}$ & $\mathrm{Nf}$ & & & I & $\mathrm{F}$ & $\mathrm{I}$ & $\mathrm{F}$ & $\mathrm{I}$ & $\mathrm{F}$ & $\mathrm{I}$ & $\mathrm{F}$ \\
\hline Controle & 9 & 9 & 100 & 128 & 7.7 & 7.7 & 7.2 & 7.4 & 101 & 84 & 46 & 50 \\
\hline BB-E1 SOL & 10 & zero & zero * & zero & 7.6 & 6.6 & 7.2 & 5.0 & 101 & 50 & 20 & 8 \\
\hline BB-E2 SOL & 10 & 1 & $10(48 \mathrm{~h}) * *$ & zero & 7.6 & 6.2 & 7.2 & 5.5 & 101 & 82 & 36 & 20 \\
\hline BB-E3 SOL & 10 & 2 & $20(48 \mathrm{~h}) * *$ & zero & 7.7 & 6.3 & 7.2 & 6.1 & 101 & 99 & 24 & 2 \\
\hline BB-E1 ST & 10 & zero & zero (48h) ** & zero & 7.2 & 6.2 & 7.2 & 5.8 & 101 & 107 & 46 & 0 \\
\hline BB-E2 ST & 10 & zero & zero (48h)** & zero & 7.3 & 7.1 & 7.2 & 5.5 & 101 & 107 & 46 & 0 \\
\hline BB-E3 ST & 10 & 7 & 70 & $37 *$ & 7.6 & 6.1 & 7.2 & 6.4 & 101 & 104 & 46 & 0 \\
\hline
\end{tabular}

$\mathrm{Ni}$ - número inicial de fêmeas

I _ valor inicial

$\mathrm{F}$ - valor final

$\mathrm{Nf}$ - número final de fêmeas vivas

*: diferença na sobrevivência e fecundidade estatisticamente significativas segundo os testes

Fisher (sobrevivência) e Dunnett's (reprodução)

**: toxicidade aguda, pois ocorreu 90,80 e $100 \%$ de mortalidade em $48 \mathrm{~h}$. 


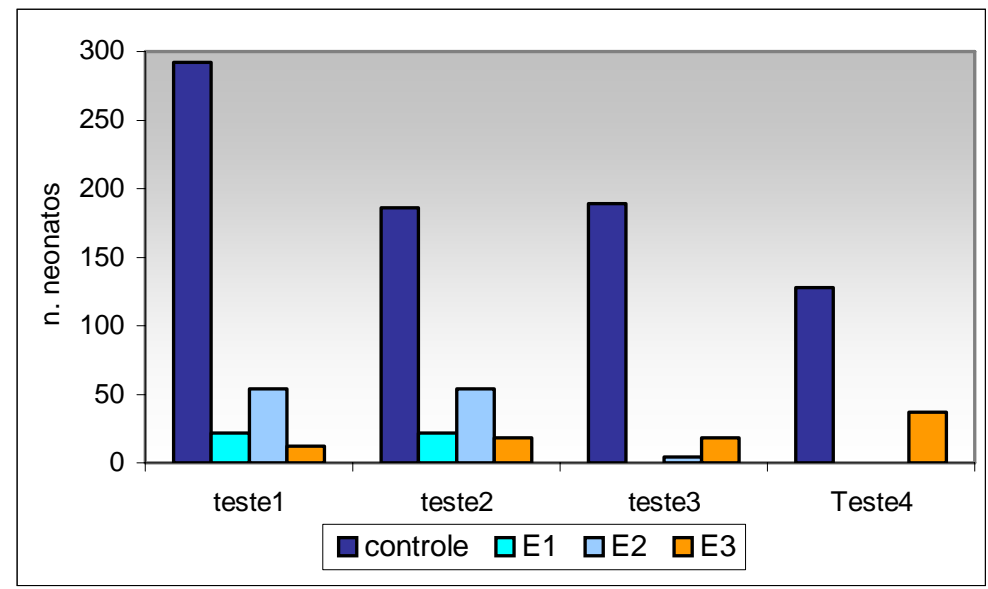

Figura 4 - Número de neonatos produzidos por Ceriodaphnia dubia exposta ao sedimento total das estações E1, E2 e E3 coletadas na represa de Barra Bonita, em testes de toxicidade crônica.

Considerando os testes de toxicidade aguda (Tabela 8) e crônica (Tabela 9), os resultados mostraram que o sedimento total foi tóxico em todas as amostragens realizadas.

Embora o objetivo dos testes de toxicidade não foi o de comparar a sensibilidade dos diferentes organismos-teste, os resultados apresentados na Tabela 8, mostraram que as duas espécies de Ceriodaphnia utilizadas, C. dubia (padronizada) e C. silvestrii, (nativa) apresentaram resultados semelhantes. A espécie Ceriodaphnia silvestrii apresenta distribuição significativa nos lagos, lagoas e reservatórios do sudeste do Brasil e os estudos realizados por FONSECA (1991e 1996) e OLIVEIRA NETO (2000) sobre a biologia e a resposta dessa espécie nos testes de toxicidade com efluentes industriais (têxtil e vinhaça), amostras ambientais de locais contaminados, metais e substânciasreferência mostraram que ela pode ser utilizada em testes de toxicidade devido à facilidade de cultivo em laboratório e sua sensibilidade, igual ou maior quando comparada às espécies padronizadas Daphnia similis e Ceriodaphnia dubia.

Considerando os resultados em termos de presença ou ausência de toxicidade para todos organismos-teste utilizados (Tabela 10), observa-se que o sedimento total foi mais tóxico e os resultados foram semelhantes para as estações analisadas. Comparando os resultados obtidos com o sedimento total e o solubilizado, de um total de 15 amostras analisadas em paralelo, o sedimento total apresentou toxicidade em $100 \%$ das amostras e o solubilizado em 67\% (10 amostras). Do total de amostras tóxicas, 11 do sedimento total (73\%) acarretaram toxicidade aguda e 4 (27\%), toxicidade crônica. Em relação ao 
solubilizado, 11 (73 \%) de 15 foram tóxicas, sendo que, desse total, 7 (64\%) aguda e 4 (36\%) crônica.

Tabela 10 - Toxicidade para pelo menos um dos organismos-teste utilizados nos testes de toxicidade aguda ou crônica com as amostras de sedimento total (ST) e solubilizado (SOL) das estações E1, E2 e E3, coletadas no reservatório de Barra Bonita no período de abril/99 a setembro/00.

\begin{tabular}{|c|c|c|c|c|c|c|c|c|c|}
\hline \multirow{2}{*}{ Estações } & \multirow{2}{*}{ Fases } & \multicolumn{4}{|c|}{1999} & \multicolumn{4}{|c|}{2000} \\
\cline { 3 - 10 } & & Abr & Set & Nov & Dez & Jan & Mar & Jun & Set \\
\hline \multirow{2}{*}{ E1-Piracicaba } & ST & TC & TA & na & TA & TC & TC & TA & TA \\
\cline { 2 - 10 } & SOL & na & na & na & TA & NT & NT & TC & TC \\
\hline \multirow{2}{*}{ E2-Tietê } & ST & TC & TA & na & TA & TC & TA & TA & TA \\
\cline { 2 - 10 } & SOL & na & na & na & TA & NT & TA & TA & TC \\
\hline \multirow{2}{*}{ E3-Barragem } & ST & TC & TA & TA & TA & TC & TA & TA & TA \\
\cline { 2 - 9 } & SOL & na & na & na & TA & NT & TA & TA & TC \\
\hline
\end{tabular}

TA: toxicidade aguda. TC: toxicidade crônica. NT: não tóxico. na: não analisada.

Por outro lado, comparando-se os resultados obtidos em relação à toxicidade aguda do solubilizado e do sedimento total para os organismos de coluna d'água, $D$. similis e/ou C.dubia, pode-se observar nas Figuras 5, 6 e 7, que em dezembro/99, janeiro/00, março/00 e junho/00 (testes 1 a 4), o solubilizado das estações E2 e E3 foi tão ou mais tóxico que o sedimento total. Apenas em setembro/00 (teste 5), as porcentagens de imobilidade do solubilizado foram menores que as do sedimento total, para as três estações de amostragem. Entre as diferentes estações, as estações E2-Tiete e E3-Barragem apresentaram as maiores correspondências de amostras tóxicas (T/T) entre as duas fases (80\%, contra 60\% para a estação E1- Piracicaba) e a estação E2 foi a que apresentou as maiores porcentagens de imobilidade (Tabela 9 e Figura 8). 


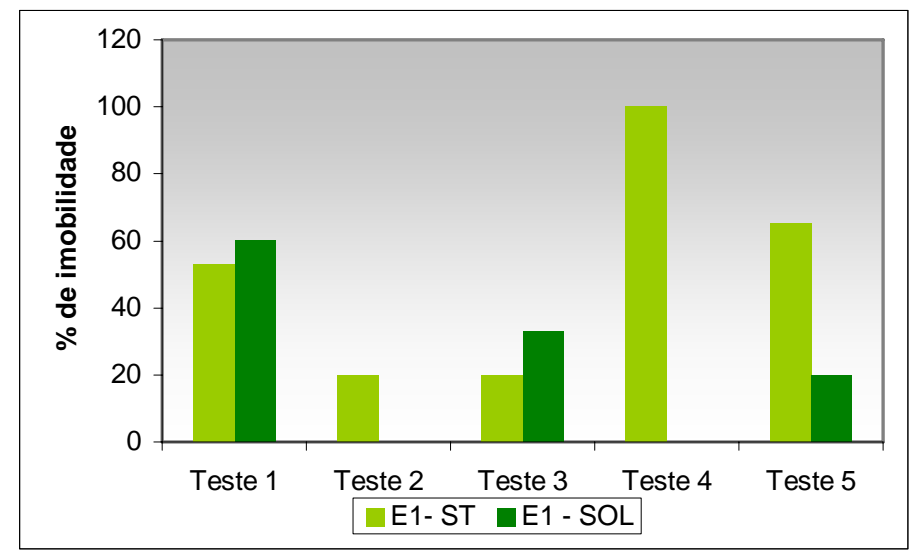

Figura 5 - Porcentagens de imobilidade de Daphnia similis e/ou C. dubia expostas às amostras de sedimento total (ST) e solubilizado (SOL) da estação E1 coletada no reservatório de Barra Bonita no período de dezembro/99 a setembro/00, em testes de toxicidade aguda.

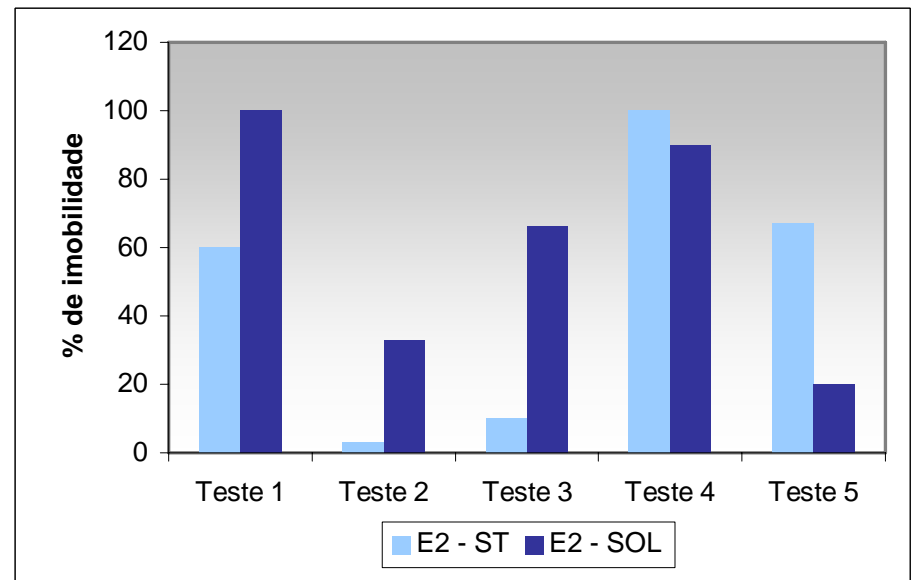

Figura 6- Porcentagens de imobilidade de Daphnia similis e/ou C. dubia expostas às amostras de sedimento total (ST) e solubilizado (SOL) da estação E2 coletada no reservatório de Barra Bonita no período de dezembro/99 a setembro/00, em testes de toxicidade aguda.

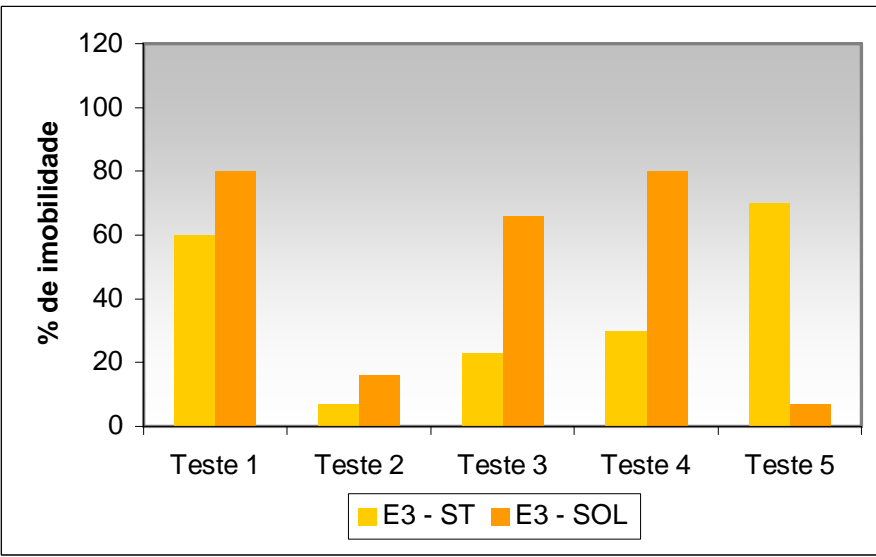

Figura 7 - Porcentagens de imobilidade de Daphnia similis e/ou C. dubia expostas às amostras de sedimento total (ST) e solubilizado (SOL) da estação E3 coletada no reservatório de Barra Bonita no período de dezembro/99 a setembro/00, em testes de toxicidade aguda. 


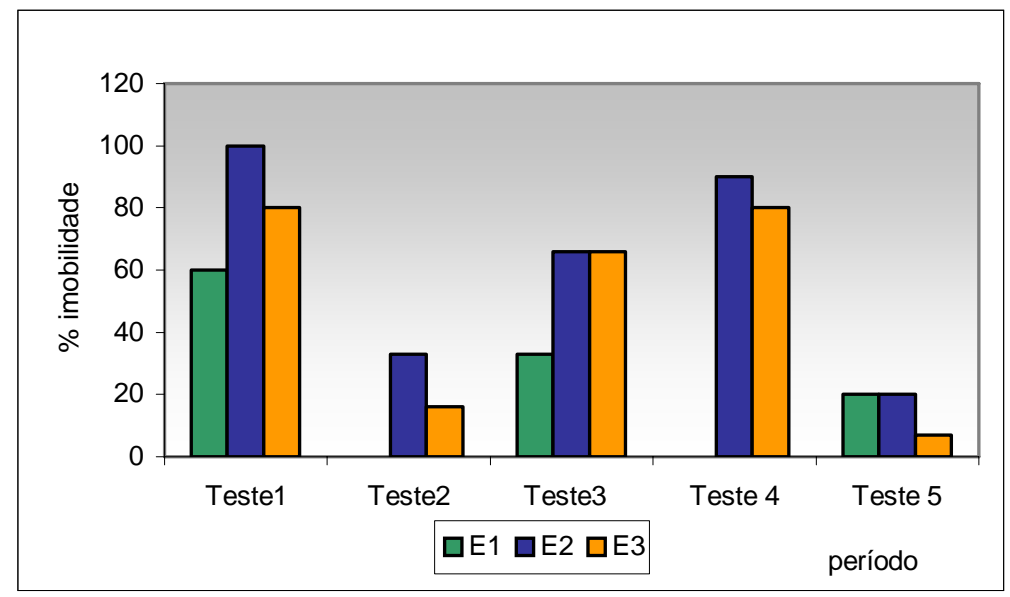

Figura 8 - Porcentagens de imobilidade de $C$. dubia expostas ao solubilizado do sedimento coletado nas estações E1, E2 e E3 do reservatório de Barra Bonita no período de dezembro/99 a setembro/00, em testes de toxicidade aguda.

A estação E3 foi analisada em diferentes estudos, sob diferentes aspectos, inclusive toxicidade. Em relação à toxicidade, na Tabela 11 estão apresentados os resultados, em intensidade de efeitos, obtidos por COSTA (2001), RODGHER (2001) e neste estudo, para as amostras de sedimento da estação E3, no período de fevereior99 a setembro/00.

Tabela 11 -Toxicidade do sedimento da estação E3, obtido em diferentes estudos e para diferentes organismos-teste em 1999 e 2000.

\begin{tabular}{|l|c|c|c|c|c|c|c|c|c|c|c|c|c|c|c|}
\hline & \multicolumn{10}{|c|}{1999} & \multicolumn{1}{|c|}{2000} \\
\cline { 2 - 17 } & fev & abr & jun & ag & set & out & nov & dez & jan & fev & mar & mai & jun & jul & set \\
\hline $\begin{array}{l}\text { COSTA } \\
(2001)\end{array}$ & TC & TC & TC & TC & -- & -- & TC & -- & -- & -- & TC & -- & -- & -- & -- \\
\hline $\begin{array}{l}\text { RODGHER } \\
(2001)\end{array}$ & -- & -- & -- & -- & -- & IT & -- & -- & -- & TC & -- & NT & -- & TC & -- \\
\hline $\begin{array}{l}\text { Presente } \\
\text { estudo }\end{array}$ & -- & TC & -- & -- & TA & -- & TA $^{2}$ & TA & TC & -- & TC & -- & TC & -- & TA \\
\hline
\end{tabular}

\footnotetext{
${ }^{1}$ : Ceriodaphnia silvestrii $\quad{ }^{2}$ : Daphnia similis
}

Considerando esses três estudos, observa-se que o sedimento desse local foi testado quanto à toxicidade quase que bimestralmente, ao longo dos anos 1999 a 2001. Em apenas uma amostragem, maio/00, não foi encontrada toxicidade sendo que, na maior parte do período a toxicidade foi crônica e não aguda. A diferença na intensidade da toxicidade detectada por COSTA (2000) e no presente estudo em novembro/99, deve-se provavelmente, às diferenças na sensibilidade entre os organismos-teste 
utilizados, respectivamente, $C$. silvestrii e $D$. similis. No entanto, embora a coleta tenha sido realizada no mesmo local e no mesmo período, não existem duas amostras ambientais iguais. SILVÉRIO (1999), encontrou toxicidade aguda para Hyalella azteca e toxicidade crônica para C. dubia, nas amostras de sedimento desse mesmo local (estação E3) em janeiro e julho de 1998.

As amostras de sedimento coletadas no reservatório de Salto Grande foram analisadas por meio de testes de toxicidade com Daphnia similis e/ou Ceriodaphnia dubia (sedimento total) e Daphnia similis e/ou Ceriodaphnia dubia, Vibrio fisheri e Spirillum volutans (solubilizado). Os testes com Chironomus xanthus, com as amostras coletadas em maio/00, agosto/00 novembro/00 e fevereiro/01 foram realizados por DORNFELD (2002).

Os resultados desses testes de toxicidade estão apresentados na Tabela 12. Na Figura 9 são apresentadas as porcentagens de imobilidade do sedimento total e do solubilizado obtidos nos testes de toxicidade aguda com C.dubia

Todas as amostras de sedimento coletadas nas estações E1 e E2, no período de estudo foram tóxicas, com exceção da amostra da estação E2, coletada em abril/02. Esses resultados mostraram o comprometimento do sedimento do reservatório de Salto Grande em relação às substâncias potencialmente tóxicas, confirmando os resultados anteriormente obtidos por ESPINDOLA et al. (1998), TONISSI (1999), PAMPLIN (1999) e DORNFELD (2002). Comparando os resultados obtidos no presente estudo com os obtidos por ESPINDOLA et al (1998) e DORNFELD (2002), parece que a toxicidade para os organismos $D$. similis e $C$. dubia está associada principalmente ao segundo compartimento do reservatório, onde estão localizadas as estações E1 e E2.

Em relação ao solubilizado, ele foi tão ou mais tóxico que o sedimento total, considerando as porcentagens de imobilidade obtidas para as duas fases, sedimento total e solubilizado, confirmando sua representatividade em relação à toxicidade do sedimento para organismos de coluna d’água (Figura 9). 
Tabela 12 - Efeito em porcentagem de imobilidade (D. similis e C. dubia no ST), CE50, 48h (C. dubia), CE20, 15' (V. fisheri) e MEC90, 30' (Spirillum volutans) para os diferentes organismos-teste, nos testes de toxicidade aguda realizados com as amostras de sedimento das estações E1e E2 coletadas no reservatório de Salto Grande.

\begin{tabular}{|c|c|c|c|c|c|c|}
\hline \multirow[b]{2}{*}{ Data } & \multicolumn{2}{|c|}{ Sedimento Total (ST) } & \multicolumn{4}{|c|}{ Solubilizado (SOL) } \\
\hline & $\begin{array}{l}D \text { similis } \\
\text { (\% imob.) }\end{array}$ & $\begin{array}{l}\text { C.dúbia } \\
\text { (\% imob) }\end{array}$ & $\begin{array}{l}D \text { similis } \\
\text { (\% imob.) }\end{array}$ & $\begin{array}{c}\text { C.dubia } \\
\text { CE50, 48h }\end{array}$ & $\begin{array}{l}\text { V.fisheri } \\
\text { CE20,15, }\end{array}$ & $\begin{array}{l}\text { S.volutans } \\
\text { MEC } 90,30 \text {, }\end{array}$ \\
\hline \multicolumn{7}{|l|}{ Estação E1 } \\
\hline março/00 & 50 & 60 & 100 & $100 *$ & $\mathrm{nr}$ & $\mathrm{nr}$ \\
\hline maio/00 & $>50$ & $\mathrm{nr}$ & 100 & 66 & $\mathrm{nr}$ & $\mathrm{nr}$ \\
\hline agosto/00 & $\mathrm{nr}$ & 100 & 56 & 47 & 25 & 90 \\
\hline novembro/00 & $\mathrm{nr}$ & 60 & $\mathrm{nr}$ & 57 & 33,5 & $\mathrm{nr}$ \\
\hline fevereiro/01 & $\mathrm{nr}$ & 83 & 100 & $\mathrm{nr}$ & NT & $\mathrm{nr}$ \\
\hline abril/01 & 20 & 40 & $\mathrm{nr}$ & 40 & NT & $\mathrm{nr}$ \\
\hline outubro/01 & 100 & 100 & $\mathrm{nr}$ & 59 & $\mathrm{nr}$ & $\mathrm{nr}$ \\
\hline \multicolumn{7}{|l|}{ Estação E2 } \\
\hline março/00 & 60 & 70 & 100 & $100^{*}$ & $\mathrm{nr}$ & $\mathrm{nr}$ \\
\hline maio/00 & $\mathrm{nr}$ & TC & 100 & 31 & $\mathrm{nr}$ & $\mathrm{nr}$ \\
\hline agosto/00 & $\mathrm{nr}$ & 100 & 100 & 72 & 15 & 90 \\
\hline novembro/00 & $\mathrm{nr}$ & 50 & $\mathrm{nr}$ & 51 & 27 & $\mathrm{nr}$ \\
\hline fevereiro/01 & $\mathrm{nr}$ & 50 & 100 & $\mathrm{nr}$ & NT & $\mathrm{nr}$ \\
\hline outubro/01 & 100 & 100 & $\mathrm{nr}$ & 22 & $\mathrm{nr}$ & $\mathrm{nr}$ \\
\hline abilr/02 & NT & NT & NT & NT & $\mathrm{nr}$ & $\mathrm{nr}$ \\
\hline
\end{tabular}

nr: não realizado $\quad$ NT: não tóxico $\quad *$ : \% imobilidade da amostra pura

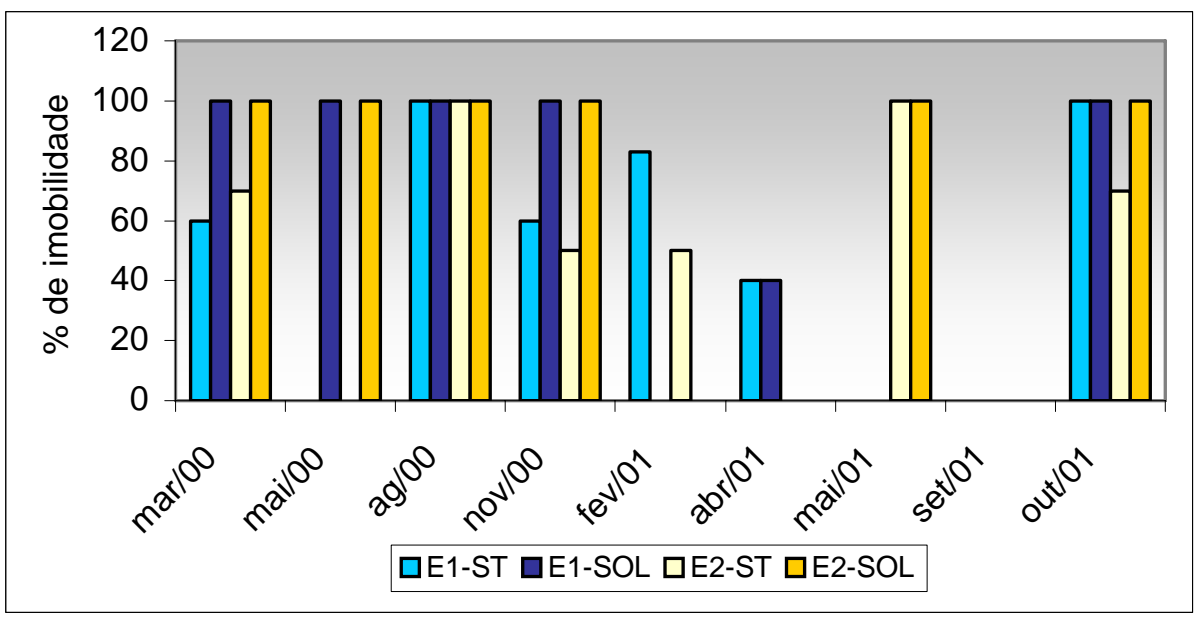

Figura 9- Porcentagens de imobilidade de C. dubia expostas ao sedimento total e solubilizado das estações E1e E2, coletadas no reservatório de Salto Grande no período de março/00 a outubro/01, em testes de toxicidade aguda.

A toxicidade detectada nesse estudo revelou uma deterioração da qualidade do sedimento e, conseqüentemente, da água dos reservatórios estudados, uma vez que, o sedimento, por sua capacidade de acumular compostos, se constitui no principal 
compartimento de avaliação de contaminação dos ecossistemas aquáticos (MOZETO \& PATELLA, 1997)

Além do impacto direto sobre a população bentônica, a contaminação dos sedimentos, pode, a longo prazo, constituir uma fonte de substancias tóxicas para o ambiente, afetando de forma adversa não só a fauna aquática como também os animais silvestres e o homem, através do contato direto e/ou consumo da água e alimentos contaminados. O mais importante é que esses impactos podem ocorrer mesmo que a água esteja de acordo com os critérios de qualidade (EPA,1992). Existem diferentes vias de exposição dos organismos aquáticos e terrestres, incluindo o homem, aos contaminantes, especialmente aos metais, e a freqüência e intensidade de exposição dependem do uso e das transformações químicas do contaminante no ambiente (BAUDO \& MUNTAU, 1990).

A avaliação dos sedimentos através de testes de toxicidade tem como vantagem principal definir qual a porção biodisponível de um contaminante, uma vez que essa porção pode ser muito diferente da quantidade total determinada pelas análises químicas. Além do mais, em locais contaminados por mais de um composto ou por uma mistura de compostos químicos, os testes de toxicidade são as únicas ferramentas capazes de avaliar o potencial tóxico dos sedimentos, pois é muito raro que apenas um contaminante possa ser responsabilizado pela toxicidade de um ambiente. Mesmo assim, não existe um método único e simples que possa medir todos os impactos de sedimentos contaminados durante todo o tempo e para todos os organismos, pois a intensidade e magnitude desses impactos são dependentes de inúmeros fatores, incluindo a heterogeneidade ambiental associada aos problemas de amostragem, variabilidade da exposição em laboratório, as diferenças de sensibilidade dos diferentes organismos-teste, os efeitos interferentes causados pela presença de inúmeros contaminantes não mensuráveis, os efeitos sinérgicos e antagônicos e as propriedades físicas do sedimento (EPA, 1992; SETAC, 1993; ANKLEY \& MOUNT, 1996).

Nesse sentido, análises integradas fornecem informações adicionais e complementares que permitem uma avaliação mais abrangente do grau e da extensão da contaminação e, dependendo do tipo de abordagem utilizada, podem apontar locais ainda não degradados, mas com possibilidades de degradação. Dentre as diferentes abordagens integradas de análise de sedimentos contaminados, a grande vantagem da utilização do estudo de Avaliação e Identificação da Toxicidade - AIT, é a identificação rápida e 
relativamente barata de tais compostos e a possibilidade de determinar, em casos de presença de múltiplos tóxicos, a contribuição relativa de cada um deles na toxicidade total (EPA, 1992; ANKLEY.\& SCHUBAUER-BERINGAN, 1995).

\subsection{3 - Controle de Qualidade dos Organismos-Teste: Testes de Sensibilidade}

A variabilidade dos resultados obtidos em testes de toxicidade depende do estado fisiológico, ou seja, da saúde dos organismos submetidos aos testes. De acordo com BAIRD et al. (1989), essa variabilidade tem três sub-componentes: heterogeneidade genética, heterogeneidade ambiental e interação genótipo/ambiente.

Considerando a componente ambiental, as condições de cultivo não padronizadas constituem uma fonte importante de variabilidade, envolvendo tanto as condições pré natais (efeitos maternos), como as condições pós nascimento. Os resultados obtidos em testes agudos com 48h de duração, realizados com neonatos provenientes de mães alimentadas com diferentes quantidades de alimento, mostraram a influência dos efeitos maternos na resposta toxicológica, principalmente aguda. Os valores de CL50;48h para dicloroanilina foram de 104 e $195 \mu$ g. $\mathrm{L}^{-1}$ para neonatos de mães alimentadas com 0.5 e

0.05 mg.L ${ }^{-1}$ de suspensão algácea, respectivamente. As condições pós-nascimento, isto é, as condições do teste em si, afetam as respostas crônicas, principalmente a fecundidade (BAIRD et al. 1989).

Do ponto de vista da variabilidade ambiental, a obtenção de neonatos em quantidade e qualidade necessárias para os testes depende da padronização e do controle das condições de cultivo (qualidade da água, quantidade e qualidade de alimento fornecido e a temperatura).

Uma das maneiras de se controlar a qualidade das culturas mantidas em laboratório é através da realização rotineira de testes de toxicidade aguda com substâncias de referência que avaliam as condições fisiológicas, ou da "saúde” dos organismos a serem utilizados nos testes, conferindo maior credibilidade aos resultados.

De acordo com recomendação da EPA (1991), uma vez estabelecida a faixa de sensibilidade a uma substância referência, a avaliação da sensibilidade dos organismosteste deve ser feita mensalmente, tomando-se o cuidado de desconsiderar os testes efetuados com lotes de organismos que apresentarem valores de CE(I)50 fora da faixa estabelecida. 
A variação entre os testes, eliminados todos os fatores relacionados com o subcomponente ambiental da variabilidade, está relacionada com a heterogeneidade genética, responsável pela diferença individual de sensibilidade de cada organismo, fator esse não controlável (PRINTES, 1996).

Nesse aspecto, os resultados obtidos nos testes de sensibilidade com Daphnia similis, Ceriodaphnia dubia e Chironomus xanthus (Figuras 10. 11 e 12), mostraram que as culturas estão sendo mantidas em condições uniformes ao longo do tempo, uma vez que os valores de CE(I)50 se situaram, em sua grande maioria, dentro das faixas de sensibilidade estabelecidas para esses organismos, o que confere confiabilidade aos resultados dos testes de toxicidade realizados com as amostras.

\section{a) Daphnia similis}

Os resultados dos testes de sensibilidade com dicromato de potássio mostraram que, com exceção do teste de $n^{0} 21$, cujo valor de CE(I)50;2h ficou abaixo da faixa de 0,04 a 0,17 mg. $\mathrm{L}^{-1}$ estabelecida por ZAGATTO (1988), as demais culturas estavam para serem utilizadas nos testes de toxicidade (Tabela 1, anexo 1) Os valores de CE(I)50;2h variaram entre 0,033 a $0,15 \mathrm{mg} . \mathrm{L}^{-1}$ de dicromato de potássio, com valor de CE50, 48h médio de $0,085 \mathrm{mg} . \mathrm{L}^{-1}$ e desvio padrão de 0,03 . Na Figura 10 estão apresentados os valores de CE50, 24h com os intervalos de confiança de cada teste de sensibilidade.

O dicromato de potássio tem sido bastante utilizado como substância referência para peixes e invertebrados, entre eles microcrustáceos, por apresentar as características necessárias para uma substância referência, tais como: disponibilidade do produto com pureza consistente, solubilidade em água, toxicidade em concentrações baixas, letalidade rápida, toxicidade não específica para peixes e invertebrados, toxicidade consistente, especialmente dentro de uma faixa de $\mathrm{pH}$ e ser reconhecida como contaminante ambiental (ZAGATTO, 1988; BOHRER, 1995). Apesar de ser um micronutriente importante para o metabolismo de animais e plantas, o cromo, em concentrações mais elevadas, causa efeitos tóxicos e sua toxicidade para a biota aquática é função de sua especiação química $\left(\mathrm{Cr}^{3+} / \mathrm{Cr}^{6+}\right)$, como também da temperatura, dureza, salinidade e $\mathrm{pH}$ (BOHRER, 1995).

A faixa de sensibilidade ao dicromato de potássio para as diferentes espécies do gênero Daphnia varia de acordo com a espécie. Para Daphnia magna as faixas estabelecidas pelas normas americanas (ISO), francesas (AFNOR) e alemãs (DIN) são, 
respectivamente, de 0,9 a 2,0 mg. $\mathrm{L}^{-1}$; 0,9 a $1,5 \mathrm{mg} \cdot \mathrm{L}^{-1}$ e 0,9 a $1,9 \mathrm{mg} . \mathrm{L}^{-1}$ para água duras, contendo 200 a 250 mg. $\mathrm{L}^{-1}$ de $\mathrm{CaCO}_{3}$. De um modo geral, a toxicidade do cromo para invertebrados varia entre 0,1 a 20 mg. $\mathrm{L}^{-1}$ (BOHRER, 1995).

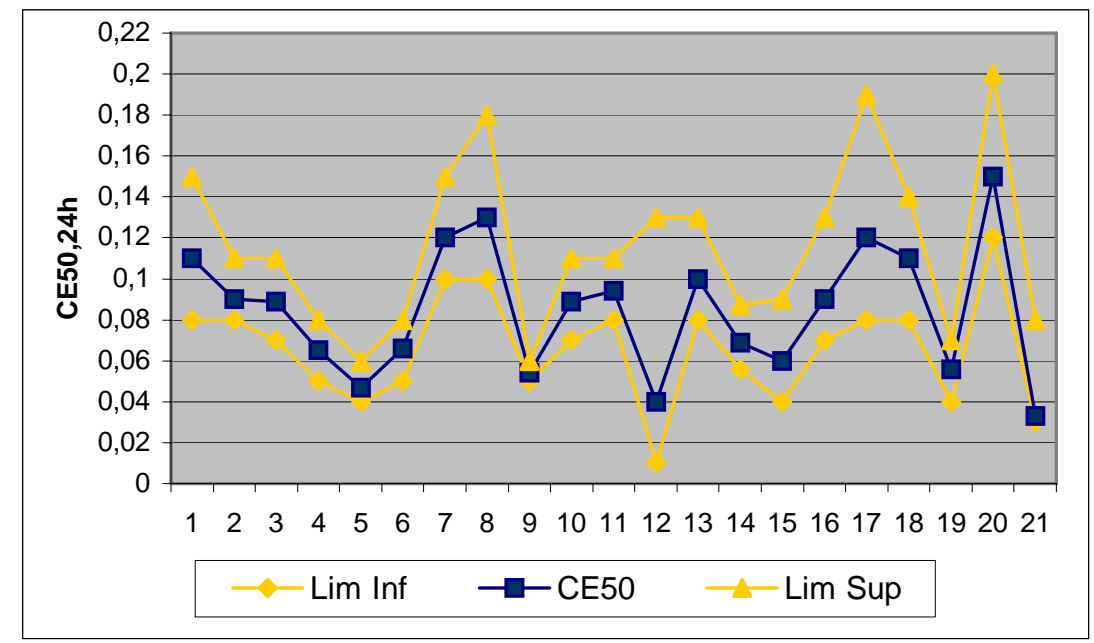

Figura 10 - Valores de CE50, 24h e os intervalos de confiança dos testes de sensibilidade de Daphnia similis ao dicromato de potássio.

\section{b) Ceriodaphnia dubia}

Os valores de CE(I)50;48h obtidos nos testes de sensibilidade com cloreto de sódio variaram de 1,15 a 1,90 g.L ${ }^{-1}$ (Tabela 2, anexo 1). Considerando a faixa de sensibilidade estabelecida por BOHRER (1995), de 1,33 a 1,82 g.L $\mathrm{L}^{-1}$, os resultados do presente estudo mostraram que, com exceção dos testes $6,9,17,25$ e 30, as culturas estavam adequadas para serem utilizadas em testes. De acordo com CETESB (1992) o valor da CE(I)50;48H deve situar-se em torno de 1,60 g.L $\mathrm{L}^{-1}$ de cloreto de sódio. O valor da CE50, 48h médio obtido nesse período de estudo foi de 1,65 com desvio padrão de 0.16. Na Figura 11 estão apresentados os valores de CE50, 48h com os intervalos de confiança de cada teste de sensibilidade.

De acordo com ALADIN (1991), espécies de cladóceros de água doce (Daphnia magna, Daphnia pulex, Daphnia longispina, Ceriodaphnia reticulata e Bosmina longirostris, entre outros) fazem o controle osmótico conservando sua hemolinfa hiperosmóstica em relação ao meio externo, reabsorvendo, pela glândula maxilar, sais ingeridos com alimento. Quando expostos a uma salinidade alta, morrem por não conseguirem manter o mecanismo osmótico. Nos embriões, esta absorção é realizada pelo órgão nucal, pois, enquanto permanecem na câmara de incubação, não recebem alimento proveniente do meio externo, sendo necessária a presença de um órgão 
osmorregulador. Depois da primeira muda, após o nascimento, este órgão desaparece e a glândula maxilar passa a ser responsável pela absorção de sais.

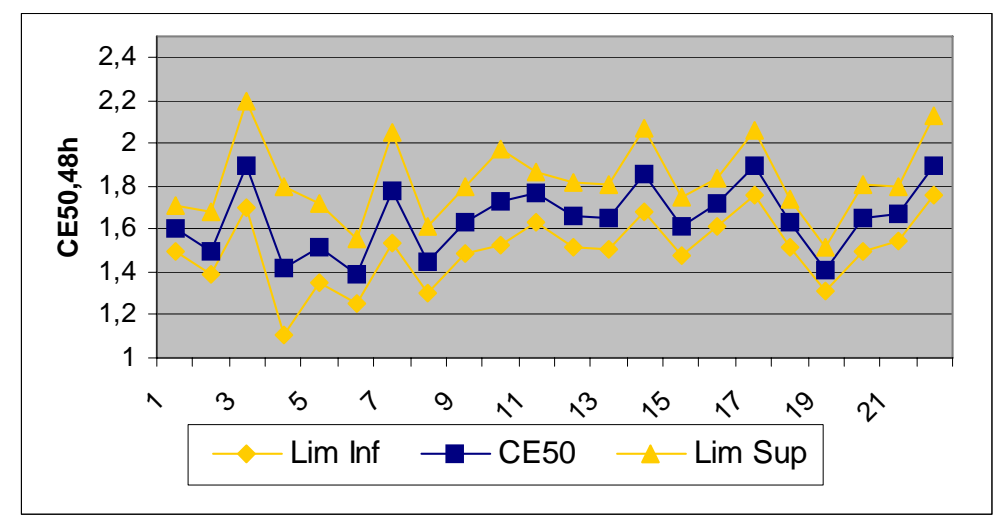

Figura 11 - Valores de CE50, 48h e os intervalos de confiança dos testes de sensibilidade de Ceriodaphnia dubia ao cloreto de sódio.

\section{c) Chironomus xanthus}

O valores de CE(I)50,96h obtidos nos testes de toxicidade com cloreto de potássio para o organismo-teste Chironomus xanthus variaram de 3,81 a 5,01 g.L ${ }^{-1}$ (tabela 3, anexo 1). Esses valores estão dentro da faixa encontrada por FONSECA (1997), para essa espécie, a qual foi de 3,3 a 6,0 g. $\mathrm{L}^{-1}$ de $\mathrm{KCl}$, o que mostra que os organismos estão sendo mantidos em condições adequadas para utilização em testes de toxicidade. O valor da CE50, 96h média obtido nos testes realizados foi de 4,75 g.L ${ }^{-1}$, com desvio padrão de 0,71. Na Figura 12 estão apresentados os valores de CE50, 96h com os intervalos de confiança de cada teste de sensibilidade.

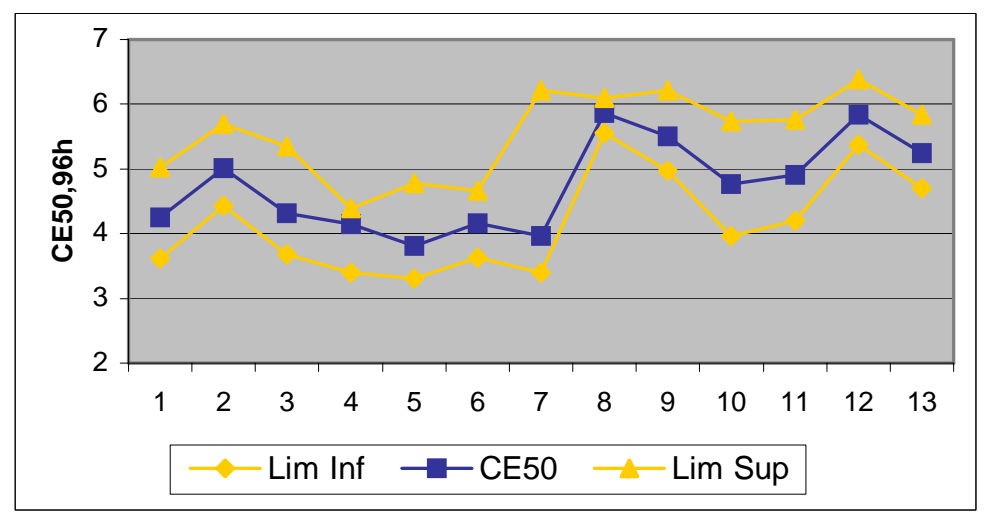

Figura 12 - Valores de CE50, 96h e os intervalos de confiança dos testes de sensibilidade de Chironomus xanthus ao cloreto de potássio. 
CAPÍTULO 2

AVALIAÇÃO E IDENTIFICAÇÃO DA TOXICIDADE (AIT) DE SEDIMENTOS DE RESERVATÓRIOS 


\section{5 - AVALIAÇÃO E IDENTIFICAÇÃO DA TOXICIDADE (AIT)}

\section{1 - REVISÃO BIBLIOGRÁFICA}

\subsection{1 -Avaliação e Identificação de Toxicidade - Aspectos Metodológicos}

A Avaliação e Identificação da Toxicidade (AIT) combina a quantificação da toxicidade com a identificação e quantificação do(s) composto(s) e/ou classe de compostos responsáveis pela toxicidade e envolve 3 fases distintas. A fase 1 consiste na identificação da natureza físico-química dos constituintes responsáveis pela toxicidade. $\mathrm{Na}$ fase 2 são aplicados os esquemas e métodos analíticos de identificação dos compostos potencialmente tóxicos e na fase 3 é feita a confirmação do(s) agente(s) suspeito(s) de causarem toxicidade. As etapas e os procedimentos de cada uma das fases envolvidas no estudo de AIT estão descritos em USEPA (1991a e 1992).

Embora essa metodologia faça parte das abordagens de análise de sedimentos contaminados propostas pela USEPA (1992), os estudos de AIT surgiram inicialmente para efluentes industriais, pela necessidade de se atingir os níveis aceitáveis de toxicidade exigidos pela legislação dos Estados Unidos, para alguns tipos de efluentes (BADARÓ-PEDROSO, 1999).

\section{a) Fase I: Caracterização do(s) Tóxico(s)}

Uma vez comprovada a toxicidade da água intersticial, as propriedades físicas/químicas das substâncias tóxicas são caracterizadas através de manipulações que alteram a biodisponibilidade de compostos com propriedades semelhantes. Os testes de toxicidade realizados simultaneamente às manipulações fornecem informações sobre a natureza dos compostos. Esta fase é bem sucedida quando se consegue estabelecer a natureza do componente responsável pela toxicidade com sua presença consistente em um número determinado de amostras.

As manipulações realizadas nessa etapa são: “ajuste de $\mathrm{pH}(\mathrm{pH} 3, \mathrm{pH}$ inicial e pH11); ajuste/filtração; ajuste/aeração (ar e nitrogênio); ajuste/coluna de C18; 
tratamentos com tiossulfato de sódio e EDTA (ácido etilenodiaminotetracético) e graduação de pH (pH entre 6 e 9)”. As classes de compostos que podem ser identificados através dessas manipulações são os metais divalentes, orgânicos não polares, oxidantes, voláteis e material particulado.

Os ajustes de $\mathrm{pH}$ realizados em muitas das manipulações dessa fase tem por objetivo detectar compostos aniônicos e catiônicos, uma vez que o comportamento desses compostos é fortemente influenciado pelo $\mathrm{pH}$. A alteração do $\mathrm{pH}$ muda significativamente a razão entre espécies ionizadas/não ionizadas em solução e, da mesma forma que essas espécies têm propriedades físico-químicas distintas, a toxicidade também é diferente. Nessa etapa, os ajustes de $\mathrm{pH}$ têm por finalidade responder duas questões:

1) a toxicidade é alterada em diferentes valores de $\mathrm{pH}$ ?

2) As mudanças de $\mathrm{pH}$ com as manipulações e os subsequentes acertos para os valores originais afetam a toxicidade?

Os testes com graduação de pH (6.0, 7.0 e 8.0) respondem à primeira questão, enquanto que os ajustes de $\mathrm{pH}$, aeração, filtração e extração da fase sólida respondem à segunda.

Nos testes com graduação de $\mathrm{pH}$, o $\mathrm{pH}$ da amostra é ajustado para uma faixa fisiologicamente aceitável antes dos testes. Em muitos casos, um composto consegue romper a membrana celular mais rapidamente em sua forma não ionizada do que em sua forma ionizada , tornando-se portanto mais tóxico. Esse teste é inicialmente realizado para amônia, um composto altamente $\mathrm{pH}$ dependente (USEPA, 1985). No entanto, alterações de $\mathrm{pH}$ podem também afetar a toxicidade de muitos pesticidas ionizáveis, bem como alterar a biodisponibilidade e toxicidade de alguns metais pesados e surfactantes.

Os testes com aeração definem se a toxicidade é devida a compostos voláteis, oxidáveis ou subláteis. Os diferentes valores de $\mathrm{pH}$ afetam a ionização dos tóxicos polares, tornando-os mais ou menos voláteis, e o potencial redox do sistema.

A filtração da amostra com diferentes pHs (inicial, 3 e 11) em filtros de fibra de vidro de $0,45 \mu \mathrm{m}$, ou acetato de celulose, no caso de suspeita de presença de metais, fornece informações sobre a toxicidade devida a fatores físicos e compostos ligados ao material particulado, o que é especialmente importante no caso de organismos-teste filtradores, como no caso dos cladóceros Daphnia similis e Ceriodaphnia dubia. 
A extração em coluna de octadecil $\left(\mathrm{C}_{18}\right)$, tem por objetivo identificar compostos orgânicos não polares nos diferentes pHs (inicial, 3 e 11). No pH inicial, a coluna remove compostos neutros, como certos pesticidas, enquanto que em $\mathrm{pH} 3$ e 11 ocorre a remoção de compostos orgânicos ácidos e básicos.

O tratamento da amostra com ácido etilenodiaminotetracético (EDTA), um quelante orgânico que forma compostos organo-metálicos não tóxicos, tem por finalidade detectar a presença de alumínio, bário, cádmio, cobalto, cobre, ferro, chumbo, manganês, níquel, estrôncio e zinco. O EDTA tem baixa especificidade para prata, cromo e tálio e não complexa metais aniônicos.

Finalmente, a toxicidade devida a compostos oxidantes, tais como íons de cloro, iodo, bromo e manganês e alguns metais divalentes, tais como cobre, cádmio e prata, pode ser identificada pelo tratamento da amostra com tiossulfato de sódio $\left(\mathrm{Na}_{2} \mathrm{~S}_{2} \mathrm{O}_{3}\right)$, que é um agente redutor e ao mesmo tempo um quelante para alguns metais.

\section{b) - Fase II: Identificação do(s) Composto (s)Tóxico(s)}

Os procedimentos da Fase II da AIT foram desenvolvidos com o objetivo de identificar compostos específicos dentre as diferentes classes identificadas na fase I. Em relação aos sedimentos, os procedimentos da fase II têm-se limitado à identificação de metais, amônia, ácido sulfídrico e compostos orgânicos não polares, que são os contaminantes mais comumente encontrados em efluentes industriais. A identificação dos compostos é feita por fracionamento químico, a partir das informações obtidas na fase I, e são específicos para cada amostra em função dos resultados obtidos. Tomando como exemplo os resultados apresentados na tabela 13, a seguir, são discutidos os procedimentos a serem seguidos na fase II.

De acordo com os resultados para a amostra 1, houve redução na toxicidade após passagem pela coluna de $\mathrm{C}_{18}$. A eluição da coluna com solução de metanol/água (Fase II) e recuperação da toxicidade na fração eluída da coluna, seguida da análise química das frações por cromatografia gasosa e espectroscopia de massa poderiam indicar a presença de compostos orgânicos não polares. A partir dos resultados obtidos para a segunda amostra (redução na toxicidade com adição de EDTA e com a coluna de $\mathrm{C}_{18}$ ), a Fase II deve incluir uma análise de metais e os procedimentos de concentração, fracionamento e identificação realizados com a amostra 1. 
Tabela 13 - Resultados obtidos na Fase 1 e classificação do composto suspeito

\begin{tabular}{l|c|c}
\hline \multicolumn{1}{c|}{ Fase 1 } & Amostra 1 & Amostra 2 \\
\hline Oxidação/redução & $\mathrm{SE}$ & $\mathrm{SE}$ \\
Adição EDTA & $\mathrm{SE}$ & $\mathrm{RT}$ \\
Graduação de pH & $\mathrm{SE}$ & $\mathrm{SE}$ \\
Ajuste de pH & & $\mathrm{SE}$ \\
Filtração & $\mathrm{SE}$ & $\mathrm{SE}$ \\
Aeração & $\mathrm{SE}$ & $\mathrm{SE}$ \\
Coluna de $\mathrm{C}_{18}$ & $\mathrm{RT}$ & $\mathrm{RT}$ \\
Fracionamento com metanol & $\mathrm{RT}$ & $\mathrm{T}$ \\
\hline & & \\
Composto suspeito & orgânicos não polares & orgânicos não polares \\
& & metais \\
\hline
\end{tabular}

Se: sem efeito na toxicidade $\mathrm{RT}$ : redução na toxicidade $\mathrm{T}$ : recuperação da toxicidade Fonte: (USEPA, 1992)

Após listado(s) o(s) possível(eis) composto(s), valores de CE50 obtidos de literatura são comparados com a concentração do(s) composto(s) químico(s) presente(s) no sedimento e identificados através de testes com os mesmos organismos-teste utilizados na Fase 1.

\section{c) - Fase III: Confirmação do(s) Tóxico(s)}

Nesta fase, os procedimentos necessários para confirmar como verdadeiros os compostos identificados como prováveis causadores da toxicidade, são: a) correlação da toxicidade observada com a toxicidade esperada em função da concentração medida do composto identificado; b) sensibilidade relativa de pelo menos duas espécies indicadoras, ou seja, se duas ou mais espécies apresentarem diferenças na sensibilidade em relação ao agente suspeito e essa mesma diferença for encontrada com a amostra, esse agente suspeito pode ser considerado verdadeiro; c) observação de sintomas (por exemplo, tempo de mortalidade) nos organismos-teste expostos ao agente tóxico; d) contaminação de amostras de sedimento com o agente suspeito; e) balanço de massa.

Em relação ao item (c), muito mais que confirmar, esse passo fornece evidências de não confirmação do composto suspeito (por exemplo, se os sintomas observados no teste com o composto forem muito diferentes dos sintomas observados com a amostra). 


\subsection{2 - Utilização do Estudo de Avaliação e Identificação da Toxicidade (AIT)}

Os procedimentos de AIT, desenvolvidos no final da década de 80, têm conseguido identificar com sucesso os compostos responsáveis pela toxicidade aguda em mais de $90 \%$ das amostras de efluentes (municipais e industriais) e sedimento, nas quais foram utilizados (USEPA, 1992).

Dentre os diferentes compostos químicos ou classes de compostos químicos, essa abordagem tem sido especialmente adequada para metais catiônicos, orgânicos não polares e amônia (ANKLEY et al. 1990; SCHUBAUER-BERIGAN \& ANKLEY, 1991; BAILEY et. al., 1995; VAN SPRANG \& JANSSEN; 1997; HO et al., 2002).

Em relação aos efluentes, devido à reconhecida utilidade ambiental e econômica da identificação dos compostos tóxicos presentes nos mesmos, essa metodologia tem sido empregada para uma variedade cada vez maior de efluentes industriais. (BOELTER et al, 1992; SAUER et al., 1997; BADARÓ-PEDROSO, 1999) THOMAS et al., 1999; JIN et al., 1999; YANG et al.. 1999; MOUNT \& HOCHETT, 2000 ) e municipais (ANKLEY \& BUKHRD, 1992; BAILEY et. al., 1995). Os principais compostos identificados por esses autores foram amônia, surfactantes, éster de fosfatos, metais, íons de cloreto, sódio e potássio (desequilibro iônico), bifenilas, PAHs, fenóis, benzopirenos e material particulado.

Além da identificação dos compostos tóxicos, o estudo de AIT ajuda a definir os procedimentos mais eficientes para a remoção ou manutenção da toxicidade dos efluentes em níveis aceitáveis.

BAILEY et. al. (1995), conseguiram identificar, através da AIT, o principal metal responsável pela toxicidade de um efluente municipal descartado continuamente na Baia de São Francisco, USA. O monitoramento mensal detectou uma toxicidade relativamente alta, pois a concentração de efeito não observável (CENO) foi menor que 10\%. Com a aplicação da AIT, observou-se uma redução de toxicidade após os tratamentos do efluente com EDTA e tiossulfato de sódio, indicando, inicialmente a presença de cátions divalentes quelados com EDTA. Os resultados obtidos com tiossulfato de sódio identificaram, especificamente, prata, cádmio, cobre e mercúrio. Considerando que, dentre esses quatro metais, o cobre foi o único presente em concentrações acima da faixa de sensibilidade para as espécies testadas (Strongylocentrotus purpuratus e Dendraster excentricus) e que o aumento de 
toxicidade com a redução temporária do $\mathrm{pH}$ tem sido associado ao cobre, os resultados mostraram o cobre como o principal responsável pela toxicidade do efluente analisado. Além da identificação do composto tóxico, os autores puderam também observar diferenças na sensibilidade das duas espécies de equinodermos utilizados nos testes de toxicidade.

JIN et al. (1999) e YANG et al. (1999), identificaram, através do estudo de AIT, os compostos benzopireno, fenol, cloronitrobenzenos, naftalenos, anilina e naftol, nos efluentes de duas indústrias químicas. Utilizando balanço de massa, os primeiros autores conseguiram determinar as porcentagens do benzopireno e do fenol na toxicidade do efluente total, respectivamente, 44,6 e 32,9\%.

No estudo realizado por MOUNT et al. (2000), nenhuma das etapas da fase I removeu a toxicidade de um efluente de indústria química. O tratamento da amostra com carvão ativado e resina de troca iônica removeu a toxicidade, indicando a presença de compostos inorgânicos, no caso o cromo hexavalente. A confirmação desses resultados foi dada pela análise química e pela comparação da concentração detectada com o valor de CE50 para o organismo-teste.

Essa metodologia tem sido utilizada também na identificação dos compostos tóxicos em amostras de água superficial e água de escoamento de regiões industriais e agrícolas.

Os estudos realizados por BAILEY et al., (1999) em água de escoamento torrencial de nove serrarias em British Columbia, Canadá, identificaram o metal zinco como responsável pela toxicidade de 42 das 58 amostras de água analisadas.

THOMAS et al. (1999) identificaram importantes compostos estrogênicos na água e no sedimento (água intersticial) dos estuários Tyne e Tees, Reino Unido, utilizando os procedimentos da AIT. Esses estuários receberam e continuam recebendo efluentes industriais e domésticos, atualmente tratados. Dentre os compostos estrogênicos, foram identificados o estradiol, o androsterone e um terceiro, desconhecido.

Amostras concentradas de água de escoamento proveniente de zona agrícola da região sudoeste da Inglaterra foram submetidas ao estudo de AIT por THOMAS et al. (2001) e os resultados identificaram a simazime e o diurom, com os principais responsáveis pela toxicidade presente nos eventos de escoamento torrencial. Além 
desses compostos, também foram identificados o nonilfenol, o sulfato de endossulfam e o pendimethalim.

Em relação ao sedimento, o sucesso da utilização do estudo de AIT depende, em grande parte, da possibilidade de obtenção de volumes adequados de água intersticial. Dependendo da composição dos sedimentos, a quantidade de sedimento necessária pode variar de 3-8 L para a Fase 1 e até 20 L para a Fase 2, considerando que em média, os sedimentos contêm cerca de 20 a 50\% de água intersticial (USEPA, 1992).

De acordo com ANKLEY \& MOUNT (1996) a primeira aplicação do AIT em amostras de sedimento foi descrita por Ankley, Katko e Arthur em 1990 e os resultados obtidos (apontando para amônia, um produto proveniente da eutrofização do ambiente como a principal responsável pela toxicidade do sedimento) implicaram em alterações nas decisões e ações nos processos de gestão de risco associado à presença de substâncias tóxicas, bem como incluiu a análise de amônia na água intersticial dentro da rotina nos estudos de avaliação de risco de sedimentos. Nesse estudo, ANKLEY et al. (1990), identificaram, através da AIT, a amônia como a principal responsável pela toxicidade aguda (Pimephales promelas, Ceriodaphnia dubia e Selenastrum capricornutum) e crônica (Ceriodaphnia dubia) da água intersticial de amostras de sedimento coletadas no sistema rio Fox / Green Bay, Wisconsin, apesar da presença ou da suspeita de presença de alguns contaminantes específicos tais como bifenilas policloradas (PCBs), hidrocarbonetos poliaromáticos (PAHs), resinas ácidas, metais pesados e pesticidas, provenientes de fontes pontuais e não pontuais.

SCHUBAUER-BERIGAN \& ANKLEY (1991), identificaram amônia, metais e compostos orgânicos não polares como os compostos responsáveis pela toxicidade da água intersticial do sedimento de um tributário do rio Illinois.

ANKLEY \& SCHUBAUER-BERIGAN (1995), realizaram uma revisão sobre os estudos utilizando os procedimentos de AIT com amostras de sedimentos, efluentes industriais, lixiviados de resíduos sólidos e de água. De um total de 16 trabalhos relacionados, 6 identificaram a amônia como composto tóxico, sendo que dentre esses, 4 foram realizados com sedimento (água intersticial). Além da amônia, foram também identificados compostos orgânicos não iônicos e metais (cádmio, níquel, cobre e zinco).

GUZZELA et al. (1996), utilizaram essa metodologia em amostras compostas de sedimento do lago Orta, Norte da Itália e os compostos tóxicos identificados foram metais e orgânicos não polares. 
BAYLEY et al. (1996), identificaram a presença dos pesticidas carbofuran ${ }^{\circledR}$ diazinon e cloropirifos em amostras de água, utilizando os procedimentos de avaliação e identificação da toxicidade. Esses compostos foram confirmados como os responsáveis pela toxicidade para o organismo-teste C. dubia.

HO et al. (1997), também utilizaram essa abordagem para identificar os compostos tóxicos presentes no sedimento de New Bedford Harbor, Massachusetts, local esse contaminado com altas concentrações de bifenilas policloradas (PCBs), hidrocarbonetos poliaromáticos (PAHs), dibenzofuranos policlorados, dibenzo-pdioxinas policloradas e metais pesados. Os resultados mostraram que os principais agentes responsáveis pela toxicidade foram as bifenilas policloradas (PCBs).

VAN SPRANG \& JANSSEN (1997), desenvolveram, a partir da metodologia convencional de AIT, uma metodologia mais simplificada para a confirmação dos compostos responsáveis pela toxicidade (Fase 3), utilizando correlações estatísticas (Pearson) para diferenciar a toxicidade causada por múltiplos tóxicos. Dessa forma, foram eliminados os procedimentos de identificação e confirmação dos tóxicos. Esse estudo foi realizado com amostras de sedimento de Upper Scheldt, Bélgica e os resultados obtidos mostraram que o principal composto responsável pela toxicidade foi a amônia.

BESSER et al. (1998), avaliaram a utilização da resina natural zeolita na remoção da toxicidade da amônia em sedimentos continentais e as possíveis interações dessa resina com cádmio e cobre. Sedimento natural e formulado foram contaminados com amônia, na forma de cloreto de amônia, em concentrações semelhantes às de sedimentos contaminados. Os resultados mostraram redução na concentração e na toxicidade da amônia. Em relação ao cádmio e cobre não houve diferenças na toxicidade e concentração desses metais nos sedimentos tratados e não tratados com a zeolita mostrando que, apesar da sua afinidade também por metais, o mecanismo de troca iônica com os metais é mais lento que o da amônia. Esse estudo fez parte de um projeto visando o desenvolvimento de procedimentos de AIT com o sedimento total.

BOUCHER \& WATZIN (1999), identificaram, na fase I do estudo de AIT, metais divalentes como os compostos responsáveis pela toxicidade do sedimento do lago Champlain, USA. Os testes de toxicidade foram feitos com C. dubia e a matriz do sedimento utilizada foi a água intersticial. Nas fase II e III o manganês foi confirmado como o principal tóxico presente no sedimento. 
HO et al. (2002), realizaram uma revisão nos estudos de AIT com água intersticial de sedimentos marinhos e de água doce e com base nos resultados obtidos nos diferentes estudos concluíram que: 1) os metais, os compostos orgânicos e amônia desempenham um papel igualmente importante na toxicidade dos sedimentos; 2) não existe uma causa única de toxicidade para um único sedimento; e 3) a amônia tem um papel importante na toxicidade da água intersticial e, sua importância só foi evidenciada a partir dos estudos de AIT.

Considerando que existem algumas interferências relacionadas com a utilização da água intersticial nos estudos de AIT, os autores acima citados se propuseram a desenvolver essa metodologia com o sedimento total. Os resultados já obtidos com amostras de sedimento marinho de cinco locais, contaminados com concentrações elevadas de metais, PAHs e PCBs, mostraram que $80 \%$ da toxicidade foi causada pelos compostos orgânicos não iônicos. Embora os metais estivessem presentes em concentrações suficientes para causar toxicidade, os sulfetos, presentes em concentrações elevadas nos sedimentos marinhos, atuaram como fase controladora, impedindo sua ação tóxica. 


\section{2 - MATERIAIS E MÉTODOS}

\subsection{1 - Estudo de Avaliação e Identificação da Toxicidade - AIT - fase1}

Os procedimentos utilizados nas diferentes etapas do estudo de AIT estão descritos a seguir e apresentados na forma de fluxograma nas Figuras 13 a 16. Esses procedimentos foram baseados em EPA (1991a e 1992).

a) Ajuste de $\mathrm{pH}$ : devido à acidez $(\mathrm{pH} 3,9$ a 4,2) apresentada pelo solubilizado das amostras de sedimento do reservatório de Salto Grande, os testes de ajuste foram realizados com uma alteração em relação ao protocolo proposto. Foi incluído um ajuste para pH7 e os testes pós-ajuste em $\mathrm{pH} 11$ foram feitos com retorno para $\mathrm{pH} 7$ e pH inicial $(3,2)$. Os acertos do $\mathrm{pH}$ para os valores requeridos nessa etapa $(\mathrm{pH} 3, \mathrm{pH} 7 \mathrm{e}$ pH11) foram feitos com adição de solução 0,1N de ácido clorídrico e de hidróxido de sódio, cuidando para que o volume final de ácido/base utilizado no ajuste inicial e no retorno das alíquotas para o pH inicial não ultrapassasse $10 \%$ em relação ao volume total da amostra.

b) Aeração com ajuste de pH: alíquotas de $80 \mathrm{ml}$ de solubilizado e de água de cultivo (brancos) nos diferentes valores de $\mathrm{pH}$ foram colocadas em béqueres de $100 \mathrm{ml}$ com uma pipeta Pasteur conectada a um distribuidor de ar ligado a uma bombinha de aquário e mantidas com agitação, sob aeração moderada (cerca de $500 \mathrm{ml}$ de ar/minuto) durante 1 hora, em capela. Após a aeração, o pH das amostras foi reajustado para os valores iniciais e as mesmas foram utilizadas nos testes de toxicidade. Os acertos de $\mathrm{pH}$ foram feitos com solução de $\mathrm{HCl}$ e/ou $\mathrm{NaOH}$ 0,1N.

c) Filtração com Ajuste de pH: alíquotas de $300 \mathrm{ml}$ do solubilizado e água de cultivo (brancos) nos diferentes valores de $\mathrm{pH}$ (inicial, $\mathrm{pH}$ e pH11), foram filtradas a vácuo em membranas de acetato de celulose com $0,45 \mu \mathrm{m}$ de porosidade e $47 \mathrm{~mm}$ de diâmetro, previamente lavadas com água ultra pura (150ml) em pHi, pH3, pH9 (coluna de C18) e pH11. Do total de amostra filtrada em cada valor de $\mathrm{pH}, 200 \mathrm{ml}$ foram separadas para a etapa de extração em coluna de C18 e a alíquota restante (cerca de 100ml) foi utilizada nos testes de toxicidade, após o reajuste dos pHs para os valores iniciais. 
d) Extração em Coluna de C18 com Ajuste de pH: o procedimento de extração em coluna $\mathrm{C}_{18}$ (octadecil) foi feito com a amostra ajustada e filtrada (reservatório de Salto Grande) e ajustada e centrifugada (reservatório de Rasgão) nos diferentes pHs e envolveu uma etapa inicial de preparo e condicionamento da coluna com metanol e água ultra pura. Em seguida, volumes adequados de água de diluição (brancos) e amostra nos diferentes valores de $\mathrm{pH}$ ( $\mathrm{pH} 3$, $\mathrm{pHi}$ e $\mathrm{pH} 9$ ) foram passados pela coluna, tomando o cuidado de não deixar a coluna secar entre as passagens da água ultra pura, água de diluição e amostra. Duas alíquotas de $40 \mathrm{ml}$ foram coletadas após o descarte de 25 e 150mL respectivamente, misturadas e utilizadas nos testes de toxicidade, após o reajuste dos pHs para o valor inicial. Especialmente nessa etapa, utiliza-se pH9 e não pH11, uma vez que a faixa de tolerância da coluna está situada entre pH3 e pH9.

Após a passagem das amostras, as colunas foram eluídas com $1 \mathrm{~mL}$ de metanol, seguido de $1 \mathrm{~mL}$ de diclorometano e os eluentes foram coletados juntamente e preparados adequadamente para os testes de toxicidade e análise cromatográfica. Para os testes de toxicidade, uma alíquota de $1 \mathrm{ml}$ dos extratos foram ressuspendidos em 30 $\mathrm{mL}$ de água de diluição, de forma a manter a concentração dos solventes abaixo dos valores de CE50 para os organismos-teste ( $V$. fisheri e $C$.dubia). Para as análises cromatográficas os eluentes das colunas foram concentrados para $1 \mathrm{~mL}$ sob fluxo de nitrogênio e injetados no cromatógrafo a gás para identificar os principais compostos (aqueles identificados com precisão acima de 90\%).

e) Graduação de $\mathrm{pH}$ : o acerto do $\mathrm{pH}$ para os valores requeridos (pH 6 - 9) foram feitos com adição de solução $0,1 \mathrm{~N}$ de ácido clorídrico e de hidróxido de sódio. Água de cultivo ajustada para os mesmos valores de $\mathrm{pH}$ foi utilizada como branco.

f) Tratamento com EDTA e Tiossulfato de Sódio: a escolha das concentrações de EDTA e tiossulfato de sódio foi baseada nos valores de CE50 destes compostos para o organismo-teste utilizado (Ceriodaphnia dubia), previamente determinados. Os testes foram realizados com a amostra pura (100\%) e diluída 50\%, tratada com cinco concentrações diferentes de EDTA/tiossulfato, correspondentes a 1x, 0,8x, 0,6x, 0,4x e 0,2x o valor do CE50 e uma sem EDTA/tiossulfato. Como a reação de complexação não é imediata, as amostras ficaram em contato com o EDTA/tiossulfato por cerca de 2 horas, antes do início dos testes de toxicidade. 
A seguir, estão apresentados os fluxogramas das diferentes etapas da fase I

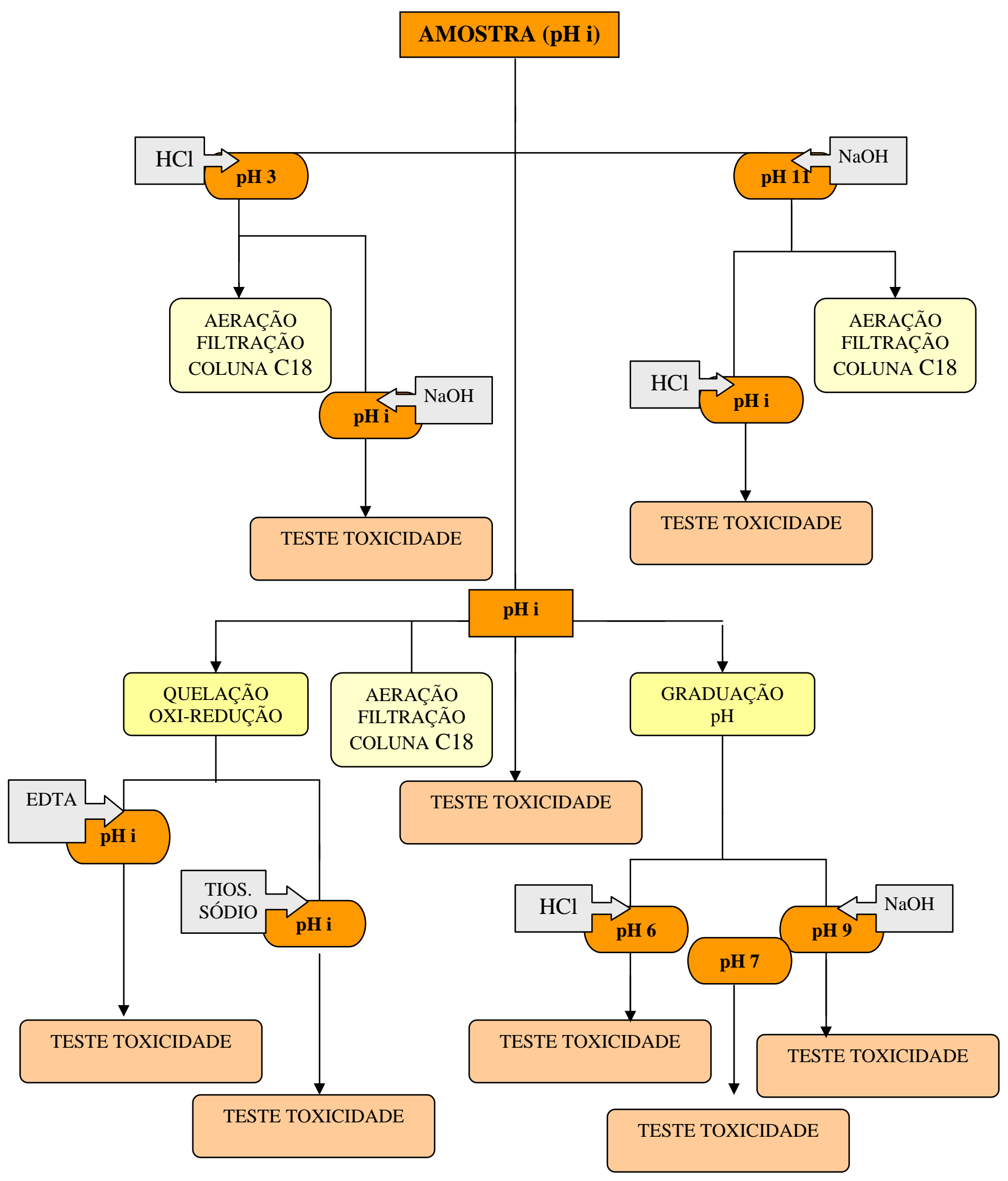

Figura 13 - AIT: Etapas para a caracterização dos tóxicos na fase I (USEPA, 1992). 


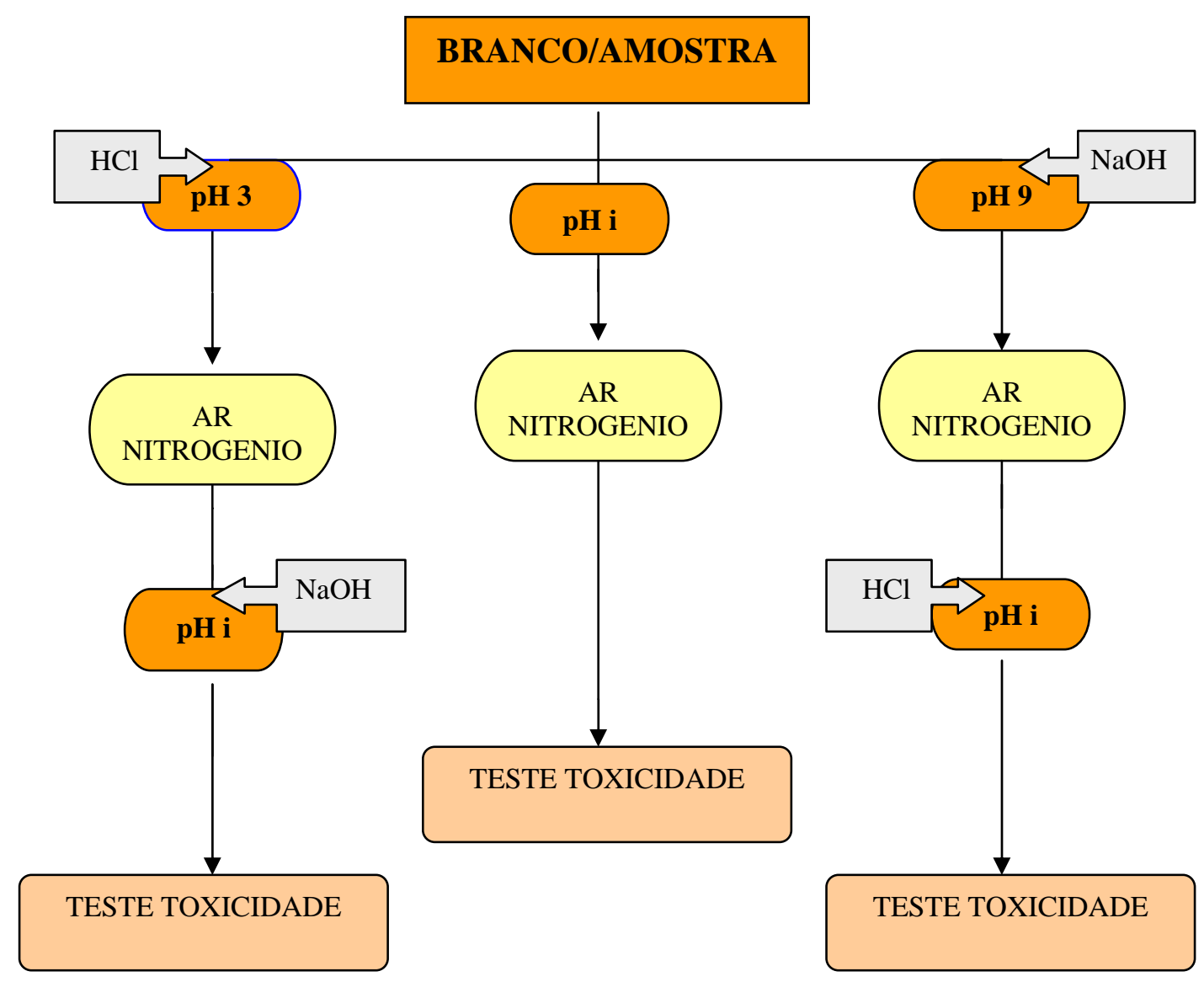

OBS: aeração / 1 hora com agitação e controle do $\mathrm{pH}$

Checar $\mathrm{pH}$ a cada 5 min na $1^{\mathrm{a}} 1 / 2$ hora e a cada 10 min no período restante

Reajustar se houver alteração $>0.2$

Remover a amostra com pipeta

Figura 14 - AIT: procedimentos da etapa de aeração com ajuste de $\mathrm{pH}$ 
FILTRAÇÃO

ETAPA 1:PREPARO DO FILTRO

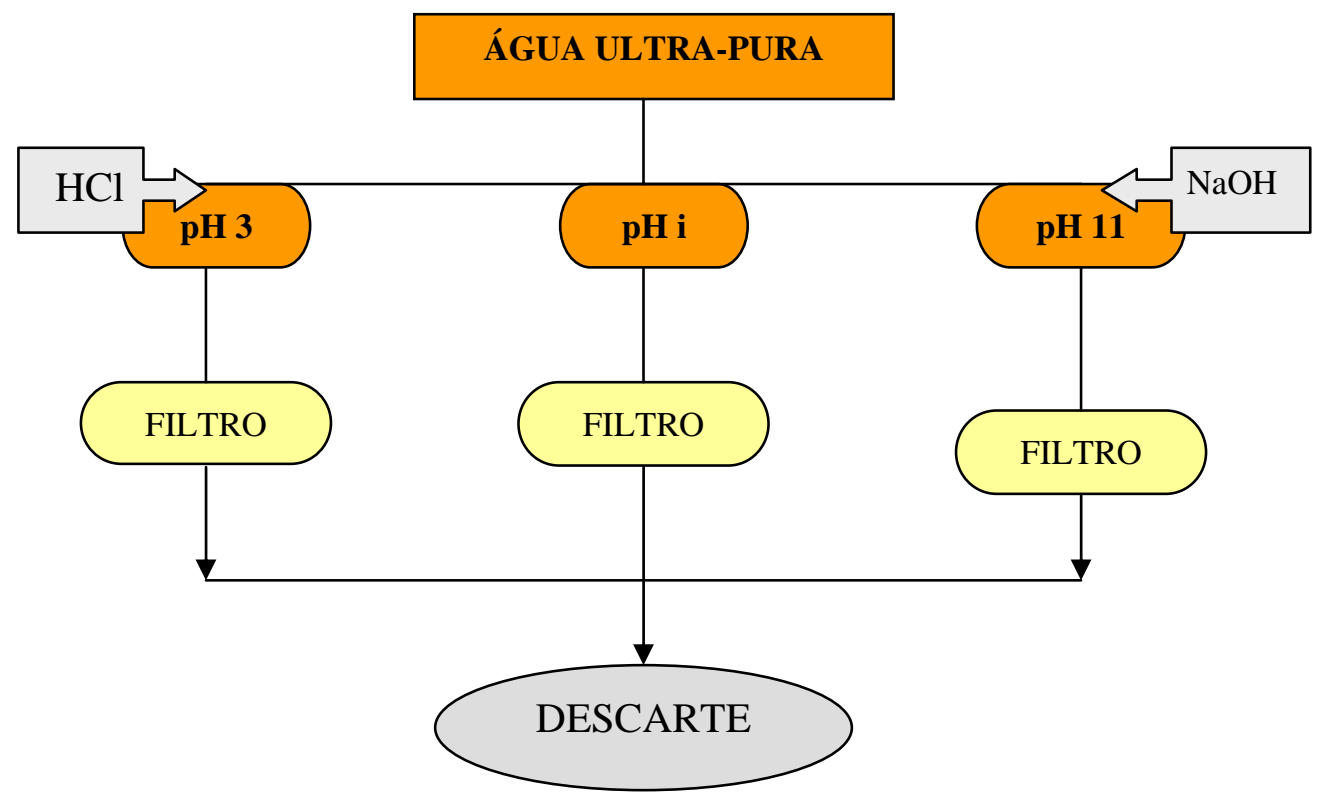

ETAPA 2:

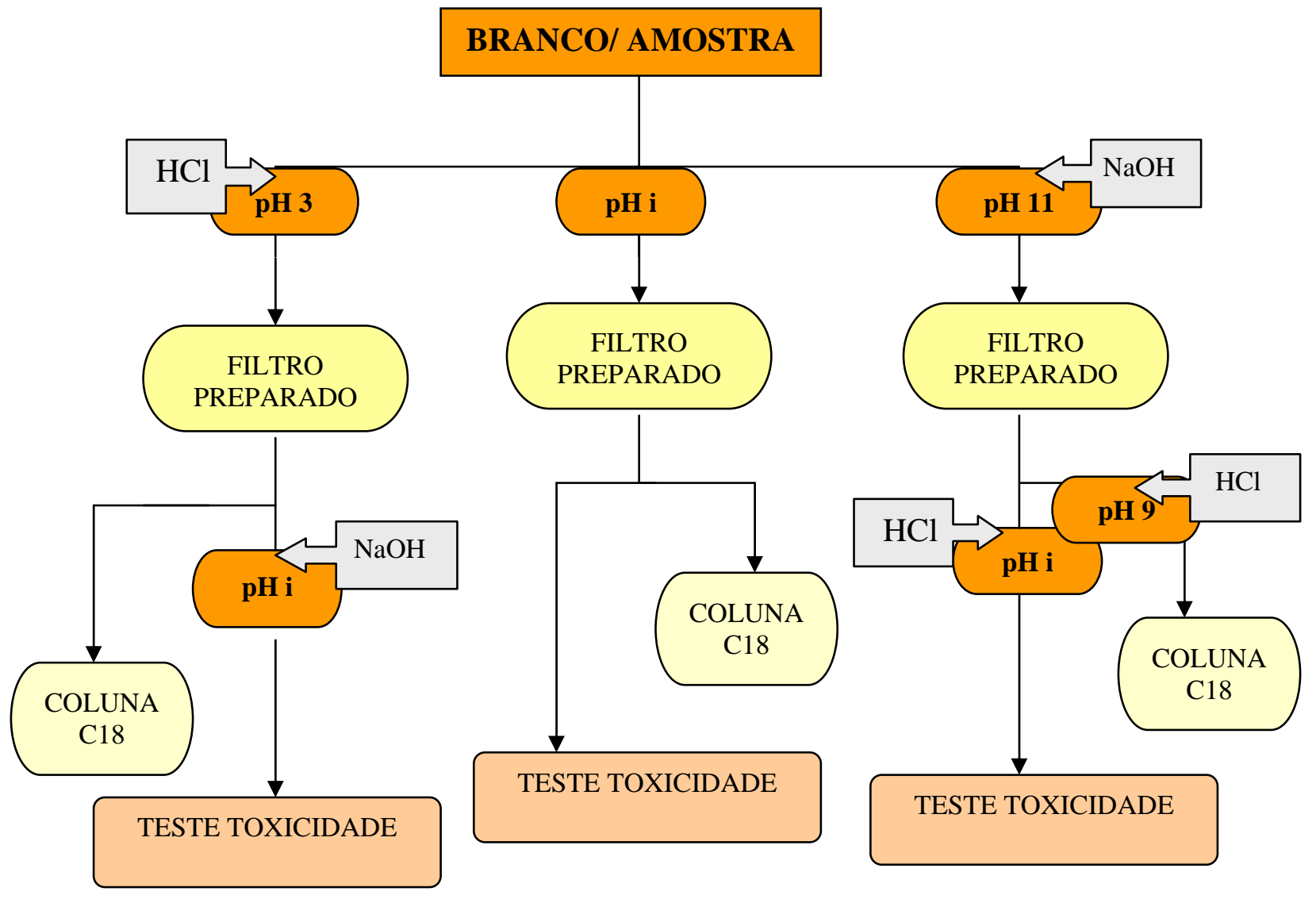

Figura 15 - AIT: procedimentos da etapa de filtração com ajuste de $\mathrm{pH}$. 
ETAPA 1: PREPARO DA COLUNA

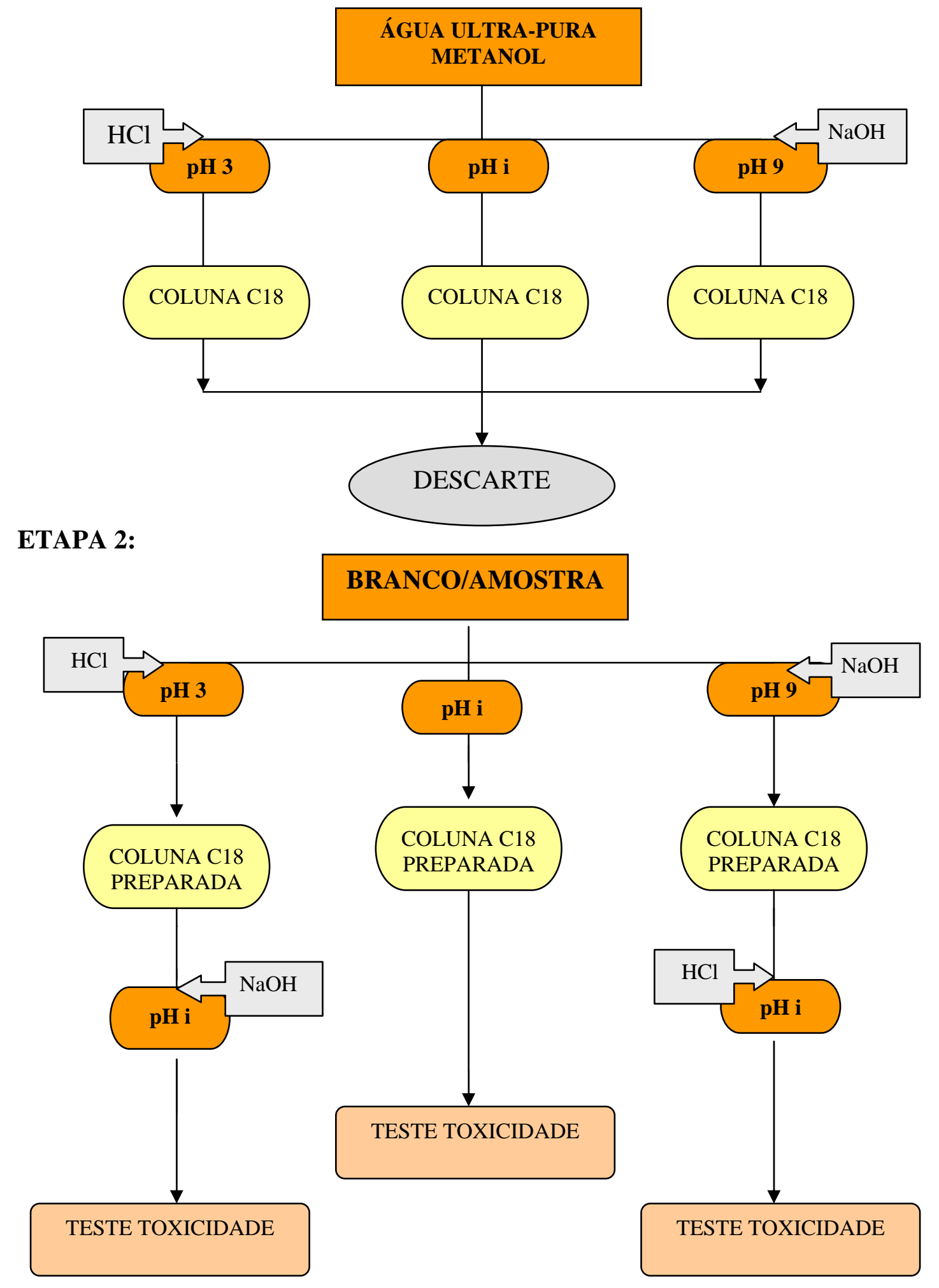

Figura 16 - AIT: procedimentos da etapa de extração em coluna de C18. 


\subsection{2- Estudo de Avaliação e Identificação da Toxicidade - Fase II}

Os procedimentos da fase II foram diferentes para cada um dos reservatórios estudados, uma vez que essa fase depende dos resultados obtidos na fase I. Dessa forma, considerando os resultados obtidos, os parâmetros determinados no solubilizado de cada um dos reservatórios foram os seguintes:

- Reservatório de Barra Bonita: metais/SVA; amônia.

- Reservatório de Salto Grande: amônia; metais/SVA; ácido sulfídrico.

- Reservatório de Rasgão: amônia; sulfetos; metais/SVA; surfactantes; cianeto; ácido sulfídrico e compostos orgânicos.

As análises dessa fase foram realizadas de acordo com as metodologias já descritas no capítulo 1, ítem 4.2.6, sub-ítem b (Análises Físicas e Químicas do Sedimento, Água Intersticial e Solubilizado).

\subsection{3 - Estudo de Avaliação e Identificação da Toxicidade - Fase III: Reservatórios Salto Grande e Rasgão}

A confirmação da amônia como responsável pela toxicidade do sedimento dos reservatórios de Salto Grande e Rasgão foi realizada e por comparação dos valores encontrados com os valores de CE50 descritos em literatura para o organismo-teste Ceriodaphnia dubia e pelo tratamento do solubilizado com a resina zeolite (clinoptilolite), uma resina mineral natural, com alta capacidade de troca iônica e afinidade por amônia e metais.

Os testes com a resina foram feitos adicionando-se $20 \mathrm{~g}$ da resina zeolita a 200 ml do solubilizado do sedimento do reservatório de Rasgão, de forma a manter uma relação v/v de 10\%. Essa solução foi mantida por 24 horas sob agitação moderada e, após o período de contato, a amostra foi filtrada em papel de filtro e analisada em relação à toxicidade e amônia. Os procedimentos utilizados foram baseados em BESSER et al (1998), com a diferença que esses autores utilizaram o sedimento total. 


\subsection{4 - Estudo de Avaliação e Identificação da Toxicidade - Considerações Metodológicas}

\section{a) Ajuste de $\mathrm{pH}$}

Os testes com ajuste de $\mathrm{pH}$ (pH3 e pH11), tem por finalidade detectar as alterações na solubilidade, na polaridade, na volatilidade, na estabilidade, na especiação, na biodisponibilidade e, finalmente, na toxicidade dos compostos determinados pelas mudanças de $\mathrm{pH}$, especialmente os ácidos e as bases. Em solução aquosa, existe um equilíbrio entre as formas ionizadas e não-ionizadas sempre que o $\mathrm{pH}$ da solução for igual ao $\mathrm{pK}$ do composto. Alterações do $\mathrm{pH}$ para valores menores ou maiores que o valor do pK mudam significativamente a razão entre espécies ionizadas/não-ionizadas e, da mesma forma que essas espécies têm propriedades físicas e químicas distintas, a toxicidade também é diferente. De um modo geral, os compostos são mais tóxicos na forma não-ionizada.

\section{- Resultados e Interferências}

O aumento da toxicidade em pH 3 e/ou pH 11, em relação ao CE50, 15min e CL50 48h do teste de toxicidade inicial ou base, pode ter 2 motivos principais:

1) concentração de íons $\mathrm{Na}^{+}$e $\mathrm{Cl}^{-}$(adicionados na forma de $\mathrm{HCl}$ e $\mathrm{NaOH}$ durante o ajuste do $\mathrm{pH}$ ) acima dos limites toleráveis dos organismos-teste.

2) reações químicas não reversíveis após o retorno da amostra para o pHi.

Nenhuma dessas causas pode ser esclarecida através dos brancos. No caso (1), a comparação com os valores de CL50 do $\mathrm{NaCl}$ e a adição na amostra de uma quantidade correspondente a esse valor, pode esclarecer a alteração da toxicidade devida ao aumento da concentração dos íons em questão.

Na situação inversa, uma redução significativa da toxicidade em pH 3 e/ou pH11, poderia indicar:

1) diluição da amostra devido à adição do $\mathrm{HCl}$ e $\mathrm{NaOH}$;

2) reações químicas irreversíveis ou não re-estabelecidas;

3) degradação do composto tóxico. 
No caso de suspeita de diluição da amostra, recomenda-se adicionar na amostra um volume de água de diluição proporcional ao volume de ácido e base adicionados e testar novamente a toxicidade. Se essa evidência for confirmada, o procedimento de ajuste deve ser repetido com soluções de ácido e base mais concentradas.

Em relação à evidência três, ou seja degradação de compostos tóxicos, muitos compostos orgânicos e inorgânicos podem ser degradados com a alteração de pH e, nesse processo de degradação pode haver perda da toxicidade. Em alguns casos, no entanto, pode haver formação de compostos mais tóxicos.

Existe também a possibilidade de perda de toxicidade devido à precipitação dos compostos, o que ocorre especialmente em $\mathrm{pH} 11$. O precipitado químico pode ser ou não ser o composto tóxico em questão, pois a remoção de compostos por precipitação ocorre por duas vias: floculação (microrganismos, sólidos em suspensão e colóides) e adsorção (metais e orgânicos). Se a perda da toxicidade estiver relacionada com a precipitação, é importante diferenciar se o composto tóxico é o próprio precipitado ou se ele foi removido pela precipitação. Em alguns casos, com o ajuste da amostra para o pH inicial, o precipitado pode ser re-solubilizado e, nesses casos, a perda da toxicidade deve ser avaliada de forma cuidadosa, pois o tóxico pode não estar biodisponível ou não ter sido totalmente dissolvido, e isso não configura perda de toxicidade da amostra. Da mesma forma, se o composto tóxico em questão for amônia, a redução da toxicidade em $\mathrm{pH}$ 3, pode não significar perda de toxicidade, mas sim que em $\mathrm{pH}$ baixo, a amônia é menos tóxica.

\section{b) Aeração com ajuste de $\mathrm{pH}$}

A aeração da amostra tem por finalidade identificar a toxicidade relacionada com a presença de compostos voláteis, subláteis ou oxidáveis. O ajuste de $\mathrm{pH}$ associado à aeração pode ajudar na interpretação dos resultados, uma vez que alguns compostos podem ser removidos ou oxidados mais facilmente em um ou outro valor de $\mathrm{pH}$. A remoção completa ou parcial dos compostos, suficiente para reduzir a toxicidade, depende das condições físicas e químicas do procedimento, sendo importante manter a mesma geometria do processo, o mesmo tempo de aeração e o $\mathrm{pH}$ constante, para todas as soluções (amostras e brancos), caso contrário os resultados não terão significado.

A aeração remove por sublação compostos com superfícies ativas, tais como resinas ácidas, sabões, detergentes e polímeros de estabilização ou de coagulação 
utilizados em indústrias químicas. Durante a aeração, a superfície ativa desses agentes se congrega na interface líquida/gás das bolhas de ar e nitrogênio e são carreadas junto com essas bolhas, depositando-se nas paredes dos recipientes das amostras. Como conseqüência ocorre formação de uma camada fina, visível ou não na parede. Para evitar que a amostra entre novamente em contato com esses compostos, a remoção da amostra para posterior ajuste do $\mathrm{pH}$ e realização dos testes de toxicidade deve ser feita cuidadosamente, com o auxílio de uma pipeta.

\section{- Resultados e Interferências}

Da mesma forma que nas etapas anteriores, os controles utilizados durante os testes têm por finalidade checar a qualidade dos organismos-teste, da água de diluição e das condições dos testes. Os brancos (água de diluição aerada em pH3, pHi e pH11), por sua vez têm por finalidade validar os resultados obtidos com as amostras nos respectivos pHs. Não se espera ocorrência de mortalidade significativa nos testes de toxicidade com os brancos aerados, em qualquer um dos valores de $\mathrm{pH}$. Se houver toxicidade, deve-se comparar com os resultados do branco ajustado sem aeração, desde que o volume de ácido e base adicionados seja o mesmo. A toxicidade nos brancos, com e sem acerto de $\mathrm{pH}$, sugere contaminação da amostra durante o procedimento de aeração.

Em relação à toxicidade das amostras pós-aeração, se houver um aumento de toxicidade comparado com a toxicidade inicial ou base, essa toxicidade foi introduzida durante a manipulação, seja por contaminação durante a aeração ou pela formação de $\mathrm{NaCl}$ durante os ajustes de pH. Nessa etapa, o ajuste, a manutenção do pH nos valores requeridos e o posterior acerto para o $\mathrm{pH}$ inicial podem requerer um volume maior de ácido e base, em relação aos demais procedimentos.

Se ocorrer redução da toxicidade em 1 ou todos valores de $\mathrm{pH}$, é importante diferenciar se os efeitos foram causados pelo borbulhamento, pela oxidação ou sublação. Essa diferenciação é feita substituindo-se o ar pelo nitrogênio e repetindo os testes de toxicidade com a amostra, ou com as amostras que apresentaram menor toxicidade. Dessa forma pode-se definir se foi a oxidação ou o borbulhamento a causa de redução de toxicidade. Uma mesma amostra pode conter compostos removíveis pela oxidação e outros removíveis pelo nitrogênio. Por exemplo: 
1) redução da toxicidade com aeração em pH3 e pHi e com nitrogênio somente em pH3. Nesse caso, pode-se descartar a presença de amônia na amostra;

2) redução da toxicidade em $\mathrm{pH} 11$, comparada com $\mathrm{pH} 3$ e pHi aeradas e teste inicial ou base. Esse resultado indica presença de amônia, que pode ser determinada pela análise química da amostra.

A redução da toxicidade devida a compostos subláteis pode ser confirmada, lavando-se vigorosamente as paredes do frasco de aeração com água de diluição. Para aumentar a concentração dos compostos recuperados, aerar um volume maior de amostra, por ex. $90 \mathrm{ml}$ e lavar com 30ml, o que resulta numa concentração nominal dos compostos recuperados, 3 vezes maior do que na amostra. Se for um composto hidrofóbico, é necessário utilizar solvente no lugar da água de diluição.

A comparação dos resultados de aeração/ajuste com os de filtração/ajuste, pode confirmar se a redução de toxicidade for devida apenas às alterações do $\mathrm{pH}$ (amostras com filtração/ajuste e aeração/ajuste devem apresentar ambas redução na toxicidade) ou devido à precipitação causada pela oxidação (resultados diferentes entre filtração/ajuste e aeração/ajuste).

A redução da toxicidade após o borbulhamento com nitrogênio está associada à presença de compostos voláteis. Em amostras de sedimento esse resultado pode indicar a presença simultânea ou não de sulfeto de hidrogênio (volátil) e de amônia (menos tóxica em pH ácido).

\section{c) Filtração com Ajuste de pH}

O processo de filtração fornece informações sobre a presença de compostos tóxicos associados com materiais filtráveis. Se por um lado, a associação com material particulado pode diminuir a toxicidade de um composto químico, tornando-o menos disponível para a coluna d’água, para alguns organismos, entre eles, os cladóceros e os organismos bentônicos, a exposição a esses contaminantes, passa a ser via ingestão. O grau em que um composto permanece adsorvido ou em solução depende de vários fatores, incluindo, carga e superfície da partícula, polaridade e carga do composto e solubilidade.

Nessa etapa, são importantes as implicações decorrentes das alterações do pH que estão diretamente relacionadas à solubilidade dos compostos, seja na formação de 
compostos metálicos insolúveis, na transformação de ácidos e bases orgânicos existentes na forma iônica para forma não iônica, na alteração da polaridade dos tóxicos aumentando a força de associação entre tóxico/particulado ou ainda na destruição ou dissolução das partículas de forma a remover a superfície de adsorção ou mesmo alterar o equilíbrio dissolvido/adsorvido. Portanto, a filtração associada com o ajuste de pH remove da amostra os compostos insolúveis ou associados com o material particulado em valores extremos de $\mathrm{pH}$ (3 e 11).

\section{- Resultados e Interferências}

A redução da toxicidade da amostra após filtração, independente do valor de $\mathrm{pH}$, quando comparada com o valor de CE15min e CL50 do teste de toxicidade base, está associada à remoção dos compostos tóxicos através de precipitação, sorção, mudanças no equilíbrio ou volatilização. Nesse estágio, seria importante tentar identificar qual desses mecanismos está envolvido na remoção da toxicidade. De qualquer forma devese tentar recuperar a toxicidade no filtro, por lavagem do mesmo com parte do filtrado ou por ultra-sonificação do filtro, com solvente ou água de diluição com pH ajustado. Com a transferência dos sólidos retidos no filtro para o filtrado em pHi, espera-se que a concentração de sólidos e a toxicidade seja semelhante à da amostra inicial. Os precipitados formados em pH3 ou pH11 precisam de um tempo para a re-solubilização ou para atingir o equilíbrio entre contaminantes nos sólidos e na solução. Os resultados obtidos após a transferência dos sólidos para o filtrado não são quantitativos, devido aos problemas de recuperação inerentes do processo. Se o material filtrado for transferido para um volume de água de diluição em pHi igual ao volume da amostra filtrada, é possível determinar a influência da matriz da amostra sobre a toxicidade do contaminante.

Os controles utilizados durante os testes têm por finalidade checar a qualidade dos organismos-teste, da água de diluição e das condições dos testes. Os brancos (água de diluição filtrada em pH3, pHi e pH11), por sua vez têm por finalidade validar os resultados obtidos com as amostras nos respectivos $\mathrm{pHs}$ e verificar possíveis interferências do $\mathrm{NaCl}$ produzido durante o ajuste de $\mathrm{pH}$ ou da remoção de tóxicos do próprio filtro em $\mathrm{pH}$ ácido ou básico. Não se espera ocorrência de mortalidade significativa nos testes de toxicidade com os brancos filtrados, em qualquer um dos valores de $\mathrm{pH}$. 
Se a recuperação da toxicidade não for possível e a perda da toxicidade não estiver associada com volatilização do composto tóxico, essa etapa não será conclusiva. Para confirmar se a volatilização foi o mecanismo responsável pela perda de toxicidade, recomenda-se filtrar a amostra sob pressão, uma vez que na filtração a vácuo pode ocorrer perda dos compostos voláteis.

A redução da toxicidade em pH11 pode estar associada a compostos surfactantes ou metais catiônicos. No caso de metais catiônicos pode-se tentar recuperar a toxicidade por ultra-sonificação do filtro durante 1 hora em água de diluição com pH3.

\section{d) Extração em Coluna de C18 com Ajuste de pH}

A extração em coluna de octadecil (C18), tem por objetivo, identificar a toxicidade causada por compostos orgânicos e complexos metálicos relativamente não polares. Ao passar pela coluna, os compostos presentes na amostra interagem com o octadecil e, em função da polaridade e solubilidade, são extraídos da amostra para o sorvente. $\mathrm{O}$ ajuste do $\mathrm{pH}$ para ácido ou base permite extrair compostos orgânicos ácidos e básicos que se tornam menos polares com a quebra do equilíbrio de espécies ionizadas/não ionizadas e, em cada um dos casos, o composto que estiver predominantemente na sua forma não ionizada será adsorvido na coluna. Em pH neutro, são adsorvidos compostos neutros, como certos pesticidas.

\section{- Resultados e Interferências}

Os controles utilizados durante os testes têm por finalidade checar a qualidade dos organismos-teste, da água de diluição e das condições dos testes. Os resultados dos testes com ajuste de $\mathrm{pH}$ e filtração com ajuste devem ser analisados a priori, para identificar possíveis artefatos de toxicidade adicionados durante as manipulações. Em relação às demais manipulações, essa é a que apresenta maior probabilidade de toxicidade nos brancos, pois além dos fatores associados ao ajuste e filtração, o método do C18 envolve o uso de resinas e metanol.

Se houver redução de toxicidade na amostra pós-coluna, é necessário fazer a eluição da mesma com metanol na proporção de $1 \mathrm{ml}$ de metanol para 200ml de amostra em 3ml de coluna e testar a toxicidade do eluído. Nas condições acima, considerando uma eficiência de sorção e eluição de $100 \%$, qualquer composto retido pela coluna estará duzentas vezes mais concentrado. O teste de toxicidade é feito diluindo-se $150 \mu \mathrm{l}$ 
do eluído em $10 \mathrm{ml}$ de água de diluição, de forma a manter a concentração do metanol (1,5\%) abaixo do valor de CL50, 48-96h para cladóceros e peixes. Nessas condições, a concentração dos compostos na amostra eluída será tres vezes maior que na amostra original. Se a toxicidade for recuperada, deve-se seguir com os procedimentos da Fase II, para identificação dos compostos suspeitos (orgânicos e surfactantes).

Alguns metais podem também ficar retidos pela coluna e, para recuperá-los deve-se eluir a coluna com água de diluição pH3 ou pH 9.

Ausência de toxicidade no eluído pode estar relacionada com o mecanismo de retenção pela coluna (outro que o de "fase sólida reversa”) ou com a inadequabilidade do solvente utilizado para eluição.

\section{e) Graduação de pH}

Os testes com graduação de $\mathrm{pH}$ têm por finalidade indicar a presença de compostos pH-dependentes, especialmente amônia e sulfeto de hidrogênio $\left(\mathrm{H}_{2} \mathrm{~S}\right)$ (Figura 1). Por definição, composto pH-dependente é aquele cujo pK permite diferenças na dissociação na faixa de pH fisiologicamente tolerável, que é de pH6 a pH9. No entanto, é importante que as duas formas do composto (ionizada e não-ionizada) causem toxicidade diferenciada aos organismos-teste.

No caso da amônia, a forma não ionizada, mais tóxica, predomina em $\mathrm{pH} \geq 9$,3; sendo que, na faixa de $\mathrm{pH}$ entre 6,5 e 8,5 há um aumento na porcentagem de $\mathrm{NH}_{3}$ de cerca de 250 vezes. Como conseqüência, a toxicidade será maior em pH 8,5 do que em pH 6,5.

A acidificação do meio pode alterar também a toxicidade de metais, aumentando ou diminuindo a porção biodisponível dos mesmos. Enquanto que para alguns metais (alumínio e chumbo) há um aumento da toxicidade em meio ácido, para outros (cádmio, cobre e zinco) há uma diminuição. Além da acidificação, a dureza do meio também atua na toxicidade dos metais. Em águas duras, a toxicidade do cobre e do chumbo para Ceriodaphnia dubia é maior em pH 6,5 do que em pH 8,0 e pH 8,5. Por outro lado, o níquel, o zinco e o cádmio são mais tóxicos em pH 8,5 do que em pH 6,5.

A presença de mais de um composto $\mathrm{pH}$-dependente pode atrapalhar a interpretação dos resultados, uma vez que o efeito do $\mathrm{pH}$ de um composto pode mascarar ou cancelar o do outro. Para amônia e metais, a diferenciação pode ser feita com a associação dos testes de graduação de pH e tratamento com EDTA. 
Outro composto pH-dependente, o sulfeto de hidrogênio, quando dissolvido, ocorre nas formas de $\mathrm{H}_{2} \mathrm{~S}$ e $\mathrm{HS}^{-}$, com predominância de uma ou outra, dependendo do pH e da temperatura. Na faixa de pH 6,0 e 8,5, a distribuição das formas não ionizadas/ ionizadas é a seguinte: $90 \% \mathrm{H}_{2} \mathrm{~S} / 10 \% \mathrm{HS}^{-}$em pH 6; 50\% $\mathrm{H}_{2} \mathrm{~S} / 50 \% \mathrm{HS}^{-}$em pH 7; e $\leq 5 \% \mathrm{H}_{2} \mathrm{~S} / 95 \% \mathrm{HS}^{-}$em $\mathrm{pH}$ 8,5. Sendo assim, a toxicidade devida ao sulfeto será maior em pH 6,5.

No caso de suspeita da presença de $\mathrm{H}_{2} \mathrm{~S}$, os resultados do teste com graduação de $\mathrm{pH}$ devem ser comparados com os testes com ajuste/aeração, pois o $\mathrm{H}_{2} \mathrm{~S}$ é rapidamente oxidado e removido por volatilização. Se o sulfeto for o composto predominante, os dois testes devem apresentar redução da toxicidade.

\section{f) Tratamento com EDTA e Tiossulfato de Sódio}

O ácido etilenodiaminotetracético (EDTA) é um quelante orgânico, que tem a propriedade de formar complexos metálicos, relativamente não tóxicos, com os metais alumínio, bário, cádmio, cobalto, cobre, ferro, chumbo, manganês, níquel, estrôncio e zinco. O EDTA tem baixa especificidade para prata, cromo e tálio e não reage com os metais aniônicos.

Os testes com tiossulfato de sódio, um agente redutor, tem por finalidade identificar os compostos oxidantes presentes na amostra, como cloro, ozônio, dióxidos, mono e dicloroaminas, brominas, íons de manganês e alguns orgânicos hidrofílicos, que, na forma reduzida, tendem a ser menos tóxicos. Além dos compostos oxidantes, o tiossulfato de sódio tem a propriedade de formar complexos metálicos com alguns metais catiônicos, tais como o cádmio, o cobre, a prata, o mercúrio e o selênio.

\section{- Resultados e Interferências}

Em relação ao EDTA, a redução da toxicidade em relação ao teste base ou o aumento no tempo de mortalidade ao longo da faixa de tiossulfato testada indicam presença de compostos oxidantes.

A acidificação da amostra após adição de EDTA $(\mathrm{pH} \leq 4)$ pode mascarar os resultados quando existe suspeita da presença de outro(s) contaminante(s), além dos metais. Por exemplo, metais e amônia ou metais e sulfeto de hidrogênio.

No caso de amônia, uma possível redução da toxicidade, pode não estar relacionada com a complexação dos metais, mas sim com o fato de que, em pH baixo, a 
amônia é menos tóxica. Por outro lado, se houver $\mathrm{H}_{2} \mathrm{~S}$ na amostra, a redução devido aos metais fica mascarada pelo aumento da toxicidade do $\mathrm{H}_{2} \mathrm{~S}$ em meio ácido. Daí a importância do controle do pH nessa etapa.

O EDTA pode também reduzir a toxicidade de surfactantes catiônicos e, nesse caso, deve-se comparar os resultados de outras manipulações que também indicam presença de surfactantes (aeração, por exemplo).

Se a toxicidade permanecer inalterada, independente da concentração de EDTA utilizada suspeita-se de ausência de metais com afinidade pelo EDTA ou quantidade insuficiente de EDTA. Por outro lado, se houver um aumento da toxicidade, essa toxicidade pode estar relacionada com a toxicidade do EDTA.

Em relação ao tiossulfato de sódio, se houver mortalidade em todas as concentrações testadas, sem a correspondente mortalidade no teste base, que nesse caso funciona também como branco essa mortalidade está associada à toxicidade do tiossulfato.

A redução da toxicidade em relação ao teste base ou o aumento no tempo de mortalidade ao longo da faixa de tiossulfato testada indicam presença de compostos oxidantes.

A redução simultânea da toxicidade na amostra tratada com tiossulfato e com EDTA (ácido etileno diaminotetracético) indica presença de metais catiônicos cádmio, cobre, prata e mercúrio. Nesse caso procede-se a etapa da identificação desses metais (Fase II). 


\section{3 - RESULTADOS E DISCUSSÃO}

\subsection{1 - Reservatório de Barra Bonita - Fases I e II.}

Os resultados dos testes de toxicidade aguda com Ceriodaphnia dubia antes e após as etapas da fase I do estudo de AIT (ajuste/aeração, graduação de pH e tratamento com EDTA) realizadas com a amostra solubilizada do sedimento da Estação E2, os valores das concentrações de metais e sulfetos simultaneamente extraídos e as relações metais/SVA estão apresentadas nas Tabelas 14 a 17. As demais etapas do estudo de AIT não foram feitas devido à perda da toxicidade da amostra no intervalo de tempo entre as primeiras etapas e as seguintes e na coleta seguinte.

Tabela 14 - Resultados obtidos na Fase 1 (parcial) com o solubilizado da amostra de sedimento da estação E2 (aporte do rio Tietê), coletada em junho/00.

\begin{tabular}{|l|c|c|c|}
\hline \multirow{2}{*}{\multicolumn{1}{|c|}{ Etapas }} & \multicolumn{2}{|c|}{ Toxicidade } & \multirow{2}{*}{ Efeito na Toxicidade } \\
\cline { 2 - 3 } & $\begin{array}{c}\% \\
\text { imobilidade* }\end{array}$ & CE50,48h(\%) & \\
\hline Teste Toxicidade Inicial & $\mathbf{1 0 0}$ & $\mathbf{6 1 , 2}$ & RT(parcial) \\
\hline Ajuste/Aeração - pHi & 40 & -- & RT \\
\hline Ajuste/Aeração - pH3 & zero & -- & RT \\
\hline Ajuste/Aeração - pH11 & zero & -- & RT \\
\hline Graduação - pH6 & zero & -- & RT \\
\hline Graduação - pH8 & 7 & -- & RT \\
\hline Adição EDTA & zero & -- & Metais / Amônia \\
\hline Compostos Suspeitos & & & Voláteis \\
\hline \multicolumn{2}{|l|}{ *: amostra pura (100\%) }
\end{tabular}

Os resultados dos testes de toxicidade com C.dubia com a amostra solubilizada após as manipulações de ajuste/aeração, graduação de pH e tratamento com EDTA mostraram redução total da toxicidade nos testes pós-graduação em pH6 e pH8; pósEDTA e pós-ajuste/aeração em pH3 e pH11. Nos testes pós-ajuste em pHi houve redução de $60 \%$ em relação à toxicidade inicial

A redução da toxicidade nas etapas de ajuste/aeração em pH3 sugere a presença de um composto ácido volátil ou oxidável que, nesse caso, poderia ser o ácido sulfídrico. No entanto, o resultados dos testes pós-graduação eliminam essa 
possibilidade, pois a toxicidade não aumentou em pH6. Da mesma forma, a redução simultânea nas etapas de pós-ajuste pH 11 e graduação pH 9, exclui a presença de amônia que, tal como o sulfeto, é um contaminante comum de sedimentos com cargas elevadas de matéria orgânica. Os resultados obtidos nessa etapa não foram conclusivos uma vez que as demais etapas de ajuste/filtração e aeração com nitrogênio e etapas confirmatórias não foram realizadas devido a perda da toxicidade da amostra.

A redução simultânea de toxicidade em pH 6 e pH 8, nos testes de graduação de pH descartou a presença dos dois compostos pH-dependentes, amônia e ácido sulfídrico $\left(\mathrm{H}_{2} \mathrm{~S}\right)$. Além desses compostos ionizáveis, amônia e $\mathrm{H}_{2} \mathrm{~S}$, os metais também podem ser detectáveis nessa etapa de graduação de $\mathrm{pH}$, na faixa de 6,0 a 8,5.

De acordo com EPA (1991), resultados obtidos com chumbo e cobre mostraram maior toxicidade para Ceriodaphnia dubia em pH 6 do que em $\mathrm{pH} 8$ ou 9, enquanto que zinco, níquel e cádmio foram mais tóxicos em pH 8 do que em $\mathrm{pH}$ 6. Uma vez que esses metais são quelados pelo EDTA, os resultados de ambos os testes (graduação de pH e tratamento com EDTA) podem diferenciar a toxicidade devida a compostos ionizáveis (amônia e ácido sulfídrico) ou metais catiônicos. Nesse caso, considerando em conjunto, a redução da toxicidade observada nos dois valores de pH (6 e 8) e no tratamento com EDTA pode estar associada à presença dos metais cobre e/ou chumbo (pH 6) e níquel, zinco e/ou cádmio (pH 8) e não à amônia ou ao ácido sulfídrico.

Da mesma forma, utilizando o critério não biológico de toxicidade, com base nas concentrações dos sulfetos volatilizáveis por acidificação (SVA) e metais simultaneamente extraídos (MSE), apresentados na Tabela 15, as relações MSE/SVA, mostraram excesso de metal em relação ao SVA (Tabela 16), indicando mais uma vez que a toxicidade detectada poderia estar sendo causada por metais, a não ser que outra fase, e não os sulfetos, estivessem regulando a disponibilidade dos metais no ambiente.

Tabela 15 - Valores das concentrações de metais e sulfetos simultaneamente extraídos (SVA) das amostras de sedimento das estações E1, E2 e E3 coletadas no reservatório de Barra Bonita (BB) em setembro/00.

\begin{tabular}{|c|c|c|c|c|c|c|c|}
\hline \multirow[b]{2}{*}{ Setembro/00 } & \multicolumn{6}{|c|}{ Metais (mg/Kg) } & \multirow{2}{*}{$\begin{array}{c}\text { SVA } \\
(\mathrm{mg} / \mathrm{Kg})\end{array}$} \\
\hline & $\mathrm{Cd}$ & $\mathrm{Cu}$ & $\mathrm{Cr}$ & $\mathrm{Pb}$ & $\mathrm{Ni}$ & Zn & \\
\hline BB-E1-Piracicaba & 0,73 & 158 & 156.5 & 284 & 326.4 & 408 & 42 \\
\hline BB-E2-Tietê & 0,87 & 192 & -- & 789.6 & 422.6 & 632 & 132 \\
\hline BB-E3-Barragem & 1,04 & 310.3 & 151.5 & 384.7 & 639.5 & 469 & 63 \\
\hline
\end{tabular}


Tabela 16 - Relações [ $\sum$ MSE]-SVA e [ $\sum$ MSE]/SVA para as amostras de sedimento das estações E1, E2 e E3 coletadas no reservatório de Barra Bonita (BB) em setembro/00.

\begin{tabular}{|l|c|c|c|c|c|}
\hline \multicolumn{1}{|c|}{ Setembro/00 } & [MSE] & SVA & [MSE] - SVA & [MSE] / SVA & $\begin{array}{c}\text { Predição de } \\
\text { Toxicidade }\end{array}$ \\
\hline BB-E1-Piracicaba & 15.63 & 1.31 & 14.23 & 11.93 & Tóxico \\
\hline BB-E2-Tietê & 23.71 & 4.12 & 19.59 & 5.75 & Tóxico \\
\hline BB-E3-Barragem & 20.56 & 1.97 & 18.59 & 10.44 & Tóxico \\
\hline BB-E3-Barragem & 20.56 & 1.97 & 18.59 & 10.44 & Tóxico \\
\hline
\end{tabular}

[ $\sum$ MSE] - SVA $>0$ : presença de toxicidade $[\Sigma \mathrm{MSE}]-\mathrm{SVA}<0$ : ausência de toxicidade

[ $\sum$ MSE]/SVA $>1$ : presença de toxicidade $\quad\left[\sum\right.$ MSE] $/$ SVA $<1$ ausência de toxicidade

Considerando cada metal individualmente (Tabela 17), os metais cobre, chumbo, níquel e zinco poderiam estar causando toxicidade na estação E1, níquel e zinco na estação E2 e cobre, níquel e zinco na estação E3. Os cálculos das relações metais/SVA, apresentados nas Tabelas 16 e 17, foram feitos com as concentrações dos metais e do SVA transformadas em mM.

De acordo com SIBLEY et al. (1996), os pontos de sustentação desse modelo são: 1) a ligação entre sulfetos e os metais catiônicos ( $\mathrm{Cd}, \mathrm{Cu}, \mathrm{Pb}, \mathrm{Ni}, \mathrm{Zn}$ ) é molarmente proporcional (1:1) e 2) a afinidade desses metais pelos sítios de ligação dos sulfetos é mais forte do que a do ferro (metal predominante associado ao sulfeto em ambientes aquáticos), garantindo-lhes vantagem competitiva na formação dos sulfetos metálicos. Considerando a proporcionalidade na formação dos sulfetos, quando a razão entre metal e SVA for menor que 1 , o número de sítios de ligação será maior que a quantidade de metal presente e todo metal estará ligado, estando, portanto, não disponível. Nesse caso, espera-se ausência de toxicidade. Inversamente, se a razão entre metal e SVA for maior que 1 , a concentração de metal excederá os sítios de ligação, resultando em excesso de metal na água intersticial e presença de toxicidade. Esses resultados confirmaram aqueles obtidos por SILVÉRIO (1999), que não encontrou correlação estatisticamente significativa entre o SVA e as concentrações de metais potencialmente disponíveis para o sedimento da represa de Barra Bonita. 
Tabela 17 - Relação [MSE] - [SVA] para as amostras de sedimento das estações E1, E2 e E3 coletadas no reservatório de Barra Bonita em setembro/00.

\begin{tabular}{|l|c|c|c|c|c|}
\hline \multirow{2}{*}{ Estações } & \multicolumn{5}{c|}{$[\mathrm{MSE}] /$ [SVA] } \\
\cline { 2 - 6 } & $\mathrm{Cd}$ & $\mathrm{Cu}$ & $\mathrm{Pb}$ & $\mathrm{Ni}$ & $\mathrm{Zn}$ \\
\hline BB-E1- Piracicaba & $<1$ & 1,9 & 1,04 & 4,2 & 4,8 \\
\hline Previsão de Toxicidade * & $\mathrm{NT}$ & $\mathrm{T}$ & $\mathrm{T}$ & $\mathrm{T}$ & $\mathrm{T}$ \\
\hline BB-E2- Tietê & $<1$ & 0,73 & 0,92 & 1,7 & 2,3 \\
\hline Previsão de Toxicidade * & $\mathrm{NT}$ & $\mathrm{NT}$ & $\mathrm{NT}$ & $\mathrm{T}$ & $\mathrm{T}$ \\
\hline BB-E3 - Barragem & $<1$ & 2,4 & 0,94 & 5,5 & 3,6 \\
\hline Previsão de Toxicidade * & $\mathrm{NT}$ & $\mathrm{T}$ & $\mathrm{NT}$ & $\mathrm{T}$ & $\mathrm{T}$ \\
\hline
\end{tabular}

*: [MSE]/SVA >1: presença de toxicidade [MSE]/SVA $<1$ ausência de toxicidade NT: não tóxico T: tóxico

Além dos sulfetos, a matéria orgânica também atua como fase controladora de metais. Embora a análise granulométrica e de matéria orgânica (Tabela 2, cap 1), tenha mostrado um sedimento com características de agregar metais, com teor de MO superior a 10\% em relação ao peso seco (sedimento orgânico) e predominância das frações argila e silte, a mesma autora não encontrou correlações significativas entre o carbono orgânico dissolvido (COD)/metais na água intersticial e para carbono orgânico total (COT)/metais potencialmente disponíveis no sedimento total, com exceção apenas para o cobre, para o qual houve uma correlação significativa $(r=0,73)$ com COT.

Portanto, embora parcial, o estudo de avaliação e identificação da toxicidade realizado com a amostra de sedimento da estação E2-Tietê apontou para os metais, como uma das classes de compostos químicos responsáveis pela toxicidade, sendo que essa evidência pode ser confirmada pelas relações entre metais/SVA.

A comparação das concentrações dos metais na água intersticial ou solubilizado com os valores de CE50 para o organismo-teste utilizado poderia confirmar de fato essa evidência.

As porcentagens de efeito tóxico obtidas nos testes de toxicidade com os brancos (água de cultivo nas mesmas condições das amostras) de cada etapa foram sempre iguais a zero ou inferiores a $10 \%$. 


\subsection{2 - Reservatório de Salto Grande}

\subsubsection{1 - Avaliação e Identificação da Toxicidade - AIT (nov/00; abr/01; mai/01)}

Nov/00: os resultados obtidos nas diferentes etapas da fase I do estudo de Avaliação e Identificação da Toxicidade com a amostra da estação E2, coletada em nov/00 estão apresentados nas Tabelas 19 e 20 e Figuras 16 e 17.

Os resultados dos testes com Daphnia similis (Tabela 19) e Ceriodaphnia dubia (Tabela 20) não foram conclusivos, pois, por motivos diferentes, nem todas as etapas e os testes subseqüentes de recuperação da toxicidade puderam ser realizadas. Em nov/00, as culturas estavam em condições inadequadas, apresentando mortalidade nos controles, o que impediu a realização de todos os testes de toxicidade necessários dentro dos prazos de validade das amostras. As amostras foram mantidas congeladas e, com o restabelecimento dos cultivos, alguns testes foram repetidos para confirmação dos resultados anteriores. As amostras descongeladas da estação E2 mantiveram os mesmos valores de $\mathrm{pH}$, a mesma toxicidade inicial e a mesma resposta em relação às manipulações realizadas.

A confirmação dos resultados com os testes subseqüentes de recuperação de toxicidade, não foram ser realizados. No entanto, considerando que em pH7, as amostras não apresentaram toxicidade, esses resultados mostraram que a toxicidade está relacionada, se não totalmente, pelo menos parcialmente, com os efeitos fisiológicos da acidez.

Os testes iniciais de ajuste de $\mathrm{pH}$ com a bactéria luminescente Vibrio fisheri sistema Microtox mostraram que, com o acerto do $\mathrm{pH}$ para a faixa de tolerância do organismo-teste em questão (5,8 a 9), as amostras perderam a toxicidade. Com esses resultados, as demais etapas não foram realizadas (Tabela 20). 
Tabela 19 - Porcentagens de efeito e valores de CE50 de Daphnia similis e Vibrio fisheri expostas ao solubilizado da amostra de sedimento da estação E2, antes (TTb) e após as diferentes etapas do estudo de TIE - Reservatório de Salto Grande em nov/00

\begin{tabular}{|c|c|c|c|c|c|c|c|c|}
\hline $\begin{array}{c}\text { Estação E1 } \\
\text { Etapas }\end{array}$ & \multicolumn{7}{|c|}{ Concentração / \% de Efeito } & \multirow{3}{*}{$\begin{array}{l}\text { Efeito na } \\
\text { Toxicidade }\end{array}$} \\
\hline \multicolumn{8}{|c|}{ Daphnia similis (CE50, 48h) } & \\
\hline & & 100 & $50 \%$ & $25 \%$ & $12 \%$ & $6 \%$ & CE50 & \\
\hline TT Base & pH i (3.9) & 100 & $\mathbf{0}$ & $\mathbf{0}$ & $\mathbf{0}$ & $\mathbf{0}$ & $71 \%(--)$ & -- \\
\hline Ajuste & pH 3 (3.9) & 100 & 0 & 0 & -- & -- & $71 \%(--)$ & SE \\
\hline \multirow{3}{*}{ Aeração } & $\mathrm{pH} 11(4.1)$ & 100 & 7 & 0 & -- & -- & $67 \%(60,5-74,3)$ & SE \\
\hline & $\mathrm{pH} 3$ (3.9) & 100 & 6 & 0 & -- & -- & $86 \%(67,6-108,6)$ & SE \\
\hline & $\mathrm{pH} 11(4.1)$ & 100 & 7 & 14 & -- & -- & $68 \%(--)$ & SE \\
\hline \multirow[t]{2}{*}{ Filtração } & pH 3 (3.9) & 100 & 53 & 20 & -- & -- & $45 \%(33,5-45,0)$ & RT \\
\hline & pH 11(4.1) & 100 & 13 & 6 & -- & -- & $65 \%(56,3-75,9)$ & SE \\
\hline \multicolumn{9}{|c|}{ Vibrio fischerii (CE50,15 min.) } \\
\hline & & 81,9 & 40,95 & 20,48 & 10,24 & & CE50 & \\
\hline T T Inicial & 3.9 & 99 & 39 & 13 & $\mathbf{0}$ & & $55 \%$ & -- \\
\hline Ajuste & $\mathrm{pH} 5.8$ & -- & -- & -- & -- & & NT & RT \\
\hline Graduação & $\mathrm{pH6}$ & -- & -- & -- & -- & & NT & RT \\
\hline Graduação & $\mathrm{pH} 7$ & -- & -- & -- & -- & & NT & RT \\
\hline Graduação & $\mathrm{pH} 9$ & -- & -- & -- & -- & & NT & RT \\
\hline
\end{tabular}


Tabela 20 - Porcentagens de imobilidade e valores de CE50,48h de Ceriodaphnia dubia expostas ao solubilizado da amostra de sedimento da estação E2, antes (TTb) e após as

\begin{tabular}{|c|c|c|c|c|c|c|c|c|}
\hline \multicolumn{2}{|c|}{ Estação E2 } & \multicolumn{6}{|c|}{$\begin{array}{c}\text { Concentração (\%) } \\
\% \text { de Imobilidade - } 48 \mathrm{~h}\end{array}$} & \multirow{3}{*}{$\begin{array}{c}\begin{array}{c}\text { Efeito } \\
\text { na } \\
\text { Toxicidade }\end{array} \\
--\end{array}$} \\
\hline \multicolumn{2}{|c|}{ Etapas } & $100 \%$ & $50 \%$ & $25 \%$ & $10 \%$ & $5 \%$ & CE50 & \\
\hline TT Inicial & pH i $(3,9)$ & 100 & 90 & 30 & $\mathbf{0}$ & $\mathbf{0}$ & $\mathbf{3 1 \%}(22,8-44,9)$ & \\
\hline \multirow[t]{3}{*}{ Ajuste } & $\mathrm{pH} 7 / 3,9$ & 100 & 60 & 20 & 0 & - & $42 \%(29,7-59,4)$ & $\mathrm{SE}$ \\
\hline & pH 7 & 50 & 10 & 0 & 0 & - & $100 \%$ & \\
\hline & $\mathrm{pH} 11 / 3,9$ & 100 & 20 & 0 & 0 & - & $61 \%(51,6-73,4)$ & $\mathrm{RT}$ \\
\hline \multirow[t]{3}{*}{ Aeração } & $\mathrm{pH} 7 / 3,9$ & 100 & 70 & 0 & 0 & - & $43 \%(35,6-53,2)$ & SE \\
\hline & $\mathrm{pH} 7$ & 50 & 10 & 0 & 0 & - & $100 \%$ & \\
\hline & $\mathrm{pH} 11 / 3,9$ & 100 & 0 & 0 & 0 & - & $71 \%(--)$ & $\mathrm{RT}$ \\
\hline \multirow[t]{3}{*}{ Filtração } & $\mathrm{pH} 7 / 3,9$ & 100 & 44 & 0 & 0 & - & $52 \%(41,3-65,4)$ & $\mathrm{RT}$ \\
\hline & $\mathrm{pH} 7$ & 0 & 0 & 0 & 0 & - & NT & RT \\
\hline & $\mathrm{pH} \mathrm{11/3,9}$ & 100 & 0 & 0 & 0 & 一 & $71 \%(--)$ & RT \\
\hline TT Base & pH i $(3,9)$ & 100 & 33 & $\mathbf{0}$ & $\mathbf{0}$ & & $56 \%(47,4-66,4)$ & -- \\
\hline \multirow[t]{3}{*}{ Coluna C18 } & $\mathrm{pH} 7$ & 0 & 0 & 0 & 0 & -- & NT & $\mathrm{RT}$ \\
\hline & pH 9 / 3,9 & 0 & 0 & 0 & 0 & -- & NT & RT \\
\hline & $\mathrm{pH} 3 / 3,9$ & 100 & 7 & 0 & 0 & -- & $67(61,7-73,8)$ & RT \\
\hline
\end{tabular}

diferentes etapas do estudo de TIE - Reservatório de Salto Grande em nov/00. 


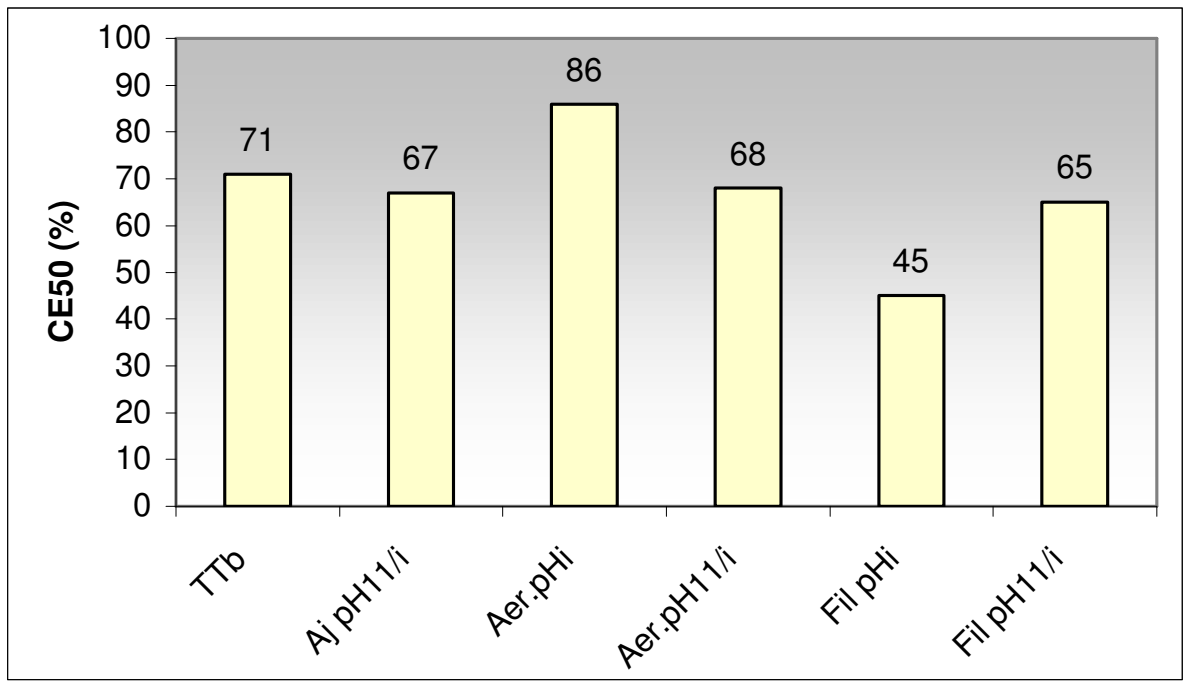

Figura 16 - Efeito das etapas do estudo de AIT na toxicidade aguda do solubilizado da amostra sedimento da estação E2 do reservatório de Salto Grande em novembro de 2000 (nov/00) expresso pelos efeitos comportamentais (imobilidade) observados para Daphnia similis.

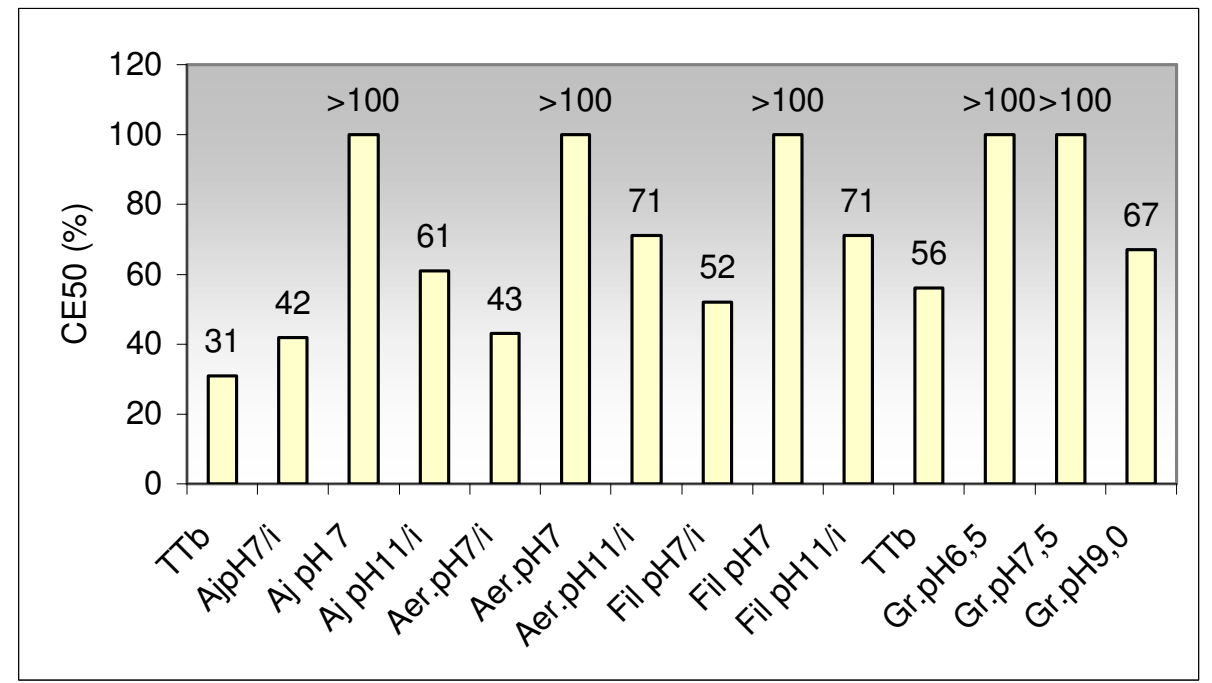

Figura 17 - Efeito das etapas do estudo de AIT na toxicidade aguda do solubilizado da amostra sedimento da estação E2 do reservatório de Salto Grande em novembro de 2000 (nov/00) expresso pelos efeitos comportamentais (imobilidade) observados para Ceriodaphnia dubia.

Abr/01: o estudo parcial de AIT realizado com as amostras solubilizadas e de água intersticial, da estação E1, coletada em abr/01 não foi conclusivo devido a perda da toxicidade da amostra entre as diferentes etapas. 
Os resultados dos testes com $V$. fisheri (Tabela 21), realizados com a água intersticial da estação E1, antes e após as etapas de ajuste e coluna de C18, mostraram que: 1) parte da toxicidade detectada pelo $V$. fisheri, na água intersticial está relacionada com a acidez e outra parte com compostos voláteis ou degradáveis. Os teses com ajuste em pH 3 e pHi (6.9), não alteraram a toxicidade. No entanto em pH 11, ocorreu redução da toxicidade; 2) a coluna de C18 eliminou a toxicidade em todos os níveis de $\mathrm{pH}$. Nos testes posteriores a amostra perdeu a toxicidade, o que impediu a confirmação dos resultados. O solubilizado não foi tóxico.

O solubilizado causou toxicidade para C. dubia com valor de CE50, 48h de $41 \%$. Na etapa pós-filtração houve perda da toxicidade. Nos testes seguintes, a amostra perdeu a toxicidade.

Tabela 21 - Valores de CE50,15' de Vibrio fisheri expostas à água intersticial e solubilizado da amostra de sedimento da estação E2, antes (TTb) e após as etapas do estudo de AIT - Reservatório de Salto Grande em abr/01.

\begin{tabular}{|c|c|c|c|c|c|c|c|c|}
\hline \multicolumn{2}{|c|}{ Amostra } & \multirow{2}{*}{ CE50 } & \multicolumn{3}{c|}{ Ajuste de $\mathrm{pH}$} & \multicolumn{3}{c|}{ Coluna C18 } \\
\cline { 4 - 9 } & & $\mathrm{pH3}$ & $\mathrm{pHi}$ & $\mathrm{pH} 11$ & $\mathrm{pH} 3$ & $\mathrm{pHi}$ & $\mathrm{pH} 9$ \\
\hline \multirow{3}{*}{ AI } & TT inicial & $\mathbf{2 8 \%}$ & $28 \%$ & $28 \%$ & $85 \%$ & -- & -- & -- \\
\cline { 2 - 9 } & TT base & $\mathbf{3 1 \%}$ & -- & -- & -- & NT & NT & NT \\
\cline { 3 - 9 } & & NT & \multicolumn{4}{c|}{ demais etapas não realizadas } \\
\hline Sol & TT inicial & NT & \multicolumn{4}{c|}{ etapas não realizadas } \\
\hline
\end{tabular}

A rápida perda da toxicidade associada à não recuperação da toxicidade no eluido do filtro, pode indicar suspeita da presença de compostos voláteis. Um aspecto importante foi que essa amostra não apresentou a mesma acidez anterior. Os valores de $\mathrm{pH}$ do sedimento, água intersticial e solubilizado foram de 6,8, 6,9 e 7,2, respectivamente.

Esses resultados mostraram a importância da realização simultânea das etapas que envolvem ajuste de $\mathrm{pH}$ e das etapas relacionadas com compostos voláteis e/ou degradáveis. Em relação à redução da toxicidade do solubilizado pós-filtração observada no teste com Ceriodaphnia dubia, comparada com o teste de toxicidade inicial, a impossibilidade de repetição dos testes devido à perda da toxicidade inicial da amostra para confirmação dos resultados obtidos, impediu qualquer conclusão. 
Mai/001: as diferentes matrizes da amostra (sedimento total, solubilizado e água intersticial) não causaram toxicidade aguda para $C$. xanthus, D. similis, C. dubia e $V$. fischeri.

\subsubsection{2 - Avaliação e Identificação da Toxicidade - AIT - Fases I e II ( Out/01)}

O estudo de AIT foi realizado com a amostra da estação E2, devido à maior toxicidade do solubilizado para o organismo-teste Ceriodaphnia dubia. Os valores de CE50,48h para C. dubia das estações E1 e E2 foram respectivamente de 59 e $22 \%$ (Tabela 13, cap.1).

Na Tabela 22 e Figuras 18 e 19 estão apresentados os resultados em porcentagens de imobilidade para as diferentes concentrações obtidos nos testes antes e após as manipulações, os valores de CE50,48h, com os limites inferiores e superiores, obtidos antes e após as etapas de ajuste, aeração, filtração, graduação de pH e coluna de C18 e o efeito das diferentes etapas na toxicidade das amostras coletadas em out/01.

Os resultados das etapas de ajuste e ajuste/aeração mostraram que as possíveis alterações na solubilidade, polaridade, volatilidade, estabilidade, especiação e/ou biodisponibilidade dos prováveis compostos tóxicos, ocorridas em $\mathrm{pH} 11$, foram reversíveis com o retorno para o $\mathrm{pH}$ inicial da amostra. Mas, considerando os resultados obtidos com a amostra em $\mathrm{pH} 7$, é possível que a toxicidade esteja relacionada com a acidez e os efeitos dessa acidez nos organismos-teste e/ou na remobilização de compostos.

Em relação aos testes com a coluna de $\mathrm{C} 18$, os resultados obtidos mostraram redução da toxicidade apenas em pH 9. A não recuperação da toxicidade no eluato, sugere duas possibilidades: 1) a coluna funcionou apenas como um filtro, retendo os tóxicos por mecanismo de adsorção e não troca iônica; 2) a espécie Ceriodaphnia dubia não apresenta sensibilidade aos possíveis compostos orgânicos presentes na amostra.

A análise conjunta dos resultados das etapas de ajuste, aeração, filtração e coluna de C18 mostrou que, no pH inicial da amostra, nenhuma das etapas influenciou na toxicidade. A redução da toxicidade nas etapas de aeração e filtração $\mathrm{pH} 11 / 7$ pode estar relacionada com a remoção física de compostos tóxicos devido à precipitação e retenção pelo filtro dos flóculos que se formaram com o aumento do pH para 11. 
Uma vez que as mudanças de $\mathrm{pH}$ alteram a solubilidade dos compostos ácidos e bases, eles podem ser removidos da solução por meio de filtração, aeração ou extração em coluna. Em sua forma não ionizada, esses compostos são menos polares que na forma ionizada, diminuindo a interação com as moléculas de água.

Tabelas 22 - Porcentagens de imobilidade e valores de CE50,48h de Ceriodaphnia dubia expostas ao solubilizado da amostra de sedimento da estação E2, antes e após as diferentes etapas do estudo de TIE - Reservatório de Salto Grande - out/01.

\begin{tabular}{|c|c|c|c|c|c|c|c|c|}
\hline \multirow{2}{*}{\multicolumn{2}{|c|}{$\frac{\text { Estação E2 }}{\text { Tratamentos }}$}} & \multicolumn{6}{|c|}{ Concentração / \% de Imobilidade } & \multirow{3}{*}{\begin{tabular}{|c|}
$\begin{array}{c}\text { Efeito na } \\
\text { Toxicidade }\end{array}$ \\
--
\end{tabular}} \\
\hline & & \multirow{2}{*}{$\begin{array}{r}100 \% \\
100\end{array}$} & \multirow{2}{*}{$\begin{array}{r}50 \% \\
100\end{array}$} & \multirow{2}{*}{$\begin{array}{r}25 \% \\
60\end{array}$} & \multirow{2}{*}{$\begin{array}{r}12 \% \\
13\end{array}$} & \multirow{2}{*}{$\begin{array}{c}6 \% \\
0\end{array}$} & \multirow{2}{*}{ 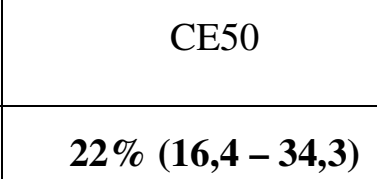 } & \\
\hline T T Inicial (TTi) & pH i (3.2) & & & & & & & \\
\hline \multirow[t]{3}{*}{ Graduação de pH } & pH 6,5 & 67 & 0 & 0 & 0 & - & $84 \%(--)$ & RT \\
\hline & $\mathrm{pH} \mathrm{7,5}$ & 0 & 0 & 0 & 0 & - & NT & RT \\
\hline & $\mathrm{pH} 9$ & 67 & 55 & 33 & 0 & - & $44.5 \%(45-69,7)$ & $\mathrm{T}$ \\
\hline T T Base (TTb) & pHi (3.2) & 100 & 100 & 13 & $\mathbf{0}$ & $\mathbf{0}$ & $33 \%(22,8-44,9)$ & -- \\
\hline \multirow{4}{*}{ Ajuste de $\mathrm{pH}$} & pH 7 (3.2) & 100 & 60 & 20 & 0 & - & $42 \%(22,6-34,9)$ & SE \\
\hline & pH 7 & 0 & 0 & 0 & 0 & -- & NT & RT \\
\hline & $\mathrm{pH} 11 / 7$ & 33 & -- & -- & -- & -- & $>100 \%$ & RT \\
\hline & $\mathrm{pH} 11 / 3.2$ & 100 & 100 & 25 & 13 & -- & $31 \%(23,6-39,9)$ & SE \\
\hline \multirow[t]{3}{*}{ Aeração/ar } & pHi 3.2 & 100 & 100 & 13 & 0 & -- & $33 \%(28,3-37,8)$ & SE \\
\hline & $\mathrm{pH} 11 / 7$ & 77 & 0.0 & 0.0 & 0.0 & -- & $77 \% *$ & RT \\
\hline & $\mathrm{pH} 11 / 3.2$ & 100 & 100 & 20 & 13 & -- & $31 \%(23,6-39,9)$ & SE \\
\hline T T Base (TTb) & pHi (3.2) & 100 & 90 & 30 & $\mathbf{0}$ & $\mathbf{0}$ & $33 \%(22,8-44,9)$ & -- \\
\hline \multirow[t]{3}{*}{ Filtração } & pHi 3.2 & 100 & 100 & 13 & 0 & -- & $32 \%(22.8-44.9)$ & SE \\
\hline & $\mathrm{pH} 11 / 7$ & 33 & 0 & 0 & 0 & -- & $>100 \%$ & RT \\
\hline & $\mathrm{pH} 11 / 3.2$ & 100 & 22 & 22 & 0 & -- & $52 \%(39,3-68,1)$ & $\mathrm{RT}$ \\
\hline TT Base (TTb) & pH i $(3,9)$ & 100 & 33 & $\mathbf{0}$ & $\mathbf{0}$ & -- & $53 \%(41,3-65,4)-$ & -- \\
\hline \multirow[t]{2}{*}{ Coluna C18 } & $\mathrm{pH} 3(3,9)$ & 100 & 33 & 0 & 0 & -- & $53 \%(41,3-65,4)$ & SE \\
\hline & $\mathrm{pH} 9(3,9)$ & 0 & 0 & 0 & 0 & -- & NT & RT \\
\hline
\end{tabular}

RT: redução da toxicidade SE: sem efeito *: \% de efeito na amostra pura 


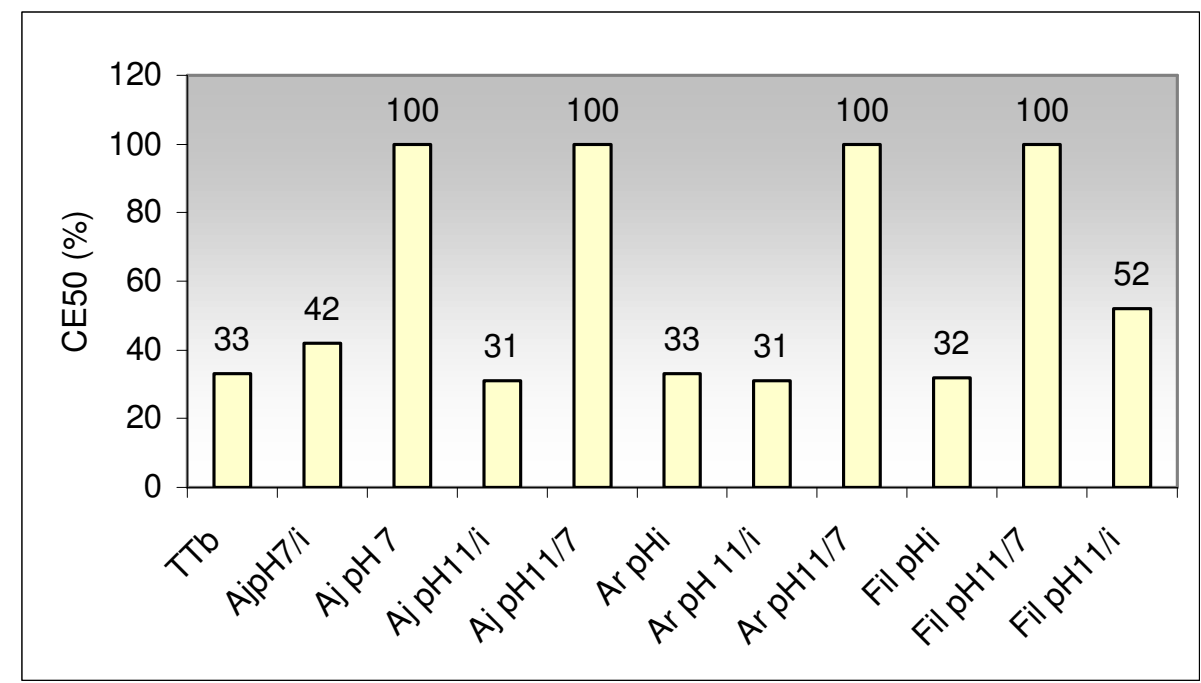

Figura 18 - Efeito das etapas do estudo de AIT na toxicidade aguda do solubilizado do sedimento do reservatório de Salto Grande em outubro de 2001 (out/01) expresso pelos efeitos comportamentais (imobilidade) observados para Ceriodaphnia dubia.

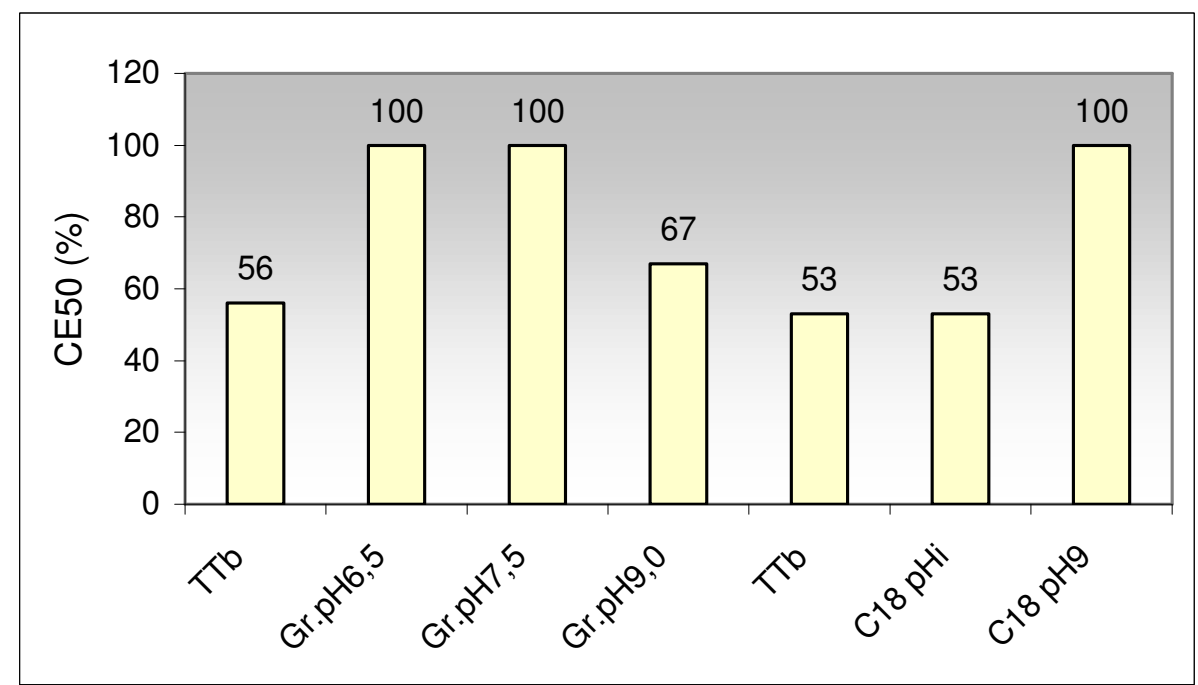

Figura 19- Efeito das etapas do estudo de AIT na toxicidade aguda do solubilizado do sedimento do reservatório de Salto Grande em outubro de 2001 (out/01) expresso pelos efeitos comportamentais (imobilidade) observados para Ceriodaphnia dubia. 
Nos testes com pH 11, pós-aeração, com o retorno para o pHi, as amostras voltaram a apresentar o mesmo nível de toxicidade, enquanto que, com o retorno para o $\mathrm{pH} 7$, a toxicidade diminuiu. Essa diferença pode estar associada à maior resolubilização dos precipitados no pH inicial, ácido, do que no pH 7. Mas, considerando o resultado do teste basal junto com os testes pós-aeração pH 3 (sem efeito tóxico), é possível que a redução da toxicidade esteja associada à amônia. Nesse valor de pH, praticamente toda amônia está na forma não ionizada, que é volátil.

A manutenção da toxicidade na etapa de ajuste/aeração pH3 mostrou que não existem compostos ácidos voláteis ou oxidáveis atuando na toxicidade. Da mesma forma, a redução da toxicidade no ajuste/aeração em pH 11 com retorno para pH 7, e a manutenção da toxicidade com o retorno para pH inicial, mostraram que os compostos não foram degradados com a mudança do $\mathrm{pH}$. Nesse caso, a perda da toxicidade estaria associada à retirada do tóxico pelos processos de precipitação ou floculação, reversíveis com o retorno da amostra para o $\mathrm{pH}$ ácido. A redução parcial da toxicidade em $\mathrm{pH}$ 7, mostrou que uma parte da toxicidade está associada à acidez e outra parte aos compostos precipitados ou floculados.

Nos testes pós-filtração, o resultado com a amostra em pH 11 com retorno para pH 3,2 mostrou diminuição de cerca de 2 vezes em relação a toxicidade basal. Por outro lado, em pH 11/7, a amostra perdeu totalmente a toxicidade. Esses resultados mostraram que parte da toxicidade está associada aos compostos que ficaram retidos pelo filtro nos testes com $\mathrm{pH} 11$, mas parte dela está associada também com a acidez. O que pode explicar a presença de toxicidade com o retorno para o pH inicial e ausência da mesma com o retorno para o $\mathrm{pH} 7$.

Os resultados semelhantes obtidos nas etapas de aeração/ajuste e filtração/ajuste, obtidos também com as amostras de nov/00 mostraram que a redução de toxicidade foi devida apenas às alterações do pH (amostras com filtração/ajuste e aeração/ajuste devem apresentar ambas redução na toxicidade)

Considerando a redução da toxicidade nos testes pós-coluna pH9 e a não recuperação da mesma nos extratos eluídos da coluna, podemos considerar que a coluna funcionou apenas como um filtro, retendo os tóxicos por mecanismo de adsorção e não troca iônica, coincidindo, portanto, com o resultado obtido na etapa pós-filtração pH11.

Apesar das alterações na solubilidade, na polaridade, na volatilidade, na estabilidade, na especiação, na biodisponibilidade e na toxicidade de um composto, 
causadas pelas mudanças de $\mathrm{pH}$, espera-se, que o ajuste do $\mathrm{pH}$ de uma solução e o posterior retorno ao seu valor inicial, em um curto intervalo de tempo, não deveria influir na toxicidade. No entanto, tem-se observado que, em alguns casos, essa alteração resulta em perda, redução ou aumento da toxicidade e os dois principais grupos de compostos afetados pelas mudanças de pH são os ácidos e as bases. Portanto, se as cinéticas das reações de $\mathrm{pH}$ forem lentas e/ou irreversíveis, essa etapa de ajuste de $\mathrm{pH}$ pode, sozinha fornecer evidências da presença de compostos tóxicos $\mathrm{pH}$-dependentes.

A redução da toxicidade em pH11 pode estar associada também a compostos surfactantes ou metais catiônicos. Uma vez que não foi realizada a análise de surfactantes nessa amostra, não foi possível concluir a respeito da presença desse composto.

Considerando a evidencia dos metais catiônicos zinco, níquel e cádmio, também apontada no teste de graduação de $\mathrm{pH}$ (toxicidade em $\mathrm{pH}$ 9), os filtros foram submetidos à ulta-sonificação durante 1 hora em água de diluição com pH3 e a recuperação da toxicidade no eluído do filtro mostrou uma possível responsabilidade de metais na toxicidade.

Em relação aos prováveis metais catiônicos responsáveis pela toxicidade, comparando as concentrações dos metais biodisponíveis encontradas para cádmio, cobre, zinco e chumbo com os valores de CE50, 48h para dureza de 40 a $48 \mathrm{mg} . \mathrm{L}^{-1}$ de $\mathrm{CaCO}^{3}$, observa-se que todas estão acima dos valores de efeito agudo.

No entanto, comparando os valores de CE50 com as concentrações dos metais detectadas no solubilizado (Tabela 23), observa-se que, dentre os metais identificados na etapa de graduação e filtração, o zinco está em concentração próxima ao valor do CE50 e o cobre, acima do valor de CE50. 
Tabela 23 - Concentrações de metais encontradas no solubilizado das amostras de sedimento das estações E1 e E2 coletadas no reservatório de Salto Grande em nov/00 e out/01.

\begin{tabular}{|c|c|c|c|c|c|c|c|c|}
\hline \multirow{2}{*}{$\begin{array}{c}\text { Salto } \\
\text { Grande }\end{array}$} & \multicolumn{9}{|c|}{ Metais $\left(\mu \mathrm{g} . \mathrm{L}^{-1}\right)$} \\
\cline { 2 - 9 } & $\mathrm{Cd}$ & $\mathrm{Cu}$ & $\mathrm{Cr}$ & $\mathrm{Pb}$ & $\mathrm{Ni}$ & $\mathrm{Zn}$ & $\mathrm{Fe}$ & $\mathrm{Mg}$ \\
\hline $\mathrm{E} 1 /$ nov00 & -- & 127 & 0.16 & 6.99 & 20.03 & 327 & 488 & 913 \\
\hline $\mathrm{E} 2$ / nov00 & -- & 149 & 0.131 & 6.29 & 23.12 & 434 & 561 & 491 \\
\hline E2 /out/01 & 0.265 & -- & 3.86 & 4,12 & 71.49 & -- & -- & -- \\
\hline $\begin{array}{c}\mathrm{CE} 50,48 \mathrm{~h} \\
\left(\mu \mathrm{gg} . \mathrm{L}^{-1}\right)\end{array}$ & 2 & $11-25$ & $28-49$ & 50 & -- & 420 & -- & - \\
\hline
\end{tabular}

O critério de efeitos não biológicos baseado na relação entre as concentrações de metais e sulfetos extraídos por acidificação - SVA (Tabelas 24, 25 e 26), mostrou que existe um excesso de SVA no sedimento analisado, de forma que os metais presentes estariam indisponíveis e, portanto não tóxico.

Tabela 24- Concentrações em $\left(\mu \mathrm{g} \cdot \mathrm{g}^{-1}\right)$ dos metais e sulfetos simultaneamente extraídos das amostras de sedimento das estações E1 e E2 coletadas no reservatório de Salto Grande em nov/00, fev/01 e out/01.

\begin{tabular}{|c|c|c|c|c|c|c|c|}
\hline \multirow[b]{2}{*}{ SG } & \multicolumn{6}{|c|}{ Metais $\left(\mu g \cdot g^{-1}\right)$} & \multirow{2}{*}{$\begin{array}{c}\text { SVA } \\
\left(\mu g . g^{-1}\right)\end{array}$} \\
\hline & $\mathrm{Cd}$ & $\mathrm{Cu}$ & $\mathrm{Cr}$ & $\mathrm{Pb}$ & $\mathrm{Ni}$ & $\mathrm{Zn}$ & \\
\hline E 1/ nov00 & 0,84 & 49,6 & 21,2 & 48,2 & 24,2 & 126 & 2473 \\
\hline E 2/ nov00 & 0,66 & 96,2 & 25,2 & 37,3 & 33,7 & 77,3 & 2088 \\
\hline E $2 /$ fev 01 & 0,74 & 107 & 36,5 & 43,3 & 28,8 & 74,4 & 1977 \\
\hline E2 /out/01 & $<\mathrm{LQ}$ & 32.96 & - & 78.8 & 12.1 & 11.5 & 1590 \\
\hline
\end{tabular}

Tabela 25- Relações [ $\sum$ MSE]-SVA e [ $\sum$ MSE]/SVA para as amostras de sedimento das estações E1 e E2 coletadas no reservatório de Salto Grande.

\begin{tabular}{|c|c|c|c|c|c|}
\hline Estações & $\begin{array}{c}\sum \mathrm{MSE} \\
(\mathrm{mM})\end{array}$ & $\begin{array}{l}\text { SVA } \\
(\mathrm{mM})\end{array}$ & 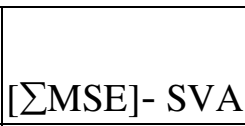 & {$\left[\sum \mathrm{MSE}\right] / \mathrm{SVA}$} & $\begin{array}{l}\text { Predição de } \\
\text { Toxicidade* }\end{array}$ \\
\hline E 1/nov00 & 3.32 & 77.28 & $-73,9$ & 0.043 & NT \\
\hline E 2/nov00 & 3.45 & 65.25 & -61.80 & 0.0529 & NT \\
\hline E 2/fev 01 & 3.53 & 61.78 & -58.25 & 0.0571 & NT \\
\hline E2/out01 & 2.7 & 49.7 & -47 & 0.05 & NT \\
\hline
\end{tabular}


Tabela 26 - Relação [MSE] / [SVA] para as amostras de sedimento das estações E1 e E2 coletadas no reservatório de Salto Grande.

\begin{tabular}{|c|c|c|c|c|c|}
\hline \multirow{2}{*}{ Estações } & \multicolumn{5}{|c|}{$[\mathrm{MSE}] /[\mathrm{SVA}]$} \\
\cline { 2 - 6 } & $\mathrm{Cd}$ & $\mathrm{Cu}$ & $\mathrm{Pb}$ & $\mathrm{Ni}$ & $\mathrm{Zn}$ \\
\hline E 1/nov00 & 0.001 & 0.01 & 0.003 & 0.005 & 0.025 \\
\hline Toxicidade* & $\mathrm{NT}$ & $\mathrm{NT}$ & $\mathrm{NT}$ & $\mathrm{NT}$ & $\mathrm{NT}$ \\
\hline E 2/nov00 & 0.001 & 0.02 & 0.18 & 0.57 & 0.018 \\
\hline Toxicidade* & $\mathrm{NT}$ & $\mathrm{NT}$ & $\mathrm{NT}$ & $\mathrm{NT}$ & $\mathrm{NT}$ \\
\hline E 2/fev 01 & 0.0003 & 0.06 & 0.008 & 0.019 & 0.044 \\
\hline Toxicidade* & $\mathrm{NT}$ & $\mathrm{NT}$ & $\mathrm{NT}$ & $\mathrm{N} \mathrm{T}$ & $\mathrm{NT}$ \\
\hline E2/out01 & - & 0.01 & 0.008 & 0.04 & 0.033 \\
\hline Toxicidade* & $\mathrm{NT}$ & $\mathrm{NT}$ & $\mathrm{NT}$ & $\mathrm{NT}$ & $\mathrm{NT}$ \\
\hline
\end{tabular}

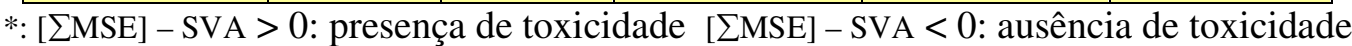
$[\Sigma \mathrm{MSE}] / \mathrm{SVA}>1$ : presença de toxicidade $[\Sigma \mathrm{MSE}] / \mathrm{SVA}<1$ ausência de toxicidade

Nos testes de graduação de $\mathrm{pH}$ houve uma redução significativa da toxicidade em pH 6,5 (4x) e pH 7,5 (total), confirmando a tendência de diminuição da toxicidade com o aumento do $\mathrm{pH}$ e eliminando a possibilidade da presença de ácido sulfídrico (toxicidade em $\mathrm{pH}$ 6,5). As concentrações de $\mathrm{H}_{2} \mathrm{~S}$ nas amostras solubilizadas das estações E1 e E2 foram de 0,63 e 0,47 mg.L $\mathrm{L}^{-1}$ (Tabela 6, capítulo1).

Em relação à toxicidade do sulfeto de hidrogênio aos organismos aquáticos, SVENSON et al. (1997), encontrou para Vibrio fisheri um valor de CE50, 15' de 86 mg.L. $\mathrm{L}^{-1}$. Embora o organismo-teste seja outro, os valores detectados no sedimento da represa de Salto Grande são no mínimo, 10 vezes menores que o valor de efeito agudo, encontrado por estes autores.

Em pH 9.5 a amostra permaneceu tóxica (CE50,48h de 44,5\%). Esse resultado sugere a presença de amônia, que além de ser um contaminante comumente presente em ambientes aquáticos, é um dos compostos iônicos que apresenta maior toxicidade em $\mathrm{pH}$ alto, devido à predominância da forma não ionizada $\left(\mathrm{NH}_{3}\right)$, mais tóxica, em relação à forma ionizada $\left(\mathrm{NH}_{4}+\right)$. Nesse caso, a redução da toxicidade na etapa de ajuste/aeração em pH 11 com retorno para pH7, reforçou essa evidência.

As concentrações de amônia encontradas nas amostras solubilizadas já foram anteriormente apresentadas na Tabela 6 , capítulo 1 . O valor médio foi de $2.8 \mathrm{mg} . \mathrm{L}^{-1}$. Vários estudos têm mostrado que a toxicidade de amostras de água intersticial ou 
solubilizado de sedimentos marinhos ou de água doce pode ser devida à amônia (WHITEMAN., 1996).

Embora a concentração de amônia encontrada para a estação E2 em out/01 (3,24 mg.L $\mathrm{L}^{-1}$ ) esteja acima dos valores de CE50,48h de $\mathrm{NH}_{3}$ para Ceriodaphnia dubia de 0.78, 1,.73 e 2,88 mg.L ${ }^{-1}$ (EPA, 1991 e ANKLEY et al., 1990), deve-se considerar que essa determinação foi feita em amônia total e não em $\mathrm{NH}_{3}$, que é a forma mais tóxica. A especiação entre as duas formas iônicas e não-iônicas depende do $\mathrm{pH}$ e temperatura. No $\mathrm{pH}$ em que foram realizados os testes de toxicidade, entre 7 e 8 , a proporção da forma não ionizada, $\mathrm{NH}_{3}$ é pequena, de forma que a maior parte dos $3,24 \mathrm{mg} . \mathrm{L}^{-1}$ deveria estar na forma de $\mathrm{NH}_{4}$. A distribuição das diferentes formas de amônia em água em função do pH é apresentada a seguir, na Tabela 27. Em destaque estão indicados o valor do pK para amônia $(9,25)$ e os valores de $\mathrm{pH}$ correspondentes a 1 ponto acima e 1 ponto abaixo do pK, onde a proporção entre as formas ionizadas e não ionizadas é de 90:10 e 10:90\% respectivamente.

Tabela 27 - Distribuição esperada da amônia na água em função do $\mathrm{pH}\left(25^{\circ} \mathrm{C}\right)$

\begin{tabular}{|l|c|c|c|c|c|c|c|c|c|c|}
\hline \multirow{2}{*}{ Amônia } & \multicolumn{10}{|c|}{$\mathrm{pH}\left(25^{\circ} \mathrm{C}\right)$} \\
\cline { 2 - 12 } & 7 & 7,5 & 8 & 8,25 & 8,5 & 9 & 9,25 & 9,5 & 10 & 10,25 \\
\hline $\mathrm{NH}_{3}(\%)$ & 1 & 2 & 5 & 10 & 15 & 36 & 50 & 64 & 85 & 90 \\
\hline $\mathrm{NH}_{4}(\%)$ & 99 & 98 & 95 & 90 & 85 & 64 & 50 & 36 & 15 & 10 \\
\hline
\end{tabular}

Fonte: Helcias B. de Padua (www.ccinet.com.br/tucunare/necessaria.htm) / EPA (1992)

No entanto, os resultados obtidos por BESSER et al. (1998), contrariaram a questão da toxicidade associada predominantemente à forma não ionizada. Avaliando os efeitos da resina zeolita na toxicidade da amônia em sedimentos continentais, os autores não encontraram diferenças nos valores de CE50 de amônia total na água intersticial dos sedimentos testados, apesar da diferença dos valores de pHs. Essa diferença correspondia a uma diferença de 10x na proporção da fração não ionizada em relação à amônia total $(0,15 \%$ em pH 6,5 contra 1,45\% em pH 7,5). Corroborando com esses resultados, outros estudos sobre a dependência toxicidade/pH, mostraram a contribuição das duas frações da amônia, a ionizada e a não ionizada na toxicidade para peixes e invertebrados e que, para o organismo bentônico Hyalella azteca, a toxicidade se mostrou pH-dependente apenas em águas com altas concentrações de sódio e potássio e não cálcio e magnésio. 
Portanto, é possível que a amônia detectada no solubilizado das estações E1 e E2 do reservatório de Salto Grande em nov/00 e out/01 possa ter tido alguma influencia na toxicidade encontrada, independente da sua dissociação.

Além de amônia e sulfetos, alguns metais também podem ser evidenciados na etapa de graduação de $\mathrm{pH}$. Nesse caso, os metais zinco, níquel e cádmio poderiam estar associados à toxicidade observada no pH9. No entanto, os resultados com EDTA, apresentados a seguir (Tabela 28), não apontaram para essa evidencia, uma vez que a toxicidade da amostra se manteve inalterada após o tratamento com EDTA.

Da mesma forma, o tratamento com tiossulfato de sódio não alterou a toxicidade da amostra, em nenhuma das concentrações utilizadas (Tabela 29).

Tabela 28 - Porcentagens de imobilidade de Ceriodaphnia dubia expostas ao solubilizado da amostra de sedimento da estação E2, após o tratamento com EDTA - Reservatório de Salto Grande - out/01.

\begin{tabular}{|c|c|c|c|c|c|c|}
\hline \multirow{2}{*}{$\begin{array}{c}\text { Concentração da } \\
\text { amostra (\%) }\end{array}$} & \multicolumn{7}{|c|}{ Volume $(\mathrm{mL})$ de EDTA $\left(1.2 \mathrm{~g} / \mathrm{L}^{*}\right)$} \\
\cline { 2 - 7 } & 0.0 & 0.2 & 0.4 & 0.6 & 0.8 & 1.0 \\
\cline { 2 - 7 } & \multicolumn{7}{|c|}{$\%$ de mortalidade/48h } \\
\hline 100 & 100 & 100 & 100 & 100 & 100 & 100 \\
\hline 50 & 100 & 100 & 100 & 100 & 100 & 100 \\
\hline Branco & 0 & 0 & 0 & 0 & 0 & 40 \\
\hline Efeito na toxicidade & - & $\mathrm{SE}$ & $\mathrm{SE}$ & $\mathrm{SE}$ & $\mathrm{SE}$ & $\mathrm{SE}$ \\
\hline
\end{tabular}

*: 10x CE50,48h para C.dubia

Tabela 29 - Porcentagens de imobilidade de Ceriodaphnia dubia expostas ao solubilizado da amostra de sedimento da estação E2, após o tratamento com tiossulfato de sódio Reservatório de Salto Grande - out/01.

\begin{tabular}{|c|c|c|c|c|c|c|}
\hline \multirow{2}{*}{$\begin{array}{c}\text { Concentração da } \\
\text { amostra (\%) }\end{array}$} & \multicolumn{5}{|c|}{ \%olume de mortalidade/48h } \\
\cline { 2 - 7 } & 0.0 & 0.2 & 0.4 & 0.6 & 0.8 & 1.0 \\
\hline 100 & 100 & 100 & 100 & 100 & 100 & 100 \\
\hline 50 & 100 & 100 & 100 & 100 & 100 & 100 \\
\hline Branco & 0 & 0 & 0 & 0 & 0 & 30 \\
\hline Efeito na toxicidade & - & $\mathrm{SE}$ & $\mathrm{SE}$ & $\mathrm{SE}$ & $\mathrm{SE}$ & $\mathrm{SE}$ \\
\hline
\end{tabular}

* 10x CE50,48h para C.dubia 
Considerando os resultados obtidos com o EDTA, ficou descartada a toxicidade devida aos metais alumínio, bário, cobre, cromo, cádmio, ferro, zinco, chumbo, manganês, níquel e estrôncio. Os resultados obtidos com tiossulfato de sódio, por sua vez, descartaram a influência de agentes oxidantes tais como cloro, ozônio, dióxidos, mono e dicloroaminas, brominas, íons de manganês e de alguns compostos orgânicos hidrofílicos, que, na forma reduzida, tendem a ser menos tóxicos, bem como dos metais catiônicos cádmio, cobre, prata, mercúrio e selênio.

Em relação aos testes com EDTA deve-se considerar que a eficiência do EDTA na remoção dos metais depende não só do pH da solução, do tipo e especiação do metal, da afinidade EDTA/metal vs metal/organismo, como também da presença de outros ligantes na solução. Nesse caso, o sulfeto estaria desempenhando o papel de fase ligante, ou controladora dos metais.

Um outro aspecto importante a ser considerado na interpretação desses resultados em relação à presença/ausência de metais, é que, uma vez que a taxa de complexação é específica para cada metal, alguns metais catiônicos podem não apresentar diminuição da toxicidade no período de duração dos testes $(48 \mathrm{~h})$, devido à baixa taxa de complexação.

Uma evidencia apontada pelos resultados em geral, é que a toxicidade encontrada no sedimento do reservatório de Salto Grande está relacionada com os efeitos fisiológicos da acidez e para o organismo-teste V.fisheri - sistema Microtox, os resultados obtidos mostraram que a acidez foi a principal causa da toxicidade.

No ambiente natural, a associação pH baixo/presença de metais constitui um fator potencial de toxicidade. Existem inúmeras causas, naturais ou não, capazes de alterar o pH de lagos e reservatórios. Atividades de dragagem, produção de ácidos húmicos e fúlvicos via decomposição e as reações redox, especialmente as de oxidação de enxofre, ferro e nitrogênio são responsáveis pela redução do $\mathrm{pH}$, o que pode ser letal para a vida aquática, seja por ação direta ou indireta através da liberação de metais pesados. Com o abaixamento do $\mathrm{pH}$ há uma competição entre os íons metálicos e os íons $\mathrm{H}^{+}$pelos sítios de adsorção/complexação nas paredes celulares dos organismos e, em ambientes muito ácidos, os íons $\mathrm{H}^{+}$vencem essa competição. Nesse caso, a toxicidade se manifesta pelo $\mathrm{pH}$ e não necessariamente pela intoxicação com metais. Essa característica dos sedimentos de produção ácida depende do balanço entre o 
potencial de produção ácida (PPA) e sua capacidade tampão (CT), representados respectivamente pela oxidação de sulfetos e de matéria orgânica e o conteúdo de carbonato do sedimento (FONSECA,1991; SILVÉRIO,1999).

Os valores de $\mathrm{pH}$ no reservatório de Salto Grande no período de estudo variaram entre 5,9 e 10,58 na coluna d'água e 5,96 e 7,16 no fundo, na interface água/sedimento (DORNFELD, 2002). No período de 1998 a 1999, os valores estiverem entre 6,04 e 7,71, embora no período de maior precipitação, os valores tenham atingido 9,9 na superfície. No fundo, na interface água/sedimento, os valores variaram entre 6,04 a 6,61 para 5 das 6 estações analisadas por TONISSI (1999). Esses resultados mostram que a acidez do sedimento/solubilizado não está relacionada com a coluna d'água, que poderia estar sofrendo um processo de acidificação.

Nesse estudo, em relação ao sedimento, os valores de $\mathrm{pH}$ mais baixos foram encontrados nas coletas de ag/00 e nov/00 com variação entre 4,3 e 5,6. Nos meses de fevereiro, abril e maio/00 a variação ficou entre 6,8 e 7,2. Comparando os valores de pH do sedimento total e solubilizado nas diferentes amostragens (Tabela 4, capítulo 1), observa-se uma similaridade entre o pH das duas fases, com exceção de out/01, quando o pH do sedimento total foi próximo de 7 e o do solubilizado foi 4.

As alterações nas condições de oxigenação e potencial redox causadas pelo processo de solubilização desse sedimento provocam um abaixamento no $\mathrm{pH}$, simulando talvez, uma situação passível de acontecer no ambiente, por conta de processos microbiológicos e químicos na interface água/sedimento e no próprio sedimento.

\subsubsection{2 - AIT: Fase III}

Para confirmação da amônia como um possível composto responsável pela toxicidade, a amostra solubilizada da estação E2 foi tratada com a resina zeolita. O teste realizado após o período de contato mostrou redução da toxicidade. Da mesma forma, a análise química realizada com as amostras antes e após o tratamento com a resina, mostrou uma diminuição de $35 \%$ na concentração de amônia. De 3,24 mg.L $\mathrm{L}^{-1}$, a

concentração abaixou para 2,19 mg. $\mathrm{L}^{-1}$. Considerando a redução de $97 \%$ obtida com a amostra solubilizada do reservatório de Rasgão, a eficiência da resina para essa amostra foi quase 3 vezes menor. 
Os testes de toxicidade realizados não mostraram uma relação muito clara entre a redução na concentração da amônia e os efeitos na toxicidade, talvez pelo efeito conjunto da acidez. Os resultados em porcentagens de imobilidade de $C$. dubia para as diferentes concentrações do solubilizado da estação E2 estão apresentados na Tabela 30.

Tabela 30 - Porcentagem de imobilidade de Ceriodaphnia dubia expostas ao solubilizado do sedimento da estação E2 do reservatório de Salto Grande, antes e após o tratamento com a zeolita.

\begin{tabular}{|l|c|c|c||c|c|c|}
\hline \multirow{2}{*}{ Concentração da amostra (\%) } & \multicolumn{3}{|c||}{ Sem zeolita } & \multicolumn{3}{c|}{ Com zeolita } \\
\cline { 2 - 7 } & 100 & 50 & 25 & 100 & 50 & 25 \\
\hline Concentração de amônia (mg.L (1) $^{-1}$ & 3.24 & 1.62 & 0.81 & 2.19 & 1.09 & 0.54 \\
\hline $\mathrm{pH}$ & 3.4 & 4.9 & 6,5 & 7,5 & 7,5 & 7.2 \\
\hline$\%$ de imobilidade & 100 & 100 & 27 & 80 & 6 & zero \\
\hline
\end{tabular}

As porcentagens de imobilidade da amostra pura, sem diluição foram de $100 \%$ sem a resina e $80 \%$ após o contato com a resina. Na amostra sem a resina, a mortalidade foi devida não só à amônia, como também à acidez $(\mathrm{pH} 3,4)$. A redução de $20 \%$ observada na amostra tratada pode estar relacionada apenas com a mudança do $\mathrm{pH}$ para 7,5 e, nesse caso, o restante da toxicidade estaria relacionada com a amônia, ainda presente $\left(2,19 \mathrm{mg} \cdot \mathrm{L}^{-1}\right)$.

A porcentagem de imobilidade na amostra 50\%, sem zeolita, com $\mathrm{pH} 4,9$, foi de 100\%. Considerando a diluição da amostra, a concentração proporcional de amônia foi de 1,62 mg. $\mathrm{L}^{-1}$. Após o contato com a resina, a porcentagem de imobilidade para a mesma concentração de amostra foi de $6 \%$, com pH inicial do teste de 7,5 e final de 7,2 e concentração proporcional de amônia de $1,09 \mathrm{mg} \cdot \mathrm{L}^{-1}$.

As porcentagens de efeito tóxico obtidas nos testes de toxicidade com os brancos (água de cultivo nas mesmas condições das amostras), de cada etapa foram sempre iguais a zero ou inferiores a $10 \%$. 


\subsection{3 - Reservatório de Rasgão}

5.3.3.1 - Considerações sobre a realização do Estudo de Avaliação e Identificação de Toxicidade no reservatório de Rasgão

O estudo de Avaliação e Identificação de Toxicidade realizado no reservatório de Rasgão foi desenvolvido em conjunto com o projeto QualiSed: "Bases Técnicas de Critério de Qualidade de Sedimentos (CQS) - Experimentos de Campo e Laboratório" sob coordenação do Dr Antonio A. Mozeto, da UFSCar e sub-coordenação do Dr Wilson Jardim, da UNICAMP e Dra Gisela Umbuzeiro, da CETESB.

Os resultados da caracterização das represas, a saber, reservatórios Billings, Rasgão, Barra Bonita, Promissão e Bariri, obtidos no primeiro ano de trabalho do referido projeto, mostraram que o reservatório de Rasgão apresentou toxicidade para todas as espécies testadas (Hyalella azteca, Ceriodaphnia dubia, Chironomus xanthus, Vibrio fisheri), indícios de mutagenicidade e ausência da comunidade bentônica. As concentrações de metais totais (cádmio, cobalto, cromo, cobre, níquel, chumbo, zinco), sulfetos volatilizáveis por acidificação (SVA) e metais simultaneamente extraídos ao SVA (cádmio, cobre, níquel, chumbo, zinco) foram superiores às encontradas nos demais reservatórios e, apenas em relação aos compostos orgânicos avaliados, os valores detectados foram inferiores aos encontrados no reservatório Billings (MOZETO, 2001). De acordo com CETESB (2002), a qualidade da água no ponto de monitoramento TIRG02900, próximo à barragem, permaneceu durante o ano de 2001, entre ruim e péssima, estando acima dos padrões de qualidade em relação aos parâmetros OD (oxigênio dissolvido), DBO (demanda bioquímica de oxigênio), $\mathrm{NH}_{3}$, surfactantes, manganês, fenol, fósforo total e coliformes fecais.

Apesar dos estoques relativamente altos de contaminantes tóxicos presentes nos sedimentos desses ambientes, existiu por parte da coordenação do projeto uma preocupação grande com a excessiva carga de matéria orgânica proveniente principalmente de esgotos domésticos não tratados ou mal tratados. A degradação dessa matéria orgânica tem contribuído de forma significativa para o aumento das concentrações de amônia e ácido sulfídrico nos ambientes aquáticos, especialmente nos sedimentos. 
Além do mais, as relações metais/sulfetos mostraram que a fase sulfídrica estaria retendo os metais no sedimento e, portanto, esses metais, embora presentes, não seriam os responsáveis pela toxicidade. Desta forma e, considerando que a identificação dos compostos responsáveis pela toxicidade é um pré-requisito fundamental para o estabelecimento de critérios de qualidade de sedimento (CQS), objetivo principal do projeto QualiSed, a coordenação do projeto decidiu pela realização do estudo de Avaliação e Identificação da Toxicidade nesse reservatório.

O trabalho em equipe permitiu a realização desse estudo utilizando, simultaneamente, a água intersticial (ARAUJO et al, dados não publicados) e o solubilizado extraídos do sedimento. Os resultados aqui apresentados se referem ao estudo de AIT realizado com o solubilizado das amostras de sedimento, coletadas em setembro/01 e dezembro/01. Em setembro/01 os testes de toxicidade antes e após as etapas da fase I foram realizados com Ceriodaphnia dubia e Vibrio fisheri. Em dezembro/01 apenas com C.dubia, para confirmação de alguns resultados.

\subsubsection{2 - Resultados do estudo de AIT - fases I e II}

Os resultados dos testes de toxicidade e análises químicas de ácido sulfídrico, amônia e surfactantes, realizadas com o sedimento total e solubilizado das amostras coletadas em setembro/01 e dezembro/01, durante a realização do estudo de AIT estão apresentadas na Tabela 30.

Tabela 30 - Resultados das análises químicas e dos testes de toxicidade realizados nas amostras de sedimento / solubilizado coletadas no reservatório de Rasgão em setembro (Set/01) e dezembro (Dez/01) de 2001.

\begin{tabular}{|c|c|c|c|c|}
\hline Parâmetros & \multicolumn{2}{|c|}{ Solubilizado } & \multicolumn{2}{c|}{ Sedimento Total } \\
\hline & Set/01 & Dez/01 & Set/01 & Dez/01 \\
\hline Ácido sulfídrico $\left(\mathrm{mg} . \mathrm{L}^{-1}\right)$ & $0,164 \mathrm{mg} . \mathrm{L}^{-1}$ & $0.08 \mathrm{mg} . \mathrm{L}^{-1}$ & & \\
\hline Surfarctantes $\left(\mathrm{mg} . \mathrm{L}^{-1}\right)$ & $0,017 \mathrm{mg} . \mathrm{L}^{-1}$ & $0.280 \mathrm{mg} . \mathrm{L}^{-1}$ & & \\
\hline Amônia $\left(\mathrm{mg} . \mathrm{L}^{-1}\right)$ & $\mathrm{nr}$ & $82 \mathrm{mg} . \mathrm{L}^{-1}$ & & \\
\hline SVA $\left(\mu \mathrm{g} . \mathrm{g}^{-1}\right)$ & $\mathrm{na}$ & $\mathrm{na}$ & 3136 & 3203 \\
\hline Toxicidade $($ C.dubia)* & 35 & 71 & $\mathrm{nr}$ & $\mathrm{nr}$ \\
\hline Toxicidade $(\text { V.fisheri) })^{* *}$ & 0.8 & $\mathrm{nr}$ & $\mathrm{nr}$ & $\mathrm{nr}$ \\
\hline na: não se aplica nr: não realizado *: CE50,48h (\%) **: CE50 20,15min. $(\%)$
\end{tabular}




\section{a) Vibrio fisheri - Sistema Microtox}

Os valores de CE20,15' obtidos nos testes de toxicidade antes e após as etapas da fase I e os efeitos observados na toxicidade da amostra em cada etapa, estão apresentados na Tabela 31.

Tabela 31- Valores de CE20,15' obtidos nos testes de toxicidade com $V$. fischeri com o solubilizado do sedimento coletado no reservatório de Rasgão em setembro/2001, antes e após as diferentes etapas do AIT

\begin{tabular}{|c|c|c|}
\hline Etapas & $\begin{array}{c}\text { CE20, 15' } \\
\text { (intervalo de confiança) }\end{array}$ & $\begin{array}{c}\text { Efeito } \\
\text { na Toxicidade }\end{array}$ \\
\hline T T Inicial & $0,8(0,6-1,0)$ & -- \\
\hline T T Basal & $4.2(3,3-5,5$ & -- \\
\hline Aeração - pHi & $5,1(4,4-5,9)$ & $\mathrm{SE}$ \\
\hline Aeração - pH3 & $2,7(1,0-7,4)$ & SE \\
\hline Aeração - pH11 & $18,3(16,5-20,3)$ & RT \\
\hline Coluna C18 pHi & NT & RT \\
\hline T T Basal & $15,6(14,4-16,8)$ & -- \\
\hline Coluna C18 pH 3 & NT & RT \\
\hline Coluna C18 pH 9 & NT & RT \\
\hline Ajuste pH 3 & $36,4(35,1-37,8)$ & RT \\
\hline Ajuste pH 11 & NT & RT \\
\hline Graduação - pH6 & $2,6(1,0-6,7)$ & AT \\
\hline Graduação - pH8 & $15,2(13,5-17,1)$ & $\mathrm{SE}$ \\
\hline Compostos Suspeitos & \multicolumn{2}{|c|}{ metais / orgânicos / voláteis } \\
\hline
\end{tabular}

Os resultados obtidos nos testes pós-ajuste mostraram diminuição da toxicidade em $\mathrm{pH} 3$ e perda total da toxicidade em $\mathrm{pH} 11$.

Analisadas em conjunto, as etapas de ajuste e ajuste/aeração mostraram que os processos de floculação ou de precipitação, e não degradação, foram responsáveis pela diminuição e mesmo perda da toxicidade. $\mathrm{O}$ aumento na toxicidade observado depois da etapa de aeração, comparado com a etapa de ajuste/pH11, foi causado, provavelmente, pela ressolubilização ou ressuspensão dos flóculos ou precipitados e mostrou que os compostos que estão influenciando a toxicidade não são voláteis. 
O aumento da toxicidade no teste de graduação pH6 indicou possível ação do ácido sulfídrico, embora a análise química tivesse mostrado que a concentração detectada na amostra em setembro/01, de 0,164 mg. $\mathrm{L}^{-1}$, está muito abaixo do valor de CE50, 15' para esse organismo-teste, que é de $86 \mathrm{mg} . \mathrm{L}^{-1}$. Por outro lado, de acordo com SVENSON (1996), a oxidação do $\mathrm{H}_{2} \mathrm{~S}$ para enxofre elementar aumenta em até 5000 vezes a toxicidade para o Microtox, pois o valor de CE50, 15' do enxofre para $V$. fisheri é de $0,0152 \mathrm{mg} . \mathrm{L}^{-1}$. Essas duas formas, presentes no sedimento, são interconvertidas em função de mudanças no potencial redox.

$\mathrm{Na}$ etapa de extração em coluna de $\mathrm{C} 18$, a toxicidade foi eliminada em todos os valores de $\mathrm{pH}$ e, posteriormente recuperada nos eluatos da coluna. Esses resultados indicaram a presença de compostos orgânicos não iônicos como responsáveis pela toxicidade.

A análise realizada por ALMEIDA (2002) nos extratos eluídos das colunas, identificou os seguintes compostos: colestanol (CAS\# 80977); caprolactan (CAS\# 105602); 2-benzotiazolinone (CAS\# 934349); 4-nonil-fenol (CAS\# 104405); 4-(1,1,3,3tetrametilbutilfenol (CAS\# 140669); ftalatos (CAS\# 84695, CAS\# 84742, CAS\# 131180, CAS\# 27554263).

Uma vez que esses compostos não foram quantificados, não foi possível relacionar de fato, a presença deles com a toxicidade. O valor de CE50, 15'do composto benzotiazol é de $1,9 \mathrm{mg} / \mathrm{l}$ e do cyclohexanone-oxime um composto próximo do caprolactan (também conhecido como cyclohexanone iso-oxime) é de $22,1 \mathrm{mg} . \mathrm{L}^{-1}$ de acordo com KAISER (s.d.).

O caprolactan é utilizado com matéria prima na indústria de nylon. Os ftalatos são característicos da presença de plásticos e alguns também são usados como repelentes de insetos. Os fenóis são característicos da presença de detergentes, sendo gerados durante o processo de degradação dos mesmos.

O colestanol é característico da presença de fezes e bile humana (http://www.merck.com/pubs/mmanual/section2/chapter16/16b.htm). Os compostos colestanol, coprostanol, estradiol e androsterone já foram detectados em sedimento do estuário de Tan-Shui e na água e sedimento dos estuários Tyne e Tees, Reino Unido. A presença de hormônios no ambiente aquático, especificamente nos sedimentos é um indicativo de contaminação antiga por esgotos. Esse composto se acumula em vários 
órgãos devido a deficiência de uma enzima hepática (27-hidroxilase), provocando arteriosclerose prematura (THOMAS et al. 1999)

De acordo com ALMEIDA (2002), um recente trabalho publicado por um grupo de cientistas de vários centros do USGS (United States Geological Survey) dos Estados Unidos também encontrou coprostanol (um esteróide semelhante ao colestanol) e o 4nonilfenol em cursos d'água dos Estados Unidos. Embora o 4-nonilfenol estivesse presente em grandes proporções, o principal contaminante foi o coprostanol. KHIM et al (1999) identificaram os compostos nonilfenol e octilfenol, no lago Shiwwa, na costa oeste da Coréia.

Em relação aos compostos orgânicos, a constatação da presença de hormônios nos ambientes aquáticos mostra, do ponto de vista ambiental, a importância de outras classes de compostos químicos, além dos agrotóxicos, PCBs e PAHs.

A perda da toxicidade em $\mathrm{pH} 11$ pode indicar a presença de surfactantes ou metais catiônicos. Em relação aos surfactantes, a comparação do resultado pós-ajuste com o resultado pós-tratamento com EDTA, confirma ou não essa evidencia. Em caso positivo, deve ocorrer redução simultânea da toxicidade, devido à afinidade EDTA/ surfactantes. A concentração de surfactantes detectada pela análise química foi de 0.017 $\operatorname{mg} . L^{-1}$.

Em relação aos metais, embora presentes, os resultados da extração simultânea metais/SVA, apresentados na Tabela 37 mostraram um controle dos metais pelo sulfeto, possibilidade essa confirmada pelos testes de toxicidade com $C$. dubia realizados póstratamento com EDTA, em que não ocorreu alteração da toxicidade.

$\mathrm{Da}$ mesma forma, se compararmos as concentrações potencialmente biodisponíveis dos metais cobre, níquel, chumbo e zinco no solubilizado com os respectivos valores de CE50, 15' para Vibrio fisheri reportados por SVENSON et al. (1996), apresentados na Tabela 32, observa-se que dentre os metais, apenas o zinco está presente em concentração superior ao valor de efeito agudo. 
Tabela 32 - Comparação das concentrações de metais presentes no solubilizado com os valores de CE50, 15'para $V$. fisheri.

\begin{tabular}{|l|c|c|c|c|c|}
\hline \multirow{2}{*}{ Rasgão } & \multicolumn{5}{|c|}{ Metais $\left(\mathrm{mg}^{-} \mathrm{L}^{-1}\right)$} \\
\cline { 2 - 6 } & $\mathrm{Cd}$ & $\mathrm{Cu}$ & $\mathrm{Ni}$ & $\mathrm{Pb}$ & $\mathrm{Zn}$ \\
\hline Solubilizado & $\mathrm{nd}$ & 0.048 & 0.057 & 0.083 & $\mathbf{1 . 8 8}$ \\
\hline CE50, $15^{\prime} *$ & 41,4 & 0,384 & 251 & 0,46 & $\mathbf{1 , 0 7}$ \\
\hline
\end{tabular}

*: SVENSON (1996)

\section{b) Ceriodaphnia dubia}

Os valores de CE50 48h e/ou porcentagens de imobilidade obtidos nos testes de toxicidade antes e após as etapas da fase I, com as amostras coletadas em setembro/01 e dezembro/01 e os efeitos observados na toxicidade da amostra estão apresentados nas Tabelas 33, 34, 35 e 39. Nas Figuras 21, 22 e 23 estão representados os valores de CE50, 48h das diferentes etapas. Amostras não tóxicas foram indicadas por CE50 $>100$.

Na Tabela 40 estão apresentados os efeitos das diferentes etapas na toxicidade do sedimento coletado em setembro/01 e dezembro/01 e os possíveis agentes químicos suspeitos.

Setembro/01: os resultados obtidos nos testes com C.dubia, com a amostra coletada em setembro/01 (Tabela 33 e Figuras 21 e 22) mostraram redução da toxicidade nos testes pós-ajuste em $\mathrm{pH} 3$ e pós-aeração em todos os valores de $\mathrm{pH}$. A redução da toxicidade nas etapas de ajuste/aeração em $\mathrm{pH} 3$ sugere a presença de um composto ácido volátil ou oxidável, que no caso de sedimentos, poderia ser o ácido sulfídrico. No entanto, a diminuição da toxicidade nos testes de graduação, pH6 elimina essa possibilidade, pois, nesse caso a toxicidade deveria ter aumentado e não diminuído. Em pH11 houve um aumento da toxicidade nos testes pós-ajuste.

Os testes com as amostras pós-coluna apresentaram redução de toxicidade em pH3, mas essa toxicidade não foi recuperada nos extratos eluídos com diclorometano e metanol. 
Tabela 33 - Valores de CE50,48h obtidos nos testes de toxicidade aguda com Ceriodaphnia dubia com a amostra solubilizada do sedimento coletado no reservatório de Rasgão em setembro/01, antes e após as diferentes etapas do AIT

\begin{tabular}{|c|c|c|c|c|c|c|c|}
\hline \multirow{2}{*}{\multicolumn{2}{|c|}{ Etapas }} & \multicolumn{5}{|c|}{$\begin{array}{c}\text { Concentração } \\
\% \text { de Imobilidade }\end{array}$} & \multirow{3}{*}{$\begin{array}{l}\text { Efeito na } \\
\text { Toxicidade }\end{array}$} \\
\hline & & \multirow{2}{*}{$\frac{100}{100}$} & \multirow{2}{*}{$\frac{50}{100}$} & \multirow{2}{*}{$\begin{array}{c}25 \\
\mathbf{0}\end{array}$} & \multirow{2}{*}{$\begin{array}{l}12 \\
--\end{array}$} & \multirow{2}{*}{$\frac{\text { CE50 }}{35 \%(--)}$} & \\
\hline T T Inicial & pHi (7.3) & & & & & & \\
\hline \multicolumn{2}{|c|}{ Graduação de pH $\mathrm{pH} 6$} & 100 & 0 & 0 & -- & $71 \%(--)$ & RT \\
\hline & $\mathrm{pH} 7$ & 100 & 100 & 0 & -- & $35 \%(--)$ & -- \\
\hline & $\mathrm{pH} 8$ & 100 & 78 & 0 & -- & 41 & SE \\
\hline T T Base & pHi (7.3) & 100 & 100 & $\mathbf{0}$ & -- & $35 \%(--)$ & -- \\
\hline \multirow[t]{2}{*}{ Ajuste de pH } & $\mathrm{pH} 3$ & 78 & 0 & 0 & -- & $78 \%$ & RT \\
\hline & $\mathrm{pH} 11$ & 100 & 100 & 100 & -- & $<25 \%$ & AT \\
\hline \multirow[t]{3}{*}{ Aeração/ar } & $\mathrm{pH} 3$ & 0 & 0 & 0 & -- & NT & RT \\
\hline & $\mathrm{pH} \mathrm{i}$ & 100 & 0 & 0 & -- & $71 \%(--)$ & RT \\
\hline & $\mathrm{pH} 11$ & 89 & 0 & 0 & -- & $73 \%(--)$ & RT \\
\hline T T Base & pHi (7.3) & 100 & 11 & $\mathbf{0}$ & - & $65 \%(56,6-75,7)$ & -- \\
\hline \multirow[t]{3}{*}{ Coluna C18 } & $\mathrm{pH} 3$ & 50 & 11 & 0 & -- & $100 \%$ & RT \\
\hline & $\mathrm{pH} \mathrm{i}$ & 100 & 90 & 0 & -- & $38 \%(33-44,1)$ & AT \\
\hline & $\mathrm{pH} 11$ & 100 & 0 & 0 & -- & $71 \%(--)$ & SE \\
\hline
\end{tabular}

RT: redução da toxicidade

SE: sem efeito

AT: aumento da toxicidade 


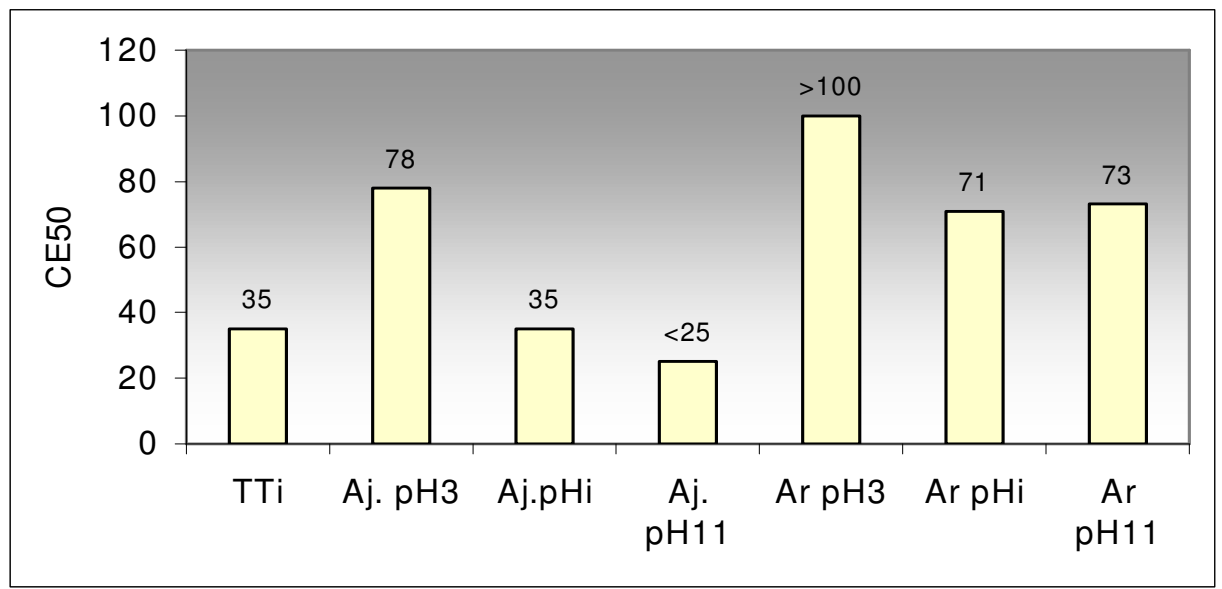

Figura 21 - Valores de CE50, 48h obtidos nos testes de toxicidade aguda com Ceriodaphnia dubia antes e após as etapas do estudo de AIT realizado com o solubilizado do sedimento coletado no Reservatório Rasgão em setembro/01.

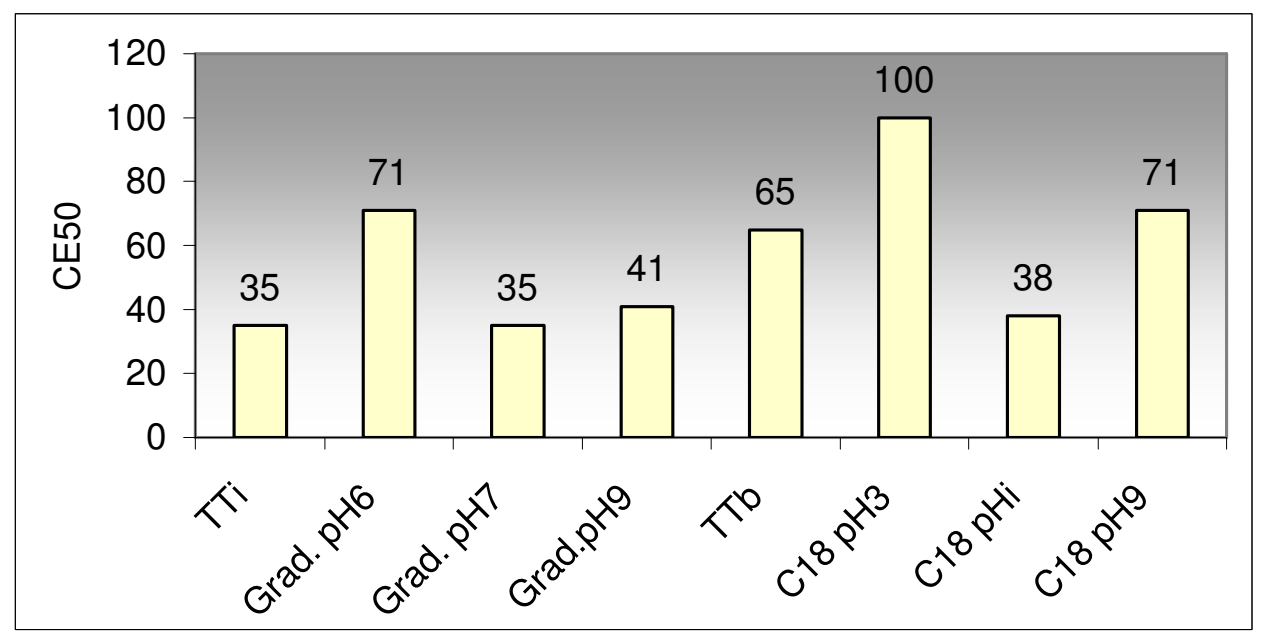

Figura 22 - Valores de CE50, 48h obtidos nos testes de toxicidade aguda com Ceriodaphnia dubia antes e após as etapas do estudo de AIT realizado com o solubilizado do sedimento coletado no Reservatório Rasgão em setembro/01.

Dezembro/01: Os resultados dos testes de toxicidade antes e após as etapas do estudo de AIT realizados com essa amostra confirmaram os resultados da primeira coleta, nos testes de graduação (redução da toxicidade em $\mathrm{pH}$ 6), ajuste (aumento da toxicidade em pH11) e aeração (redução total da toxicidade em pH3). Os testes de aeração com nitrogênio mostraram que parte da toxicidade encontrada é devida a compostos ácidos voláteis (Tabela 34 e Figura 23). 
Tabela 34 - Valores de CE50,48h obtidos nos testes de toxicidade aguda com Ceriodaphnia dubia com a amostra solubilizada do sedimento coletado no reservatório de Rasgão em dezembro/01, antes e após as diferentes etapas do AIT.

\begin{tabular}{|c|c|c|c|c|c|c|c|}
\hline \multirow{3}{*}{ Etapas } & \multirow{3}{*}{$\mathrm{pH}$} & \multicolumn{5}{|c|}{ Concentração (\%) } & \multirow{3}{*}{$\begin{array}{c}\text { Efeito na } \\
\text { Toxicidade }\end{array}$} \\
\hline & & \multicolumn{5}{|c|}{$\%$ de Imobilidade } & \\
\hline & & 100 & 50 & 25 & 12 & CE50 & \\
\hline T T Inicial & pHi (7.3) & 100 & $\mathbf{0}$ & $\mathbf{0}$ & $\mathbf{0}$ & $71 \%(--)$ & -- \\
\hline \multirow[t]{3}{*}{ Graduação de pH } & $\mathrm{pH} 6$ & 90 & 0 & 0 & 0 & $74 \%(--)$ & SE \\
\hline & $\mathrm{pH} 7$ & 100 & 0 & 0 & 0 & $71 \%(--)$ & - \\
\hline & $\mathrm{pH} 9$ & 100 & 0 & 0 & 0 & $71 \%(--)$ & $\mathrm{SE}$ \\
\hline T T Base & pHi (7.3) & 100 & $\mathbf{0}$ & $\mathbf{0}$ & $\mathbf{0}$ & $71 \%(--)$ & -- \\
\hline \multirow[t]{3}{*}{ Ajuste de pH } & $\mathrm{pH} 3$ & 100 & 0 & 0 & 0 & $71 \%(--)$ & SE \\
\hline & $\mathrm{pH} \mathrm{i}$ & 100 & 0 & 0 & 0 & $71 \%(--)$ & - \\
\hline & pH 11 & 100 & 30 & $\mathbf{0}$ & $\mathbf{0}$ & $56 \%(）$ & AT \\
\hline \multirow[t]{3}{*}{ Aeração/ar } & pH 3 & 11 & $\mathbf{0}$ & $\mathbf{0}$ & $\mathbf{0}$ & $>100 \%$ & RT \\
\hline & $\mathrm{pH} \mathrm{i}$ & 100 & 0 & 0 & 0 & $71 \%(--)$ & SE \\
\hline & pH 11 & 100 & 0 & 0 & 0 & $71 \%(--)$ & $\mathrm{SE}$ \\
\hline \multirow[t]{3}{*}{ Aeração/nitrogênio } & pH 3 & $\mathbf{0}$ & $\mathbf{0}$ & $\mathbf{0}$ & $\mathbf{0}$ & NT & RT \\
\hline & $\mathrm{pH} \mathrm{i}$ & 33 & 0 & 0 & 0 & $>100 \%$ & $\mathrm{RT}$ \\
\hline & $\mathrm{pH} 11$ & 100 & 0 & 0 & 0 & $71 \%(--)$ & SE \\
\hline T T Base & pHi (7.3) & 100 & $\mathbf{0}$ & $\mathbf{0}$ & $\mathbf{0}$ & $71 \%(--)$ & - \\
\hline \multirow[t]{3}{*}{ Coluna C18 } & $\mathrm{pH} 3$ & 80 & 0 & 0 & 0 & $77 \%(--)$ & SE \\
\hline & $\mathrm{pH} \mathrm{i}$ & 100 & 0 & 0 & 0 & $71 \%(--)$ & SE \\
\hline & $\mathrm{pH} 11$ & 100 & 0 & 0 & 0 & $71 \%(--)$ & SE \\
\hline
\end{tabular}




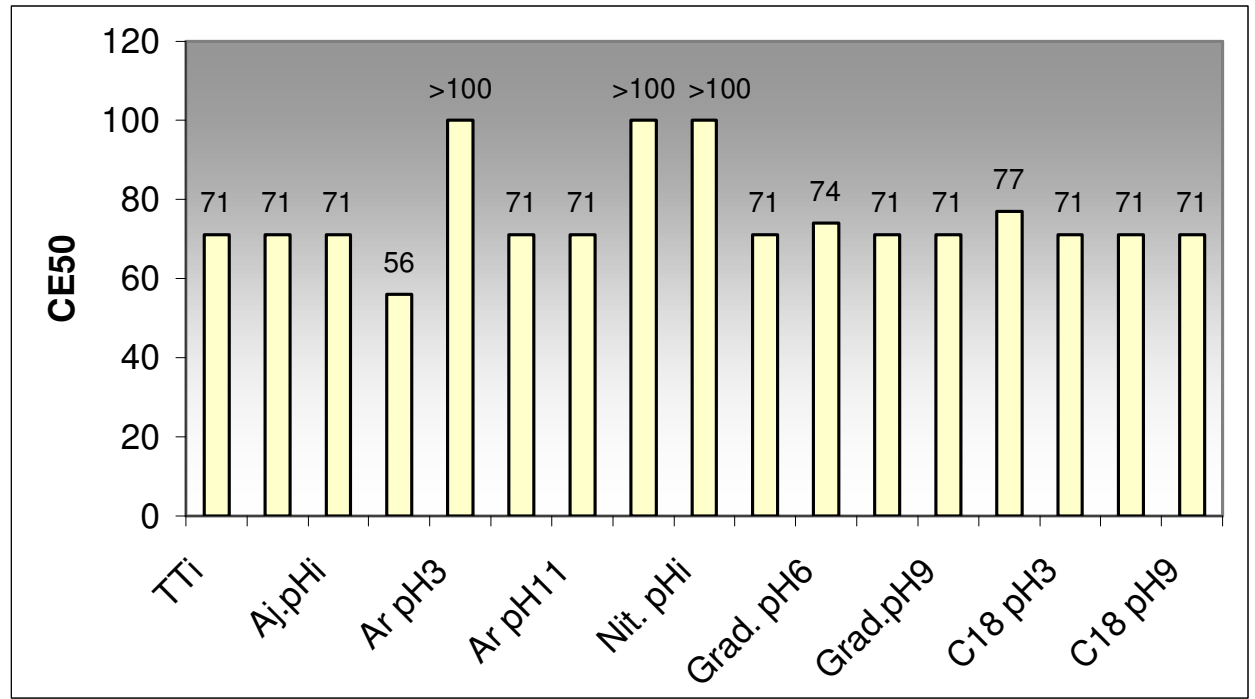

Figura 23 - Valores de CE50, 48h obtidos nos testes de toxicidade aguda com Ceriodaphnia dubia antes e após as etapas do estudo de AIT realizado com o solubilizado do sedimento coletado no Reservatório Rasgão em dezembro/01.

O aumento da toxicidade no teste pós-ajuste $\mathrm{pH} 11$, associada aos resultados do teste de graduação e aeração indica que a amônia, e não o ácido sulfídrico, é o responsável pela toxicidade. Nesse caso, a redução e a perda da toxicidade em pH3 nos testes pós-ajuste e pós-aeração poderia ser explicada pelo fato de que a amônia é menos tóxica em pH baixo.

A comparação dos resultados de toxicidade com os resultados da análise de amônia (Tabela 30) confirmou a hipótese da amônia ser um dos compostos responsáveis pela toxicidade nos testes com Ceriodaphnia dubia. Considerando as diferenças na dissociação entre as formas $\mathrm{NH}_{4}$ (menos tóxica) e $\mathrm{NH}_{3}$ (mais tóxica), em pH 7,5, a concentração de $\mathrm{NH}_{3}$ no solubilizado, durante a realização os testes, foi de 1,6 mg. $\mathrm{L}^{-1}$, estando, portanto, dentro da faixa de valores tóxicos. $\left(0,78 \mathrm{mg} . \mathrm{L}^{-1}, 1,73\right.$ e 2,88 mg.L $L^{-1}$ ), reportados por EPA (1991) e ANKLEY et al. (1990).

Vários estudos de AIT com sedimentos têm encontrado resultados semelhantes, onde a amônia é o único ou um dos compostos responsáveis pela toxicidade. ANKLEY \& SCHUBAUER-BERIGAN (1995), realizaram uma revisão sobre os procedimentos de AIT com sedimentos e, dos 16 trabalhos relacionados, seis identificaram a amônia como composto tóxico.

Em relação aos testes com a coluna de C18, os resultados foram semelhantes, aos obtidos com a amostra coletada em setembro/01: redução da toxicidade em pH 3 
sem recuperação no eluato. A não recuperação da toxicidade no eluato sugere três possibilidades: 1) a coluna funcionou apenas com um filtro, retendo os tóxicos por mecanismo de adsorção e não troca iônica; 2) redução devida apenas ao ajuste de pH , uma vez que os resultados dos testes pós-ajuste foram semelhantes; 3) a espécie Ceriodaphnia dubia não apresenta sensibilidade aos compostos orgânicos colestanol (CAS\# 80977); caprolactam (CAS\# 105602); 2-benzotiazolinone (CAS\# 934349); 4nonil-fenol (CAS\# 104405); 4-(1,1,3,3-tetrametilbutilfenol (CAS\# 140669); ftalatos (CAS\# 84695, CAS\# 84742, CAS\# 131180, CAS\# 27554263) detectados pela análise de cromatografia (ALMEIDA, 2002)

Nos testes de toxicidade realizados após o tratamento com EDTA (Tabela 35) a toxicidade permaneceu inalterada, mostrando que os metais, apesar de presentes, não foram os compostos responsáveis pela toxicidade.

Tabela 35 - Porcentagens de imobilidade de Ceriodaphnia dubia expostas ao solubilizado da amostra de sedimento coletada no reservatório de Rasgão em dezembro/01, após o tratamento com EDTA, em testes de toxicidade aguda.

\begin{tabular}{|c|c|c|c|c|c|c|}
\hline \multirow{4}{*}{$\begin{array}{l}\text { Concentração } \\
\text { Amostra (\%) }\end{array}$} & \multicolumn{6}{|c|}{$\%$ de mortalidade $/ 48 \mathrm{~h}$} \\
\hline & \multicolumn{6}{|c|}{ Volume $(\mathrm{mL})$ de EDTA $(1.2 \mathrm{~g} / \mathrm{L}) *$} \\
\hline & 0.0 & 0.2 & 0.4 & 0.6 & 0.8 & 1.0 \\
\hline & -- & $(0.24 \mathrm{~g} / \mathrm{l})$ & $(0.48 \mathrm{~g} / \mathrm{l})$ & $(0.72 \mathrm{~g} / 1)$ & $(0.96 \mathrm{~g} / \mathrm{l})$ & $(0.12 \mathrm{gl})$ \\
\hline 100 & 100 & 100 & 100 & 100 & 100 & 100 \\
\hline Branco & zero & zero & zero & zero & zero & 100 \\
\hline $\begin{array}{l}\text { Efeito na } \\
\text { toxicidade }\end{array}$ & -- & SE & SE & SE & SE & -- \\
\hline
\end{tabular}

*: 10x CE50,48h para C.dubia $\quad$ SE: sem efeito

Os resultados da análise de extração simultânea SVA/metais, apresentados na Tabela 37, confirmaram essa evidencia. Na Tabela 36 estão apresentadas as concentrações de metais e SVA simultaneamente extraídos das amostras de sedimento coletadas em setembro/01 e outubro/01. 
Tabela 36- Concentração em $\left(\mu \mathrm{g} . \mathrm{g}^{-1}\right)$ dos metais e sulfetos (SVA) simultaneamente extraídos das amostras de sedimento coletadas no reservatório e Rasgão em setembro/01 e dezembro/01.

\begin{tabular}{|c|c|c|c|c|c|c|}
\hline \multirow{2}{*}{ Período } & \multicolumn{5}{|c|}{ Metais $\left(\mu \mathrm{g} \cdot \mathrm{g}^{-1}\right)$} & SVA \\
\cline { 2 - 6 } & $\mathrm{Cd}$ & $\mathrm{Cu}$ & $\mathrm{Ni}$ & $\mathrm{Pb}$ & $\mathrm{Zn}$ & $\left(\mu \mathrm{g} \cdot \mathrm{g}^{-1}\right)$ \\
\hline Setembro/01 & 6 & 3,5 & 45 & 32 & 961 & 3136 \\
\hline Dezembro/01 & 3 & 179 & 50 & 92 & 982 & 3203 \\
\hline
\end{tabular}

Tabela 37 - Relações [ $\sum$ MSE]-SVA e [ $\sum$ MSE]/SVA para as amostras de sedimento coletadas no reservatório de Rasgão em setembro/01 e dezembro/01.

\begin{tabular}{|c|c|c|c|c|c|}
\hline Sedimento & $\begin{array}{c}{\left[\sum \mathrm{MSE}\right.} \\
(\mathrm{mM})\end{array}$ & $\begin{array}{c}\text { SVA } \\
(\mathrm{mM})\end{array}$ & {$[\Sigma \mathrm{MSE}]-\mathrm{SVA}$} & {$\left[\sum \mathrm{MSE}\right] / \mathrm{SVA}$} & $\begin{array}{c}\text { Predição de } \\
\text { Toxicidade* }\end{array}$ \\
\hline Setembro/01 & 15.7 & 98 & -82.3 & 0.16 & Não Tóxico \\
\hline Dezembro/01 & 19.2 & 100.1 & -81 & 0.19 & Não Tóxico \\
\hline
\end{tabular}

*:[ $\Sigma$ MSE]-SVA $>0$ : presença de toxicidade $\left[\sum M S E\right]-S V A<0$ : ausência de toxicidade

[ $\Sigma \mathrm{MSE}] / \mathrm{SVA}>1$ : presença de toxicidade $\left[\sum \mathrm{MSE}\right] / \mathrm{SVA}<1$ ausência de toxicidade

As concentrações dos metais $\mathrm{Cd}, \mathrm{Cu}, \mathrm{Ni}, \mathrm{Pb}$ e $\mathrm{Zn}$, encontradas no solubilizado estão apresentadas na Tabela 38. Os destaques em negrito correspondem às concentrações acima dos valores de CE50,48h, para a espécie Ceriodaphnia silvestrii e que poderiam estar causando a toxicidade detectada nos testes, não fosse o controle exercido pelo sulfeto.

Tabela 38 - Valores das concentrações de metais encontradas no solubilizado das amostras de sedimento coletadas no reservatório de Rasgão outubro/01

\begin{tabular}{|c|c|c|c|c|c|}
\hline \multirow{2}{*}{ Rasgão } & \multicolumn{5}{|c|}{ Metais $\left(\mathrm{mg.L}^{-1}\right)$} \\
\cline { 2 - 6 } & $\mathrm{Cd}$ & $\mathrm{Cu}$ & $\mathrm{Ni}$ & $\mathrm{Pb}$ & $\mathrm{Zn}$ \\
\hline Solubilizado & $\mathrm{nd}$ & $\mathbf{0 . 0 4 8}$ & 0.057 & $\mathbf{0 . 0 8 3}$ & $\mathbf{1 . 8 8}$ \\
\hline CE50,48h * & 0.062 & $0.025-011$ & - & 0.05 & 0.42 \\
\hline
\end{tabular}

* dados de OLIVEIRA-NETO (1999); MASUTTI (2001): OLIVEIRA-NETO et al (2002)

Quanto ao tratamento com tiossulfato de sódio (Tabela 39), os resultados mostraram redução da toxicidade em duas das concentrações utilizadas. Uma vez que não ocorreu redução simultânea da toxicidade nos testes com EDTA, esse resultado 
indicou a influência de compostos oxidantes, tais como cloro e ozônio, por exemplo, e alguns orgânicos hidrofílicos na toxicidade.

Tabela 39 - Porcentagens de imobilidade de Ceriodaphnia dubia expostas ao solubilizado da amostra de sedimento coletada no reservatório de Rasgão em dezembro01, após o tratamento com tiossulfato de sódio.

\begin{tabular}{|c|c|c|c|c|c|c|}
\hline \multirow{2}{*}{$\begin{array}{c}\text { Concentração da } \\
\text { Amostra (\%) }\end{array}$} & \multicolumn{5}{|c|}{ \%olume de mortalidade $/ 48 \mathrm{~h}$ de tiossulfato de sódio $(9 \mathrm{~g} / \mathrm{L})$} & $*$ \\
\cline { 2 - 7 } & 0.0 & 0.2 & 0.4 & 0.6 & 0.8 & 1.0 \\
& -- & $(0.18 \mathrm{~g} / \mathrm{l})$ & $(0.36 \mathrm{~g} / \mathrm{l})$ & $(0.54 \mathrm{~g} / \mathrm{l})$ & $(0.72 \mathrm{~g} / \mathrm{l})$ & $(0.9 \mathrm{~g} / \mathrm{l})$ \\
\hline 100 & 100 & 100 & 100 & $\mathbf{5 0}$ & zero & 100 \\
\hline Branco & zero & zero & zero & zero & zero & 40 \\
\hline Efeito na toxicidade & -- & $\mathrm{SE}$ & $\mathrm{SE}$ & $\mathbf{R T}$ & $\mathbf{R} T$ & -- \\
\hline
\end{tabular}

*: 10x CE50,48h para C.dubia $\quad$ SE: sem efeito $\quad$ RT: redução da toxicidade

Na Tabela 40 estão apresentados os resultados das diferentes etapas, em termos de efeito final na toxicidade, obtidos com as amostras coletadas no reservatório de Rasgão em setembro/01 e dezembro/01 e os possíveis tóxicos responsáveis pela toxicidade.

Considerando as diferentes etapas do estudo de AIT, os resultados obtidos indicaram que os compostos ácidos voláteis (ácido sulfídrico), os compostos orgânicos não iônicos e amônia foram os possíveis compostos responsáveis pela toxicidade detectada nos testes realizados com V.fisheri, sistema Microtox e C. dúbia para o sedimento do reservatório de Rasgão. 
Tabela 40 - Efeitos causados pelas diferentes etapas do estudo de AIT, na toxicidade das amostras de sedimento coletadas em setembro/01 e dezembro/01, no reservatório de Rasgão e possíveis tóxicos suspeitos.

\begin{tabular}{|c|c|c|c|c|c|}
\hline AIT / Etapas & $\mathrm{pH}$ & $\begin{array}{c}\text { Efeito na } \\
\text { toxicidade } \\
\text { setembro/01 }\end{array}$ & $\begin{array}{l}\text { Composto } \\
\text { suspeito }\end{array}$ & $\begin{array}{c}\text { Efeito na } \\
\text { toxicidade } \\
\text { dezembro/01 }\end{array}$ & $\begin{array}{c}\text { Composto } \\
\text { suspeito }\end{array}$ \\
\hline \multirow[t]{3}{*}{ Graduação } & PH6 & RT & & SE & \\
\hline & $\mathrm{pH} 7$ & - & & - & \multirow[t]{2}{*}{ amônia } \\
\hline & $\mathrm{pH} 9$ & RT & & $\mathrm{SE}$ & \\
\hline \multirow[t]{3}{*}{ Ajuste } & $\mathrm{pH} 3$ & RT & \multirow{3}{*}{ amônia } & SE & \multirow{3}{*}{ amônia } \\
\hline & $\mathrm{pHi}$ & - & & - & \\
\hline & $\mathrm{pH} 11$ & AT & & $\mathrm{AT}$ & \\
\hline \multirow[t]{3}{*}{ Aeração } & $\mathrm{pH} 3$ & RT & \multirow{3}{*}{$\begin{array}{c}\text { compostos } \\
\text { voláteis }\end{array}$} & RT & \multirow{3}{*}{$\begin{array}{c}\text { acidos } \\
\text { voláteis } \\
\text { amônia }\end{array}$} \\
\hline & $\mathrm{pHi}$ & RT & & $\mathrm{SE}$ & \\
\hline & $\mathrm{pH} 11$ & RT & & SE & \\
\hline \multirow[t]{3}{*}{ Coluna C18 } & $\mathrm{pH} 3$ & RT & \multirow{3}{*}{$\begin{array}{l}\text { orgânicos } \\
\text { ácidos }\end{array}$} & RT & \multirow{3}{*}{$\begin{array}{l}\text { orgânicos } \\
\text { ácidos }\end{array}$} \\
\hline & $\mathrm{pHi}$ & AT & & SE & \\
\hline & $\mathrm{pH} 9$ & SE & & SE & \\
\hline EDTA & $\mathrm{pHi}$ & $\mathrm{NC}$ & -- & SE & - \\
\hline $\begin{array}{l}\text { Tiossulfato de } \\
\text { sódio }\end{array}$ & $\mathrm{pHi}$ & $\mathrm{NC}$ & - & RT & \\
\hline
\end{tabular}

Dentre esses compostos, a amônia foi confirmada como o principal composto responsável pela toxicidade causada para Ceriodaphnia dubia, como comprovaram os resultados obtidos na fase III, através do tratamento da amostra com a resina zeólita.

Nos resultados obtidos por ARAÚJO et al (dados não publicados) com a água intersticial da mesma amostra de sedimento, a amônia também foi identificada e confirmada, como o principal composto tóxico responsável pela toxicidade.

\subsubsection{3 - Resultados do Estudo de AIT-Fase III}

Além da confirmação pela análise química, esses resultados foram confirmados com a resina zeólita, que tem afinidade por amônia.

No teste de toxicidade aguda com Ceriodaphnia dubia (Tabela 41), realizado após o período de contato com a resina, a toxicidade foi totalmente eliminada. Da mesma forma, a análise química realizada com as amostras antes e após o tratamento 
com a resina, mostrou uma diminuição de $97 \%$ na concentração de amônia. De 82 $\mathrm{mg} . \mathrm{L}^{-1}$, a concentração baixou para $2,0 \mathrm{mg} . \mathrm{L}^{-1}$.

Tabela 41 - Porcentagem de imobilidade de Ceriodaphnia dubia nos testes de toxicidade aguda realizados com o solubilizado da amostra de sedimento, antes e após o tratamento com a zeólita.

\begin{tabular}{|c|c|c|c|c|c|c|c|}
\hline \multirow{3}{*}{\multicolumn{2}{|c|}{ Tratamento }} & \multirow{2}{*}{\multicolumn{5}{|c|}{$\begin{array}{c}\text { Concentrações } \\
\% \text { de Imobilidade }\end{array}$}} & \multirow{4}{*}{$\begin{array}{c}\begin{array}{c}\text { Efeito na } \\
\text { toxicidade }\end{array} \\
-\end{array}$} \\
\hline & & & & & & & \\
\hline & & 100 & 50 & 25 & 12.5 & 6.25 & \\
\hline Sem zeólita & $\mathrm{pH} 7.7$ & 100 & 100 & 0.0 & 0.0 & 0.0 & \\
\hline Com zeólita & pH 8 & 0.0 & 0.0 & 0.0 & 0.0 & 0.0 & RT \\
\hline
\end{tabular}




\section{6 - CONCLUSÕES}

A caracterização físico-química do sedimento dos reservatórios de Barra Bonita e Salto Grande revelou um sedimento reduzido e anóxico, com alta carga de nutrientes.

A comparação dos dois ambientes mostrou, para os locais analisados, uma tendência do sedimento do reservatório de Salto Grande a uma maior acidificação, refletida também na solubilização das amostras.

Os sedimentos dos reservatórios de Salto Grande e de Barra Bonita causaram toxicidade aguda ou crônica em todo o período de estudo e essa toxicidade detectada mostra a deterioração da qualidade dos mesmos.

O solubilizado foi tão ou mais tóxico que o sedimento total, confirmando a viabilidade e adequabilidade da utilização do mesmo para avaliar os efeitos da ressuspensão ou da difusão de contaminantes do sedimento para a coluna d'água.

O estudo de Avaliação e Identificação da Toxicidade realizado no reservatório de Barra Bonita indicou os metais como uma das classes de compostos químicos responsáveis pela toxicidade e as relações entre as concentrações dos metais e dos sulfetos extraídos por acidificação - SVA, confirmaram essa evidência.

O estudo de Avaliação e Identificação da Toxicidade realizado no reservatório de Salto Grande mostrou que a acidez foi a principal causa da toxicidade detectada para o organismo-teste Vibrio fisheri, seja por ação direta da própria acidez ou ação indireta, como fator indutor de reações de remobilização de contaminantes, especialmente metais, a partir do sedimento. 
Além da acidez, é possível que a amônia possa ter tido alguma influência na toxicidade encontrada no sedimento do reservatório de Salto Grande para Ceriodaphnia dubia, independente da sua dissociação.

A Avaliação e Identificação da Toxicidade realizada no reservatório de Rasgão indicou que os compostos ácidos voláteis, os compostos orgânicos não iônicos, e amônia foram os responsáveis pela toxicidade detectada nos testes com V.fisheri, sistema Microtox e Ceriodaphnia dubia.

Dentre os compostos apontados na fase I, as análises de identificação da fase II identificaram os compostos orgânicos Cholestanol (CAS\# 80977); Caprolactam (CAS\# 105602); 2-benzotiazolinone (CAS\# 934349); 4-nonil-fenol (CAS\# 104405); 4-(1,1,3,3tetrametilbutilfenol (CAS\# 140669); ftalatos (CAS\# 84695, CAS\# 84742, CAS\# 131180, CAS\# 27554263 e amônia nas amostras do solubilizado desse sedimento.

O tratamento com a resina zeólita (fase III) foi eficiente na remoção da toxicidade do sedimento do reservatório de Rasgão, confirmando a responsabilidade da amônia na toxicidade desse ambiente.

As relações entre as concentrações de metais e sulfetos extraídos por acidificação - SVA revelaram que existe um excesso de SVA nos sedimentos dos reservatórios de Salto Grande e Rasgão, de forma que os metais presentes estariam indisponíveis e, portanto, não disponíveis para causar efeitos tóxicos. No entanto, a associação $\mathrm{pH}$ baixo e presença de metais pode constituir um fator potencial de toxicidade para o reservatório de Salto Grande.

O estudo de Avaliação e Identificação da Toxicidade - AIT, aplicada nas amostras de sedimento dos reservatórios de Barra Bonita, Salto Grande e Rasgão permitiu identificar os principais compostos associados à toxicidade desses ambientes, sendo, portanto, uma metodologia a ser incorporada na caracterização dos ecossistemas aquáticos. 


\section{7 - CONSIDERAÇÕES FINAIS}

A avaliação dos sedimentos através de testes de toxicidade é importante e necessária, pois estes definem qual a porção biodisponível de um contaminante, uma vez que essa porção pode ser muito diferente da quantidade total determinada pelas análises químicas. Em locais contaminados por mais de um composto ou por uma mistura de compostos químicos, os testes de toxicidade são as únicas ferramentas capazes de avaliar o potencial tóxico dos sedimentos.

Não existe um método único e simples que possa medir todos os impactos de sedimentos contaminados em todo o tempo e para todos os organismos, pois a intensidade e a magnitude desses impactos dependem dos efeitos causados pela presença de inúmeros contaminantes não mensuráveis, das interações aditivas, sinérgicas e antagônicas e das propriedades físicas e químicas do sedimento.

Análises integradas que fornecem informações adicionais e complementares aos testes de toxicidade possibilitam, na maioria das vezes, diminuir as incertezas da extrapolação dos resultados obtidos no laboratório para o ambiente real, possibilitando uma avaliação mais abrangente do grau e da extensão da contaminação e dos possíveis riscos associados a essa contaminação.

Dentre as diferentes abordagens integradas de análise de sedimentos contaminados, a vantagem da utilização do estudo de Avaliação e Identificação da Toxicidade - AIT, é a identificação de tais compostos e a possibilidade de determinar, em casos de presença de múltiplos agentes químicos, a contribuição de cada um deles na toxicidade total.

No entanto, a aplicação dessa metodologia de forma adequada exige, sem dúvida, um trabalho de equipe, pois envolve um número grande de etapas e testes de toxicidade e, em se tratando de amostras ambientais, que apresentam uma variabilidade intrínseca, o intervalo de tempo entre uma etapa e outra pode alterar a toxicidade da amostra impossibilitando a continuidade do estudo. 
A utilização desse estudo em ambientes temperados tem identificado com sucesso diferentes substâncias tóxicas associadas aos sedimentos. A utilização em ambientes tropicais, especialmente no Brasil, onde a principal fonte de contaminação dos ecossistemas aquáticos é constituída pelo esgoto doméstico não tratado, fica mais difícil interpretar de forma clara e precisa os resultados das diferentes etapas.

Os resultados obtidos para o reservatório de Salto Grande mostraram a necessidade de aprofundar os estudos das relações e processos microbiológicos e químicos na interface água/sedimento, e no próprio sedimento, considerando as condições ambientais específicas dos nossos ambientes.

Sem dúvida alguma, antes de mais nada, é necessário minimizar a carga de poluentes que chega aos ecossistemas aquáticos, através do tratamento adequado dos esgotos, da utilização correta dos agrotóxicos e da remoção da toxicidade dos efluentes industriais ou da sua manutenção em níveis aceitáveis.

Em relação às hipóteses propostas, a toxicidade encontrada nas amostras de sedimento e seu solubilizado e a contaminação dos mesmos por substâncias químicas (metais, compostos orgânicos, amônia, nitrogênio e fósforo, confirmaram o papel dos sedimentos como depósito de contaminantes e fonte de contaminação. No entanto, as relações metais/SVA mostraram que nem sempre as chamadas "substâncias tóxicas" são responsáveis pela toxicidade. Em relação aos metais, os resultados obtidos no estudo de AIT com as amostras dos reservatórios de Salto Grande e Rasgão, mostraram que a toxicidade não estava relacionada com os metais. 


\section{8 - REFERENCIAS BIBILIOGRÁFICAS}

ADAMS, W.J.; KIMERLY, R.A.; BARNETT JÚNIOR, J,W. (1992). Sediment quality and aquatic life assessment. Environmental Science and Technology, v.26, n.10, p.18651873.

ALADIN, N.V (1991). Salinity tolerance and morphology of the osmoregulation organs in cladocera with specil reference to Cladocera from the Aral Sea. Hydrobiologia. 225: 291-299

ALLAN, J.D. (1976). Life history patterns in zooplankton. The American Naturalist, v.110, n.971, p.165-180.

ALLEN, H. E.; FU, G. \& DENG, B. (1993). Analysis of acid-volatile sulfide (AVS) and simultaneously extracted metals (SEM) for the estimation of potencial toxicity in aquatic sediments. Environmental Toxicology and Chemistry, v.12, p.1441-1453.

ALMEIDA, F.V. (2002). Bases técnico-científicas para o desenvolvimento de critérios de qualidade de sedimentos (CQS) referentes a compostos orgânicos não-iônicos: Experimentos de campo e laboratório. (Relatório FAPESP 98/09603-8)

ARAUJO, R.P. A (1998). Avaliação da toxicidade de sedimentos ao anfipodo de água doce Hyalella meinert Stebbing, 1899 (Crustacea, Amphipoda). São Paulo. 184p. Dissertação (Mestrado). Departamento de Ecologia Geral, Instituto de Biociências, Usp

ARAÚJO ${ }^{1}$, R.P.A.; BOTTA-PASCHOAL ${ }^{2}$ C.M.R;, SIVÉRIO ${ }^{2}$, P.F.; ALMEIDA ${ }^{3}$,F.V. ROCHA $^{4}$, O.; SHIMIZU ${ }^{5}$ G.Y; UMBUZEIRO ${ }^{1}$ G.A., JARDIM, ${ }^{3}$ W.J.; MOZETO ${ }^{4}$, A.A. Toxicity Identification Evaluation (TIE) applied to Rasgão reservoir, in Tietê system, São Paulo State, Brasil (em preparação)

ANKLEY, G.T.; KATKO, A \& ARTHUR, J.W. (1990). Identification of ammonia as an important sediment-associated toxicant in the lower Fox River and Green Bay, Wisconsin. Environmental Toxicology and Chemistry, v.9, p.313-322.

ANKLEY, G.T. (1991). Predicting the toxicity of bulk sediments to aquatic organisms with aqueous test fractions: pore water vs elutriate. Environmental Toxicology and Chemistry, v.10, p.1359-1366.

ANKLEY, G. \& BUCHARD, L.P. (1992). Identification of surfactants as toxicants in primary effluent. Environmental Toxicology and Chemistry, v.15, n. 12, p.2138-2146

ANKLEY, G.T.\& SCHUBAUER-BERINGAN, M.K. (1995) Background and overview of current sediment toxicity identification procedures. Journal of Aquatic ecossystem Health 4: $133-419$.

ANKLEY, G.T. (1996). Evaluation of metal/acid-volatile sulfide relationships in the prediction of metal bioaccumulation by benthic macroinvertebrates. Environmental Toxicology and Chemistry, v.15, n. 12, p.2138-2146. 
ANKLEY, G.T \& MOUNT, D.R. (1996). Retrospective analysis of the ecological risk of contaminant mixtures in aquatic sediments. Human and Ecological Risk Assessment: v.2, n.3, p.434-440.

ANKLEY, G.T. et al. (1996). Use of equilibrium partitioning to establish sediment quality criteria for nonionic chemicals: a reply to IANNUZZI et al. Environmental Toxicology and Chemistry, v.15, n.7, p.1019-1024.

APHA - AMERICAN PUBLIC HEALTH ASSOCIATION; AMERICAN WATER WORK ASSOCIATION; WATER POLLUTION CONTROL FEDERATION (1992). Standard methods for the examination of water and wastewater. 18.ed. New York. $1268 \mathrm{p}$.

ASHLEY, J.T.F. \& BAKER, J.E. (1999). Hydrofobic organic contaminants in superficial sediments of Baltimore Harbor: inventories and sources. Environmental Toxicology and Chemistry . vol. 18, n 5, p. 838-849.

BADARÓ-PEDROSO (1999). Avaliação dos efeitos e identificação da toxicidade da água de produção de petróleo sobre algumas espécies de organismos marinhos. São Carlos. 230p. Tese (Doutorado) Escola de Engenharia de São Carlos - USP.

BAIRD, D.J. et al. (1989). The daphnia bioassy: a critique. Hydrobiologia. v.188/189, p.403-406.

BAILEY, H.C. et al. (1995). Application of toxicity identification procedures to the echinoderm fertilization assay to identify toxicity in a municipal effluent. Environmental Toxicology and Chemistry, v.14, n.12, p.2181-2186.

BAILEY, H.C; DIGIORGIO, C; KROLL, K \& HINTON , D.E. (1996). Development of procedures for identifying pesticide toxicity in ambient waters: carbofuran, diazinon, chlorpyrifos. Environmental Toxicology and Chemistry vol. 15, n. 6, p. 837-845.

BAILEY H.C.; ELPHICK, J.R.; POTTER, A.; CHAO, E.; KONASEWICH, D. \& ZAK, J.B. (1999). Causes of toxicity in stormwater runoff from sawmills. Environmental Toxicology and Chemistry vol. 18, n 7, p. 1485-1491.

BAUDO \& MUNTAU, 1990. Lesser known in-place pollutants and difuse source problems. p.1-15. In: R. Baudo; J. Giesy \& H. Muntau. Sediments: Chemistry and Toxicity of In-Place Pollutants. Michigan. Lewis Publishers.

BERRY, W.J. et al. (1996). Predicting the toxicity of metal-spiked laboratory sediments using acid-volatile sulfide and interstitial water normalizations. Environmental Toxicology and Chemistry, v.15, n.12, p.2067-2079.

BERVOETS, L.; WILS, C.; VERHYEN, R. (1996). Tolerance of Chironomus riparius larvae (Diptera: Chironomidae) to salinity. Bull. Environ.Contam. Toxicol. 57:829-835

BESSER, J.M. et al. (1996). Effects of spatial and temporal variation of acid-volattle sulfide on the bioavailability of copper and zinc in freshwater sediments. Environmental Toxicology and Chemistry, v.15, n.3, p.286-293.

BESSER, J.M. et al. (1996a). Assessment of sediment quality in dredged and undredged areas of the Trenton Channel of the Detroit River, Michigan USA, using the sediment quality triad. J. Great Lakes Res. v.22, n.3, p.683-696.

BESSER, J.M.; INGERSOLL, G.C.; LEONARD, E.N. \& MOUNT, D.R. (1998). Effect of zeolite on toxicity of ammonia in freshwater sediments: implications for toxicity 
identification procedures. Environmental Toxicology and Chemistry, v.17, n.11, p.23102317.

BESSER, J.M. et al (1998). Effect of zeolite on toxicity of ammonia in freshwater sediments: implications for toxicity identification evaluation procedures. Environmental Toxicology and Chemistry, v.17, n.11, p.2310-2317.

BODAR, C.W.M. et al. (1988) Effects of cadmium on consumption, assimilation, and biochemical parameters of Daphnia magna: possible implications for reproduction. Comp. Biochem Physiol., v.90(c), p.341-346.

BOELTER, A.M. et al. (1992). Environmental effects of saline oil-field discharges on surface waters. Environmental Toxicology and Chemistry, v.11, p.1187-1195.

BOHRER, M.B.C. (1995) Biomonitoramento das lagoas de tratamento terciário do sistema de tratamento dos efluentes líquidos industriais (SITEL) do Polo Petroquímico do Sul, /Triunfo, RS, através da comunidade zooplanctônica. São Carlos/SP. 349p. Tese (Doutorado) CCBS. Universidade Federal de São Carlos .

BORGLIN, S; WILKE, A.; JEPSEM, R. \& LICK, W. (1996). Parameters affecting the desorption of hydrophobic organic chemicals from suspended sediments. Environmental Toxicology and Chemistry. vol. 15, no. 10, p.2254-2262.

BOUCHER, A.M. \& WATZIN, M.C. (1999). Toxicity identification evaluation of metalcontaminated sediments using an artificial pore water containing dissolved organic carbons. Environmental Toxicology and Chemistry vol. 18, no. 3, p.509-518

BOUDOU, A.; RIBEYRE, F. (1989). Aquatic ecotoxicology: fundamentals concepts and methodologies. Florida, CRC Press. v.1, p.36-51.

BRONDI, S..H.G. (2000). Determinação de multiresíduos de agrotóxicos em águas de abastecimento.do município de Araraquara: Ribeirão das Cruzes, Ribeirão Anhumas e Córrego do Paiol. p:5-15. Tese (Doutorado). Escola de Engenharia de São Carlos-USP

BURTON, G.A. \& MACPHERSON, C. (1994). Sediment toxicity issues and methods. In: Handbook of Ecotoxicology. Boca Raton, Florida. Lewis Publishers. p.2-71.

CÁCERES, O. TUNDISI, J,G, \& CASTELLAN, O.A.M. (1987). Residues of organochloric pesticids in reservoirs in São Paulo State. Ciência e Cultura, v.39, p.259264.

CALHEIROS, D.F. (1993. Ecotoxicologia de compostos organoclorados persistentes em um sistema eutrófico: represa de Barra Bonita (Médio Tietê, SP). São Carlos. 168p. Dissertação. (Mestrado). Universidade São Paulo).

CALIJURI, M.C. \& TUNDISI, J.G. (1990). Limnologia comparada das represas do Lobo (Broa) e Barra Bonita - Estado de São Paulo: mecanismos de funcionamento e bases para o gerenciamento. Revista Brasileira de Bioogia 50 (4): 893-913.

CALMANO, W.; HONG, J.; FORSTNER, U. (1993). Binding and mobilization of heavy metal in contaminated sediments affected by $\mathrm{pH}$ and redox potentia. Water Science Technology, 28 (8-9) : 223-235. 1993.

CARR, R.S.; MONTAGNA, P. A.; BIEDENBACH, J.M.; KALKE, R.; KENNICUTT, M.C.; HOOTEN, R. \& CRIPE, G. (2000). Impact of storm-water outfalls on sediment quality in Corpus Christi Bay, Texas, USA. Environmental Toxicology and Chemistry, v.19, n.3, p.561-574. 
CETESB (1988). Bioensaio de toxicidade aguda utilizando-se Spirillum volutans. Método de ensaio. São Paulo. /Norma Técnica L5.228/

CETESB (1991). Bioensaios microbianos aplicados no controle de contaminantes tóxicos ambientais. São Paulo. p.1-14.

CETESB (1992). "Água - Métodos de avaliação da toxicidade de poluentes a organismos aquáticos. v1 (série didática)".

CETESB (2001). Bioensaio de toxicidade aguda com "Photobacterium phosphoreum" sistema Microtox. São Paulo. /Norma Técnica L5.227 /

CETESB (2002). Qualidade das águas interiores do Estado de São Paulo. São Paulo. 230p. /Relatório/.

COSTA, J. B. da (2001). Avaliação ecotoxicológica da água e sedimento de tributários do reservatório de Barra Bonita (Médio Tietê Superior - SP). São Carlos,. 281p. Dissertação (Mestrado). Escola de Engenharia de São Carlos-USP

Di TORO, D.M. et al. (1992). Acid-volatile sulfide predicts the acute toxicity of cadmium and nickel in sediments. Environmental Science and Technology, v.26, n.1, p.96-101.

DORNFELD, C. B. (2002). Utilização de análises limnológicas, bioensaios de toxicidade e macroinvertebrados bentônicos para o diagnóstico ambiental do reservatório de Salto Grande (Americana, SP). São Carlos. 196p. Dissertação (Mestrado). Escola de engenharia de São Carlos, USP.

DUTKA, B.J. (1986) Methods for microbiological analysis of waters, wastewaters and sediments. Canada Centre Inland Waters, Burlington, Ontario.

ESPINDOLA, E.L.G. et al. (1998). Avaliação ecotoxicológica de sedimento como instrumento de controle de qualidade da água do reservatório de Salto Grande, Americana - SP. In: IV Simpósio de Ecossistemas Brasileiros. Volume IV. Águas de Lindóia, SP. São Paulo. p.99-111. /Anais/

ESTEVES, F. A. (1988). Fundamentos de Limnologia. Rio de Janeiro. Editora Interciencia / FINEP. p.291-306.

FAIREY, R.; ROBERTS, C.; JACOBI, M.; LAMERDIN, R.C.; DOWNING, J.; HUNT, J; ANDERSON, B.; NEWMAN, J.; TJEERDEMA, R.; STEPHENSON, M. \& WILSON, C. (1998) Assessment of sediment toxicity and chemical concentrations in the San Diego Bay Region, California, USA. Environmental Science and Technology, v.17, n.8, p.1570-1581.

FRACCACIO, R. (2001) Utilização de bioensaios ecotoxicológicos com Danio rerio (Cypriniformes, Cyprinidae) e análises limnológicas para a avaliação ambiental dos reservatóriosdo médio e baixo Tietê. São Carlos. 233p. Dissertação (Mestrado). Escola de Engenharia de São Carlos-USP.

FONSECA, A. L. (1991). A biologia das espécies Daphnia laevis, Ceriodaphnia silvestrii (Crustacea Cladocera) e Poecilia reticulata (Pisces Poecillidae) e o comportamento destes em testes de toxicidade aquática com efluentes industriais. Dissertação (Mestrado). Escola de Engenharia de São Carlos-USP.

FONSECA, A L. (1997). Avaliação da qualidade da água na bacia do rio Piracicaba através de testes de toxicidade com invertebrados. São Carlos. 210p. Tese (Doutorado) Escola de Engenharia de São Carlos, USP. 
FORSTNER, U., AHLF, W., CALMANO, W., KERSTEN, M. \& SCHOER, J. (1989) Assessment of metal mobility in sludges and solid wastes. In: Brockaert J.A.C., Gucer, S. \& Adams, F. (eds). Metal Speciation in the Environment. NATO ASI Series G (Ecological Sciences) 23. p:2-41

FORSTNER, U. (1990). Inorganic sediment chemistry and elemental speciation. p. 61-107. In: R. Baudo; J. Giesy \& H. Muntau. Sediments: Chemistry and Toxicity of In-Place Pollutants. Michigan. Lewis Publishers.

FORSTNER, U.; AHLF, W. \& CALMANO, W. (1993). Sediment quality objectives and criteria development in Germany. Water Science and Technology, v.28, n.8/9, p.307316.

GÄCHTER, R. \& MEYER, J.S. (1990). Mechanisms controlling fluxes of nutrients across the sediment/water interface in a eutrophic lake. P.131-162. In: R. Baudo; J. Giesy \& H. Muntau. Sediments: Chemistry and Toxicity of In-Place Pollutants. Michigan. Lewis Publishers.

GERSICH, F.M. et al. (1986). The precision of daphnid (Daphnia magna Straus, 1820) static acute toxicity tests. Arch. Environonmental Contaminant Toxicology 13:741-749.

GIANESELLA-GALVÃO, S.M. (1981). - Produção primária e suas relações com alguns fatores físico-químicos em reservatórios do Estado de São Paulo. Vol. I e II. Tese (Doutorado). IO, USP, São Paulo

GIESY, J.P et al.. (1988). A comparison of three sediment bioassay method using Detroit river sediments. Environmental Toxicology and Chemistry, v.7, p.483-498.

GIESY, J.P.; HOKE, R.H. (1989). Freshwater sediment toxicity bioassessment: rationale for species selection and test design. Journal of Great Lakes Research, v.15, n.4, p.539569.

GIESY, J.P.; ROSIU, C.J.; GRANEY, R.L.; HENRY, M.G. (1990). Benthic invertebrate bioassays with toxic sediment and pore water. Environmental Toxicology and Chemistry, v.9, p.233-248.

GOLTERMAN, H. L.; CLYMO, R. S. \& OHNSTAD, M. A. M. (1978). Methods of Chemical and Phisical Analysis of Freshwater. IBP Handbook n.8. Blackwell Scientific Publications. Oxford. 213p.

GUCHTE, C.VAN; MAAS-DIEPEVEEN, J.L. (1987). Screening sediments for toxicity: a water concentration related problem. 24p. /Paper presented at 14th Annual Aquatic Toxicity Workshop, Toronto, Canadá, 1987/

GUZZELLA, L. et al. (1996). Toxicity identification evaluationof Lake Orta (northern Italy) sediments using the Mc-system. Ecotoxicological and Environmental Safety 35. 231-235

HALL Jr., L.W. et al. (1998). Ecological risk assessment of copper and cadmiun in surface waters of Chesapeake Bay watershed. Environmental Toxicology and Chemistry, v.17, n.6, p.1172-1189.

HAMILTON, M. et al.(1977). Trimmed Spearman - karber method for estimating median lethal concentrations in toxicity biossays. Environmental ScienceTechnology. v.11(7) p.714- 719 . 
HANSEN, D.J. et al. (1996). Predicting the toxicity of metal-contaminated field sediments using interstitial concentration of metals and acid-volatile sulfide normalizations. Environmental Toxicology and Chemistry, v.15, n.12, p.2080-2094.

HARRIS, H.J. et al. (1990). Ecotoxicology and ecossystem integrity: The Great Lakes examined. Environmental Science and Technology, v.24, n.5, p.598-603.

HOKE, R.A; ANKLEY, G.T.; PETERS, J.F. (1995). Use of a freshwater sediment quality database in a evaluation of sediment quality criteria based on equilibrium partitioning and screening-level concentrations. Environmental Toxicology and Chemistry, v.14, n.3, p.451-459.

HO, K.T.; BURGESS, R.M.; PELLETIER, M.C.; SERBST, J.R.; RYBA, S.A.; CANTWELL, M.G.; KUHN, A. \& RACZELOWSKI, P. (2002). An overview of toxicant identification in sediments and dredged materials. Marine Pollution Bulletin 44:286-293.

HOFFMAN, D.J. et al. (1994). Handbook of ecotoxicology. Boca Raton, Fl. Lewis Publishers.

JACKSON, J. (1991) Heavy metals and others inorganic toxic substances. In: MATSUI, S., (ed). Toxic substances management in lakes and reservoirs. OTSU, ILEC - UNEPE .4. Cap5, p:65-79 (Guielines of Lake Management).

JIN, H. et al. (1999). A case study on identifying the toxicant in effluent discharged from a chemical plant. Marine Pollution Bulletin. v.39. n 1-12.p.122-125.

KAISER, K.L.E (sd). COMPUTOX ${ }^{T M}$ - Toxicity database, 1990-1994. Version 4.01. Format:QPW5.0, Burlington:Ontario.

KHIM, J.S.; VILLENEUVE, D.L.; KANNAN, K.; LEE, K.T.; SNYDER, S.A.; KOH, C.H. \& GIESY, J.P. (1999). Alkylphenols, polycyclic aromatic hydrocarbons, and organochlorines in sediment from lake Shihwa, Korea: Instrumental and bioanalytical characterization. Environmental Toxicology and Chemistry, v.18, n.11 p.2424-2432.

KNEZOVICH, J.P.; HARRISON, F.L.; WILHELM, R.G. (1987). The bioavailability of sediment-sorbed organic chemicals: a review. Water, Air and Soil Pollution, v.32, p.233-245.

LACERDA, L. D. (1998). Trace metals biogeochemistry and diffuse pollution in mangrove ecosystems. ISME Mangrove Ecosystems Occasional Papers $\mathrm{n}^{\circ}$ 2. 65p. LAWS, E.A. (1993). Aquatic pollution: an introductory text. 2ed. New York, John Wiley. p.192-215, 354-411.

LANDRUM, P.F., \& J.A. ROBBINS. (1990). Bioavailability of sediment-associated contaminants to benthic invertebrates. In: R. Baudo; J. Giesy \& H. Muntau. Sediments: Chemistry and Toxicity of In-Place Pollutants. Michigan. Lewis Publishers.

LIBER, K. et al.. (1996). Effects of acid-volatile sulfide on zinc bioavailability and toxicity to benthic macroinvertebrates: a spiked-sediment field experiment. Environmental Toxicology and Chemistry, v.15, n.12, p.2113-2125.

MATSUI, S., ed (1991). Toxic substances management in lakes and reservoirs. OTSU, ILEC - UNEPE .4. (Guielines of Lake Management).

MASUTTI, M. (2001). Análise da distribuição de metais-traço (Cr e Cu) em ecossistema aquático: um experimento em mesocosmo. Relatório FAPESP, Processo $\mathrm{n}^{0}$ 00/ 04464-1 
MELETTI, P.C. (1997). Avaliação da qualidade da água na bacia do Rio Piracicaba através de testes de toxicidade aguda com peixes. São Carlos. 148p. Dissertação (Mestrado) Escola de Engenharia de São Carlos, USP.

MERK. The Merck manual of dignosis and therapy. Section 2. Endocrine and metabolic disorders. Disponível em: $<$ http://www.merck.com/pubs/mmanual/section2/chapter16/16b.htm $>$. (Acesso em: 4 de novembro. 2002).

MOZETO A. A. \& PATELLA, E.(1997). Como avaliar a qualidade de água de mananciais. Ciência Hoje. 22(127): 16-19.

MOZETO, A. A., cord. (2001). Bases Técnicas de Critérios de Qualidade de Sedimentos (CQS): Experimentos de Campo e Laboratório.p:25-50. ( Relatório I - FAPESP/ Processo no 98/12177-0).

MOZETO, A. A., cord. (2002). Bases Técnicas de Critérios de Qualidade de Sedimentos (CQS): Experimentos de Campo e Laboratório.p:25-50. (Relatório II FAPESP/ Processo no 98/12177-0) (em execução)

MOUNT, D..J. \& HOCKETT, R. (2000). Use of toxicity identification evaluation methods to characterize, identify and confirm hexavalent chromium toxicity in a industrial effluents. Wat. Res. vol. 34, no. 4, pp. 1379-1385.

NAVAS-PEREIRA, D. et al (1985). Níveis de contaminação por metais pesados e pesticidas na água, sedimento e peixes da Represa de Barra Bonita. In: CONGRESSO BRASILEIRO DE ENGENHARIA AMBIENTAL, 13, Maceió. 1985. / Resumos/

NASCIMENTO, M.R.L. \& MOZETO, A.A. (2001). Valores de referência para metais pesados e contaminação em sedimentos fluviais e lacustres na bacia do rio Tietê. In: Bases Técnicas de Critérios de Qualidade de Sedimentos (CQS): Experimentos de Campo e Laboratório.p:25-50. ( Relatório I - FAPESP/ Processo no 98/12177-0).

NIPPER, M. \& CARR (1998). Ecotoxicologia de sedimentos marinhos. V Encontro Brasileiro de Ecotoxicologia (ECOTOX). Itajaí, Santa Catarina. Anais. p.8.

NORBERT-KING, T.J.; ANKLEY, G.T. \& ROBERT, E. (1991). Application of toxicity identification evaluation procedures to the ambient waters of the Colusa basin drain. Environmental Toxicology and Chemistry, v.10, p.891-901.

OKAMURA, H.; LUO, R. \& AOYAMA, I. (1996). Ecotoxicity assessment of the aquatic environmental around lake Kojimsa, Japan. Environmental Toxicology and Water Quality: An International Journal. v11: 213-221

OLIVEIRA NETO, A.L (1999). Influência de alguns metais pesados (Cd, $\mathrm{Cr}, \mathrm{Pb})$ em organismos planctônicos lacustres de região subtropical. São Carlos. 85p Tese (Doutorado). Escola de Engenharia de São Carlos-USP.

OLIVEIRA-NETO, A.L., BOTTA-PASCHOAL, C.M.R., SALVELA, C. \& MIRANDA, V.F. Toxicidade de alguns elementos-traço $(\mathrm{Cd}, \mathrm{Pb}, \mathrm{Cr}, \mathrm{Zn}$ e $\mathrm{Cu})$ para a espécie de cladócera Ceriodaphnia silvestrii. (2001). In: $4^{\text {a }}$ reunión Anual de SETAC Latinoamericana. Buenos Aires. /Resumos/

PAMPLIN, P.A. Z. (1999). Avaliação da qualidade ambiental da represa de Americana (SP-Brasil) com ênfase no estudo da comunidade sde macroinvertebrados bentônicos e parâmetros ecotoxicológicos. São Carlos. 112p. Dissertação (Mestrado) - Escola de Engenharia de São Carlos, Universidade de São Paulo. 
PESCH, C.E.; HANSEN, D.J.; BOOTHMAN, W.S. (1995). The role of acid-volatile sulfide and interstitial water metal concentrations in determining bioavailability of cadmium and nickel from contaminated sediments to the marine polychaete Neanthes arenaceodentata. Environmental Toxicology and Chemistry, v.14, n.1, p.129-141.

PLETTE, A. C., et al. (1999). Bioavailability of heavy metals in terrestrial and aquatic systems: a quantitative approach. Environmental Toxicology and Chemistry, 18 (9): 1882-1890.

PRINTES, L.B. (1996). Biomonitoramento da micro-região carbonífera do baixo Jacuí, $R S$, através de testes de toxicidade com cladócera e implantaçào de cultivo e definição da faixa de sensibilidade de Hyalella azteca (crustacea: amphipoda) ao cloreto de sódio ( $\mathrm{NaCl}$ ). Porto Alegre, RS. 253p. Dissertação (Mestrado) Universidade Federal do Rio Grande do Sul

RAND, G.M. (eds) (1995). Fundamentals of aquatic toxicology - effects, environmental fate, and risk assessment. Flórida, Taylor \& Francis.

REYNOLDSON, T.B. \& DAY, K.E. (1998). Biological guidelines for the assessment of sediment quality in the Laurentian Great Lakes. NWRI. Environment Canada, Burlington, Ontario, Canada.

RODGHER, S. (2001). Estudos ecotoxicológicos e limnológicos nos reservatórios em cascata do médio e baixo rio Tietê: uma análise espacial e temporal. São Carlos. 213p. Dissertação (Mestrado). Escola de Engenharia de São Carlos-USP.

ROSS, P.E. \& HENEBRY, M. S. (1989). Use of four microbial tests to assess the ecotoxicological hazard of contaminated sediments. Toxicity Assessment: An International Journal v.4, p.1-21.

SALOMONS, W; FÖRSTNER, U. (1984). Metals in the Hydrocicle. Berlin, Springer Verlag. 349p.

SAUER, T.D.; HELDER, J.C.; BROWN, J.S. \& WARD, T. (1997). Toxicity identification evaluations of produced water effluents. Environmental Toxicology and Chemistry, v.16, n.10. p.2020-2028.

SCHIEWE, M.A.; HAWK, E.G.; ACTOR, D.I.; KRAHN, M.M. (1985). Use of bacterial bioluminescence assay to assess toxicity of contaminated marine sediments. Canadian Journal of Fisheries and Aquatic Sciences, v.42, p.1244-1248

SCHUBAUER-BERINGAN, M. K. \& ANKLEY, G.T. (1991). The contribution of ammonia, metals and nonpolar organic compounds to the toxicity of sediment intersticial water from an Illinois River tributary. Environmental Toxicology and Chemistry, v.10. p. 925-939

SETAC - SOCIETY OF ENVIRONMENTAL TOXICOLOGY AND CHEMISTRY (1993). Guidance document on sediment toxicity tests and bioassays for freshwater and marine environments. In: WORKSHOP ON SEDIMENT TOXICITY ASSESSMENT, Renesse, The Netherlands, 1993. Edited by I.R Hill, P. Matthiessen \& F. Heimbach. SETAC. 105p.

SIBLEY, P.K., ANKLEY, G.T.; COTTER, A.M. \& LEONARD, E.N. (1996 ). Predicting chronic toxicity of sediments spiked with zinc: an evaluation of the acid-volatile sulfide models using a life cycle test with the midge Chironomus tentans. Environmental Toxicology and Chemistry, v.15, n.12, p.2102-2112. 
SIJM, D. KRAAIJ, R. BELFROID, A. (2000). Bioavailability in soil or sediment: exposure of different organisms and approach to study it. Environmental Pollution 108 (2000) 113-119.

SILVÉRIO, P.F. (1999). Partição, biodisponibilidade e toxicidade de metais pesados a organismos bentônicos em sedimentos. São Carlos, SP. 78p. Dissertação (Mestrado). Departamento de Química, UFSCar.

STEWART. J.A. \& KONETSKY, B.K. (1998) Longevity and reproduction of C. dubia in receiving waters. ETC, v.17, n.6.p.1165-1171.

STRIXINO, T.S. \& STRIXINO, G. (1981). Ciclo de vida de Chironomus santicaroli Strixino \& Strixino, (Diptera: Chironomidae). Revta. Bras. Ent.., v.26, n.2, p.183-189.

SVENSON, A.; RICKING, M.; REMBERGER, M. \& ROTTORP, J. (1997). Sediment contaminants and Microtox toxicity tested in a direct contact exposure test. Environmental Toxicology and Water Quality: An International Journal. v11. p.293300

SVENSON, A.; VKTOR, T. \& REMBERGER, M. (1998). Toxicity of elemental sulfur in sediments. Environmental Toxicology Water Quality. 13: 217-224

THOMAS, K.V.; THAIN, J.E.\& WALDOCK, M.J. (1999). Identification of toxic substances in United kingdom estuaries. Environmental Toxicology and Chemistry, v.18, n.3, p.401-411.

THOMAS K.V., MARK R. HURST, M.R.; MATTHIESSEN, P. \& WALDOCK, M.J.(2001). Characterization of estrogenic compounds in water samples collected from united kingdom estuaries. Environmental Toxicology and Chemistry vol. 20, n 10, p. 2165-2170.

TONISSI, F.B. (1999). Avaliação ecotoxicológica de reservatório de Salto Grande, Americana (SP), como subsídio para a análise da qualidade ambiental do sistema. 137p. Dissertação (Mestrado). Escola de Engenharia de São Carlos-USP.

TRINDADE, M. (1980). Nutrientes em sedimentos da represa do Broa: Itirapina, S.P. São Carlos, SP. Dissertação (Mestrado). Universidade Federal de São Carlos, UFSCar.

UNITED STATES ENVIRONMENTAL PROTECTION AGENCY. (1989). USEPA600/4-89/001. Short-term methods for estimating the chronic toxicity of effluents and receiving waters to freshwater organisms. 2.ed. Cincinnati, OH. 250p.

UNITED STATES ENVIRONMENTAL PROTECTION AGENCY. (1991) Methods for Aquatic Toxicity Identification Evaluations. Phase I Toxicity Characterization Procedures. second edition. EPA/600/6-91/003. Enviromental Protection Agency, Washington, DC., USA

UNITED STATES ENVIRONMENTAL PROTECTION AGENCY. (1991a) USEPA/600/6-91/007. Sediment toxicity identification evaluation: phase I (characterization), phase II (identification) and phase III (confirmation) modifications of effluent procedures. Duluth.

UNITED STATES ENVIRONMENTAL PROTECTION AGENCY. (1992). USEPA/823/R-92/006. Sediment Classification Methods Compendium. Washington, D.C.. Environmental Protection Agency/ Sediment Oversight Technical Commitee. Paginação irregular. 
UNITED STATES ENVIRONMENTAL PROTECTION AGENCY. (1994). USEPA/600/R -94/024. Methods for measuring the toxicity and bioaccumulation of sediment associated contaminants with freshwater invertebrates. Washington. D.C., $133 \mathrm{p}$.

VAN SPRANG, P. A \& JANSSEN, C.R. (1997). Identification and confirmation of ammonia toxicity in contaminated sediments using a modified toxicity identification evaluation approach. Environmental Toxicology and Chemistry, v.16, n.12, p.25012507.

WANG, F. \& CHAPMAN, P.M. (1999). Biological implications of sulfide in sediment - a review focusing on sediment toxicity. Environmental Toxicology and Chemistry, v.18, n.11, p.2526-2532.

WINNER, R.W.. (1985). Bioaccumulation and toxicity of copper as affected by interactions between humic acid and water hardness. Water Res., 19:449-455.

WINNER, R.W. \& GAUSS, J.D. (1986). Relationship between chronic toxicity and bioaccumulation of copper, cadmium and zinc as affected by water hardness and humic acid. Aquatic Toxicology, 8:149-161.

WHITEMAN, F. W. (1996). Evaluation of interstitial water as a route of exposure for ammonia in sediment tests with benthic macroinvertebrates. Environmental Toxicology and Chemistry, v.15, n.5, p.794-801.

YANG, L. et al. (1999). Application of the simplified toxicity identification evaluation procedures to a chemical works effluent.

ZAGATTO, P.A. (1988). Sensibilidade de Daphnia similis: controle e qualidade de culturas. Ambiente, v.2, n.2, p.79-83. 


\section{I - Solução Tampão:}

1) Dissolver $16,9 \mathrm{~g}$ de $\mathrm{NH}_{4} \mathrm{Cl}$ em $143 \mathrm{~mL}$ de $\mathrm{NH}_{4} \mathrm{OH}$;

2) Pesar $1,179 \mathrm{~g}$ de EDTA e $780 \mathrm{mg}$ de $\mathrm{MgSO}_{4} .7 \mathrm{H}_{2} \mathrm{O}$ ou $644 \mathrm{mg}$ de $\mathrm{MgCl}_{2} .6 \mathrm{H}_{2} \mathrm{O}$ e dissolver em $50 \mathrm{~mL}$ de $\mathrm{H}_{2} \mathrm{O}$ destilada;

3) Adicionar sob agitação a solução 2 na solução 1 e completar o volume para 250 $\mathrm{mL}$ com água destilada.

Armazenar em frascos de polietileno ou vidro Pyrex..

\section{II - Solução de EDTA:}

EDTA --10---3,723 g

água destilada qsp ---:------1000 mL

Armazenar em frascos de polietileno ou vidro Pyrex.e proteger da luz

III - Padronização da solução de EDTA

a) secar $\mathrm{CaCO}_{3}$ a $105^{\circ} \mathrm{C}$ por 1 hora.

b) deixar esfriar e pesar $1 \mathrm{~g} \mathrm{em}$ um béquer pequeno

c) adicionar $\mathrm{HCl} 1: 1$ até a completa dissolução

d) após a dissolução, colocar a solução em um erlenmeyer de $500 \mathrm{~mL}$ com $200 \mathrm{~mL}$ de água destilada e deixar ferver para expelir o $\mathrm{CO}_{2}$.

e) após esfriar (temperatura ambiente), adicionar 3 gotas de vermelho de metila.

f) se a solução ficar avermelhada, adicionar algumas gotas de $\mathrm{NH}_{4} \mathrm{OH}$ até que a solução fique amarelada $(\mathrm{pH} \cong 6,3)$.

g) transferir a solução para um balão volumétrico de $1000 \mathrm{~mL}$, completando o volume para $1000 \mathrm{~mL}$ com água destilada.

h) carregar a bureta com EDTA

i) em um erlenmeyer de $125 \mathrm{~mL}$, adicionar o volume exato $(50 \mathrm{~mL})$ da solução de $\mathrm{CaCO}_{3}$,

$1 \mathrm{~mL}$ da solução tampão e o indicador negro de ericromo $\mathrm{T}$.

j) anotar o volume de EDTA gasto.

Obs.: quando se adiciona o indicador, a solução fica violeta. O ponto final da titulação é indicado pela mudança da cor para azul.

III.1 - Cálculo do fator: considerando que "cada $1 \mathrm{~mL}$ de solução de $\mathrm{CaCO}_{3} \cong 1 \mathrm{mg}$ de $\mathrm{CaCO}_{3} "$,

$$
\mathrm{F}=\frac{\mathrm{mg} \mathrm{CaCO}}{\mathrm{mL} \mathrm{EDTA}}=\frac{\mathrm{mL} \mathrm{CaCO}_{3}}{\mathrm{mLEDTA}}
$$




\section{IV - Determinação da dureza $(\mathrm{mg} / 1 \mathrm{CaCO})$}

a) adicionar $50 \mathrm{~mL}$ da amostra $\mathrm{em}$ um erlenmeyer de $125 \mathrm{~mL}+1 \mathrm{~mL}$ da solução tampão e o indicador negro de ericromo $T$.

b) titular com EDTA até o ponto de viragem para o azul.

c) calcular a dureza $\left(\mathrm{mg} / \mathrm{l}\right.$ de $\left.\mathrm{CaCO}_{3}\right)$ de acordo com as fórmulas abaixo:

$$
\text { dureza }=\frac{\text { Vol. de EDTA }(\mathrm{mL}) \times 1000 \times \text { fator }(\mathrm{F})}{\text { Vol. Amostra }}
$$

\section{ALIMENTAÇÃO DOS CULTIVOS}

- Alimento Composto (ração para truta e levedura)

Ração para truta:

1. Adicionar $5 \mathrm{~g}$ de ração $\mathrm{em} 1000 \mathrm{~mL}$ de água destilada.

2. Manter sob aeração contínua por uma semana. Durante esse período, completar o volume de água de modo a compensar a perda de água evaporada.

3. Após aeração, deixar sedimentar por algumas horas, filtrar o sobrenadante em rede de plâncton de aproximadamente 45 um e descartar o material sedimentado.

4. Distribuir em frascos de $200 \mathrm{~mL}$ devidamente etiquetados e mantê-los em freezer a $-20^{\circ} \mathrm{C}$ até o momento de uso.

Levedura

1. Adicionar $1,0 \mathrm{~g}$ de fermento biológico seco em $200 \mathrm{~mL}$ de água destilada.

2. Deixar sob agitação por cerca de 5 minutos até dissolução completa e utilizálo imediatamente no preparo do alimento composto.

Para cada lote de ração preparada, calcula-se o peso seco do alimento por mililitro ou o teor de sólidos totais em suspensão e a partir do resultado obtido, calcula-se o volume de alimento a ser adicionado por dia nas culturas, de forma a manter a concentração de sólidos em suspensão de $14 \mathrm{mg} / \mathrm{litro}$. 
Meio L.C. OLIGO (CETESB, 1992)

\begin{tabular}{|c|c|c|}
\hline Reagentes & Massa & $\mathrm{Vol} / \mathrm{L}$ \\
\hline Solução 1 & & $1 \mathrm{ml}$ \\
\hline $\mathrm{Ca}\left(\mathrm{NO}_{3}\right) \cdot 4 \mathrm{H}_{2} \mathrm{O}$ & $4 \mathrm{~g}$ & \\
\hline Água bideionizada & $100 \mathrm{ml}$ & \\
\hline Solução 2 & & $1 \mathrm{ml}$ \\
\hline $\mathrm{KNO}_{3}$ & $10 \mathrm{~g}$ & \\
\hline Água bideionizada & $100 \mathrm{ml}$ & \\
\hline Solução 3 & & $1 \mathrm{ml}$ \\
\hline $\mathrm{MgSO}_{4} \cdot 7 \mathrm{H}_{2} \mathrm{O}$ & $3 \mathrm{~g}$ & \\
\hline Água bideionizada & $100 \mathrm{ml}$ & \\
\hline Solução 4 & & $1 \mathrm{ml}$ \\
\hline $\mathrm{K}_{2} \mathrm{HPO}_{4}$ & $4 \mathrm{~g}$ & \\
\hline Água bideionizada. & $100 \mathrm{ml}$ & \\
\hline , & & \\
\hline Solução 5 & & $0.5 \mathrm{ml}$ \\
\hline $\mathrm{CuSO}_{4} .5 \mathrm{H}_{2} \mathrm{O}$ & $30 \mathrm{mg}$ & \\
\hline$\left(\mathrm{NH}_{4}\right) 6 \mathrm{Mo}_{7} \mathrm{O}_{24} \cdot 4 \mathrm{H}_{2} \mathrm{O}$ & $60 \mathrm{mg}$ & \\
\hline $\mathrm{ZnSO}_{4} .7 \mathrm{H}_{2} \mathrm{O}$ & $60 \mathrm{mg}$ & \\
\hline $\mathrm{CoCl}_{2} \cdot 6 \mathrm{H}_{2} \mathrm{O}$ & $60 \mathrm{mg}$ & \\
\hline $\mathrm{Mn}\left(\mathrm{NO}_{3}\right) 2.4 \mathrm{H}_{2} \mathrm{O}$ & $60 \mathrm{mg}$ & \\
\hline $\mathrm{C}_{6} \mathrm{H}_{8} \mathrm{O}_{7}$ & $60 \mathrm{mg}$ & \\
\hline $\mathrm{H}_{3} \mathrm{BO}_{3}$ & $60 \mathrm{mg}$ & \\
\hline Água bideionizada & $1000 \mathrm{ml}$ & \\
\hline Solução 6 & & $0.5 \mathrm{ml}$ \\
\hline $\mathrm{C}_{6} \mathrm{H}_{5} \mathrm{FeO}_{7} .5 \mathrm{H}_{2} \mathrm{O}$ & $1,625 \mathrm{~g}$ & \\
\hline $\mathrm{FeSO}_{4} .7 \mathrm{H}_{2} \mathrm{O}$ & $0,625 \mathrm{~g}$ & \\
\hline $\mathrm{FeCl}_{3} .6 \mathrm{H}_{2} \mathrm{O}$ & $0,625 \mathrm{~g}$ & \\
\hline Água bideionizada & $1000 \mathrm{ml}$ & \\
\hline Solução 7 & & $1 \mathrm{ml}$ \\
\hline $\mathrm{NaHCO}_{3}$ & $15 \mathrm{~g}$ & \\
\hline Água bideionizada & $1000 \mathrm{ml}$ & \\
\hline
\end{tabular}

Ajustar o $\mathrm{pH}$ desse meio com $\mathrm{Hcl}$ ou $\mathrm{NaOH}$ para 7,1 mais ou menos 0,1 . Autoclavar a $121^{\circ} \mathrm{C} / 15 \mathrm{~min}$ 
Tabela 1 - Valores de CE50, 24h e intervalo de confiança de dicromato de potássio para Daphnia similis.

\begin{tabular}{|c|c|c|c|}
\hline Testes & $\begin{array}{c}\text { Limite Inferior } \\
\text { do Intervalo de } \\
\text { Confiança }\end{array}$ & $\begin{array}{c}\text { CE50, } \\
24 \mathrm{~h}\end{array}$ & $\begin{array}{c}\text { Limite Superior } \\
\text { do Intervalo de } \\
\text { Confiança }\end{array}$ \\
\hline 1 & 0,08 & 0,11 & 0,15 \\
2 & 0,08 & 0,09 & 0,11 \\
3 & 0,07 & 0,089 & 0,11 \\
4 & 0,05 & 0,065 & 0,08 \\
5 & 0,04 & 0,047 & 0,06 \\
6 & 0,05 & 0,066 & 0,08 \\
7 & 0,1 & 0,12 & 0,15 \\
8 & 0,1 & 0,13 & 0,18 \\
9 & 0,05 & 0,054 & 0,06 \\
10 & 0,07 & 0,089 & 0,11 \\
11 & 0,08 & 0,094 & 0,11 \\
12 & 0,01 & 0,04 & 0,13 \\
13 & 0,08 & 0,1 & 0,13 \\
14 & 0,056 & 0,069 & 0,087 \\
15 & 0,04 & 0,06 & 0,09 \\
16 & 0,07 & 0,09 & 0,13 \\
17 & 0,08 & 0,12 & 0,19 \\
18 & 0,08 & 0,11 & 0,14 \\
19 & 0,04 & 0,056 & 0,07 \\
20 & 0,12 & 0,15 & 0,2 \\
21 & 0,03 & 0,033 & 0,08 \\
\hline \multicolumn{2}{|c|}{ CE50,24 h médio } & & 0,085 \\
\hline \multicolumn{2}{|c|}{ Desvio padrão } & & 0,03 \\
\hline
\end{tabular}


Tabela 2 - Valores de CE50, 48h e intervalos de confiança de cloreto de sódio para Ceriodaphnia dúbia.

\begin{tabular}{|c|c|c|c|}
\hline Testes & $\begin{array}{c}\text { Limite Inferior } \\
\text { do Intervalo de } \\
\text { Confiança }\end{array}$ & CE50,48h & $\begin{array}{c}\text { Limite Superior } \\
\text { do Intervalo de } \\
\text { Confiança }\end{array}$ \\
\hline 1 & 1,5 & 1,6 & 1,71 \\
2 & 1,39 & 1,5 & 1,68 \\
3 & 1,7 & 1,9 & 2,2 \\
4 & 1,11 & 1,42 & 1,8 \\
5 & 1,35 & 1,52 & 1,72 \\
6 & 1,25 & 1,39 & 1,56 \\
7 & 1,54 & 1,78 & 2,05 \\
8 & 1,3 & 1,45 & 1,61 \\
9 & 1,49 & 1,63 & 1,8 \\
10 & 1,53 & 1,73 & 1,97 \\
11 & 1,63 & 1,77 & 1,87 \\
12 & 1,52 & 1,66 & 1,82 \\
13 & 1,51 & 1,65 & 1,81 \\
14 & 1,68 & 1,86 & 2,07 \\
15 & 1,48 & 1,61 & 1,75 \\
16 & 1,61 & 1,72 & 1,84 \\
17 & 1,76 & 1,9 & 2,06 \\
18 & 1,52 & 1,63 & 1,74 \\
19 & 1,31 & 1,41 & 1,52 \\
20 & 1,5 & 1,65 & 1,81 \\
21 & 1,55 & 1,67 & 1,8 \\
22 & 1,76 & 1,9 & 2,13 \\
\hline CE50,48 h médio & \multicolumn{2}{|c|}{0,65} \\
\hline \multicolumn{2}{|c|}{ Desvio padrão } & \multicolumn{2}{|c|}{} \\
\hline
\end{tabular}


Tabela 3 - Valores de CE50, 96h e intervalos de confiança de cloreto de potássio para Chironomus xanthus.

\begin{tabular}{|c|c|c|c|}
\hline Testes & \begin{tabular}{|c|}
$\begin{array}{c}\text { Limite Inferior } \\
\text { do Intervalo de } \\
\text { Confiança }\end{array}$ \\
\end{tabular} & CE50,96h & $\begin{array}{l}\text { Limite Superior } \\
\text { do Intervalo de } \\
\text { Confiança }\end{array}$ \\
\hline 1 & 3,61 & 4,25 & 5,02 \\
\hline 2 & 4,43 & 5,01 & 5,69 \\
\hline 3 & 3,68 & 4,31 & 5,35 \\
\hline 4 & 3,39 & 4,14 & 4,39 \\
\hline 5 & 3,31 & 3,81 & 4,78 \\
\hline 6 & 3,63 & 4,16 & 4,66 \\
\hline 7 & 3,39 & 3,97 & 6,21 \\
\hline 8 & 5,55 & 5,86 & 6,1 \\
\hline 9 & 4,97 & 5,5 & 6.21 \\
\hline 10 & 3,97 & 4,77 & 5,74 \\
\hline 11 & 4,2 & 4,91 & 5,76 \\
\hline 12 & 5,37 & 5,84 & 6,38 \\
\hline 13 & 4,7 & 5,24 & 5,84 \\
\hline \multicolumn{2}{|c|}{ CE $50,96 \mathrm{~h}$ médio } & \multicolumn{2}{|r|}{4,75} \\
\hline \multicolumn{2}{|c|}{ Desvio padrão } & \multicolumn{2}{|r|}{0,71} \\
\hline
\end{tabular}


Salto Grande - E2novembro/00 - Solubilização: 04.12.00

GW-BASIC 3.10

(C) Copyright Microsoft 1983,1984

Compatibility Software GW-BASIC V3.10

Copyright (c) 1984 by Phoenix Software Associates Ltd.

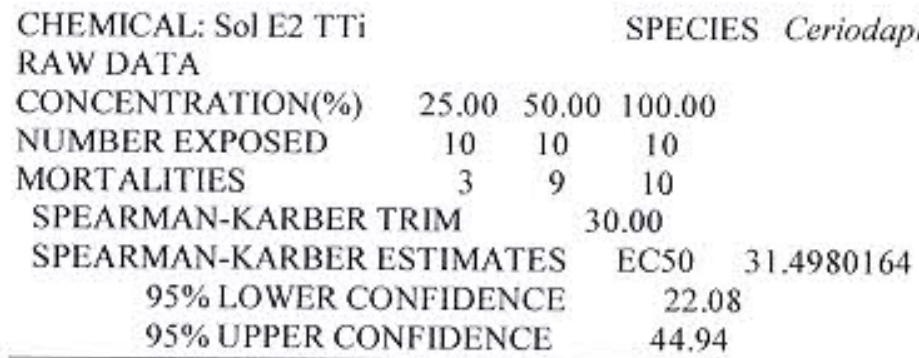


CHEMICAL SolE2 pH11/3.9 filtrada SPECIES Ceriodaphnia dubia

RAW DATA

CONCENTRATION (\%) $\quad 25.00 \quad 50.00 \quad 100.00$

NUMBER EXPOSED $\quad 10 \quad 10 \quad 10$

$\begin{array}{llll}\text { MORTALITIES } & 0 & 0 & 10\end{array}$

SPEARMAN-KARBER TRIM $\quad 0.00$

SPEARMAN-KARBER ESTIMATES EC50 70.7106705

95\% CONFIDENCE LIMITS ARE NOT RELIABLE

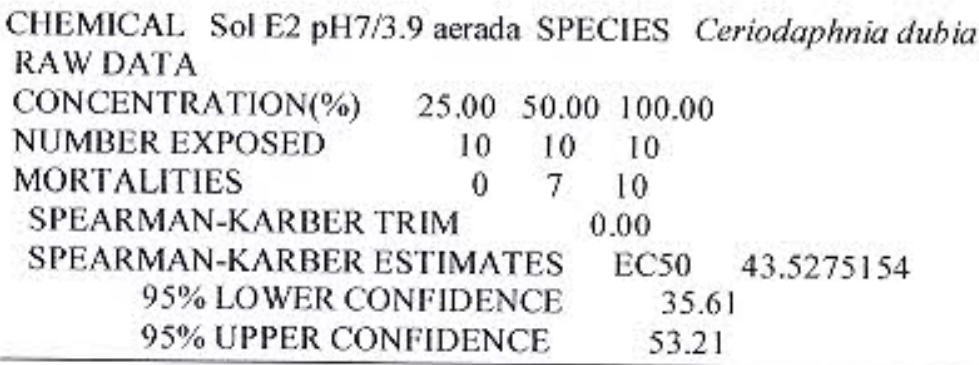

CHEMICAL SolE2 pH7/3.9 aerada SPECIES Ceriodaphnia dubia

RAW DATA

CONCENTRATION(\%) $\quad 25.00 \quad 50.00 \quad 100.00$

NUMBER EXPOSED $\quad 10 \quad 10 \quad 10$

MORTALITIES $\quad 0 \quad 7 \quad 10$

SPEARMAN-KARBER TRIM $\quad 0.00$

SPEARMAN-KARBER ESTIMATES EC50 43.5275154

95\% LOWER CONFIDENCE $\quad 35.61$

95\% UPPER CONFIDENCE $\quad 53.21$

CHEMICAL Sol E2 pH11/3.9 aerada SPECIES Ceriodaphnia dubia
RAWDATA if

CONCENTRATION (\%) $\quad 25.00 \quad 50.00 \quad 100.00$

$\begin{array}{llll}\text { NUMBER EXPOSED } & 10 & 10 & 10\end{array}$

MORTALITIES

$\begin{array}{lll}0 & 0 & 10\end{array}$

SPEARMAN-KARBER TRIM $\quad 0.00$

SPEARMAN-KARBER ESTIMATES EC50 70.7106705

95\% CONFIDENCE LIMITS ARE NOT RELIABLE

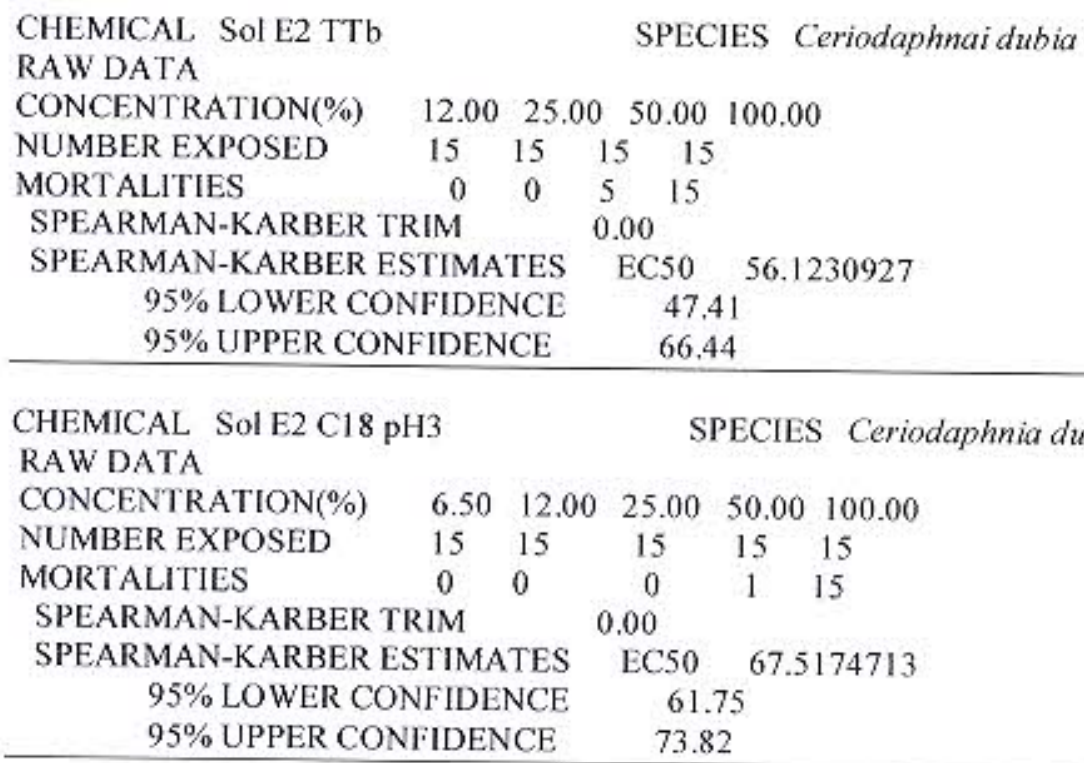




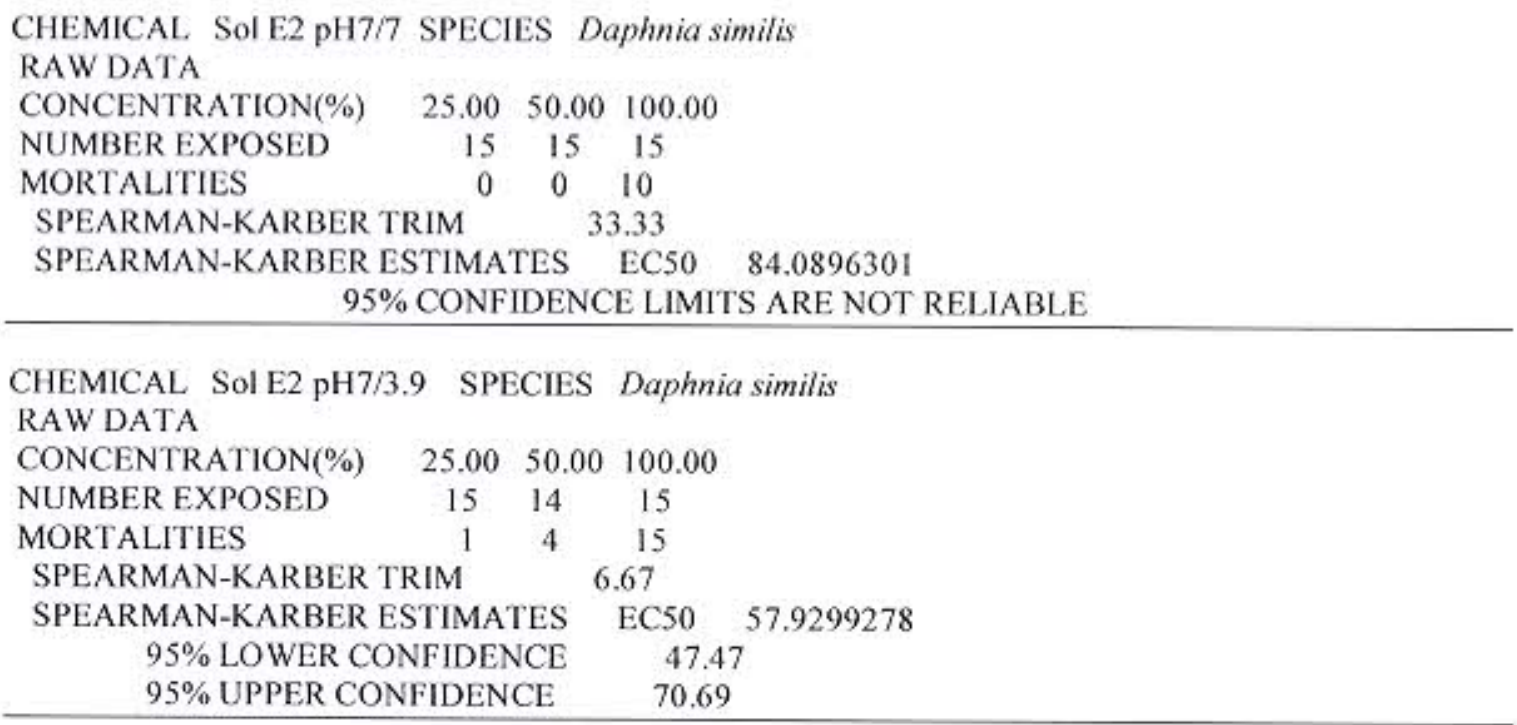

CHEMICAL SolE2 pH7/3.9 aerado SPECIES Daphnia similis RAW DATA

Salto Grande E2 - Novembro/00 - Solubilizado 22.11.00

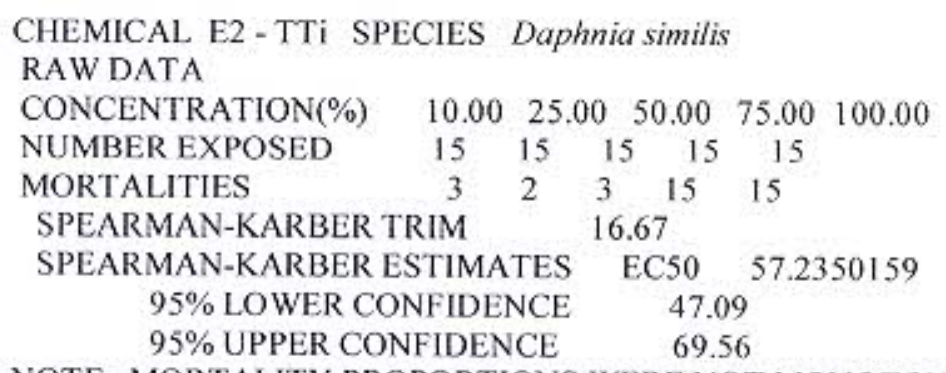




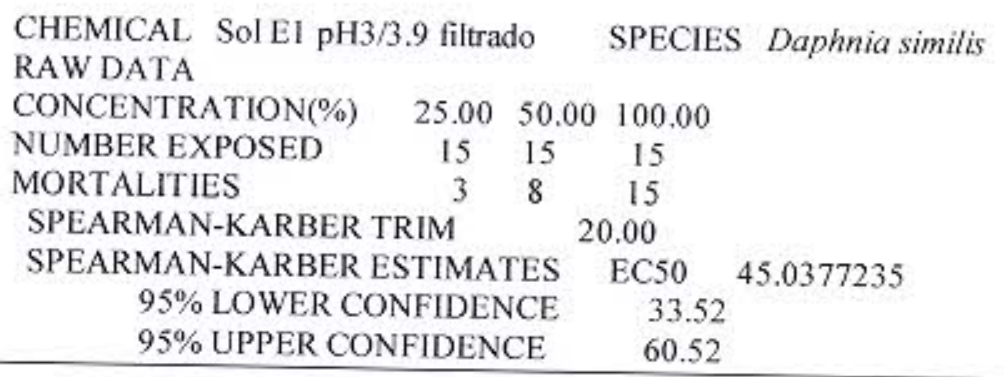


Salto Grande E2 - Outubro/01 / Solubilizado

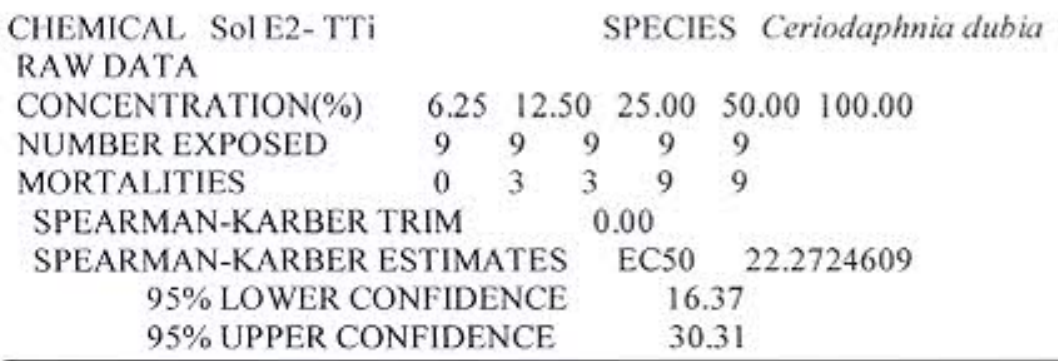




\begin{tabular}{|c|c|c|}
\hline $\begin{array}{l}\text { CHEMICAL Sol E2 pHII } \\
\text { RAW DATA }\end{array}$ & $\mathrm{pHi}$ & SPECIES Ceriodaphnia dubia \\
\hline CONCENTRATION(\%) & $12.50 \quad 25.00$ & $\begin{array}{llll}0 & 50.00 & 100.00\end{array}$ \\
\hline NUMBER EXPOSED & 99 & $9 \quad 9$ \\
\hline MORTALITIES & 2 & 9 \\
\hline SPEARMAN-KARBER & RIM 1 & 11.11 \\
\hline SPEARMAN-KARBER I & STIMATES & EC50 30.6916542 \\
\hline $95 \%$ LOWER CO & NFIDENCE & 23.62 \\
\hline $95 \%$ UPPER CO & JFIDENCE & 39.87 \\
\hline $\begin{array}{l}\text { CHEMICAL SolE2 aer pI } \\
\text { RAW DATA }\end{array}$ & & SPECIES Ceriodaphnia dubia \\
\hline CONCENTRATION(\%) & $12.50 \quad 25.00$ & $50.00 \quad 100.00$ \\
\hline NUMBER EXPOSED & 9 & 99 \\
\hline MORTALITIES & 0 & 9 \\
\hline SPEARMAN-KARBER T & RIM 0 & 0.00 \\
\hline SPEARMAN-KARBER E & STIMATES & EC50 32.7346115 \\
\hline $95 \%$ LOWER CO & NFIDENCE & 28.31 \\
\hline 95\% UPPER CON & FIDENCE & 37.85 \\
\hline
\end{tabular}

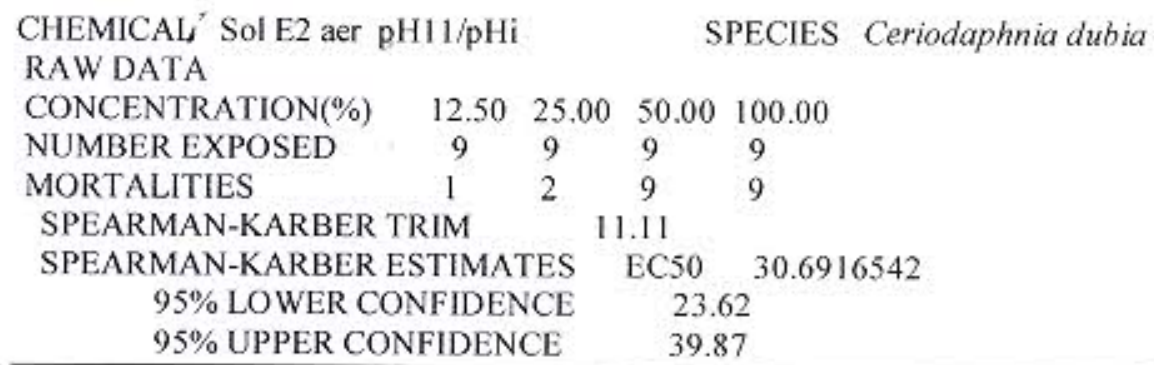




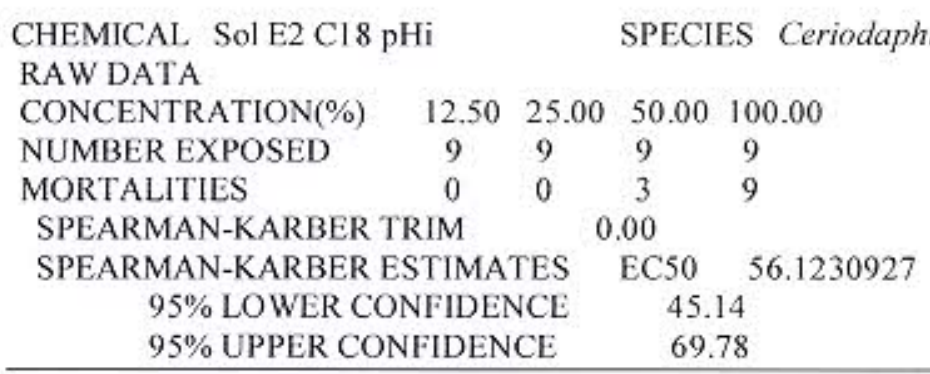

Rasgão - Setembro/01

CHEMICAL SOlRg-TTi SPECIES C.dubia

RAW DATA

CONCENTRATION(\%) $\quad 25.00 \quad 50.00 \quad 100.00$

$\begin{array}{llll}\text { NUMBER EXPOSED } & 9 & 9 & 9\end{array}$

$\begin{array}{llll}\text { MORTALITIES } & 0 & 9 & 9\end{array}$

SPEARMAN-KARBER TRIM 0.00

SPEARMAN-KARBER ESTIMATES $\quad$ EC50 35.3553352

95\% $\%$ CONFIDENCE LIMITS ARE NOT RELIABLE

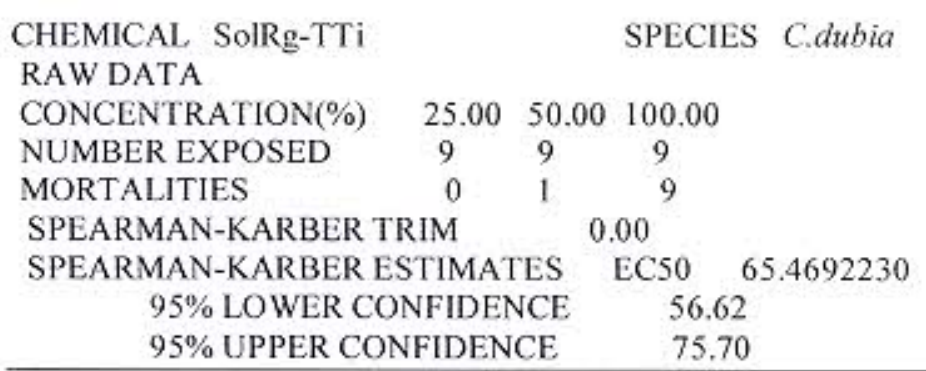

